MÁRCIO RODRIGUES DA SILVA

ESTUDO DO EFEITO DA FASE $\beta$ NA USINABILIDADE DE LIGAS DE LATÃO LIVRES DE CHUMBO 
MÁRCIO RODRIGUES DA SILVA

ESTUDO DO EFEITO DA FASE $\beta$ NA USINABILIDADE DE LIGAS DE LATÃO LIVRES DE CHUMBO

Dissertação apresentada à Escola Politécnica da Universidade de São Paulo, como requisito a obtenção do título de Mestre em Ciências 


\section{MÁRCIO RODRIGUES DA SILVA}

Dissertação apresentada à Escola

Politécnica da Universidade de São Paulo, como requisito a obtenção do título de Mestre em Ciências

Área de Concentração:

Projeto e Fabricação

Orientador: Prof. Dr. Izabel Fernanda Machado 


\section{Catalogação-na-publicação}

Silva, Márcio Rodrigues da

Estudo do efeito da fase beta na usinabilidade de ligas de latão livres de chumbo / M. R. Silva -- São Paulo, 2015.

$132 \mathrm{p}$.

Dissertação (Mestrado) - Escola Politécnica da Universidade de São Paulo. Departamento de Engenharia Mecatrônica e de Sistemas Mecânicos.

1.Latão 2.Isento de chumbo 3.Usinabilidade 4.Microestrutura I.Universidade de São Paulo. Escola Politécnica. Departamento de Engenharia Mecatrônica e de Sistemas Mecânicos Il.t. 
A minha amada esposa, Érika e ao meu pai, Geraldo, verdadeiro exemplo de dedicação. 


\section{AGRADECIMENTOS}

Gostaria de agradecer primeiramente a Deus, por me ajudar a compreender o que a ciência não explica, e por me permitir viver com uma família maravilhosa.

Nela tenho minha amada esposa Érika, para a qual não existem formas de agradecer todo o amor, paciência e apoio nos momentos difíceis e de ausência. Prometo passear mais vezes contigo nos sábados ensolarados (E porque não nos chuvosos...).

Agradeço também toda a educação e exemplo de caráter dado pelo meu pai, Geraldo. Ele sempre me diz que "não há vitória sem luta", e caro pai, você tem toda a razão do mundo. São as nossas lutas que nos transformam, e com isso também transformamos para melhor um pedacinho do mundo de cada vez.

A minha amada e dedicada mãe, Maria, a minha madrasta Rosemeire por cuidar tão bem do meu pai e da minha irmã Amanda, ao meu irmão Marcelo e sua esposa Carla. Aos meus queridos sobrinhos Rodrigo e Pedro, aviso que o tio vai ter mais tempo para brincar com vocês.

Além da minha amada família, ao longo desta caminhada, preciso agradecer primeiramente quatro pessoas, por todo o incentivo: A minha orientadora Izabel Machado, por me ajudar em cada detalhe deste processo com muita dedicação, confiança e conhecimento. Ao Wilson Carlos da Silva Jr., por me permitir o acesso a este mundo de conhecimento, e também pelos conselhos e apoio. Valcir Shigueru Omori, que desde a pré escola acompanha os meus passos e abre caminhos à minha frente e ao Luiz Dessotti Sobrinho, o qual mesmo com todas as críticas alheias, acreditou na sinceridade da minha proposta e sempre me proporcionou recursos e apoio para seguir em frente.

A Regina Celi Venâncio, em nome de todo o conselho curador da Fundação Salvador Arena, por toda a estrutura disponibilizada para execução dos trabalhos. Aproveito para agradecer a memória do Engenheiro Salvador Arena, o qual tive o prazer de conhecer quando criança, sendo ele a verdadeira prova de que tudo é possível, quando se tem uma vontade verdadeira de ajudar ao próximo. 
Aos amigos do Centro Educacional da Fundação Salvador Arena: Silvio Peixoto, André Ferrus, Marco Aurélio, Fabio, Nilson, Agnaldo, Robson, Átila, Ricardo, Rubens, Rogério, Nádia e Cristina por todas as dicas e ajudas.

Aos amigos do laboratório da Termomecanica São Paulo S.A por toda a ajuda prestada nos testes: Adilson, Silmara, Marcolino, Cleber, Marcos, Welington, Robson, Ricardo, Estevan, Kaue, Manoel, Marcelo, Paulo, João Carlos, Aldemir, Odair e Helvio.

Aos amigos do time de engenharia da Termomecanica São Paulo S.A: Julio Gonzales, Paulo Suyama, Fabio, Vinícius, Mauricio, Marcos, Danilo, Arnon, Gabriel, Waldir, Raphael, Reginaldo, Celso, Beatriz, Daniela, Fernanda, Thiago França e Thiago Gamba, por todo o auxílio prestado, tanto na disponibilização dos materiais e recursos para realização dos ensaios, e com as contribuições técnicas.

Aos amigos da equipe de produção da Termomecanica São Paulo S.A, Luiz Henrique Caveagna, José Comar, Fabio, Marcio, Marcos dal Santo, Antônio, Carlos, Bruno, Marquinho, Valtemir, Osvair e João.

A Ricardo Freitas, da empresa Iscar, pela disponibilização das ferramentas para realização do ensaio, e ao Raphael em nome de toda a equipe do Laboratório de Fenômenos de Superfícies da Escola Politécnica da USP. 


\section{RESUMO}

SILVA, M.R. Estudo do efeito da fase $\boldsymbol{\beta}$ na usinabilidade de ligas de latão livres de chumbo. 2015. 132 f. Dissertação (Mestrado) - Escola Politécnica da Universidade de São Paulo, São Paulo, 2015.

Este trabalho visou estudar o efeito dos parâmetros microestruturais da liga de latão 60/40 isenta de chumbo, com enfoque na observação da influência de 4 diferentes frações volumétricas e morfologias da fase $\beta$ nos aspectos de usinabilidade. Os resultados foram comparados com duas referências comerciais de ligas de latão, sendo uma de corte livre com adição de chumbo, e outra de latão $70 / 30$ isenta de fase $\beta$. Esta comparação foi feita por meio dos ensaios de caracterização microestrutural, ensaios mecânicos de dureza Vickers, tração uniaxial e ensaios de usinabilidade. Na avaliação da usinabilidade foram estudadas as morfologias macro e microestrutural dos cavacos, rugosidade final das peças usinadas, medição das forças de corte e análise da vida útil da ferramenta. Esta comparação de desempenho em usinabilidade busca viabilizar a gradativa substituição das ligas de latão com chumbo por ligas isentas de metais pesados, preenchendo uma demanda crescente de mercado por este tipo de produto. A fase $\beta$ exerce uma importante influência na redução das forças de corte e rugosidade, além do fato de que o efeito térmico cumpre um papel importante no comportamento em usinagem dos latões, evidenciado pela alteração das frações volumétricas das fases $\alpha$ e $\beta$ no cavaco analisado, a qual é associada a uma transformação de ordemdesordem.

Palavras chave: Latão. Isento de chumbo. Usinabilidade. Microestrutura. 


\section{ABSTRACT}

SILVA, M.R. Study on effect of phase $\boldsymbol{\beta}$ alloys in machinability of lead-free brasses. 2015. 132 f. Dissertação (Mestrado) - Escola Politécnica da Universidade de São Paulo, São Paulo, 2015.

This work presents a study of microstructural features of lead-free 60/40 brasses on their machinability, which was focused on the observation of four different volumetric fractions and morphologies of $\beta$ phase. Two commercial brasses were used as base materials: a free cutting brass with lead and a 70/30 brass without $\beta$ phase, respectively. These materials were manufactured through hot extruded, cold worked and heat treated rods of these three different alloys, and submitted a microstructure analysis, and mechanical characterization by Vickers hardness and a uniaxial tensile test. Machinability tests were conducted to evaluate the morphology and microstructure of the chips and the final roughness of the workpieces, cutting forces and tool wear test. The results help to evaluate the feasibility of substitution of the leaded brasses for brasses without heavy metals, filling a growing demand for this product in the industry. The $\beta$ phase has a strong influence on cutting forces and roughness reduction as well as the thermal effect plays an important role in the volume fraction of $\alpha$ and $\beta$ phases of the analyzed chip, which was related to the presence of $\beta$ phase and an order-disorder transformation.

Key words: Brass. Lead-free. Machinability. Microstructure. 


\section{LISTA DE FIGURAS}

Figura 1 - Perfis extrudados da liga UNS-C28000 (CDA, 2005). .20

Figura 2 - Diagrama de Fases Cu-Zn com destaque para a região contendo 38 40\% de zinco, característico da liga Metal Muntz (Adaptado de ASM METALS HANDBOOK, 1990b)

Figura 3 - Exemplo de microestrutura típica de Latões Muntz (NOBEL et al, 2014) .22 Figura 4 - Comparativo entre o reticulado desordenado ( $\beta$, Esquerda), esquerda e o reticulado ordenado ( $\beta$ ', Direita), (Adaptado de CULLITY, 1956). .23

Figura 5 - Representação esquemática da formação de dois domínios de estrutura ordenada (Adaptado de BROOKS, 1985) 24

Figura 6 - Variação do parâmetro de ordenação (S) com a temperatura para $\mathrm{AuCu}_{3}$ e CuZn (CULLITY, 1953) 25

Figura 7 - Latão $\alpha-\beta^{\prime}$ recozido a $800^{\circ} \mathrm{C}$ e resfriado lentamente até $25^{\circ} \mathrm{C}$ (LEE et al, 2003). A fase $\alpha$ e $\beta^{\prime}$ estão indicadas na micrografia .26

Figura 8 - Latão recozido a $800^{\circ} \mathrm{C}$ e resfriado em água até $25^{\circ} \mathrm{C}$ (LEE et al, 2003).26 Figura 9 - Efeito da taxa de resfriamento na dureza da liga UNS-C28000 (Adaptado de ASM HANDBOOK, 1990c)

Figura 10 - Correlação de dureza no segundo tratamento térmico seguido de resfriamento rápido (Adaptado de ASM HANDBOOK, 1990c)...

Figura 11 - Diferenças entre estruturas $\alpha$ e $\beta$ ' finamente dispersas e grosseiras, em função da temperatura do segundo aquecimento. (Adaptado de ASM HANDBOOK, 1990)

Figura 12 - Microestrutura típica de um latão de corte livre com chumbo (Latão CLA) (HOFMANN e MAGD, 2004) 29

Figura 13 - Representação do processo de torneamento (Adaptado de GROOVER, 2007) .32

Figura 14 - Ângulo de saída (Y) para uma ferramenta de torno (Adaptado de COSTA, 2006)

Figura 15 - Representação dos ângulos de folga ( $\alpha f)$, de cunha da ferramenta ( $\beta f)$, de saída $(\mathrm{Y})$, de posição $(\mathrm{X})$, de ponta da ferramenta (દf) e de posição secundária ( $\mathrm{X}$ ') (Adaptado de COSTA, 2006)

Figura 16 - Mecanismo básico do processo de corte na usinagem (Adaptado de SHAW, 2005) 
Figura 17 - Comparativo entre o corte oblíquo (a) e ortogonal (b) (ASM HANDBOOK, 1990d) .36

Figura 18 - Diagramas de forças no corte ortogonal (Adaptado de GROOVER, 2007)

Figura 19 - Representação das forças de corte e avanço (a) e Círculo de Merchant

(b) (Adaptado de GROOVER, 2007) .38

Figura 20 - Definição de As (Adaptado de GROOVER, 2007) .39

Figura 21 - Modelo de Piispanen "Modelo das cartas de baralho" (Adaptado de GROOVER, 2007 e MACHADO et al., 2011)

Figura 22 - Definição da velocidade de cisalhamento (vz) (MACHADO et al., 2011)

Figura 23 - Curvas tensão x deformação de engenharia para o Aço AISI 1040

submetido a diferentes taxas de deformação (MEYERS, CHAWLA 2009)

Figura 24 - Curva Tensão de escoamento x taxa de deformação (GROOVER, 2007)

Figura 25 - Curva tensão x deformação para o latão 63/37 para diferentes taxas de deformação (Adaptado de TSAO; CAMPBELL, 1973)

Figura 26 - Curva tensão de cisalhamento x taxa de deformação para o latão 63/37 (Adaptado de TSAO; CAMPBELL, 1973).

Figura 27 - Dispositivo Hat-shaped para medições de tensões de cisalhamento e sua correlação com o cavaco formado na usinagem (Adaptado de HOFMANN E MAGD, 2004)

Figura 28 - Variação do trabalho específico para ligas de latão submetidas a diversas taxas de deformação (Adaptado de HOFMANN E MAGD, 2004).

Figura 29 - Comportamento mecânico da liga UNS-C28000 em função da variação do trabalho a frio empregado (ASM HANDBOOK, 1990) .46

Figura 30 - Análise da deformação de bicristal de latão $\alpha-\beta$ em temperaturas abaixo da transformação ordem desordem. (KHEZRI-YAZDAN; SUBRAMANIAN, 1984a).47 Figura 31 - Aspecto da fratura do bicristal de latão $\alpha-\beta$ submetido à temperatura de $538^{\circ} \mathrm{C}$ (KHEZRI-YAZDAN; SUBRAMANIAN, 1984b)

Figura 32 - Tensões de escoamento para latão beta policristalino, testado em elevadas temperaturas e taxas de deformação (a) $0,01 \mathrm{~min}^{-1}$; (b) $0.02 \mathrm{~min}^{-1}$; (c) 0.05 $\min ^{-1}$; (d) $0.10 \mathrm{~min}^{-1}$; (e) $0.15 \mathrm{~min}^{-1}$; (f) $0.20 \mathrm{~min}^{-1}$ (KHEZRI-YAZDAN; 
Figura 33 - Distribuição do calor gerado na usinagem distribuído no cavaco, na ferramenta e na peça (Adaptado de SCHMIDT, 1950).

Figura 34 - Gradiente térmico observado por medição por radiação infravermelha do corte ortogonal de aço de corte livre (BOOTHROYD, 1975)

Figura 35 - Curva experimental de Boothroyd para a fração de calor transferida para a peça (BOOTHROYD, 1975; TAY; 1993; TRENT; WRIGHT, 2000) .53

Figura 36 - Temperaturas geradas no processo de corte (Adaptado de BOOTHROYD, 1975) .54

Figura 37 - Deformação microestrutural na seção transversal do cavaco decorrente da zona de cisalhamento secundária (BOOTHROYD, 1975).... .55

Figura 38 - Definição de desgaste do flanco $V_{b}$ (Adaptado de ASM METALS HANDBOOK, 1995) .56

Figura 39 - Curva de desgaste da Ferramenta e curva de vida para torneamento de aço com ferramentas de metal duro (MACHADO et al, 2011). .56

Figura 40 - Tipos comuns de cavacos (Adaptado de GERMAN COPPER INSTITUTE, 2010) 58

Figura 41 - Classificação da forma dos cavacos (Adaptado de GERMAN COPPER INSTITUTE, 2010)

Figura 42 - Cavaco contínuo de latão emaranhado à peça usinada (KLOCKE et al, 2012a) 60

Figura 43 - Tipos mais comuns de cavacos gerados no processo de usinagem (ISO 3685, 1993)

Figura 44 - Rugosidade cinemática (GERMAN COPPER INSTITUTE, 2008). 62

Figura 45 - Perfil usinado: a) Sem fluxo lateral; (b) Com fluxo lateral (MACHADO et al, 2011) 62

Figura 46 - Definição de Rugosidade média (Ra) (Adaptado de ASM HANDBOOK, 1995) 63

Figura 47 - Definição de Rugosidade de profundidade média (Rz) (ASM

HANDBOOK, 1995) 63

Figura 48 - Microestrutura de latão com adição de bismuto (ATSUMI et al, 2011) ..65

Figura 49 - Microestrutura típica de latões com silício (NOBEL et al, 2014) .66

Figura 50 - Efeito da velocidade de corte nas diferentes ligas fundidas de Latão Silício com até $4 \%$ de Si, Latão com chumbo e Latão 60/40 sem chumbo. 
Parâmetros ap $=0,5 \mathrm{~mm}$ e $\mathrm{f}=0,08 \mathrm{~mm} /$ rot. Ferramenta H123 (Adaptado de TAHA et. al, 2012) .66

Figura 51 - Fotomicrografia de latão com partículas de grafite, obtidos pela metalurgia do pó (IMAI et al, 2010)

Figura 52 - Força de corte e temperatura de ferramenta no torneamento longitudinal externo em diferentes ligas de cobre. Parâmetro de corte utilizados $\gamma=10^{\circ}, x=95^{\circ}$, $\mathrm{vc}=200 \mathrm{~m} / \mathrm{min}, \mathrm{f}=0,2 \mathrm{~mm} / \mathrm{rot}, \mathrm{ap}=3 \mathrm{~mm}$, fluido de corte $=$ emulsão, $7 \%$ (KLOCKE et al, 2012b) ..... 68

Figura 53 - Formas de cavacos resultantes do torneamento longitudinal externo em várias ligas de cobre. Parâmetro de corte utilizados $\gamma=10^{\circ}, X=95^{\circ}$, vc $=200 \mathrm{~m} / \mathrm{min}$, fluido de corte $=$ emulsão, 7\% (KLOCKE et al, 2012b).

Figura 54 - Desgaste máximo do flanco ao ligar vários materiais de cobre, nas condições: $v c=200 \mathrm{~m} / \mathrm{min}, \mathrm{ap}=1 \mathrm{~mm}, \mathrm{f}=0,1 \mathrm{~mm}$, emulsão (KLOCKE et al, 2012a)

Figura 55 - Cavacos gerados a partir de ferramentas com geometrias de quebra cavaco. Parâmetros utilizados: $v c=300 \mathrm{~m} / \mathrm{min}, f=0,04 \mathrm{~mm}, p=0,25 \mathrm{~mm}$ (KLOCKE et al, 2012b) .70

Figura 56 - Comparação das formas de cavaco obtidas pela variação do método de refrigeração. Parâmetros utilizados: $v c=125 \mathrm{~m} / \mathrm{min}, f=0,03 \mathrm{~mm}, p=0,25 \mathrm{~mm}$ (Adaptado de KLOCKE et al, 2012a) .71 Figura 57 - Representação esquemática dos processos de fabricação dos materiais A1, A2, A3 e A4 .73

Figura 58 - Referência para utilização das temperaturas de processo e tratamento térmico

Figura 59 - Torno utilizado no experimento com a respectiva montagem da ferramenta .75

Figura 60 - Representação esquemática da ferramenta utilizada (ISCAR, 2015) ...76

Figura 61 - Representação esquemática da ferramenta de corte (ISCAR, 2015) ....76

Figura 62 - Ensaio de rugosidade. .77

Figura 63 - Dinamômetro piezoelétrico Kistler utilizado nos experimentos .78

Figura 64 - Microestrutura do material relativo ao grupo A1 (x200, Reagente $\mathrm{FeCl}_{3}+$ Etanol $+\mathrm{HCl})$

Figura 65 - Microestrutura do material relativo ao grupo A2 (x200, Reagente $\mathrm{FeCl}_{3}+$ Etanol $+\mathrm{HCl})$ 
Figura 66 - Microestrutura do material relativo ao grupo A3 (x200, Reagente $\mathrm{FeCl}_{3}+$ Etanol $+\mathrm{HCl})$ .81

Figura 67 - Microestrutura do material relativo ao grupo A4 (x200, Reagente $\mathrm{FeCl}_{3}+$ Etanol $+\mathrm{HCl})$ .82

Figura 68 - Microestrutura do material relativo ao grupo B1 (x200, Reagente $\mathrm{FeCl}_{3}+$ Etanol $+\mathrm{HCl})$ .82

Figura 69 - Microestrutura do material relativo ao grupo C1 (x200, Reagente $\mathrm{FeCl}_{3}+$ Etanol $+\mathrm{HCl})$ 82

Figura 70 - Micrografia das seções transversal (Esquerda) e longitudinal (Direita) do material $A 1$, para quantificação da fração de fase $\beta$ (200X).

Figura 71 - Micrografia das seções transversal (Esquerda) e longitudinal (Direita) do material A2, para quantificação da fração de fase $\beta$ (200X). .84

Figura 72 - Micrografia das seções transversal (Esquerda) e longitudinal (Direita) do material A3, para quantificação da fração de fase $\beta$ (200X).

Figura 73 - Micrografia das seções transversal (Esquerda) e longitudinal (Direita) do material A4, para quantificação da fração de fase $\beta$ (200X).

Figura 74 - Micrografia das seções transversal (Esquerda) e longitudinal (Direita) do material C1, para quantificação da fração de fase $\beta$ (200X)

Figura 75 - Quantificação de chumbo do material C1, em amostra sem ataque metalográfico (500X)

Figura 76 - Análise de variância para a fração volumétrica de fase $\beta$ ' nos diferentes materiais. .85

Figura 77 - Análise dos dados de dureza Vickers .87

Figura 78 - Análise dos dados de microdureza Vickers para a fase $\beta$. .88

Figura 79 - Cavacos obtidos para a velocidade de corte de $60 \mathrm{~m} / \mathrm{min}$ .90

Figura 80 - Cavacos obtidos para a velocidade de corte de $100 \mathrm{~m} / \mathrm{min}$. .91

Figura 81 - Cavacos obtidos para a velocidade de corte de $140 \mathrm{~m} / \mathrm{min}$. .92

Figura 82 - Cavacos obtidos para a velocidade de corte de $180 \mathrm{~m} / \mathrm{min}$ .93

Figura 83 - Micrografias dos cavacos obtidos para a velocidade de corte de 60 $\mathrm{m} / \mathrm{min}$

Figura 84 - Micrografias dos cavacos obtidos para a velocidade de corte de 100 $\mathrm{m} / \mathrm{min}$ .96

Figura 85 - Micrografias dos cavacos obtidos para a velocidade de corte de 140 $\mathrm{m} / \mathrm{min}$ 
Figura 86 - Micrografias dos cavacos obtidos para a velocidade de corte de 180 $\mathrm{m} / \mathrm{min}$

Figura 87 - Análise em microscópio eletrônico de varredura dos cavacos gerados na velocidade de corte de $60 \mathrm{~m} / \mathrm{min}$.

Figura 88 - Análise em microscópio eletrônico de varredura dos cavacos gerados na velocidade de corte de $180 \mathrm{~m} / \mathrm{min}$, para o material A1 99

Figura 89 - Análise em microscópio eletrônico de varredura dos cavacos gerados na velocidade de corte de $180 \mathrm{~m} / \mathrm{min}$, para o material A3 .99

Figura 90 - Comparativo entre o grau de recalcamento dos cavacos usinados .....100 Figura 91 - Medição da espessura elementar de cavaco para o material A1, usinado a $60 \mathrm{~m} / \mathrm{min}$. 101

Figura 92 - Medição da espessura elementar de cavaco para o material A2, usinado a $100 \mathrm{~m} / \mathrm{min}$ 102

Figura 93 - Resultados da avaliação da curvatura da raiz do cavaco $\left(w_{0} t_{c}\right)$, para as diferentes velocidades de corte 103

Figura 94 - Comparativo da fração volumétrica de fase $\beta$ da liga Latão $60 / 40$ nos cavacos obtidos

Figura 95 - Medição da Fase $\beta$ nos cavacos obtidos para a velocidade de corte de $60 \mathrm{~m} / \mathrm{min}$. 104

Figura 96 - Medição da Fase $\beta$ nos cavacos obtidos para a velocidade de corte de $100 \mathrm{~m} / \mathrm{min}$. 105

Figura 97 - Medição da Fase $\beta$ nos cavacos obtidos para a velocidade de corte de $140 \mathrm{~m} / \mathrm{min}$ 105

Figura 98 - Medição da Fase $\beta$ nos cavacos obtidos para a velocidade de corte de $180 \mathrm{~m} / \mathrm{min}$. 106

Figura 99 - Fração volumétrica dos elementos cobre e zinco na fase $\beta$ da liga Latão $60 / 40$ 106

Figura 100 - Forças de corte obtidas nos ensaio de torneamento 107

Figura 101 - Análise do diagrama de fases binário cobre-zinco 110

Figura 102 - Análise do flanco da ferramenta utilizada no material A1 em lupa estereoscópica (Aumento 20X) e MEV (Aumento 290x)

Figura 103- Análise do flanco da ferramenta utilizada no material A2 em lupa estereoscópica (Aumento 20X) e MEV (Aumento 290x) 
Figura 104- Análise do flanco da ferramenta utilizada no material A3 em lupa estereoscópica (Aumento 20X) e MEV (Aumento 290x)

Figura 105 - Análise do flanco da ferramenta utilizada no material A4 em lupa estereoscópica (Aumento 20X) e MEV (Aumento 290x)

Figura 106 - Análise do flanco da ferramenta utilizada no material B1 em lupa estereoscópica (Aumento 20X) e MEV (Aumento 290x)

Figura 107 - Análise do flanco da ferramenta utilizada no material C1 em lupa estereoscópica (Aumento 20X) e MEV (Aumento 290x) 115

Figura 108 - Rugosidades $\mathrm{Ra}$ e $\mathrm{Rz}$ dos materiais usinados no processo 1 116

Figura 109 - Rugosidades $\mathrm{Ra}$ e $\mathrm{Rz}$ dos materiais usinados no processo 2 116

Figura 110 - Rugosidades $\mathrm{Ra}$ e $\mathrm{Rz}$ dos materiais usinados no processo 3

Figura 111 - Rugosidades $\mathrm{Ra}$ e $\mathrm{Rz}$ dos materiais usinados no processo 4 117

Figura 112 - Análise em MEV da superfície do material C1 (2900 X) 


\section{LISTA DE TABELAS}

Tabela 1 - Composição química dos materiais estudados ....................................74

Tabela 2 - Dimensões do inserto utilizado no ensaio (ISCAR, 2015) …..................76

Tabela 3 - Principais dimensões e ângulos da ferramenta utilizada (ISCAR, 2015). 76

Tabela 4 - Parâmetros de corte utilizados nos experimentos .................................77

Tabela 5 - Propriedades físicas dos latões utilizados nos experimento.

(LOCONSOLO; NOBILI, 1995).

Tabela 6 - Frações volumétricas de fase $\beta$ e caminhos livres médio dos materiais analisados

Tabela 7 - Análise de variância do percentual de fase $\beta^{\prime}$ (SS - Quadrado das Somas, GL - Graus de Liberdade e MS - Quadrado das médias) .86

Tabela 8 - Valores obtidos nos ensaios de tração uniaxial e dureza Vickers. .86

Tabela 9 - Valores obtidos nos ensaios de dureza e microdureza Vickers .86

Tabela 10 - Comparativo de redução das durezas da fase $\alpha$ e $\beta$ nos materiais de Latão 60/40

Tabela 11 - Análise de variância da dureza (SS - Quadrado das Somas, GL - Graus de Liberdade e MS - Quadrado das médias)

Tabela 12 - Analise de variância da microdureza da fase $\beta$ (SS - Quadrado das

Somas, GL - Graus de Liberdade e MS - Quadrado das médias) 88

Tabela 13 - Comparativo do grau de recalcamento dos cavacos em referência ao material $\mathrm{C} 1$

Tabela 14 - Comparativo das forças de corte ...............................................107

Tabela 15 - Comparativo de redução das forças de corte .....................................108

Tabela 16 - Resultados analíticos das temperaturas máximas atingidas no processo de corte

Tabela 17 - Taxas de deformação avaliadas.

Tabela 18 - Análise de variância das rugosidades $R a$ e $R z$ dos materiais usinados no processo 1

Tabela 19 - Análise de variância das rugosidades $R a$ e $R z$ dos materiais usinados no processo 2 .

Tabela 20 - Análise de variância das rugosidades $R a$ e $R z$ dos materiais usinados no processo 3. 
Tabela 21 - Análise de variância das rugosidades $R a$ e $R z$ dos materiais usinados no processo 4 


\section{LISTA DE SÍMBOLOS}

a $\quad$ Fase alfa dos latões

af Ângulo de folga da ferramenta de usinagem

$\left[^{\circ}\right]$

$\beta \quad$ Fase beta desordenada dos latões

B' $\quad$ Fase beta ordenada dos latões

Bf Ângulo de cunha da ferramenta de usinagem

Y Ângulo de saída da ferramenta de usinagem

$\Gamma \quad$ Parcela de calor gerado transferido à peça

$\Delta s \quad$ Deslocamento lateral do elemento cisalhado

$\Delta y \quad$ Espessura elementar do cavaco

$\dot{\varepsilon} \quad$ Taxa de deformação do cavaco no processo de usinagem

$\varepsilon \quad$ Grau de deformação do cavaco no processo de usinagem

¿f Ângulo de ponta da ferramenta de usinagem

$\kappa \quad$ Fase rica em silício nos latões

$\theta_{0} \quad$ Temperatura ambiente

Өf Temperatura total da zona de cisalhamento secundária

Өm Temperatura média na zona de cisalhamento secundária

Omáx Temperatura máxima do contato entre a ferramenta e o cavaco

Os Temperatura média na zona de cisalhamento primária

Өt Parcela relativa ao aumento de temperatura na ferramenta

$\tau \quad$ Tensão de cisalhamento

$\rho \quad$ Densidade do material a ser usinado

$\sigma \quad$ Tensão presente em elevadas taxas de deformação

$\varphi \quad$ Ângulo de cisalhamento

$X \quad$ Ângulo de posição

X' Ângulo de posição secundária

$\omega$ Ângulo relacionado ao coeficiente de atrito

ap Profundidade de corte

As Área do plano de cisalhamento

C Calor específico do material a ser usinado

C Coeficiente de resistência à taxa de deformação

d Diâmetro da peça 


\begin{tabular}{|c|c|c|}
\hline$f$ & Avanço em mm por revolução & {$[\mathrm{mm} / \mathrm{rot}]$} \\
\hline $\mathrm{F}$ & Força de atrito do corte ortogonal & {$[N]$} \\
\hline Fc & Força de corte no torneamento cilíndrico & {$[N]$} \\
\hline $\mathrm{Ff}$ & Força de avanço no torneamento cilíndrico & {$[N]$} \\
\hline Fn & Força normal ao plano de cisalhamento do corte ortogonal & {$[N]$} \\
\hline $\mathrm{Fp}$ & Força passiva no torneamento cilíndrico & {$[N]$} \\
\hline Fs & Força de cisalhamento do corte ortogonal & {$[N]$} \\
\hline $\mathrm{k}$ & Condutividade térmica & {$[\mathrm{W} / \mathrm{mK}]$} \\
\hline $\mathrm{I}_{1}$ & Comprimento total do suporte da ferramenta & {$[\mathrm{mm}]$} \\
\hline Ic & Comprimento de contato ferramenta/cavaco & {$[\mathrm{mm}]$} \\
\hline If & Comprimento da aresta da ferramenta & {$[\mathrm{mm}]$} \\
\hline $\mathrm{m}$ & Sensibilidade à taxa de deformação & \\
\hline $\mathrm{N}$ & Força normal do corte ortogonal & {$[N]$} \\
\hline $\mathrm{n}$ & Número de rotações por minuto & {$\left[\mathrm{min}^{-1}\right]$} \\
\hline$P_{f}$ & Taxa de calor gerado na zona de cisalhamento secundária & {$[\mathrm{J} / \mathrm{s}]$} \\
\hline$P_{m}$ & Taxa de calor total gerado & {$[\mathrm{J} / \mathrm{s}]$} \\
\hline$P_{s}$ & Taxa de calor gerado na zona de cisalhamento primária & {$[\mathrm{J} / \mathrm{s}]$} \\
\hline $\mathrm{R}$ & Força resultante no corte ortogonal & {$[N]$} \\
\hline $\mathrm{R}^{\prime}$ & Reação à força resultante no corte ortogonal & {$[\mathrm{N}]$} \\
\hline$r_{c}$ & Grau de recalcamento do cavaco & \\
\hline rf & Raio de arredondamento da ponta da ferramenta & {$[\mathrm{mm}]$} \\
\hline $\mathrm{Ra}$ & Rugosidade média & {$[\mu \mathrm{m}]$} \\
\hline $\mathrm{Rz}$ & Rugosidade de profundidade média & {$[\mu \mathrm{m}]$} \\
\hline S & Parâmetro de ordenação de longo alcance & \\
\hline Sf & Espessura do inserto da ferramenta & {$[\mathrm{mm}]$} \\
\hline $\mathrm{T}$ & Temperatura Real & {$\left[{ }^{\circ} \mathrm{C}\right]$} \\
\hline $\mathrm{Te}$ & Temperatura crítica & {$\left[{ }^{\circ} \mathrm{C}\right]$} \\
\hline$t_{0}$ & Espessura do cavaco não deformado & {$[\mathrm{mm}]$} \\
\hline$t_{c}$ & Espessura do cavaco deformado & {$[\mathrm{mm}]$} \\
\hline $\mathrm{Tf}$ & Critério de vida da ferramenta & {$[\mathrm{s}]$} \\
\hline $\mathrm{V}_{\mathrm{b}}$ & Desgaste do flanco da ferramenta & {$[\mathrm{mm}]$} \\
\hline vc & Velocidade de corte & {$[\mathrm{m} / \mathrm{min}]$} \\
\hline $\mathrm{v}_{\text {cav }}$ & Velocidade do cavaco & {$[\mathrm{m} / \mathrm{min}]$} \\
\hline vf & Velocidade de avanço & {$[\mathrm{m} / \mathrm{min}]$} \\
\hline
\end{tabular}


Vz Velocidade de cisalhamento

W Trabalho de deformação por cisalhamento

w largura de corte

$w_{0} t_{c} \quad$ Largura da zona de deformação secundária

Z Número térmico adimensional

ae Nível de significância estatística

SS Quadrado das somas

GL Número de graus de liberdade

MS Quadrado das médias

$F_{0} \quad$ Valor do teste de hipóteses $F$ observado

$F_{c} \quad$ Valor do teste de hipóteses F crítico 


\section{SUMÁRIO}

1 INTRODUÇÃO ...................................................................................18

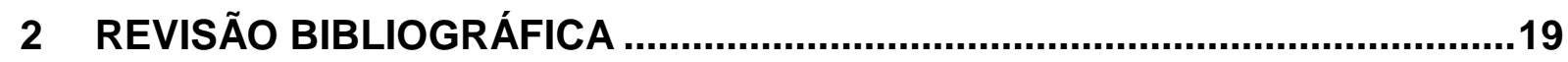

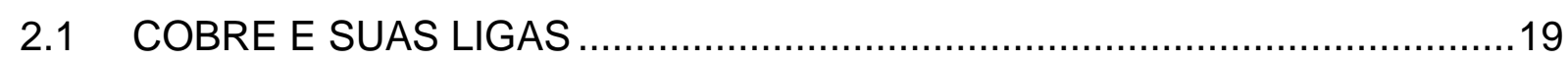

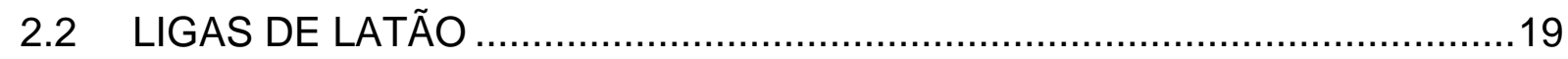

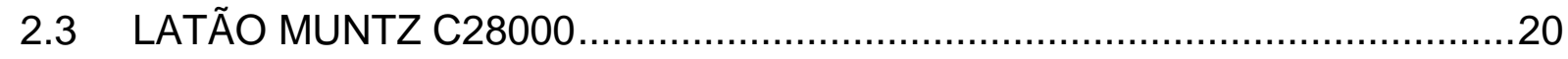

2.4 CARATERÍSTICAS MICROESTRUTURAIS DO LATÃO 60/40 ......................21

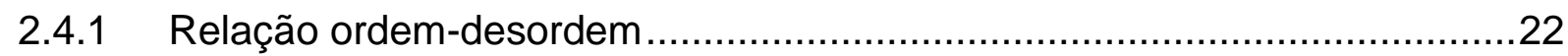

2.4.2 Variáveis de tratamento térmico relevantes para a liga $60 / 40 \ldots \ldots \ldots \ldots \ldots \ldots \ldots . . .26$

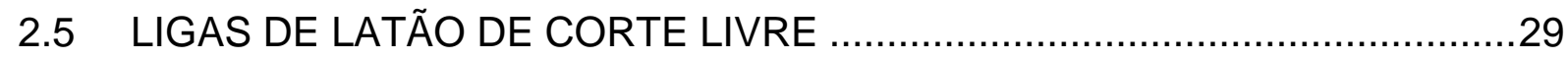

2.6 EFEITOS DO CHUMBO NA SAÚDE HUMANA ….....................................30

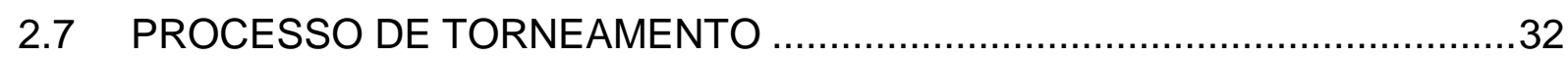

2.7.1 Principais ângulos do processo de torneamento ..........................................33

2.7.2 Mecanismos fundamentais da usinagem .................................................

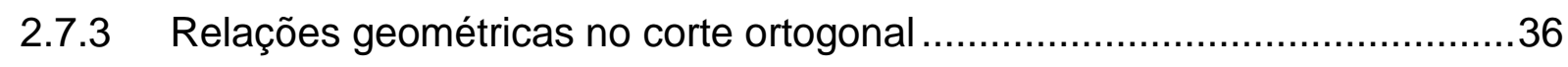

2.7.4 Esforços do processo de torneamento ...................................................37

2.7.5 Deformações existentes no processo de torneamento ................................39

2.7.6 Taxas de deformação presentes nos processos de usinagem ....................41

2.8 COMPORTAMENTO DOS MATERIAIS METÁLICOS QUANTO A TAXA DE DEFORMAÇÃO

2.8.1 Comportamento dos latões quanto às elevadas taxas de deformação .........44

2.8.2 Influência da transformação ordem-desordem no comportamento mecânico em diferentes taxas de deformação e temperatura ..................................................4

2.9 CALOR GERADO NO PROCESSO DE USINAGEM ….............................49

2.9.1 Modelo analítico para as temperaturas geradas na usinagem .....................51

2.9.2 Modelo analítico de Boothroyd (1975).................................................52

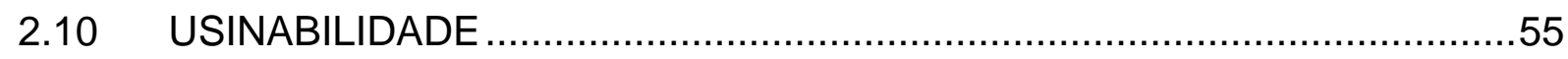

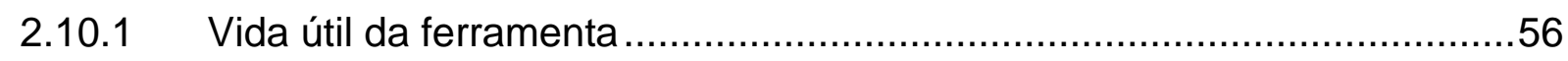




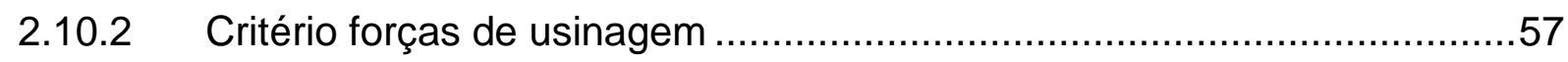

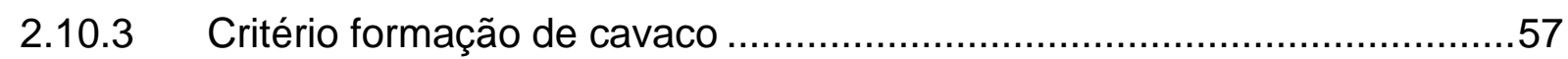

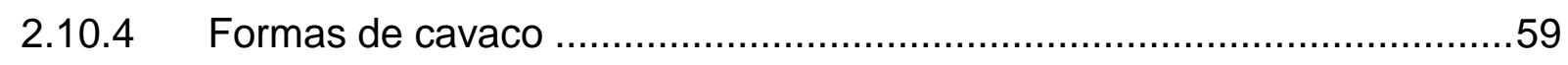

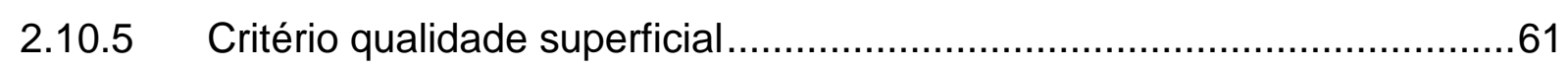

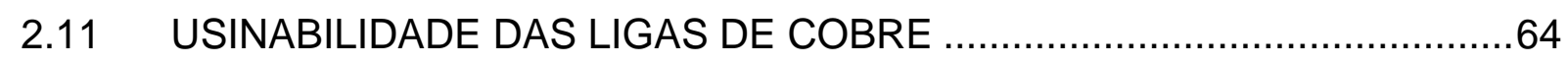

2.12 DESENVOLVIMENTO DE LATÕES DE CORTE LIVRE ISENTOS DE

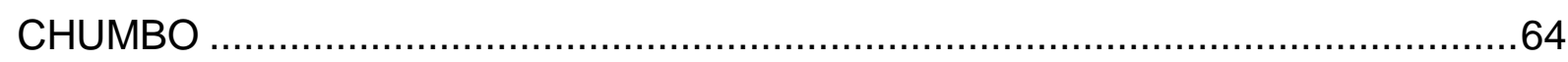

2.12.1 Efeitos da composição química na usinabilidade de latões isentos de chumbo 65

2.12.2 Melhoria da usinabilidade de latões isentos de chumbo pela alteração dos

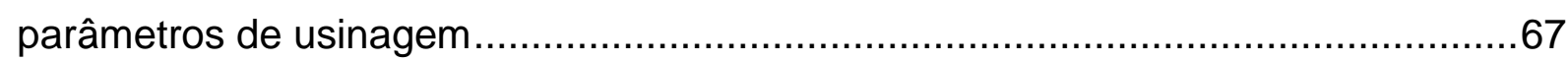

3 PROCEDIMENTO EXPERIMENTAL.............................................................72

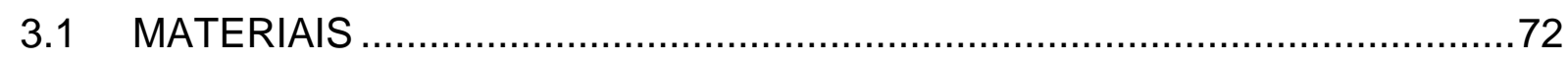

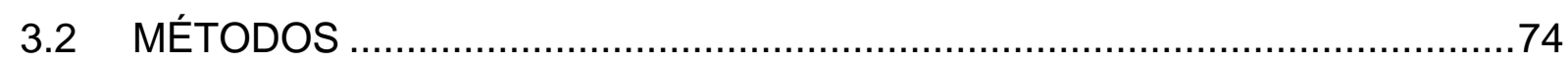

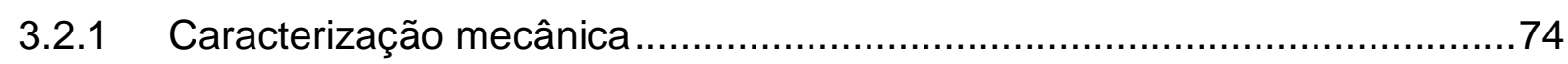

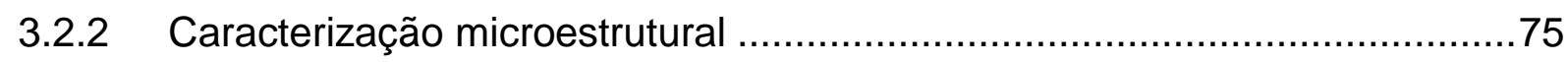

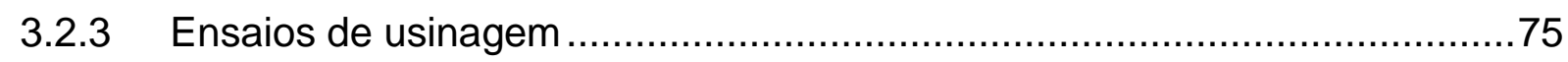

3.2.4 Análise da rugosidade das peças usinadas ..................................... 77

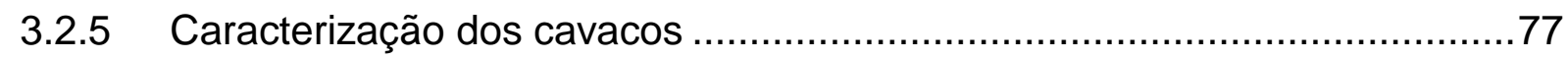

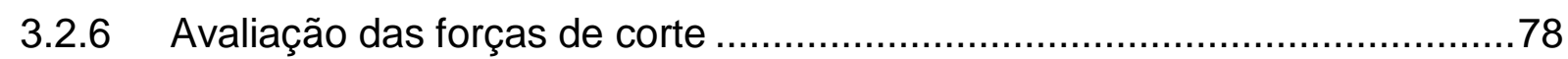

3.2.7 Análise do desgaste da ferramenta............................................... 78

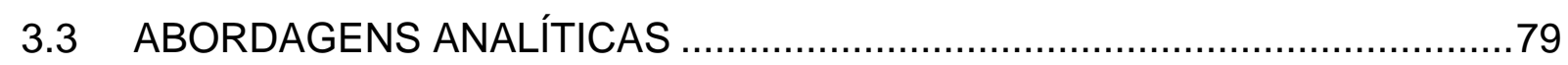

3.3.1 Determinação analítica das temperaturas geradas na usinagem ...............79

3.3.2 Determinação analítica das taxas de deformação existentes .....................79

3.3.3 Análise estatística dos resultados ................................................ 79

4 RESULTADOS E DISCUSSÃO .............................................................. 80

4.1 CARACTERIZAÇÃO MICROESTRUTURAL DOS MATERIAIS .....................80

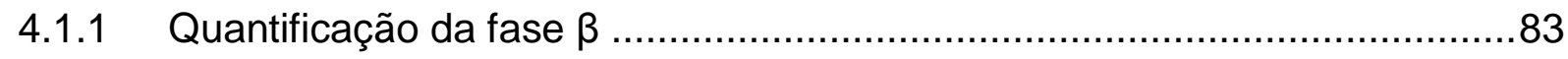


4.2 CARACTERIZAÇÃO MECÂNICA DOS MATERIAIS ..........................................

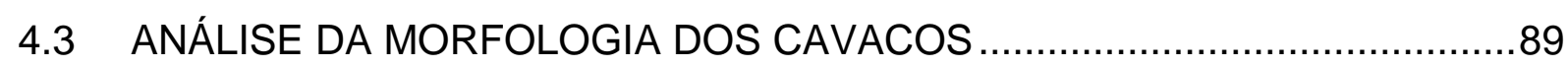

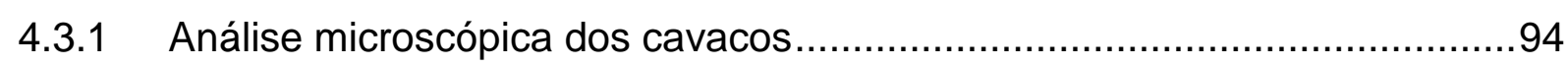

4.3.2 Análise microestrutural dos cavacos ......................................................101

4.4 ANÁLISE DAS FORÇAS DE CORTE....................................................107

4.5 TEMPERATURA MÁXIMA ATINGIDA NO PROCESSO DE CORTE ...........109

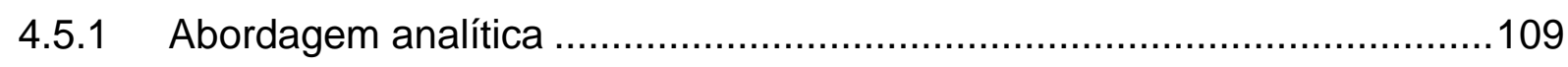

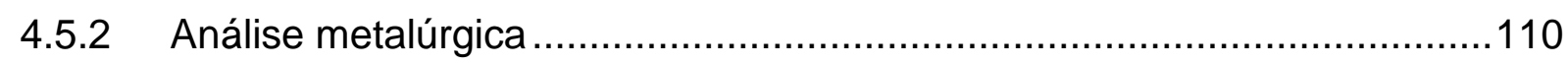

4.6 ANÁLISE DAS TAXAS DE DEFORMAÇÃO .........................................111

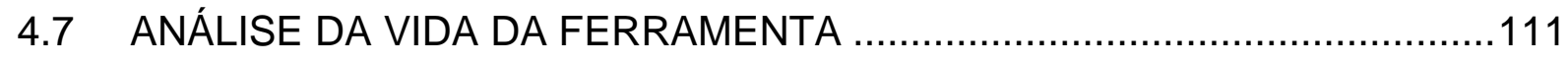

4.8 ANÁLISE COMPARATIVA DE RUGOSIDADE .......................................115

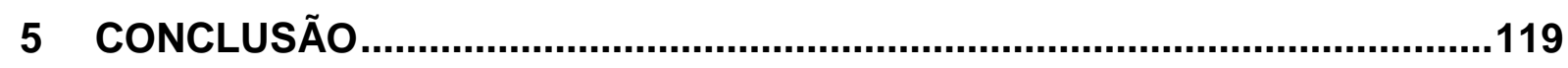

6 SUGESTÕES DE TRABALHOS FUTUROS …….........................................121

7 REFERÊNCIAS BIBLIOGRÁFICAS .....................................................122 


\section{INTRODUÇÃO}

As ligas binárias bifásicas de latão têm em sua composição cobre e zinco, sendo que o zinco representa mais de $37 \%$ em massa. Estes latões apresentam importantes transformações de fase, descritas pelas transformações de ordemdesordem e com isso possuem propriedades mecânicas diferenciadas de outros latões comerciais. (CULLITY, 1956; COUTINHO, 1980; KHEZRI-YAZDAN; SUBRAMANIAN, 1984a; BROOKS, 1985; ASM METALS HANDBOOK, 1990a)

A adição de 1,5 a $3 \%$ de chumbo nestes latões binários tem sido a solução mais comum no mercado de latões usináveis desde o início do século passado, sendo estes denominados como latões de corte livre. A presença do chumbo na microestrutura dos latões, na forma de precipitados na matriz cobre-zinco, facilita a ruptura do cavaco por atuarem como concentradores de tensão. Além disso, o baixo ponto de fusão do chumbo permite a formação de um filme fino que lubrifica e, consequentemente, diminui a tensão de cisalhamento no corte, aumentando a vida útil da ferramenta de usinagem (COUTINHO, 1980; TRENT; WRIGHT, 2000; VILARINHO et al, 2005; HOFMANN; MAGD, 2002; ATSUMI et al, 2011; NOBEL et al, 2014). Entretanto, face ao conhecido efeito nocivo do elemento chumbo, diferentes demandas para eliminação deste elemento vêm sendo elaboradas, principalmente no que diz respeito ao mercado de produtos eletrônicos, automotivo e conexões para água potável. (ELV, 2000; ROHS, 2002; CA CODE 116876, 2005; REACH, 2006; S.152, 2007; TAHA et al, 2012; KLOCKE et al, 2012; NOBEL et al, 2014)

Com essa motivação dos efeitos deletérios do chumbo, e pelo fato das pesquisas do ramo até o momento terem enfatizado o estudo da composição química dos latões ou aspectos tecnológicos da usinagem de metais, decidiu-se por observar um diferente ponto de vista, baseado no desenvolvimento de diferentes características microestruturais de latões binários com $40 \%$ de zinco, com atenção à contribuição das diferentes morfologias da fase $\beta$, obtidas em processos de tratamento térmico industriais, para o processo de usinagem. 


\section{REVISÃO BIBLIOGRÁFICA}

O desenvolvimento de ligas de latão sem chumbo com usinabilidade melhorada depende do conhecimento do comportamento mecânico e microestrutural destes materiais no processo de usinagem, principalmente devido à influência de complexas transformações de fase, que ocorrem mediante diferentes tratamentos térmicos e maiores quantidades de zinco.

\subsection{COBRE E SUAS LIGAS}

O cobre e suas ligas constituem um dos principais grupos de metais comerciais, sendo amplamente utilizados na indústria, devido à sua excelente condutividade elétrica e térmica, além de elevada resistência à corrosão. A possibilidade de ligar o cobre com outros elementos expande o campo de aplicação do mesmo, permitindo a formação de diferentes ligas, entre as quais é possível citar os bronzes, cuproníqueis e os latões, considerado o principal em termos comerciais. (COUTINHO, 1980; BROOKS, 1985; ASM METALS HANDBOOK, 1990c; TAHA et al, 2012; KLOCKE et al, 2012; NOBEL et al, 2014)

\subsection{LIGAS DE LATÃO}

Os latões são ligas de cobre e zinco, e estão entre os materiais mais antigos de engenharia. São largamente utilizados na indústria devido a sua elevada trabalhabilidade, a qual permite a obtenção de geometrias complexas pelos mais variados processos convencionais de fabricação, para a obtenção de produtos semielaborados, como barras, perfis, ou chapas, bem como produtos acabados forjados e usinados. (ASM METALS HANDBOOK, 1990c; TAHA et al, 2012; KLOCKE et al, 2012; NOBEL et al, 2014)

Uma vez que a solubilidade máxima do zinco no cobre é de $38,5 \%$, as ligas comerciais de cobre e zinco com até $37 \%$ de zinco em massa são denominados latões alfa livres de chumbo. Já os latões bifásicos apresentam mais do que $37 \%$ de zinco em massa e nestes está presente uma segunda fase, denominada de fase $\beta$. (ASM METALS HANDBOOK, 1990c; GARCÍA et al, 2009; ATSUMI et al, 2011) 
As ligas bifásicas de latão $\alpha+\beta$ apresentam transformações de fases específicas, as quais resultam em diferentes microestruturas e propriedades mecânicas. Será dada ênfase neste trabalho ao estudo das propriedades da liga de Latão Muntz C28000, uma vez que se trata da liga mais representativa do mercado. (BROOKS, 1985; GARCÍA et al, 2009; ATSUMI et al, 2011)

\subsection{LATÃO MUNTZ C28000}

A liga Latão Muntz C28000 é uma liga da família dos latões binários, de composição química padrão com cobre entre 59,0 a 63,0\% em massa, e zinco corresponde ao restante. São toleradas nestas ligas impurezas máximas de 0,03\% de chumbo e $0,07 \%$ de ferro. O Latão Muntz recebeu esta denominação comercial em homenagem ao seu inventor, o qual desenvolveu esta liga para a fabricação de chapas trabalháveis a quente, usadas para substituir o cobre na proteção de cascos de navios de madeira contra bioincrustação, com a vantagem de apresentar menor custo (ASM METALS HANDBOOK, 1990c; CDA, 2005).

O latão Muntz é também frequentemente descrito como latão 60/40, ou pelas designações de norma CA280 ou UNS-C28000, sendo que os seus padrões de fabricação estão previstos na norma ASTM B-36: Vergalhões, tiras e barras de latão binário. Esta liga possui as melhores propriedades mecânicas entre as ligas de latão binários comerciais, porém pode ser mais suscetível a dezincificação e a corrosão sob tensão. Devido a estas características, a mesma é largamente utilizada em aplicações arquitetônicas, tais como ferragens residenciais decorativas, além de parafusos e válvulas destinadas a condução de vapor, tubos para trocadores de calor, vergalhões para solda e fabricação de produtos forjáveis. Devido a sua boa conformabilidade a quente, este material pode ser fornecido nos mais diversos perfis extrudados, como mostra a Figura 1 (ASM METALS HANDBOOK, 1990c; COUTINHO, 1980; ASTM B-36, 2013).

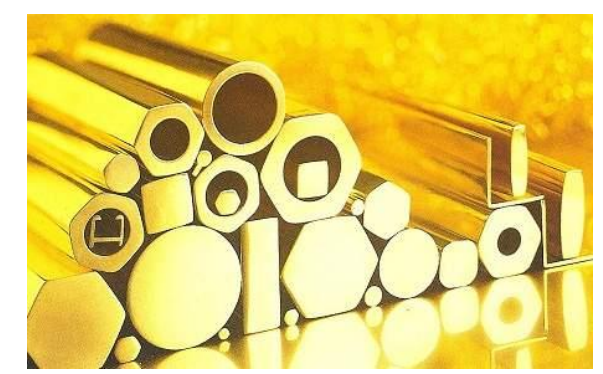

Figura 1 - Perfis extrudados da liga UNS-C28000 (CDA, 2005) 


\subsection{CARATERÍSTICAS MICROESTRUTURAIS DO LATÃO 60/40}

Devido ao teor de zinco da liga Latão 60/40, a mesma apresenta uma microestrutura duplex, contendo a fase $\alpha$ e a fase $\beta$. O diagrama de fase da Figura 2 apresenta, dentro da área destacada em vermelho, a faixa de composição química desta liga. (ASM METALS HANDBOOK, 1990a).

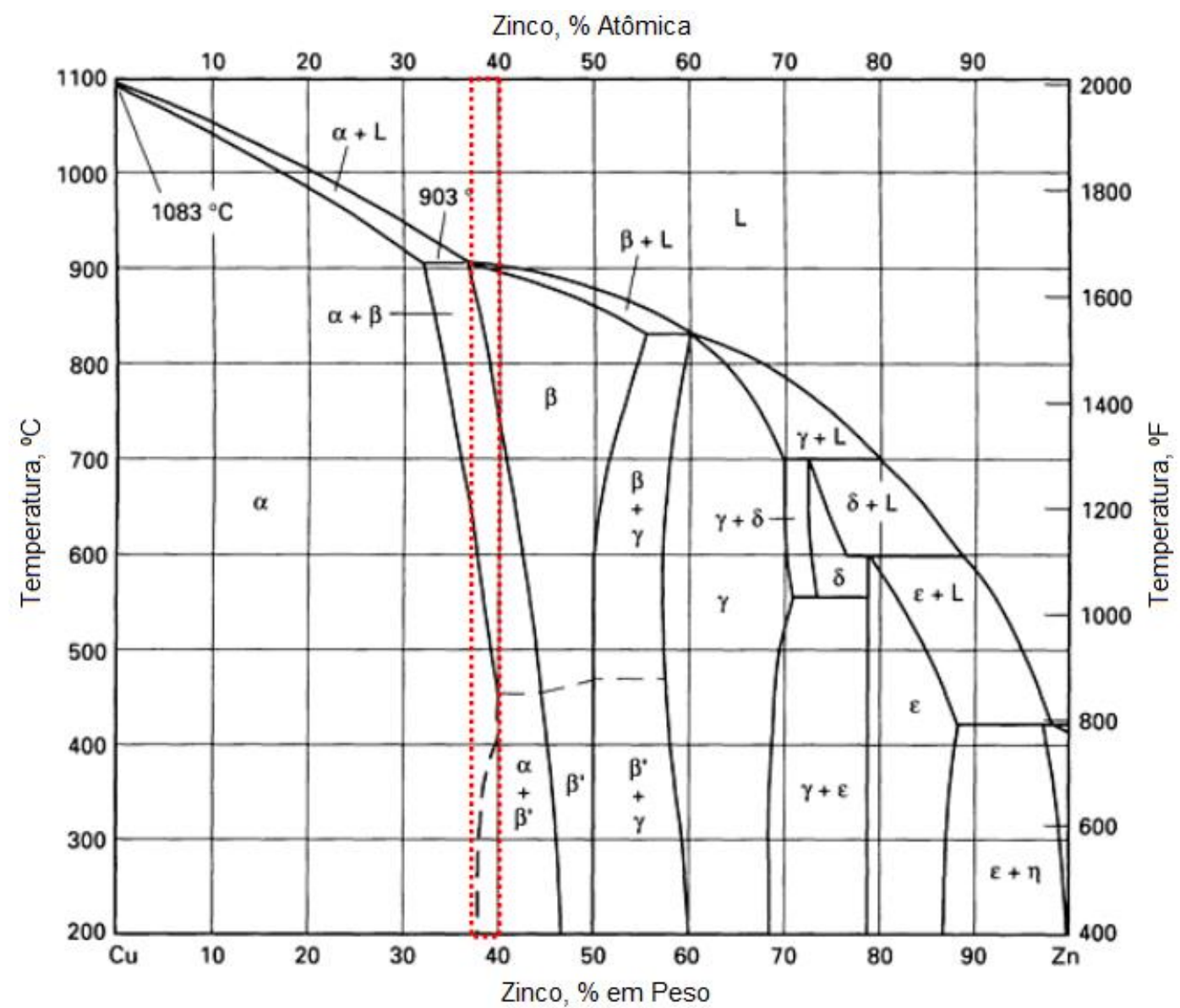

Figura 2 - Diagrama de Fases Cu-Zn com destaque para a região contendo 38 - 40\% de zinco, característico da liga Metal Muntz (Adaptado de ASM METALS HANDBOOK, 1990b),

A fase $\alpha$ apresenta elevada ductilidade a frio, e é descrita como uma solução sólida substitucional com o limite de solubilidade do zinco de 38,5\%, e tem a mesma estrutura cristalina do cobre, cúbica de face centrada. (CULLITY, 1956; COUTINHO, 1980; KHEZRI-YAZDAN; SUBRAMANIAN, 1984a, BROOKS, 1985).

Já a fase $\beta$ apresenta uma variação de composição entre 46 e 50\% de zinco em massa, sendo estável em temperatura ambiente. Pode ser representada pela fórmula CuZn, sendo definida como um composto intermetálico. (CULLITY, 1956; COUTINHO, 1980; KHEZRI-YAZDAN; SUBRAMANIAN, 1984a, BROOKS, 1985). 
As fases $\alpha$ e $\beta$ podem ser observadas utilizando técnicas de microscopia após ataque metalográfico em cloreto férrico $\left(\mathrm{FeCl}_{3}\right)$, sendo que a fase $\alpha$ corresponde às regiões mais claras e a fase $\beta$ às regiões mais escuras presentes na microestrutura, em função do ataque ser mais profundo nas regiões ricas desta fase, conforme mostra a Figura 3. (ASM METALS HANDBOOK, 1990a; COUTINHO; 1980).

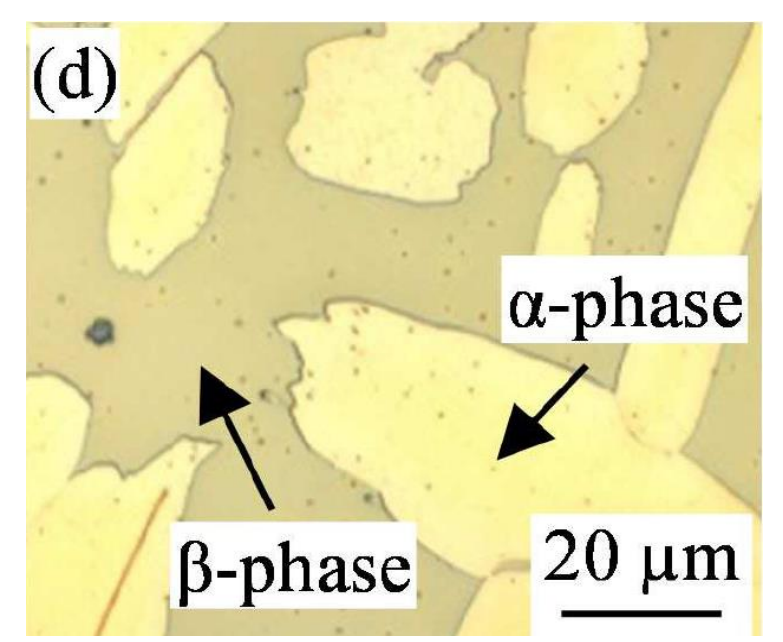

Figura 3 - Exemplo de microestrutura típica de Latões Muntz (NOBEL et al, 2014)

\subsubsection{Relação ordem-desordem}

A fase $\beta$ pode apresentar duas configurações distintas, ao observar pelo posicionamento relativo entre os átomos de cobre e zinco, sendo uma com os átomos dos dois elementos distribuídos de maneira aleatória ou desordenados, e outra com os átomos em posições específicas no reticulado cristalino ou ordenados. A este fenômeno se dá o nome de relação ordem-desordem. (CULLITY, 1956; BROOKS, 1985; KHEZRI-YAZDAN; SUBRAMANIAN, 1984a; NILSEN, SUBRAMANIAN, 1984; GIALANELLA; LUTTEROTTI, 2001).

Este comportamento é oriundo da existência de uma energia característica de ligação entre os átomos de cobre e zinco, a qual gera uma tendência dos átomos ocuparem posições preferenciais um em relação ao outro no reticulado cristalino, ou seja, com uma tendência de ordenação da estrutura. Desta forma, o arranjo desordenado estará presente em altas temperaturas, no qual devido ao aumento da energia térmica se observa uma maior vibração no reticulado atômico, reduzindo a influência das ligações preferenciais. A esta estrutura desordenada dá-se o nome de fase $\beta$, a qual é cúbica de corpo centrado. (CULLITY, 1956; BROOKS, 1985; KHEZRI-YAZDAN; SUBRAMANIAN, 1984a; GIALANELLA, LUTTEROTTI, 2001). 
Porém, em temperaturas abaixo de $454^{\circ} \mathrm{C}$, em função da redução da vibração do reticulado atômico, observa-se a transformação da fase $\beta$ em uma nova forma, de característica ordenada, denominada $\beta^{\prime}$. A estrutura $\beta^{\prime}$ é uma célula cúbica de corpo centrado, com átomos de zinco no centro e os átomos de cobre nos cantos (ou viceversa). A Figura 4 abaixo ilustra o esquema comparativo entre a fase desordenada $\beta$ e a ordenada $\beta^{\prime}$. (CULLITY, 1956; BROOKS, 1985; KHEZRI-YAZDAN; SUBRAMANIAN, 1984a; GIALANELLA, LUTTEROTTI, 2001).

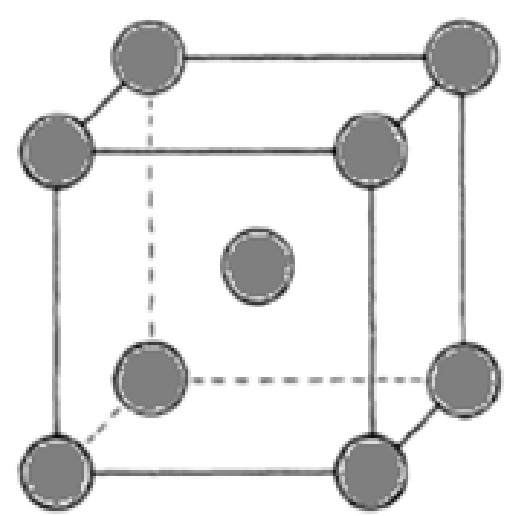

Desordem

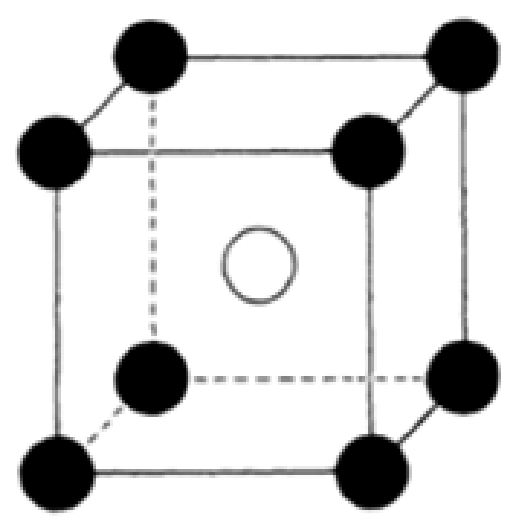

Ordem

Figura 4 - Comparativo entre o reticulado desordenado ( $\beta$, Esquerda), esquerda e o reticulado ordenado ( $\beta$ ', Direita), (Adaptado de CULLITY, 1956)

A formação de uma estrutura ordenada a partir de uma matriz desordenada, da mesma estrutura cristalina, envolve a troca localizada de posições atômicas, por intermédio do mecanismo de lacunas para obtenção da estrutura desejada. Este processo é representado esquematicamente na Figura 5, sendo o início da transformação marcado pela nucleação de uma região ordenada, representada em (b), com o posterior crescimento gradativo da ordenação na interface $\beta / \beta^{\prime}$, assumindo o arranjo da região $\beta$ ' ordenada, representado em (c) (BROOKS, 1985; PADILHA, 2000). Quando duas interfaces de regiões vizinhas se encontram (d), o arranjo dos átomos pode estar fora de sequência (fora de fase). A esta interface entre duas regiões ordenadas se dá o nome de contorno de antifase, e as regiões fechadas são chamadas domínios (PADILHA, 2000).

As propriedades da estrutura $\beta^{\prime}$ ordenada dependerão do grau de perfeição da organização dos átomos na estrutura cúbica de corpo centrado dentro dos domínios e também do tamanho do domínio. Estes domínios dependem da temperatura e do tempo envolvido na formação $\beta$ ' a partir de $\beta$ (BROOKS, 1985). 
(a)

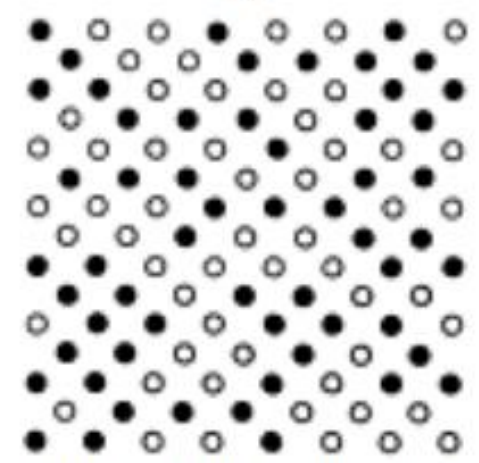

Solução Sólida desordenada

(c)

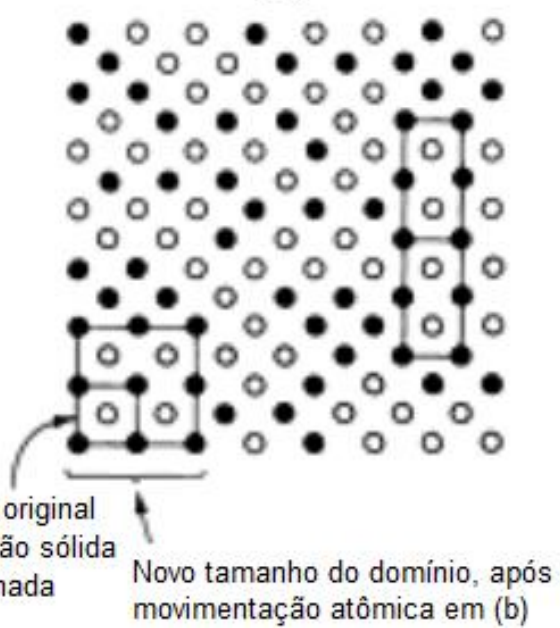

(b)

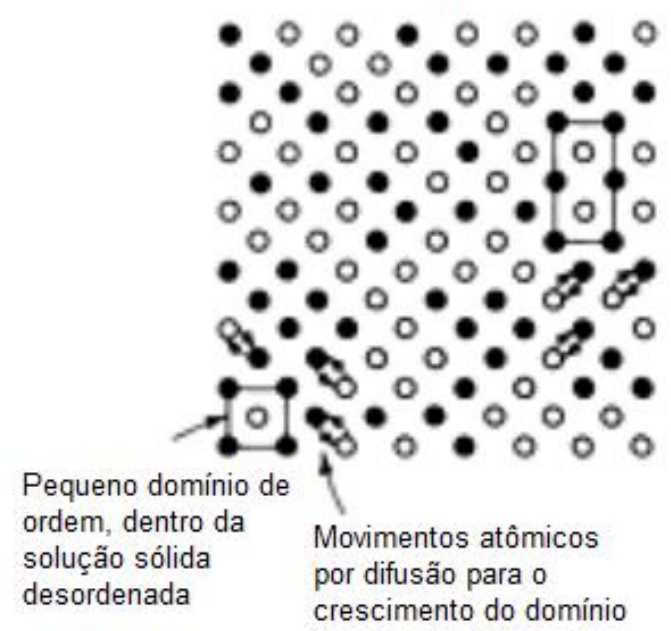

(d)

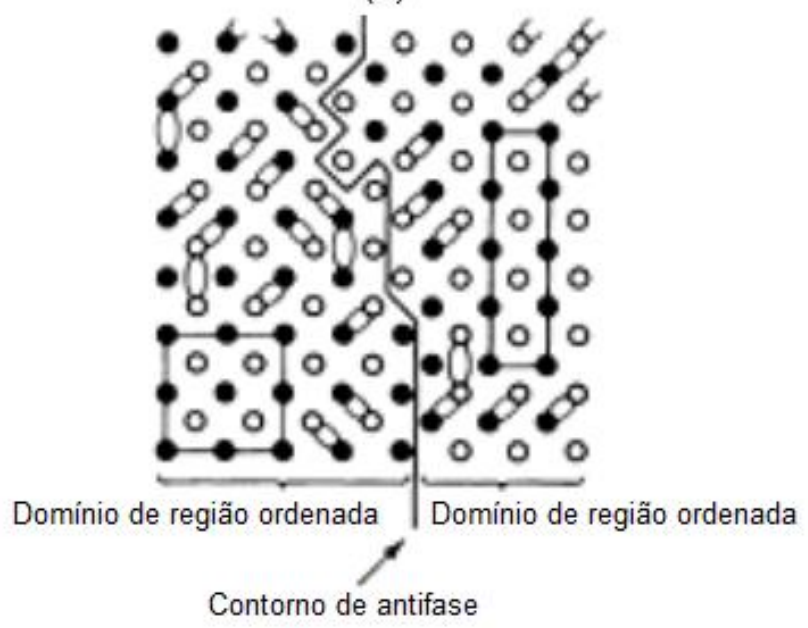

Figura 5 - Representação esquemática da formação de dois domínios de estrutura ordenada (Adaptado de BROOKS, 1985)

Para melhor definir esta estrutura, se utiliza o parâmetro de ordenação de longo alcance $(S)$, sendo $S=1$ o parâmetro definido para estruturas totalmente ordenadas e $S=0$ para uma estrutura totalmente desordenada. Valores intermediários indicam a coexistência das duas situações. A Figura 6 mostra um comparativo entre duas ligas de comportamento ordem-desordem, a liga CuZn e a liga $\mathrm{AuCu}_{3}$, evidenciando uma diferença na velocidade de transformação na qual o parâmetro de ordem para o CuZn diminui continuamente até zero ao passo que T (Temperatura Real) se aproxima de Te (Temperatura crítica), enquanto que para o $\mathrm{AuCu}_{3}$ esta relação permanece alta mesmo em valores muito próximos a Te, seguido de uma redução abrupta a zero em $\mathrm{T} / \mathrm{Te}=1$. Portanto, por ser mais lenta, $\mathrm{a}$ transformação no $\mathrm{AuCu}_{3}$ permite a retenção da estrutura desordenada em qualquer temperatura mediante resfriamento rápido. No CuZn, por outro lado, o ordenamento é tão rápido que a desordem observada em altas temperaturas não é mantida na 
temperatura ambiente, não importa 0 quão rápido seja 0 resfriamento. Consequentemente, pode-se afirmar que para qualquer amostra de CuZn na temperatura ambiente será observada uma estrutura completamente ordenada, ou seja, com a fase $\beta^{\prime}$ (CULLITY, 1953).

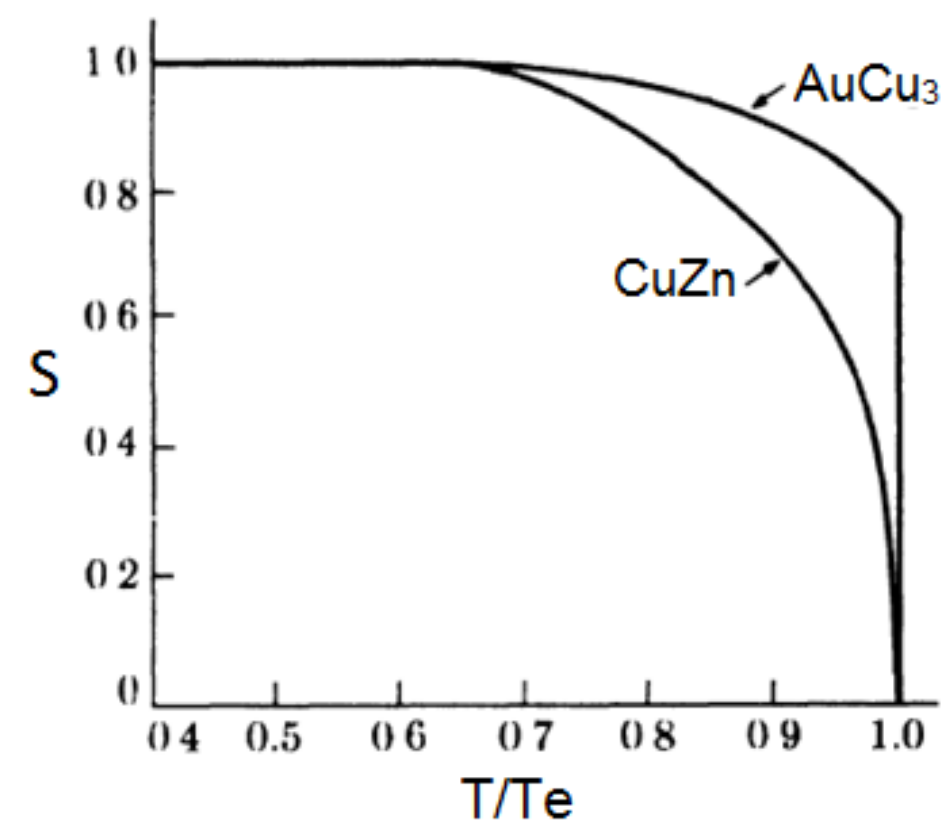

Figura 6 - Variação do parâmetro de ordenação (S) com a temperatura para $\mathrm{AuCu}_{3}$ e $\mathrm{CuZn}$ (CULLITY, 1953)

O comportamento do CuZn indica para a formação simultânea de muitos pontos de nucleação de estrutura ordenada, os quais após poucas mudanças atômicas permitirão contato entre os domínios. Devido a isso, existe a possibilidade de gerar domínios finamente dispersos, com uma quantidade representativa de contornos de antifase, contribuindo para o endurecimento da liga (BROOKS, 1985). Portanto, latões onde somente está presente a fase $\beta$ ', não são adequados para utilização comercial, devido ao fato desta estrutura ser quebradiça. Porém, as ligas com fase $\beta^{\prime}$ coexistindo com a fase $\alpha$ dúctil são úteis, pois neste caso a presença da fase $\beta$ ' traz uma vantagem importante, a de poder aumentar a usinabilidade da liga. (BROOKS, 1985; COUTINHO, 1980; ASM METALS HANDBOOK, 1990a).

Diante disso, a avaliação do parâmetro de tratamento térmico é importante no aspecto de determinar as melhores características microestruturais para melhorar o processo de usinagem, sem prejudicar de maneira significativa o desempenho do produto em serviço. 


\subsubsection{Variáveis de tratamento térmico relevantes para a liga 60/40}

Tomando como referência o diagrama de fases representado na figura 2, observa-se a possibilidade de homogeneizar a liga UNS-C28000 em uma região com onde só a fase $\beta$ é estável (temperaturas da ordem de $800^{\circ} \mathrm{C}$ ). Em etapa posterior, utilizando uma velocidade de resfriamento baixa é possível, em temperaturas abaixo de $800^{\circ} \mathrm{C}$, obter uma microestrutura $\alpha+\beta$ ' como a apresentada na figura 7. (BROOKS, 1985; NILSEN, SUBRAMANIAN, 1984; LEE et al, 2003; SUÁREZ et al, 2015). Todavia, se esta mesma liga for resfriada bruscamente (em água até $25^{\circ} \mathrm{C}$ ), obtém-se uma estrutura essencialmente $\beta^{\prime}$, ilustrada na Figura 8 . (BROOKS, 1985; NILSEN, SUBRAMANIAN, 1984; LEE et al, 2003; MAPELLI; VENTURINI, 2006; SUÁREZ et al, 2015).

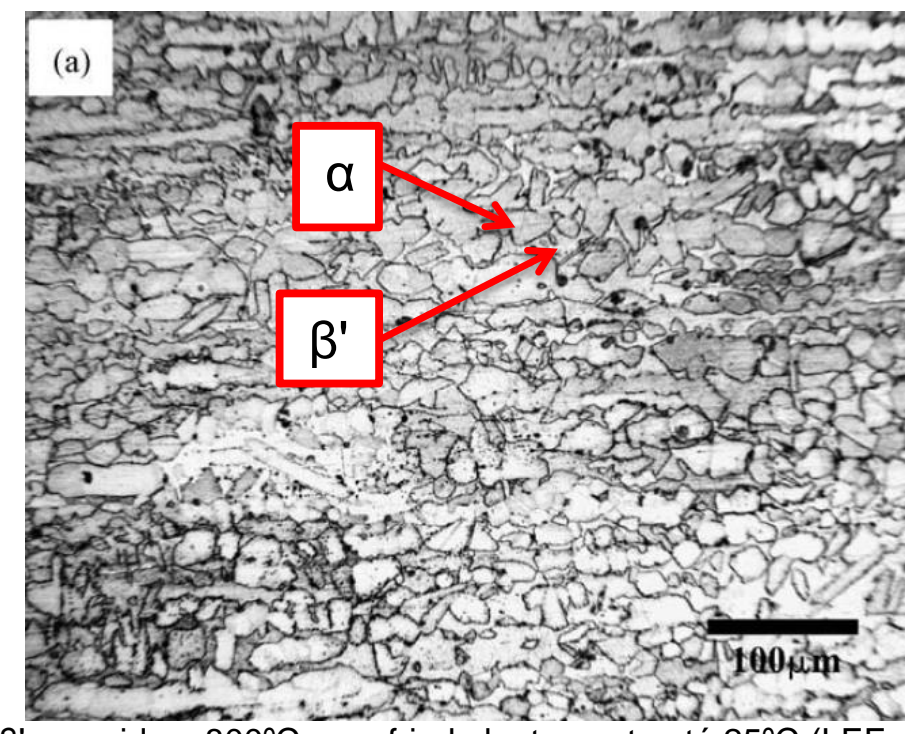

Figura 7 - Latão $\alpha$ - $\beta^{\prime}$ recozido a $800^{\circ} \mathrm{C}$ e resfriado lentamente até $25^{\circ} \mathrm{C}$ (LEE et al, 2003). A fase $\alpha$ e $\beta^{\prime}$ estão indicadas na micrografia

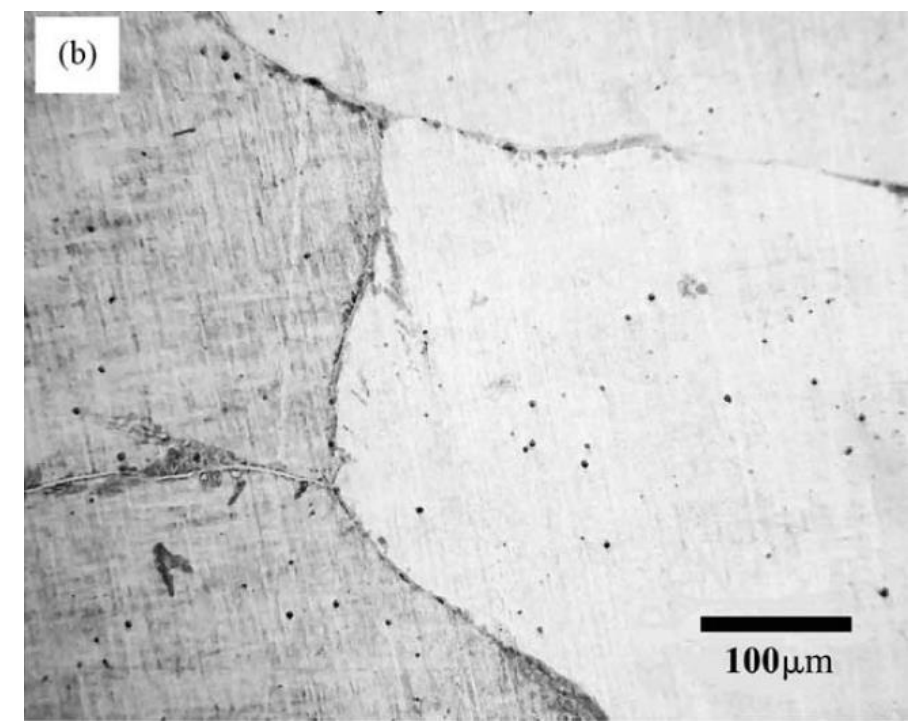

Figura 8 - Latão recozido a $800^{\circ} \mathrm{C}$ e resfriado em água até $25^{\circ} \mathrm{C}$ (LEE et al, 2003) 
As diferentes microestruturas obtidas conduzem a uma significativa diferença de dureza, sendo observado o valor de $62 \mathrm{HB}$ (68 HV) para o material resfriado em forno e $95 \mathrm{HB}(108 \mathrm{HV})$ para o material resfriado em água, conforme esquema apresentado na Figura 9.

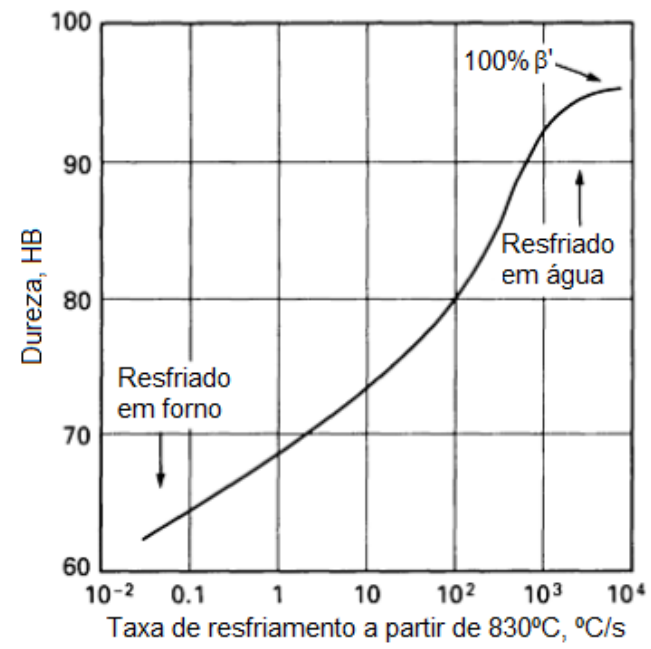

Figura 9 - Efeito da taxa de resfriamento na dureza da liga UNS-C28000 (Adaptado de ASM HANDBOOK, 1990c)

É possível a obtenção de um novo ganho de dureza, ao reaquecer estes materiais nas temperaturas indicadas na Figura 10, seguidos de um novo resfriamento rápido, podendo alcançar valores de até 125HB (143 HV). (BROOKS, 1985; ASM HANDBOOK, 1990c).
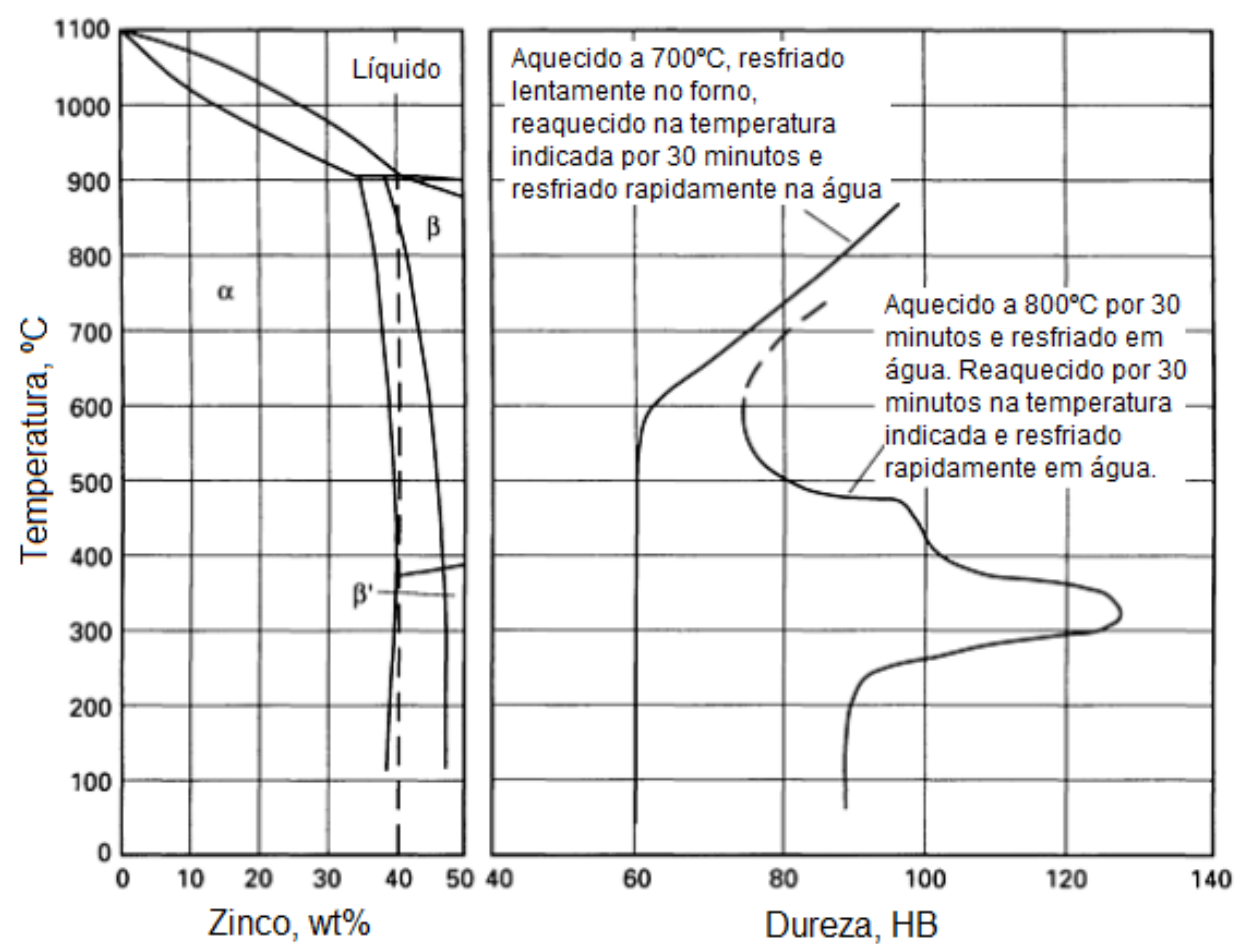

Figura 10 - Correlação de dureza no segundo tratamento térmico seguido de resfriamento rápido (Adaptado de ASM HANDBOOK, 1990c) 
Esta dureza máxima é obtida em uma faixa de temperatura de aproximadamente $300^{\circ} \mathrm{C}$ e é decorrente da formação de um precipitado finamente disperso de fase $\alpha$ sobre a fase $\beta^{\prime}$ ordenada. (BROOKS, 1985; ASM HANDBOOK, 1990c).

A dureza final é consideravelmente influenciada pela taxa de resfriamento do segundo recozimento. A Figura 11(a) mostra a microestrutura de um material resfriado em água. Ocorre neste caso uma elevada taxa de resfriamento, sendo observada uma maior taxa de nucleação. No entanto, os grãos de a não têm tempo para crescer significativamente, pois em temperaturas mais baixas a difusão é menor. (BROOKS, 1985; ASM HANDBOOK, 1990c).

Por outro lado, a microestrutura da Figura 11(b) é obtida quando se submete o material a uma taxa de resfriamento muito baixa, ocorrendo a formação de poucos núcleos de fase $\alpha$, e consequentemente resultando em grãos de $\alpha$ de maior tamanho relativo. Esta microestrutura apresenta dureza menor em comparação ao caso citado anteriormente. (BROOKS, 1985; ASM HANDBOOK, 1990c).

Portanto, para estas ligas, a sequência de tratamentos térmicos tem papel relevante na determinação da microestrutura e das propriedades mecânicas.
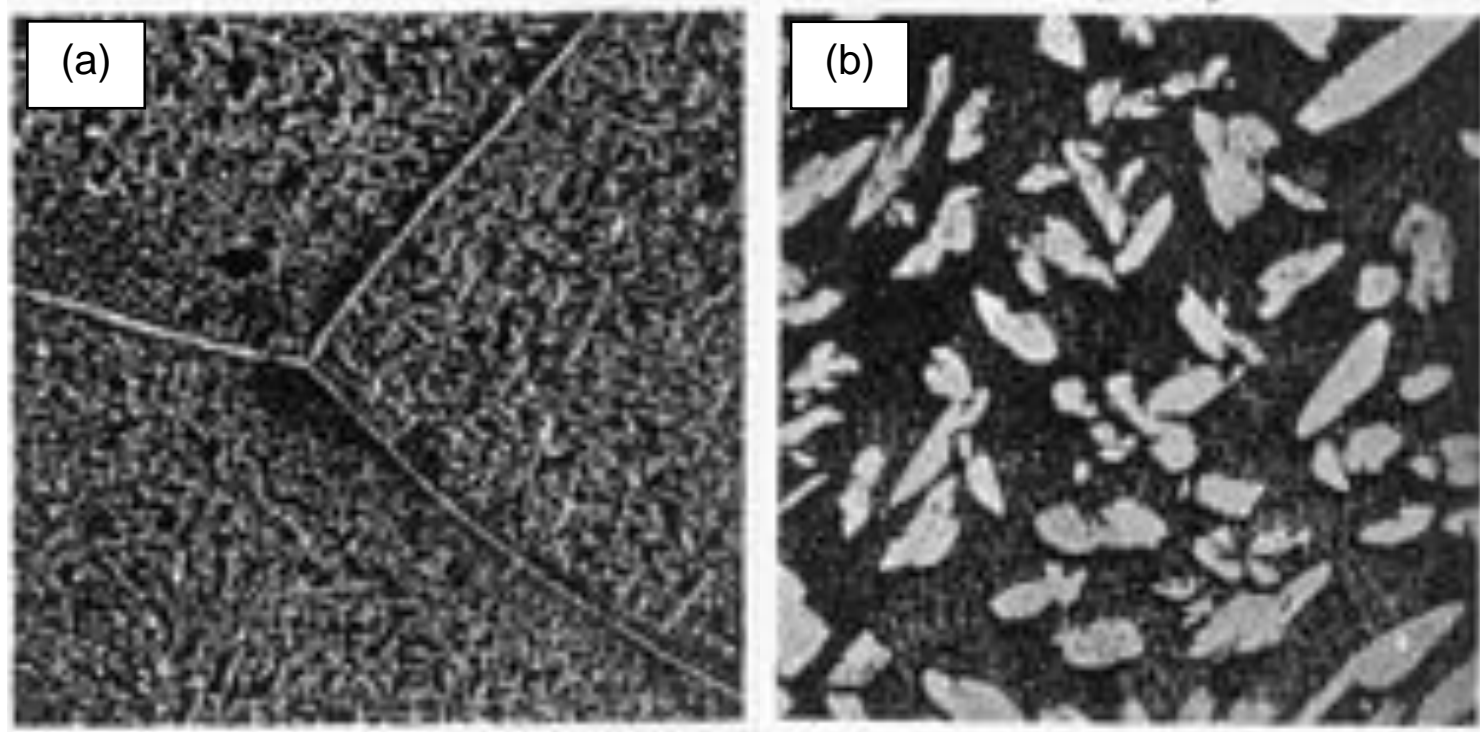

Figura 11 - Diferenças entre estruturas $\alpha$ e $\beta^{\prime}$ finamente dispersas e grosseiras, em função da temperatura do segundo aquecimento. (Adaptado de ASM HANDBOOK, 1990) 


\subsection{LIGAS DE LATÃO DE CORTE LIVRE}

Entre as aplicações das ligas de latão bifásicas, convém ressaltar o bom desempenho das mesmas nas diversas operações de usinagem, permitindo a fabricação de peças com acabamento superficial excelente, aliado a baixas forças de corte e desgaste da ferramenta. Além disso, essas ligas apresentam de boa conformabilidade a quente, fazendo com que sejam utilizadas em larga escala em componentes submetidos ao forjamento. Dentro deste contexto, as ligas de latão bifásico com a adição de chumbo, em teores de 1,5 a $3 \%$, são a solução mais comum no mercado de usinados, em função da sua característica de formação de cavacos curtos. Esta família de produtos é denominada de latões de corte livre. (COUTINHO, 1980; TRENT; WRIGHT, 2000; VILARINHO et al, 2005; HOFMANN; MAGD, 2002; ATSUMI et al, 2011; NOBEL et al, 2014).

O latão CLA, ou Corte Livre Americano (UNS-C36000) é a liga mais representativa dos latões que têm chumbo como elemento de liga, e possui uma microestrutura constituída de três fases: $\alpha, \beta$ ' os quais apresentam aspectos de formação similares ao exposto anteriormente para a Liga 60/40, e chumbo, o qual é um constituinte insolúvel em ligas de cobre. Na Figura 12, observa-se a matriz de cor amarela a qual se constitui da fase $\alpha$, a fase $\beta$ ' pela cor verde limão e chumbo, caracterizado pelos nódulos escuros dispersos na microestrutura. (COUTINHO, 1980; TRENT; WRIGHT, 2000; VILARINHO et al, 2005; HOFMANN; MAGD, 2002; ATSUMI et al, 2011; NOBEL et al, 2014).

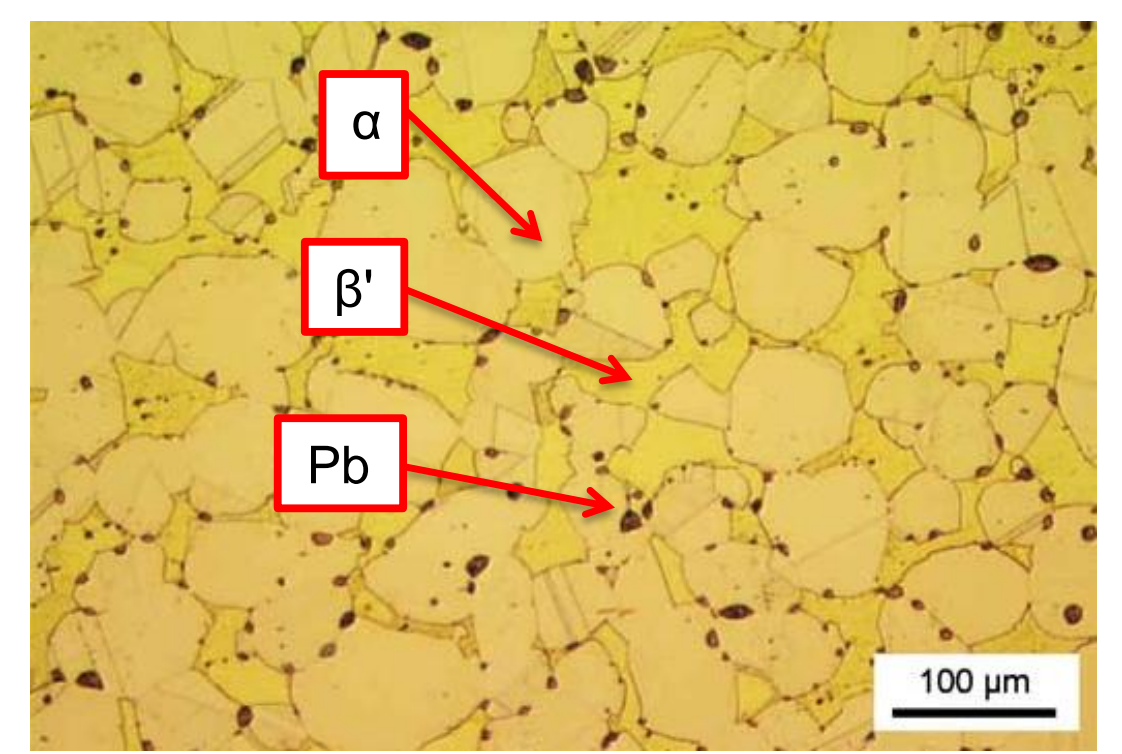

Figura 12 - Microestrutura típica de um latão de corte livre com chumbo (Latão CLA) (HOFMANN e MAGD, 2004) 
Esta microestrutura confere excelente usinabilidade, pois o elemento chumbo age de forma sinérgica com a estrutura $\alpha-\beta$ ', permitindo a ruptura dos cavacos em pequenos fragmentos, além de permitir relativa lubrificação na superfície da aresta cortante da ferramenta durante o processo de corte, o que aumenta significativamente a vida útil da mesma (COUTINHO, 1980; TRENT; WRIGHT, 2000; VILARINHO et al, 2005; HOFMANN; MAGD, 2002; ATSUMI et al, 2011; NOBEL et al, 2014).

O aspecto negativo do uso do chumbo é que, por ser um metal pesado e de manipulação nociva à saúde humana, existem inúmeras orientações e especificações legais definindo o uso de ligas livres de chumbo em muitas áreas. (ELV, 2000; ROHS, 2002; CA CODE 116876, 2005; REACH, 2006; S.152, 2007; TAHA et al, 2012; KLOCKE et al, 2012; NOBEL et al, 2014).

\subsection{EFEITOS DO CHUMBO NA SAÚDE HUMANA}

O chumbo constitui um metal abundante na crosta terrestre. Seu baixo ponto de fusão e elevada maleabilidade permitiu ser um dos primeiros metais manufaturados pelo homem, com evidências de sua utilização na Ásia Menor em 4000 A.C. Devido ao seu intensivo uso ao longo da história, muitos relatos de intoxicações foram atribuídos ao mesmo, sendo Hipócrates o primeiro a identificar o chumbo como o causador dos sintomas até então desconhecidos. A primeira descrição moderna de saturnismo foi realizada em 1839 por Tanqurel, com base em 1.200 casos estudados (NAKAMURA, 2002).

A principal via de contaminação é a inalação de fumos e poeiras, sendo estas mais frequentes do ponto de vista ocupacional, pois geralmente estão ligados a todo o tipo de processo de fabricação. Por ingestão, até $16 \%$ do chumbo pode ser absorvido por adultos, e em crianças, o percentual absorvido através da via digestiva é de $50 \%$, afetando diretamente a estrutura óssea, sistema circulatório e nervoso, gerando efeitos irreversíveis (MOREIRA, 2004).

O conhecimento do risco que a utilização do chumbo representa à saúde humana tem motivado os órgãos de saúde a exigir controles cada vez mais rígidos dos níveis do elemento em toda a cadeia produtiva, sendo muitos destes solicitando 
a redução gradativa de seu emprego. (NAKAMURA, 2002; MOREIRA, 2004; TAHA et al, 2012; KLOCKE et al, 2012; NOBEL et al, 2014)

Os principais órgãos responsáveis por estas especificações são a diretiva RoHS (Restrição da utilização de determinadas Substâncias Perigosas em Equipamentos Elétricos e Eletrônicos), a ELV (Diretiva sobre Veículos em Fim de Vida) a qual será submetida a uma nova revisão em 2015, bem como a diretiva europeia 98/83/EC, a qual desde 2013 estabelece um limite de liberação máxima de $10 \mu \mathrm{g}$ de chumbo por litro de água oriunda de conexões para água potável. Dentro deste contexto, e considerando o ponto de vista da medicina o qual demonstra a inexistência de níveis seguros para a contaminação com chumbo, as leis dos estados americanos da Califórnia (AB1953) e Vermont (S.152) limitam a quantidade máxima de $0,25 \%$ de chumbo em conexões e válvulas de ligas de latão para água potável. (ELV, 2000; ROHS, 2002; CA CODE 116876, 2005; REACH, 2006; S.152, 2007; TAHA et al, 2012; KLOCKE et al, 2012; NOBEL et al, 2014).

Baseado nestes aspectos, a necessidade de desenvolver ligas de latão isentas de chumbo adaptadas ao processo de usinagem é um requisito fundamental para atendimento da indústria em curto e médio prazo, uma vez que há a possibilidade da legislação brasileira se adaptar ao estabelecido pelas normas norte americanas e europeias, e por questões mercadológicas, visando o atendimento do mercado de exportações, principalmente no que diz respeito à indústria de equipamentos eletrônicos, automotivos e metais sanitários.

Para isso, é fundamental compreender os fenômenos envolvidos nos processos de usinagem, no intuito de desenvolver condições econômicas e técnicas favoráveis para a substituição das ligas.

Um fator preponderante neste desenvolvimento está no entendimento de que as condições de solicitações mecânicas, taxas de deformação e temperaturas as quais os materiais metálicos estão submetidos nos processos de usinagem são diferentes das observadas em condições convencionais (ou quasi-estáticas). Este entendimento exige uma compreensão dos fundamentos, bem como um equacionamento mais detalhado dos mecanismos presentes no processo de usinagem. 


\subsection{PROCESSO DE TORNEAMENTO}

O torneamento é um processo mecânico de usinagem destinado à obtenção de superfícies de revolução com auxílio de uma ou mais ferramentas monocortantes. Para tanto, a peça gira em torno do eixo principal de rotação da máquina e a ferramenta se desloca simultaneamente segundo uma trajetória coplanar com o referido eixo (ABNT NBR 6175, 1971), sendo que a Figura 13 representa o processo de torneamento cilíndrico externo, com os principais elementos envolvidos.

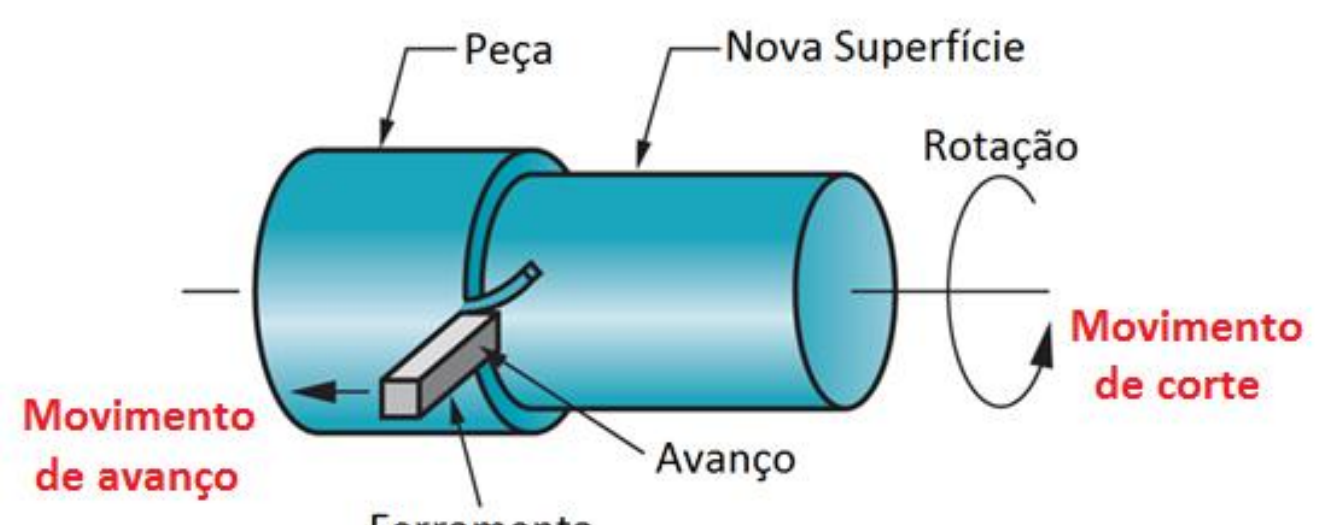

Ferramenta

Figura 13 - Representação do processo de torneamento (Adaptado de GROOVER, 2007)

Ao analisar o processo da Figura 13, observa-se a existência de 3 movimentos os quais influenciam na saída do cavaco. O movimento de corte é definido como o movimento entre a ferramenta e a peça que provoca remoção de cavaco durante uma única rotação da peça. $O$ movimento de avanço é definido como o movimento relativo ao deslocamento da ferramenta ao longo da peça possibilita uma remoção contínua do cavaco. Já o movimento efetivo é a resultante entre os movimentos de corte e avanço, realizados simultaneamente. (BOOTHROYD, 1975; ABNT NBR 6162, 1989)

Os movimentos anteriormente citados ocorrem em velocidades específicas, sendo a velocidade de corte ( $\mathrm{vc}$ ) é a velocidade instantânea do ponto de referência da aresta cortante da ferramenta, segundo a direção e o sentido de corte. Para processos com movimentos de rotação, como no caso do processo de torneamento escolhido, o valor é obtido pela equação 1 , no qual vc é a velocidade de corte em $\mathrm{mm} / \mathrm{min}$, d é o diâmetro da peça em $\mathrm{mm}$ e $\mathrm{n}$ é o número de rotações por minuto (BOOTHROYD, 1975; ABNT NBR 6162, 1989; MACHADO et al, 2011). 


$$
v c=\frac{\pi \cdot d \cdot n}{1000}
$$

A velocidade de avanço (vf) é a velocidade instantânea no ponto de referência da aresta de corte, segundo a direção e o sentido de avanço, definida pela equação 2, onde f é o avanço em mm por revolução e $\mathrm{n}$ é o número de rotações por minuto (BOOTHROYD, 1975; ABNT NBR 6162, 1989; MACHADO et al, 2011).

$$
v f=f \cdot n
$$

A seleção da velocidade efetiva mais adequada, e consequentemente das velocidades de corte e avanço, depende da operação de usinagem e dos materiais da peça e ferramenta (MACHADO et al, 2011)

\subsubsection{Principais ângulos do processo de torneamento}

Dentre os principais ângulos do processo de torneamento é possível citar o ângulo de saída $(\mathrm{y})$, mostrado na Figura 14, e definido como o ângulo entre a superfície de saída e o plano de referência da ferramenta. $O$ mesmo possui influência na força e na potência necessária ao corte, no acabamento superficial e no calor gerado. $O$ ângulo de saída pode ser positivo, nulo ou negativo e sua determinação depende das características do material a ser usinado. (ABNT NBR 6163, 1980; COSTA, 2006; MACHADO et. al, 2011)

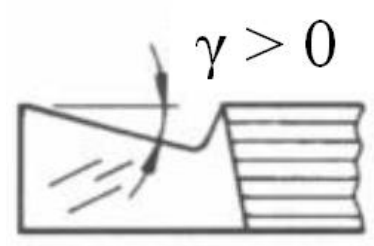

ângulo de saida positivo

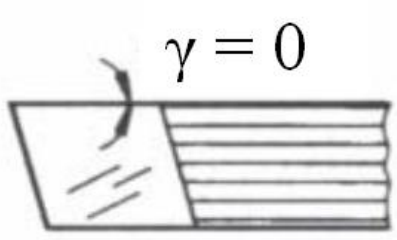

ângulo de saída nulo

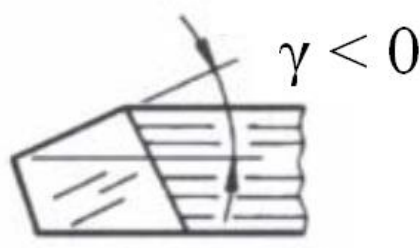

ângulo de saída negativo

Figura 14 - Ângulo de saída (Y) para uma ferramenta de torno (Adaptado de COSTA, 2006)

A Figura 15 indica os outros ângulos de corte. $O$ ângulo de folga (af), determinado pelo ângulo entre a superfície de folga e o plano de corte. A principal função do mesmo é evitar o atrito entre a peça e a superfície de folga da ferramenta. Tanto of quanto $y$ influenciam no valor do ângulo $\beta f$, o qual é definido como o ângulo de cunha da ferramenta, ligado principalmente à rigidez e resistência mecânica da 
ferramenta de corte. (ABNT NBR 6163, 1980; COSTA, 2006; MACHADO et. al, 2011). É importante comentar que os símbolos utilizados para esta descrição são diferentes dos usuais, no intuito de diferenciá-los das denominações o das fases.

$O$ ângulo de posição $(X)$ é definido entre o plano de corte e o plano de trabalho e influi diretamente na direção de saída do cavaco, o ângulo de ponta (₹f) é definido como o ângulo entre os planos principal de corte e o secundário e o ângulo de posição secundária $(X$ ') é observado entre o plano secundário de corte e o plano de trabalho. (ABNT NBR 6163, 1980; COSTA, 2006; MACHADO et. al, 2011).
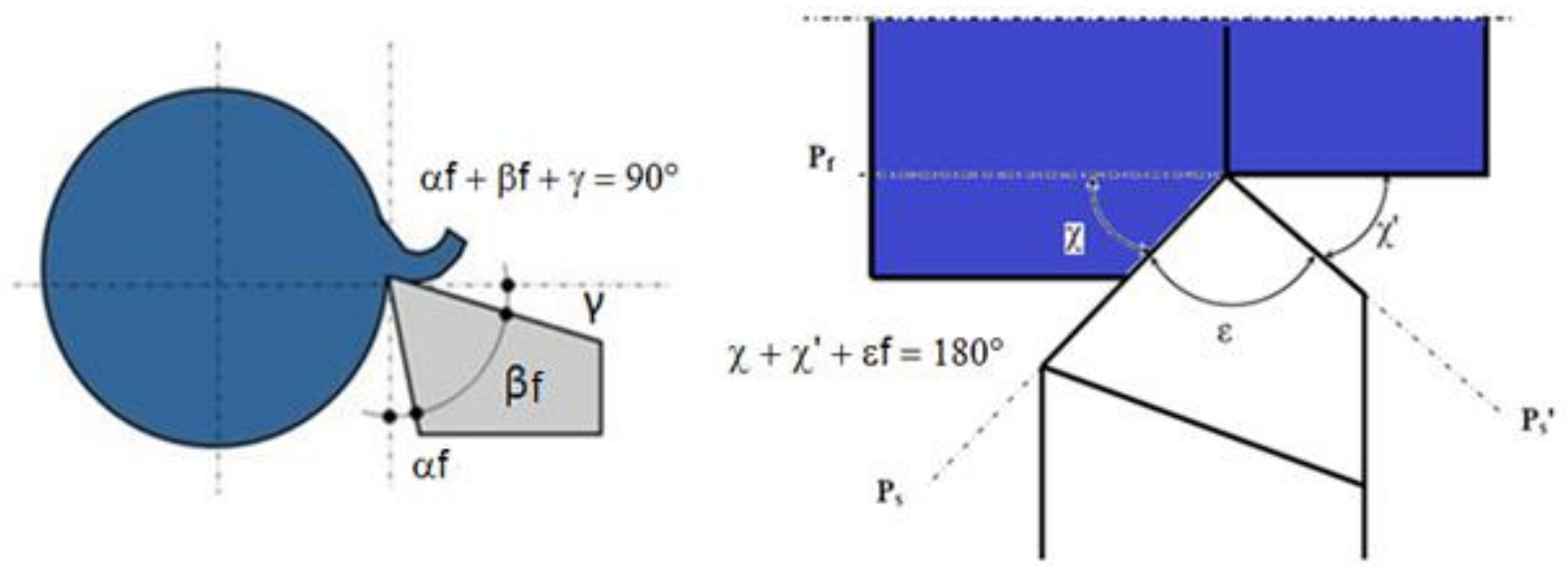

Figura 15 - Representação dos ângulos de folga (af), de cunha da ferramenta ( $\beta f)$, de saída ( $\mathrm{v}$ ), de posição $(X)$, de ponta da ferramenta ( $(\mathcal{} f)$ e de posição secundária $\left(X^{\prime}\right)$ (Adaptado de COSTA, 2006)

\subsubsection{Mecanismos fundamentais da usinagem}

O mecanismo básico que envolve o processo de corte na usinagem é o apresentado na Figura 16, o qual consiste por uma deformação por cisalhamento localizada imediatamente abaixo da aresta cortante da ferramenta. O movimento relativo entre a ferramenta e a peça exerce uma compressão no material que está sendo usinado e induz uma deformação por cisalhamento. Essa deformação leva a um processo de falha do material, formando o cavaco. O resultado do processo é a geração de uma nova superfície cilíndrica. (SHAW, 2005, ASM HANDBOOK, 1990d; MACHADO et. al, 2011).

A formação do cavaco pode ser analisada em três regiões de interesse, as quais são mostradas na Figura 16. A zona de cisalhamento primária é observada na região em que é formado um plano de cisalhamento entre o material não deformado e o material deformado pelo processo de corte, cujo ângulo é definido como ângulo de cisalhamento $(\phi)$. O cálculo desse ângulo é feito levando em conta a deformação 
do cavaco e o ângulo de saída da ferramenta. Já a zona de cisalhamento secundária se forma na interface entre o cavaco e a face da ferramenta, enquanto que a zona terciária inclui a nova superfície de revolução gerada. (MERCHANT, 1945; SHAW, 2005, ASM HANDBOOK, 1990d; MACHADO et. al, 2011).

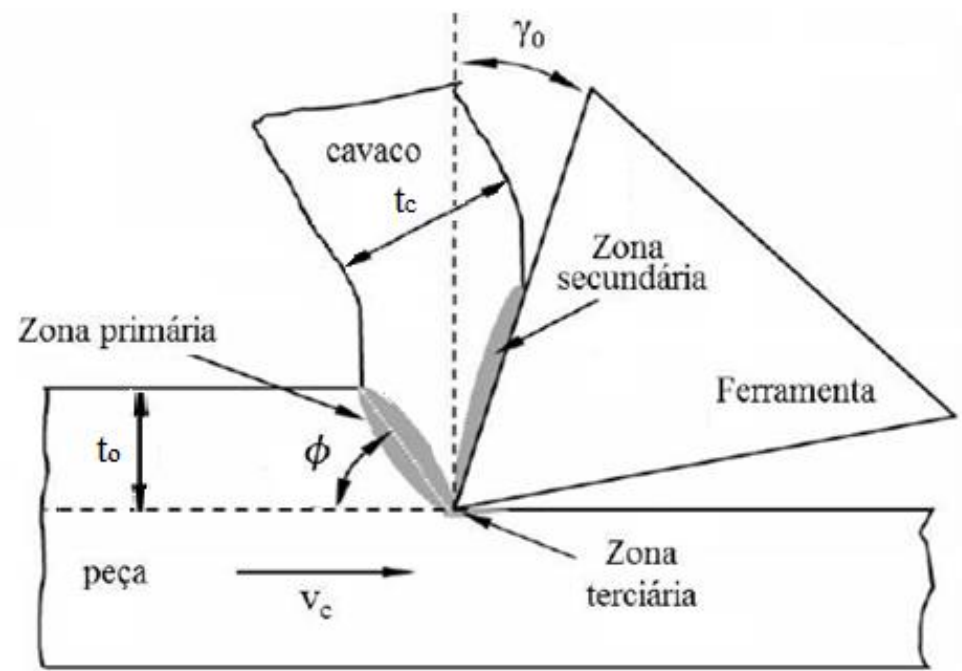

Figura 16 - Mecanismo básico do processo de corte na usinagem (Adaptado de SHAW, 2005)

De forma simplificada pode-se afirmar que na zona de cisalhamento primária, o principal interesse é relacionado com as características de deformação plástica do material a ser usinado, na zona de cisalhamento secundária, observa-se a maior influência das condições de atrito e desgaste da ferramenta e na região terciária é concentrada a maior contribuição para a integridade e rugosidade superficial da superfície gerada. (MERCHANT, 1945; SHAW, 2005, ASM HANDBOOK, 1990d; MACHADO et. al, 2011).

O correto entendimento do que ocorre nestas três regiões envolve a integração de conhecimento de vários campos de conhecimento, entre eles a física do estado sólido, ciência dos materiais, tribologia, princípios de metalurgia física, conceitos de físico-química, teoria da plasticidade e mecânica da fratura, bem como termodinâmica e transferência de calor. (SHAW, 2005)

Para fins de estudos é possível simplificar a geometria de corte partindo de um modelo tridimensional (também denominado oblíquo), mais comum em processos industriais, para um modelo bidimensional (ortogonal), os quais são comparados na Figura 17. O modelo ortogonal possui modelamento matemático mais simples, e é utilizado para as equações fundamentais da usinagem. $\mathrm{O}$ modelo 
ortogonal pode ser observado na prática em situações de torneamento de acabamento em um tubo de parede fina, como apresentado na Figura 17b. (ASM HANDBOOK, 1990d). Trabalhos em usinagem de aços inoxidáveis indicaram que, apesar das diferenças em alguns casos relativos à deformação final e tensão de cisalhamento, a usinagem de barras ou tubos apresenta a mesma tendência de comportamento com relação à variação das condições de corte, e com isso as condições de corte oblíquo podem ser consideradas satisfatórias para a análise do comportamento do material em usinagem, com a vantagem que o modelo de corte oblíquo apresentar preparação experimental mais simples em comparação com o modelo ortogonal. (SHAW, 2005; MACHADO et al, 2011; BARBOSA, 2014)
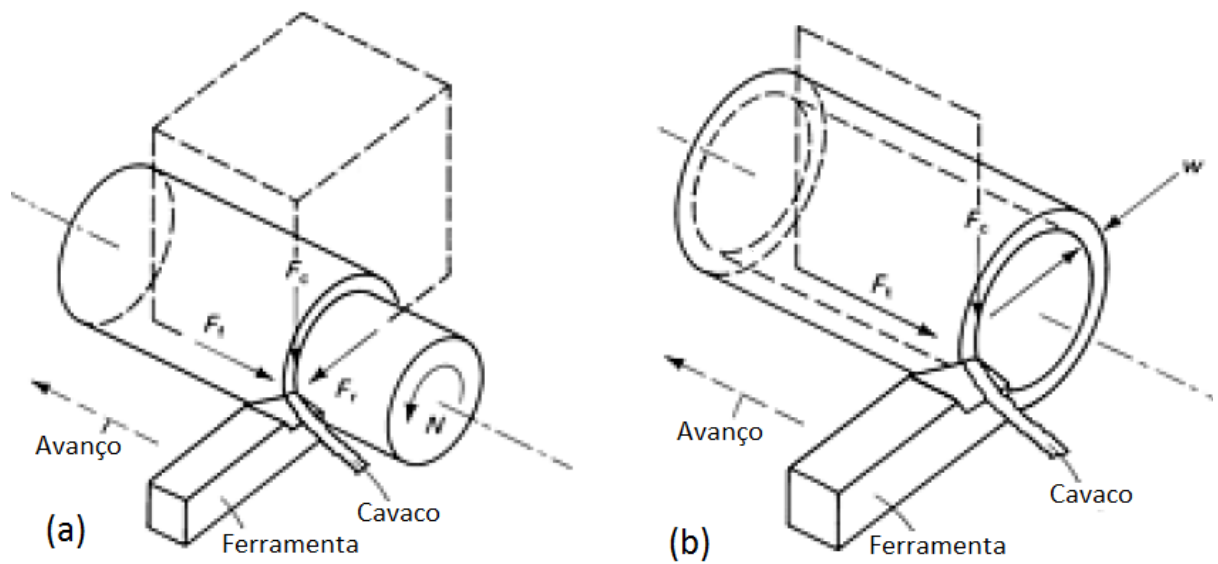

Figura 17 - Comparativo entre o corte oblíquo (a) e ortogonal (b) (ASM HANDBOOK, 1990d)

\subsubsection{Relações geométricas no corte ortogonal}

Para entendimento dos esforços e deformações presentes no processo de usinagem, é importante a definição prévia de alguns parâmetros que auxiliarão nos equacionamentos matemáticos. Pela teoria de Merchant, o grau de recalcamento do cavaco $\left(r_{c}\right)$ é obtido pela relação (3) abaixo: (MERCHANT, 1945; MACHADO et. al, 2011)

$$
r_{c}=\frac{t_{c}}{t_{o}}
$$

Onde $r_{c}$ é o grau de recalcamento do cavaco, $t_{o}$ a espessura do cavaco não deformado e $t_{c}$ a espessura do cavaco deformado. É possível observar na Figura 17 que, devido à tensão de cisalhamento existente no processo ocorrerá na região do cavaco uma deformação plástica, causando o aumento de espessura $\left(t_{c}>t_{0}\right)$ e consequentemente o valor de $r$ sempre será maior do que 1 . Considera-se que a 
largura do cavaco se manterá constante em função do estado plano de deformações. Através das relações geométricas no plano de cisalhamento, é possível relacionar o ângulo do plano de cisalhamento $(\phi)$ com o grau de recalcamento do cavaco, e o ângulo de saída da ferramenta ( $\mathrm{Y}$ ), utilizando a equação (4) (BOOTHROYD, 1975, SHAW, 2003; MACHADO et. al, 2011):

$$
\tan \phi=\frac{\cos \gamma}{r_{c} \cdot \operatorname{sen} \gamma}
$$

\subsubsection{Esforços do processo de torneamento}

A Figura 18 apresenta o modelo de corte ortogonal, com o qual é possível definir um sistema de forças de 2 componentes, tendo por referência o plano de cisalhamento. A resultante $R$ consiste na força de atrito $F$ e a força normal $N$, atuantes na área de contato entre a ferramenta e o cavaco. A força resultante $\mathrm{R}^{\prime}$ consiste de uma força de cisalhamento (Fs), e uma força normal ao plano de cisalhamento ( $F n)$, atuantes na área do plano de cisalhamento, e admite-se que as forças R e R' são iguais, colineares e orientadas em direções opostas. (MERCHANT, 1945; BOOTHROYD, 1975; TRENT; WRIGHT, 2000; MACHADO et al, 2011; SHAW, 2005).

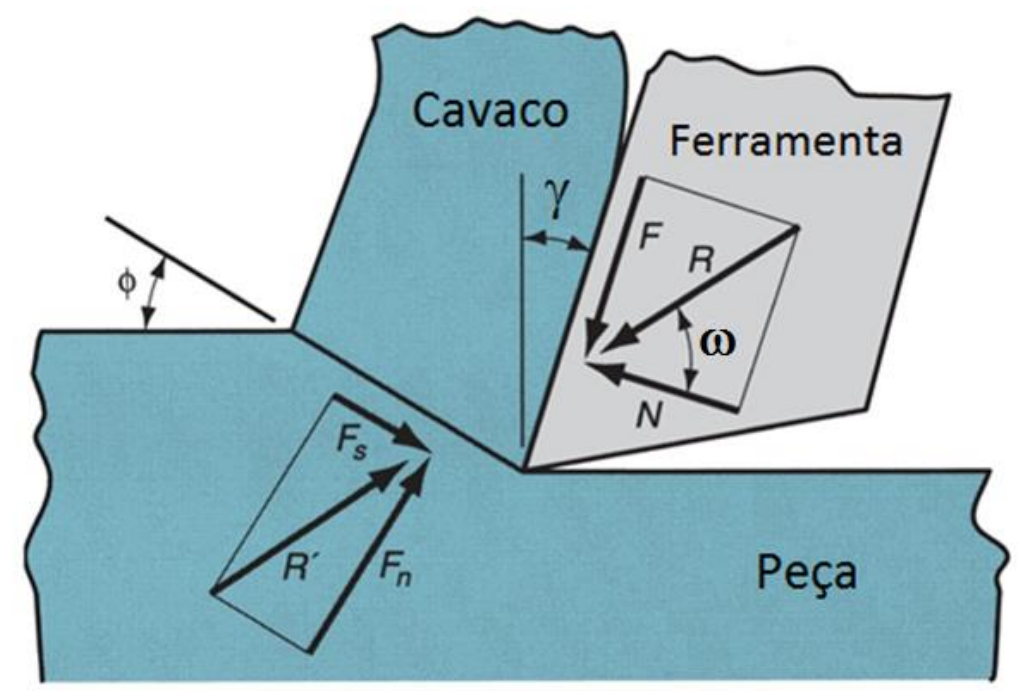

Figura 18 - Diagramas de forças no corte ortogonal (Adaptado de GROOVER, 2007)

Observa-se na relação entre a força normal $\mathrm{N}$ e a força resultante $\mathrm{R}$, a formação de um ângulo, o qual é utilizado para descrever o coeficiente de atrito do processo de usinagem na área de contato ferramenta/cavaco. O mesmo é definido pela equação (5) do coeficiente de atrito. Este valor também poderá ser expresso 
em termos de $\omega$, definido como ângulo relacionado ao coeficiente de atrito. (MERCHANT, 1945).

$$
\mu=\frac{F}{N}=\tan \omega
$$

Estas forças não são facilmente obtidas através de medição direta no processo de usinagem, porém as mesmas têm relação com as forças de corte $(F c)$ e avanço (Ff) as quais estão definidas na Figura 19 (a), as quais podem ser determinadas através de medição por célula de carga. A relação entre as mesmas é obtida por intermédio de relações trigonométricas do denominado círculo de Merchant, demonstrado na Figura 19 (b) as quais conduzem para as relações matemáticas indicadas nas equações (6), (7), (8) e (9). (MERCHANT, 1945; MACHADO et. al, 2011; ASM HANDBOOK, 1990d)

$$
\begin{gathered}
\mathrm{F}=\mathrm{F}_{\mathrm{c}} \cdot \sin \gamma+\mathrm{F}_{\mathrm{t}} \cdot \cos \gamma \\
\mathrm{N}=\mathrm{F}_{\mathrm{c}} \cdot \cos \gamma-\mathrm{F}_{\mathrm{t}} \cdot \sin \gamma \\
\mathrm{F}_{\mathrm{s}}=\mathrm{F}_{\mathrm{c}} \cdot \cos \phi-\mathrm{F}_{\mathrm{t}} \cdot \sin \phi \\
\mathrm{F}_{\mathrm{n}}=\mathrm{F}_{\mathrm{c}} \cdot \sin \phi+\mathrm{F}_{\mathrm{t}} \cdot \cos \phi
\end{gathered}
$$
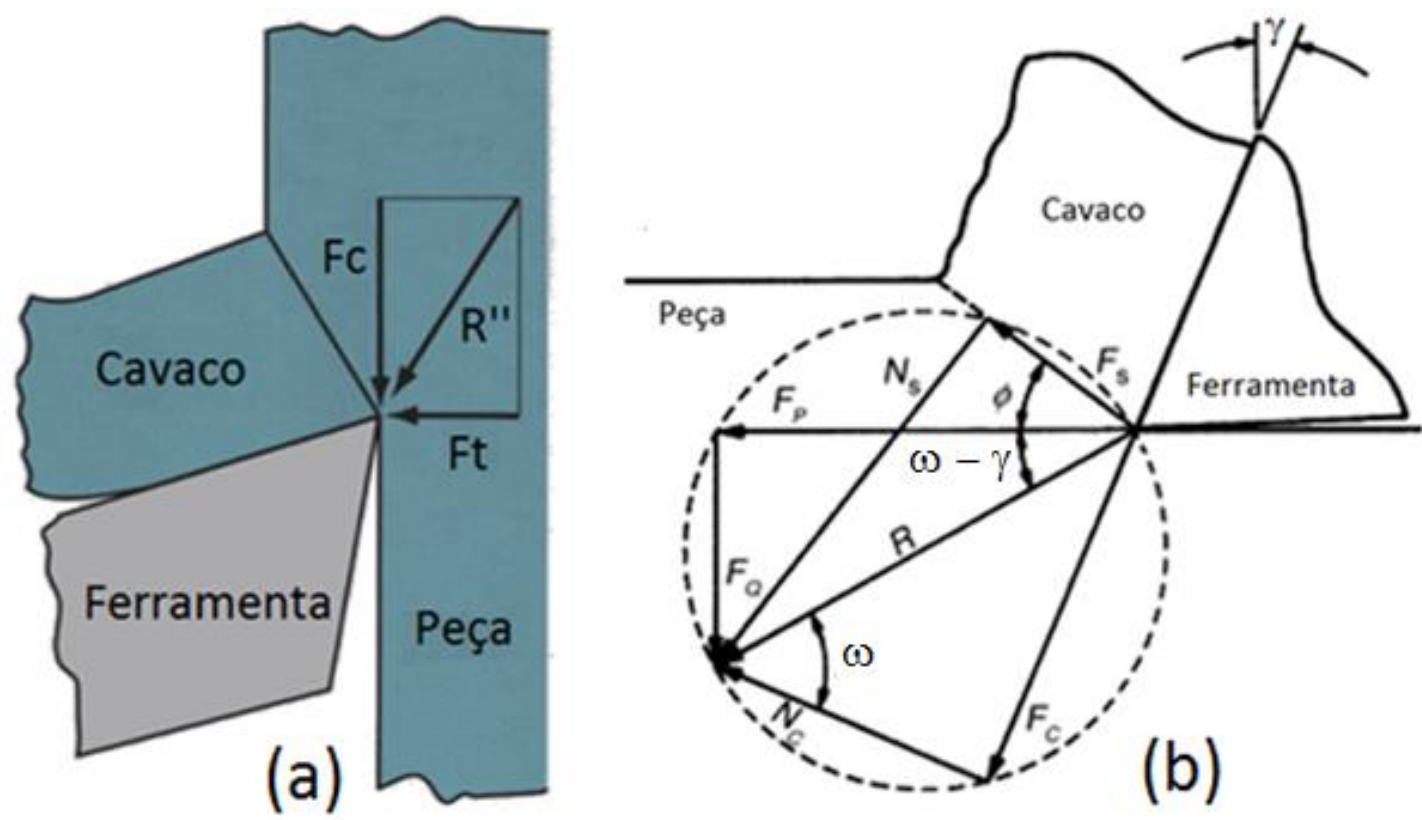

Figura 19 - Representação das forças de corte e avanço (a) e Círculo de Merchant (b) (Adaptado de GROOVER, 2007) 
A equação (10) define a tensão de cisalhamento $(\tau)$ gerada pela distribuição uniforme da força de cisalhamento (Fs) sobre o plano de cisalhamento (As), mostrado na Figura 20. Este plano de cisalhamento é formado a partir do ângulo de cisalhamento $(\phi)$ e corresponde à largura de corte $(w)$ multiplicado pela profundidade de corte $\left(t_{0} /\right.$ sen $\left.\phi\right)$. (SHAW, 2003; MACHADO, et al 2011).

$$
\tau=\frac{F s}{A s}=\frac{\left(R^{\prime} \cdot \cos (\phi+\omega-\alpha) \cdot \operatorname{sen} \phi\right)}{A s}
$$

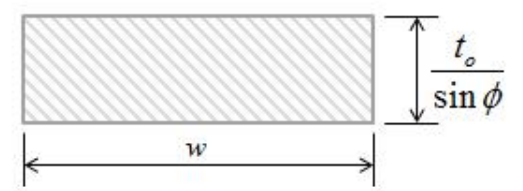

$$
\text { Onde: } A_{s}=\frac{t_{o} \cdot w}{\sin \phi}
$$

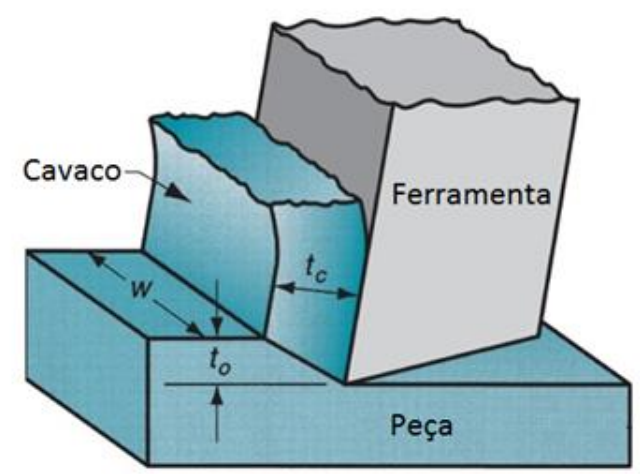

Figura 20 - Definição de As (Adaptado de GROOVER, 2007)

Uma vez que existirá um ângulo de cisalhamento $(\phi)$ no qual to será mínimo, com a consequente redução de As e $\tau$, definido matematicamente pela derivada da equação (10) em $\phi$ e igualando a mesma em zero, obtém-se a equação (11) abaixo (SHAW, 2003; ERNST; MERCHANT, 1941):

$$
\phi=45-\left(\frac{\omega}{2}\right)+\left(\frac{\gamma}{2}\right)
$$

Pela equação (11) é possível verificar que é possível variar o ângulo do plano de cisalhamento alterando-se o ângulo de saída da ferramenta ou o coeficiente de atrito (adição de lubrificantes). A variação deste ângulo terá fundamental influência no valor da tensão aplicada no processo de corte (SHAW, 2003; ERNST; MERCHANT, 1941; MACHADO et al, 2011).

\subsubsection{Deformações existentes no processo de torneamento}

A deformação plástica observada nos cavacos formados pode ser aproximada pelo modelo de planos de cisalhamento simples, conhecido como "modelo das cartas de baralho" o qual foi proposto e desenvolvido inicialmente por Piispanen, no 
qual a formação de cavacos é interpretada como uma série de planos paralelos, com deslizamento relativo em função da tensão de cisalhamento aplicada, conforme demonstrado na Figura 21. (MERCHANT, 1945; BOOTHROYD, 1975; TRENT; WRIGHT, 2000; ASTAKHOV, 2006; MACHADO et al, 2011; SHAW, 2005)

Estudar o elemento cisalhado em destaque na Figura 21 isoladamente antes e depois de passar pelo plano de cisalhamento pode trazer resultados importantes, pois se verifica a presença de dois valores, o deslocamento lateral do elemento cisalhado $(\Delta \mathrm{s})$ e a espessura elementar do cavaco $(\Delta \mathrm{y})$ (MACHADO et al, 2011).

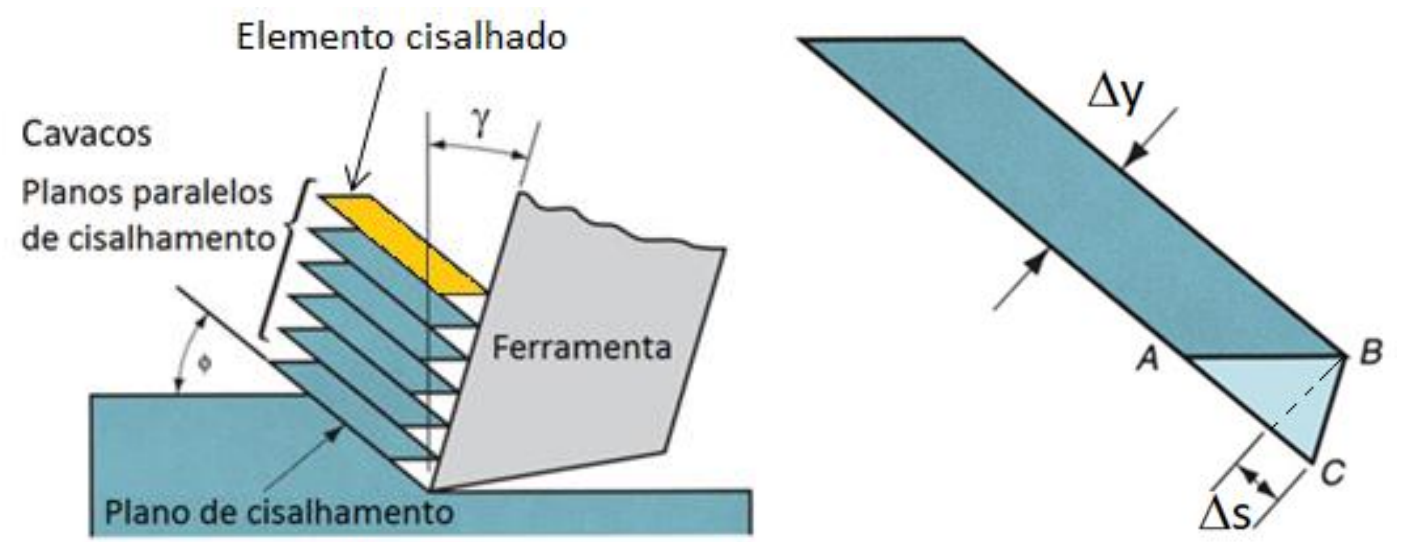

Figura 21 - Modelo de Piispanen "Modelo das cartas de baralho" (Adaptado de GROOVER, 2007 e MACHADO et al., 2011)

O grau de deformação do processo de usinagem $(\varepsilon)$, ou deformação angular deste elemento pode ser obtido por relação trigonométrica, da qual se extrai a equação (12), e pode ser expressa também em termos dos principais ângulos, conforme equação (13). (MACHADO et al, 2011)

$$
\begin{gathered}
\varepsilon=\frac{\Delta s}{\Delta y} \\
\varepsilon=\tan (\phi-\gamma)+\operatorname{cotg} \phi
\end{gathered}
$$

A substituir a equação (11) em (13) obtém-se a equação (14) abaixo, em termos de grau de recalcamento do cavaco $\mathrm{r}_{\mathrm{c}}$, e ângulo de saída Y (MACHADO et al, 2011; DAVIM; MARANHÃO, 2008).

$$
\varepsilon=\frac{1+r_{c}^{2}-2 \cdot r_{c} \cdot \operatorname{sen} \gamma}{r_{c} \cdot \cos \gamma}
$$




\subsubsection{Taxas de deformação presentes nos processos de usinagem}

Os equacionamentos matemáticos obtidos na seção 2.7 .5 possibilitam avaliar a taxa de deformação imposta no processo de usinagem. A taxa de deformação é definida como a taxa de variação da deformação em função do tempo de acordo com a equação (15) abaixo (DIETER, 1981; MEYERS, CHAWLA, 2009).

$$
\dot{\varepsilon}=\frac{\partial \varepsilon}{\partial t}
$$

Para o processo de usinagem, a velocidade com que o material é cisalhado no plano de cisalhamento, é obtida através da relação das equações (12) e (15), conforme segue abaixo, obtendo a equação (16). (MACHADO et al, 2011)

$$
\dot{\varepsilon}=\frac{\partial \varepsilon}{\partial t}=\frac{\partial}{\partial t}\left(\frac{\partial S}{\partial Y}\right)=\frac{\partial}{\partial y}\left(\frac{\partial S}{\partial t}\right)=\frac{\partial}{\partial y} v_{z}
$$

Por meio das relações trigonométricas apresentadas na Figura 22, é possível definir a velocidade de cisalhamento (vz), descrita pela equação (17). (MACHADO et al, 2011). Substituindo (17) em (16), obtém-se uma equação que define a taxa de deformação, conforme equação (18) (MACHADO et al, 2011).

$$
\begin{gathered}
v_{z}=v c \cdot \frac{\cos \gamma}{\cos (\phi-\gamma)} \\
\dot{\varepsilon}=\frac{1}{\Delta y} \cdot v c \cdot\left(\frac{\cos \gamma}{\cos (\phi-\gamma)}\right)
\end{gathered}
$$

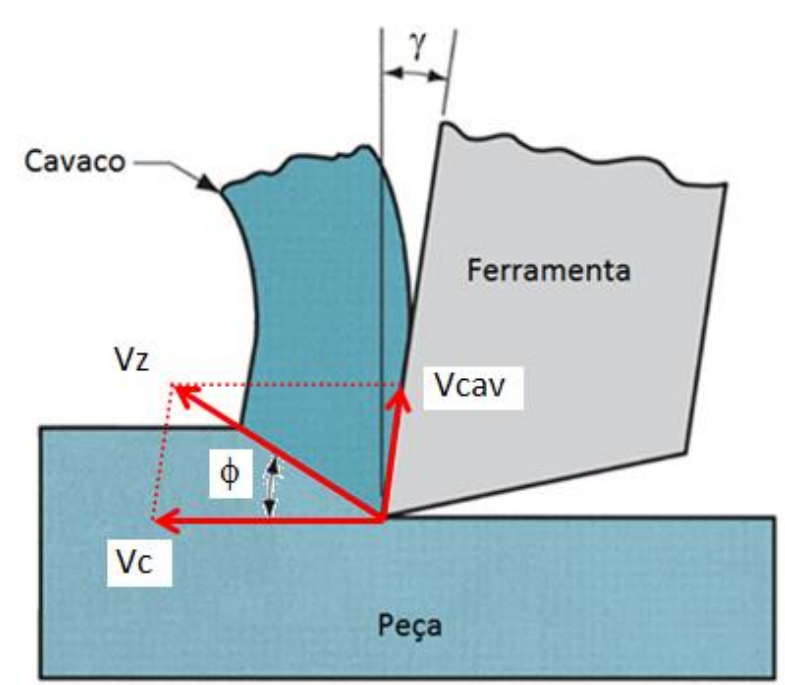

Figura 22 - Definição da velocidade de cisalhamento (vz) (MACHADO et al., 2011) 
Baseado nos seguintes dados de corte: velocidade de corte (vc) de $300 \mathrm{~m} / \mathrm{min}$, espessura elementar de cavaco $(\Delta y)$ de $21 \mu \mathrm{m}$, grau de recalcamento do cavaco de 2,1 e ângulo de saída (y) de - $6^{\circ}$, valores os quais substituídos em (12), dão o valor de $\phi=33^{\circ}$. Da equação (15), obtém-se o valor de 2,8 para a deformação em cisalhamento $\varepsilon$ e da equação (19) é possível obter um valor de taxa de deformação de $30,1 \cdot 10^{4} \mathrm{~s}^{-1}$ (DAVIM E MARANHÃO, 2008; DENKENA, 2007).

Experimentos de usinagem realizados com latões, utilizado ferramentas com ângulo de saída positivo de $15^{\circ}$, indicaram para valores de $\phi$ entre $12^{\circ}$ e $33^{\circ}$, e os valores estimados para $\Delta y$ variaram entre $10 \mu \mathrm{m}$ e $25 \mu \mathrm{m}$ (GANE 1981 apud HOFMANN; MAGD, 2004). Com isso é possível afirmar que o processo de usinagem encontra-se em uma faixa de taxas de deformação entre $10^{4}$ a $10^{6} \mathrm{~s}^{-1}$, sendo esta muito superior em comparação à maioria dos processos de conformação $\left(5 \mathrm{~s}^{-1}\right)$ ou nas velocidades normalmente empregadas em testes de tração ou de torção. (DIETER, 1981).

Esta diferença é um dos principais fatores, os quais influenciam nas diferenças encontradas nos valores da tensão de cisalhamento obtidos em ensaios de tração padronizados e nos cálculos de força de corte de usinagem (DIETER, 1981; SHAW, 2003; MACHADO et al, 2011). Diante deste fato, afirma-se que o processo de usinagem envolve altas taxas de deformação, o que implica em um estudo mais complexo do comportamento mecânico dos materiais metálicos sob estas condições.

\subsection{COMPORTAMENTO DOS MATERIAIS METÁLICOS QUANTO A TAXA DE DEFORMAÇÃO}

As tensões observadas em materiais submetidos a altas taxas de deformação são frequentemente descritas por equações constitutivas que relacionam deformação, taxa de deformação e geralmente temperatura. (MEYERS, CHAWLA 2009)

$$
\sigma=f(\varepsilon, \dot{\varepsilon}, T)
$$

A Figura 23 apresenta curvas de escoamento do Aço AISI 1040 submetido a diferentes taxas de deformação por compressão, no qual se verifica aumento da tensão de escoamento com o aumento da taxa de deformação. Ao analisar esta 
variação no modelo proposto na Figura 24 para um material genérico, e organizando os dados em uma curva log-log, obtém-se uma reta cujo coeficiente angular é definido como o parâmetro "m" ou "sensibilidade à taxa de deformação". (GROOVER, 2007; MEYERS; CHAWLA, 2009)

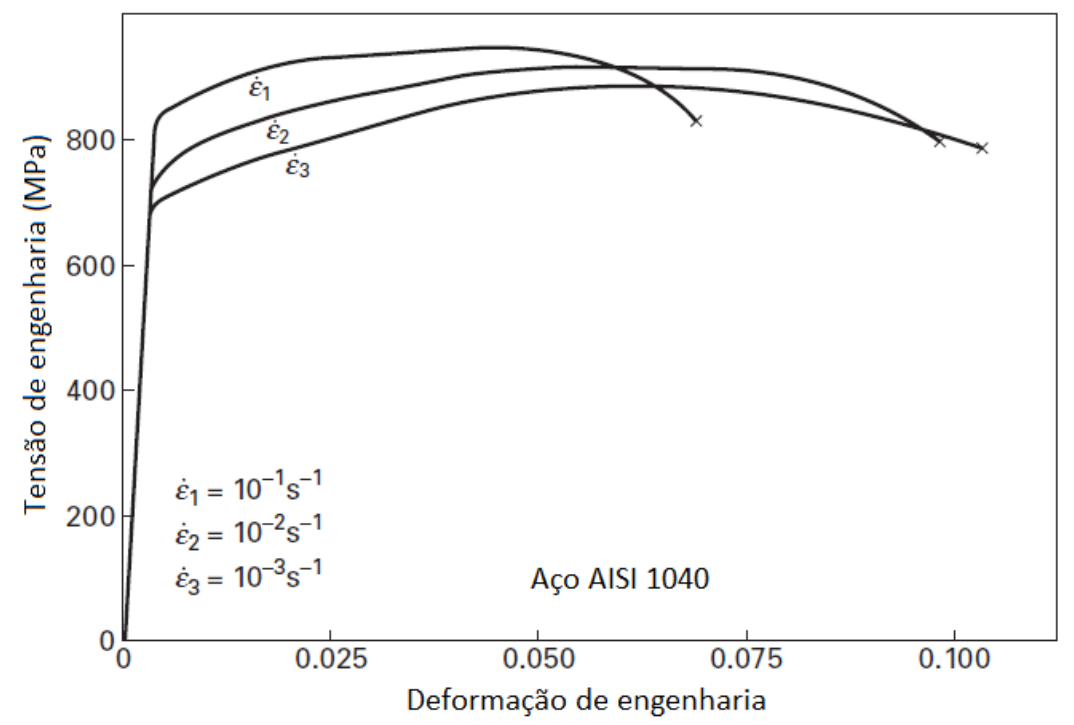

Figura 23 - Curvas tensão $x$ deformação de engenharia para o Aço AISI 1040 submetido a diferentes taxas de deformação (MEYERS, CHAWLA 2009)
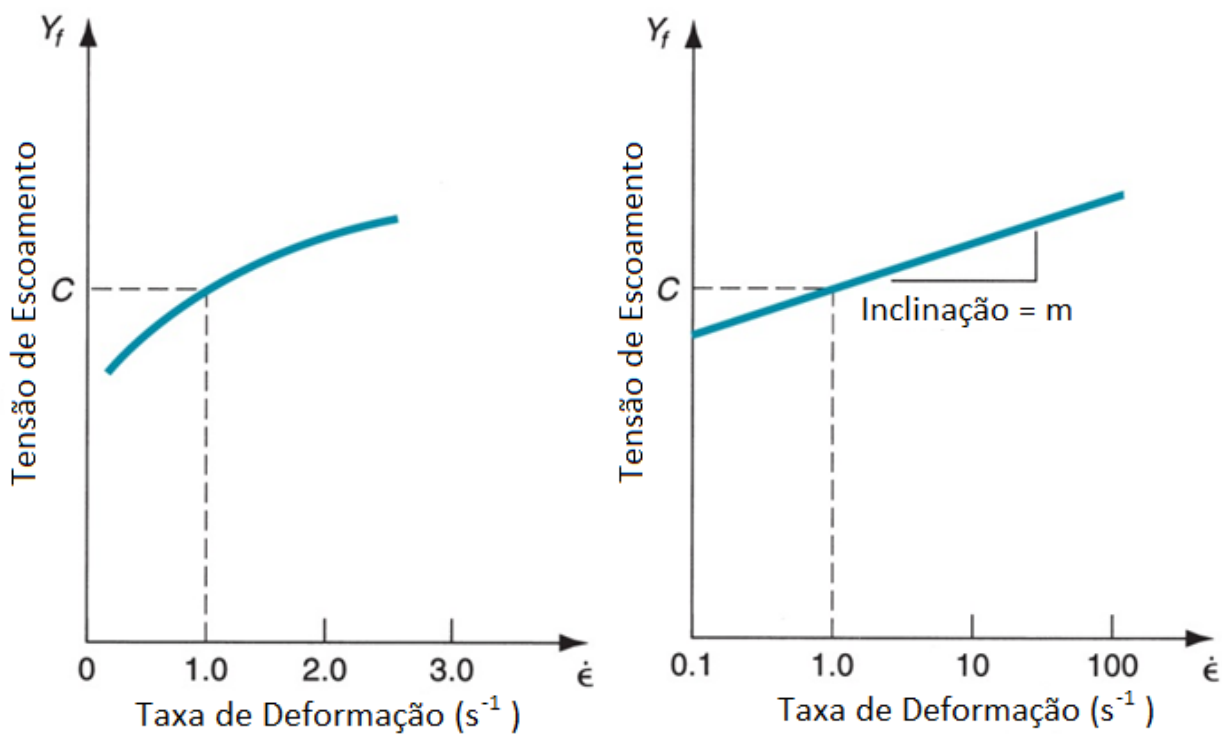

Figura 24 - Curva Tensão de escoamento x taxa de deformação (GROOVER, 2007)

A equação (20) é extraída da reta log-log demonstrada na figura 24 , sendo $C$ denominado como coeficiente de resistência à taxa de deformação. (MEYERS; CHAWLA, 2009)

$$
\sigma_{e s c}=C \cdot \dot{\varepsilon}^{m}
$$




\subsubsection{Comportamento dos latões quanto às elevadas taxas de deformação}

Estudos comparativos realizados com amostras de cobre comercialmente puro e latão 63/37, os quais foram submetidos a testes de barra torsional de Hopkinson em taxas de deformação entre $8 \times 10^{2} \mathrm{~s}^{-1}$ a $2,5 \times 10^{3} \mathrm{~s}^{-1}$ e ensaio de tração quase estático $\left(4,3 \times 10^{-3} \mathrm{~s}^{-1}\right)$ indicam, conforme as figuras 25 e 26 , uma considerável sensibilidade à taxa de deformação, porém menor do que a observada em materiais com estrutura cúbica de corpo centrado. Outro ponto importante observado, está no latão 63/37 apresentar maior sensibilidade à taxa de deformação em comparação ao cobre comercialmente puro para as mesmas deformações, sendo que esta diferença foi atribuída à presença de fase $\beta$ ', com estrutura cúbica de corpo centrado. (TSAO; CAMPBELL, 1973)

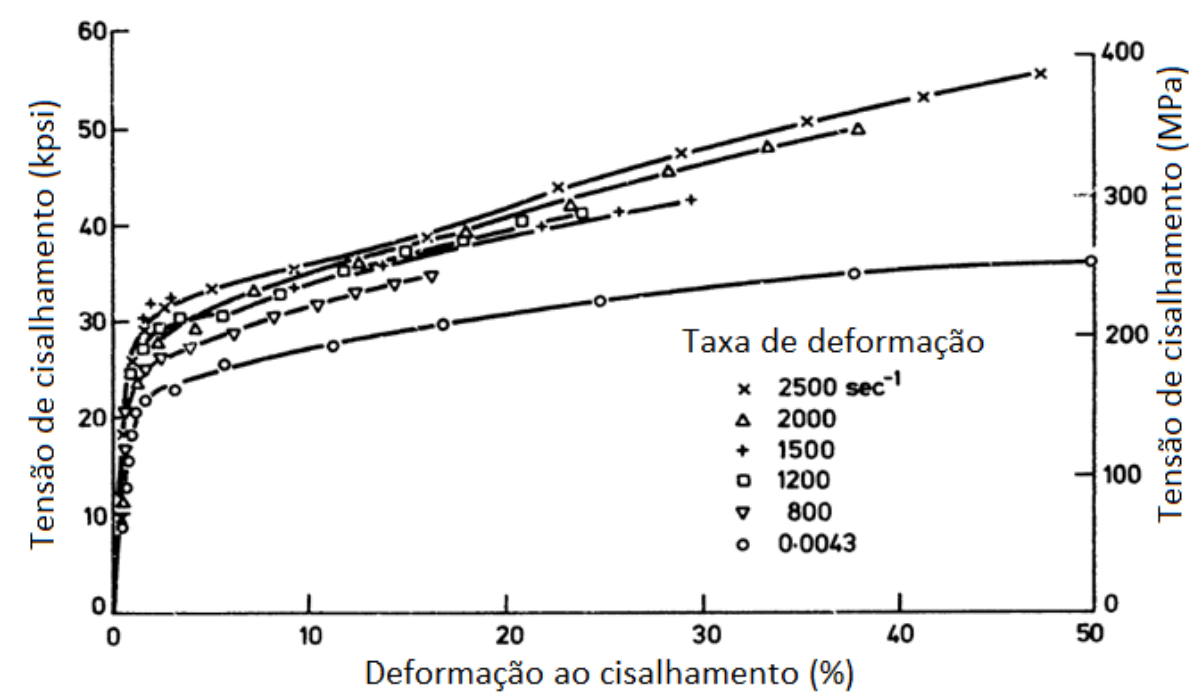

Figura 25 - Curva tensão x deformação para o latão 63/37 para diferentes taxas de deformação (Adaptado de TSAO; CAMPBELL, 1973)

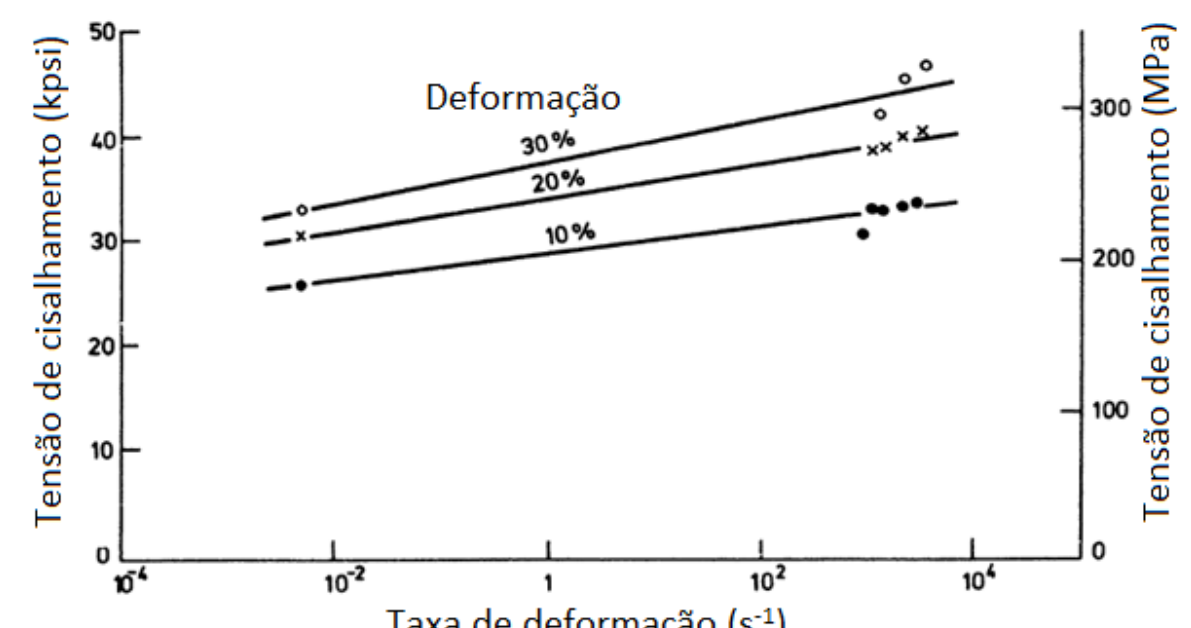

Figura 26 - Curva tensão de cisalhamento x taxa de deformação para o latão 63/37 (Adaptado de TSAO; CAMPBELL, 1973) 
Hofmann e Magd (2004) realizaram outra abordagem para avaliação do comportamento mecânico de ligas comerciais de latão em altas taxas de deformação, entre elas duas livres de chumbo: M38 (CuZn37) e MX2 (CuZn41Fe), e outras com a presença de chumbo, sendo elas: Z45 (CuZn36Pb2As), Z41 (CuZn40Pb2), e Z32 (CuZn39Pb3). Estas ligas foram submetidas aos ensaios de tração quasi-estáticos e ao ensaio de impacto por barra de Hopkinson. Com o objetivo de avaliar a condição de cisalhamento puro, os autores optaram por utilizar no teste de impacto um corpo de prova denominado hat shaped (formato de chapéu), o qual é ilustrado no desenho esquemático da Figura 27. O parâmetro $B$ pode ter o seu tamanho correlacionado com a espessura do cavaco. (HOFMANN; MAGD, 2004)

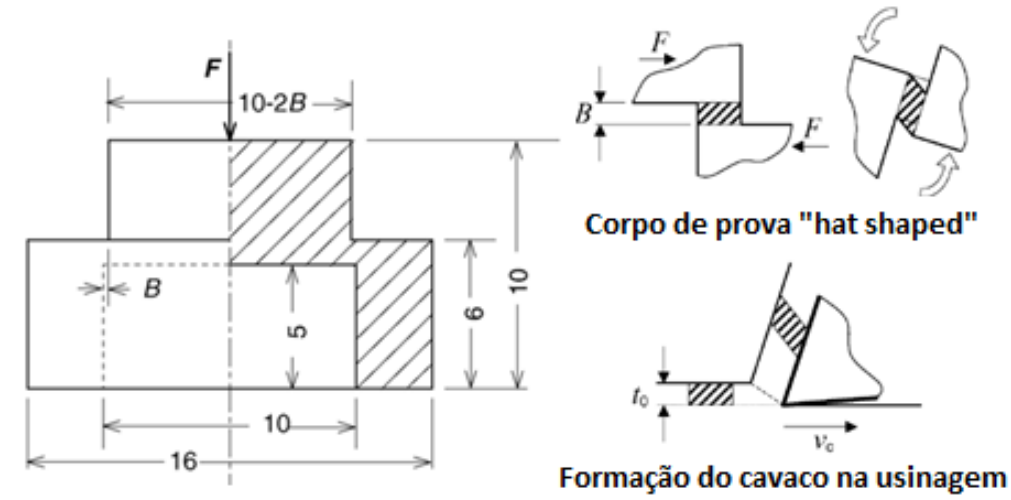

Figura 27 - Dispositivo Hat-shaped para medições de tensões de cisalhamento e sua correlação com o cavaco formado na usinagem (Adaptado de HOFMANN E MAGD, 2004)

Os resultados obtidos nos ensaios de barra de Hopkinson foram consideravelmente maiores em comparação aos resultados obtidos nos ensaios de tração convencional, como esperado. Como referência, a liga MX2 (CuZn41Fe), apresentou cerca de $950 \mathrm{MPa}$ no ensaio da barra de Hopkinson e $373 \mathrm{MPa}$ no ensaio de tração convencional. (HOFMANN; MAGD, 2004),

Os valores obtidos nos testes da barra de Hopkinson com os corpos de prova descritos anteriormente foram analisados pelo ponto de vista do trabalho de deformação por cisalhamento por unidade de volume para separação o material (W) e a deformação equivalente até a ruptura, definido pela equação (21). Estes dados podem ser correlacionados de forma preliminar com a propensão de um material formar cavacos quebradiços. Os resultados obtidos no teste estão indicados na Figura 28. (HOFMANN; MAGD, 2004). 


$$
W=\int_{0}^{\sqrt{3} \cdot \varepsilon f} \tau \cdot d \gamma
$$

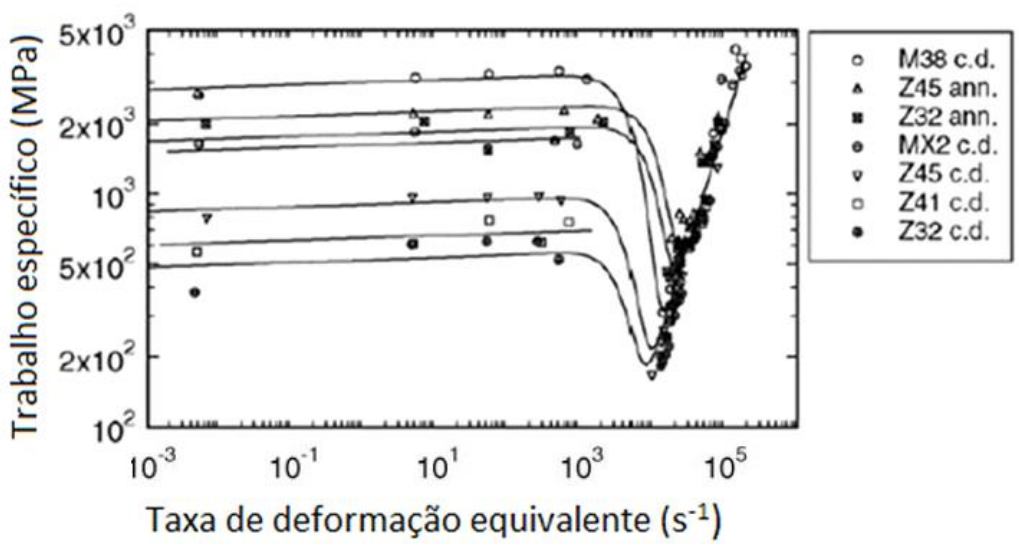

Figura 28 - Variação do trabalho específico para ligas de latão submetidas a diversas taxas de deformação (Adaptado de HOFMANN E MAGD, 2004)

Verifica-se que, para uma mesma dureza e limite de resistência a tração, as ligas com chumbo (Z32, Z41, Z35) apresentaram menores valores para W em comparação as ligas sem chumbo (M38 e MX2). Outro aspecto importante a ser avaliado é o comportamento das ligas Z45 e Z32 ao comparar o estado recozido com o encruado, indicando que a quantidade de trabalho a frio é muito importante no comportamento do material no processo de usinagem. A figura 29 apresenta as alterações limite de escoamento e resistência em função do encruamento para a liga UNS-C28000 (ASM HANDBOOK 1990a).

Em processo de usinagem onde se observam altas taxas de deformação as avaliações apresentadas em ensaios são importantes para a avaliação do material e de formação de cavaco.

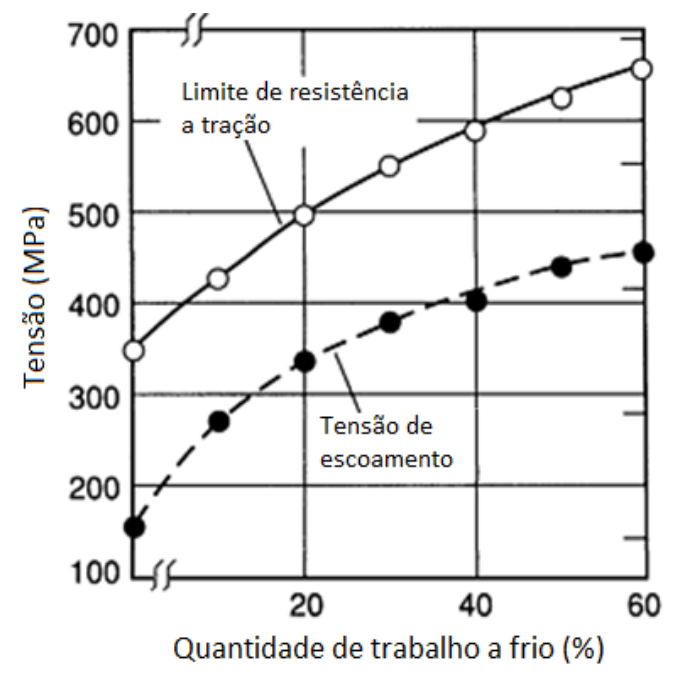

Figura 29 - Comportamento mecânico da liga UNS-C28000 em função da variação do trabalho a frio empregado (ASM HANDBOOK, 1990) 


\subsubsection{Influência da transformação ordem-desordem no comportamento mecânico em diferentes taxas de deformação e temperatura}

No intuito de observar o efeito das taxas de deformação em materiais sujeitos às transformações ordem-desordem, foi realizado um experimento com bicristais de latão $\alpha-\beta$ ', em temperaturas de 371 e $427^{\circ} \mathrm{C}$, localizadas abaixo da temperatura de transformação $\beta^{\prime} \rightarrow \beta$, com a consequente presença da fase $\beta^{\prime}$ ordenada. Para a observação da fase $\beta$ desordenada, foram conduzidos tratamentos em temperaturas de $438^{\circ} \mathrm{C}$ e $538^{\circ} \mathrm{C}$, acima da temperatura de transformação. Também foi avaliado o comportamento das amostras em diferentes taxas de deformação: 0,01 $\min ^{-1}, 0,02$ $\min ^{-1}, 0,05 \min ^{-1}, 0,10 \min ^{-1}, 0,15 \min ^{-1}$ e $0,20 \mathrm{~min}^{-1}$. (KHEZRI-YAZDAN; SUBRAMANIAN, 1984a, 1985b, 1985c). Em todas as taxas de deformação utilizadas em temperaturas abaixo da transformação $\beta^{\prime} \rightarrow \beta$, observou-se comportamento mecânico similar ao presente na temperatura ambiente, caracterizados por tensões de escoamento relativamente altas, sendo que em todas as amostras a deformação plástica teve início nas regiões de fase a através do mecanismo de deslizamento de discordâncias, mostrado na Figura 30a.

O gradativo aumento das linhas de deslizamento conduz para uma interação destas com as regiões de interface, resultando na deformação plástica da fase $\beta$. $O$ material apresentou falhas pela formação de trincas nos contornos de grão de fase $\beta$, em decorrência da deformação não uniforme, mostrado na Figura 30b. (KHEZRIYAZDAN; SUBRAMANIAN, 1984a)

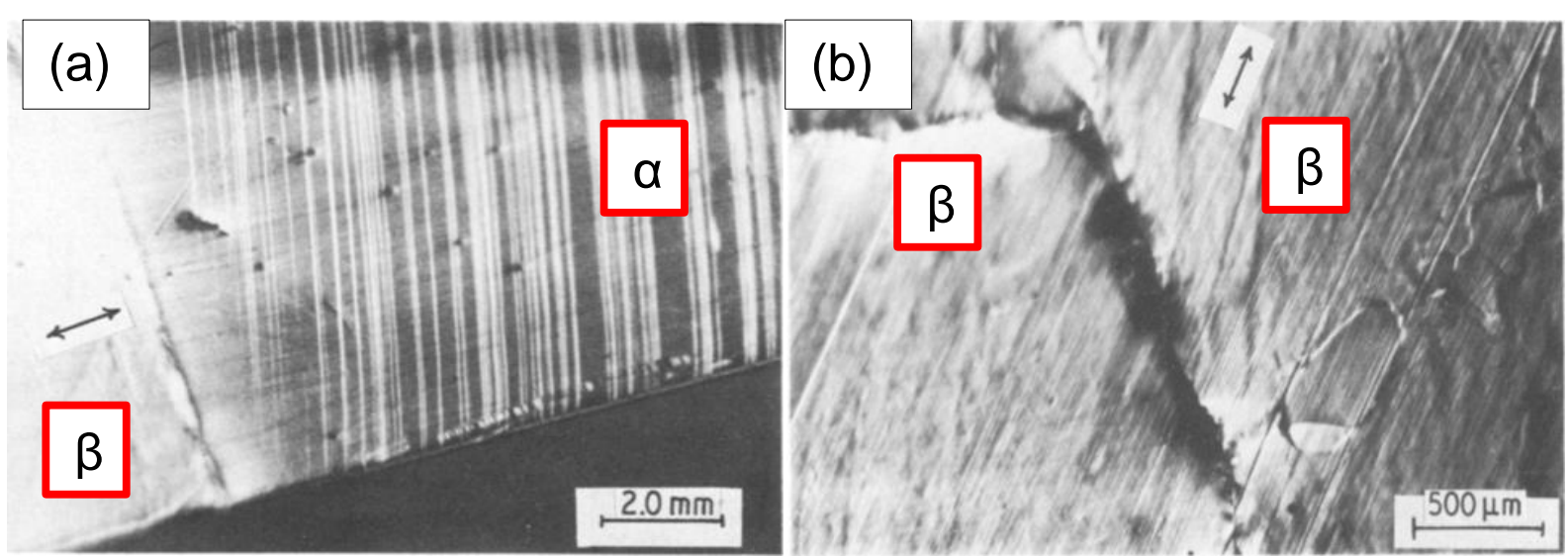

Figura 30 - Análise da deformação de bicristal de latão $\alpha-\beta$ em temperaturas abaixo da transformação ordem desordem. (KHEZRI-YAZDAN; SUBRAMANIAN, 1984a) 
Um comportamento distinto é observado em amostras testadas em temperaturas acima da transformação $\beta^{\prime} \rightarrow \beta$, no qual a deformação plástica é iniciada no cristal de fase $\beta$, através do mecanismo de movimentação dos contornos de grão. Nesta temperatura verifica-se que a fase a não se deforma significativamente. As falhas nesta situação ocorrem devido a fraturas intergranulares nos grãos de fase $\beta$. (KHEZRI-YAZDAN; SUBRAMANIAN, 1984b)

Esta diferença se torna mais pronunciada na temperatura de $538^{\circ} \mathrm{C}$, na qual a deformação plástica ocorre pelo mecanismo de movimentação de discordâncias, sem a evidência de encruamento, sendo que a fase $\beta$ apresenta maior ductilidade do que a fase $\alpha$. A Figura 31 abaixo indica que o monocristal de fase $\beta$ sofre extensa deformação antes da fratura, sendo a ruptura final caracterizada por uma significativa estriç̧ão do corpo de prova. (KHEZRI-YAZDAN; SUBRAMANIAN, 1984b, 1984c)
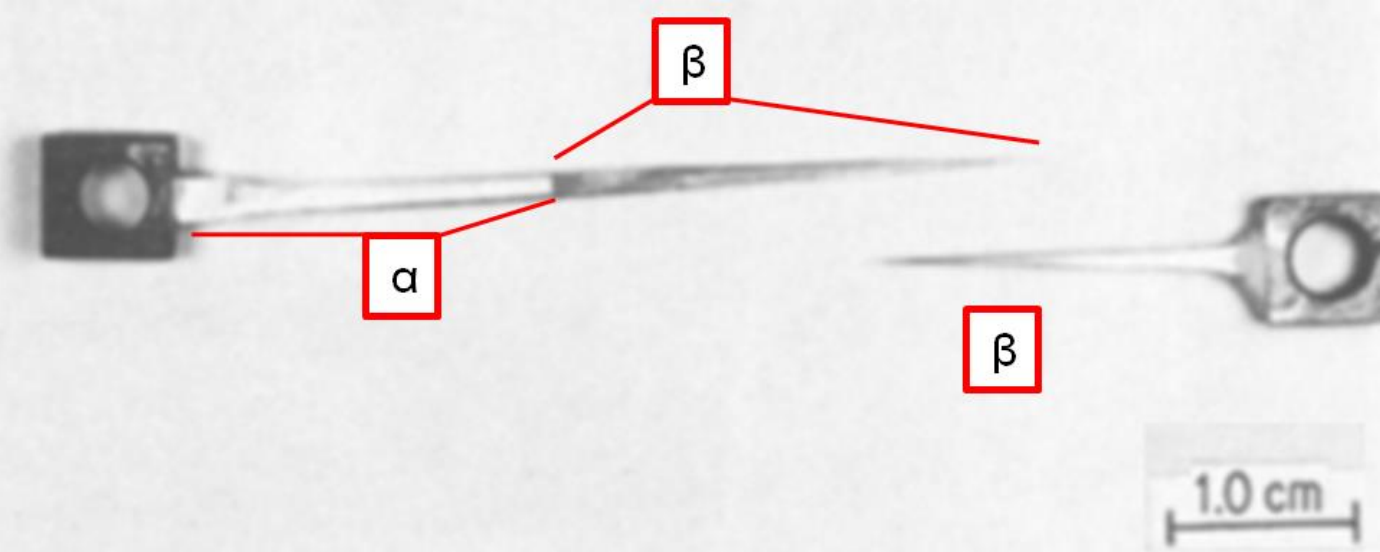

Figura 31 - Aspecto da fratura do bicristal de latão $\alpha-\beta$ submetido à temperatura de $538^{\circ} \mathrm{C}(\mathrm{KHEZRI}-$ YAZDAN; SUBRAMANIAN, 1984b)

Quanto à taxa de deformação, a Figura 32 mostra que o comportamento de deformação da fase $\beta$ é altamente sensível a taxa de deformação, sendo que esta sensibilidade não é afetada por variações de temperatura. (KHEZRI-YAZDAN; SUBRAMANIAN, 1984c).

Outro aspecto importante é o relativo ao comportamento da microestrutura deformada em temperatura acima da transformação ordem-desordem, no qual os grãos de fase $\alpha$, menos dúcteis nestas condições se acomodam em forma de placas, e a fase $\beta$ se comporta de maneira dúctil neste regime, acomodando os cristais lenticulares de fase de forma alinhada. (BARO, 1971 apud KHEZRIYAZDAN; SUBRAMANIAN, 1984b) 


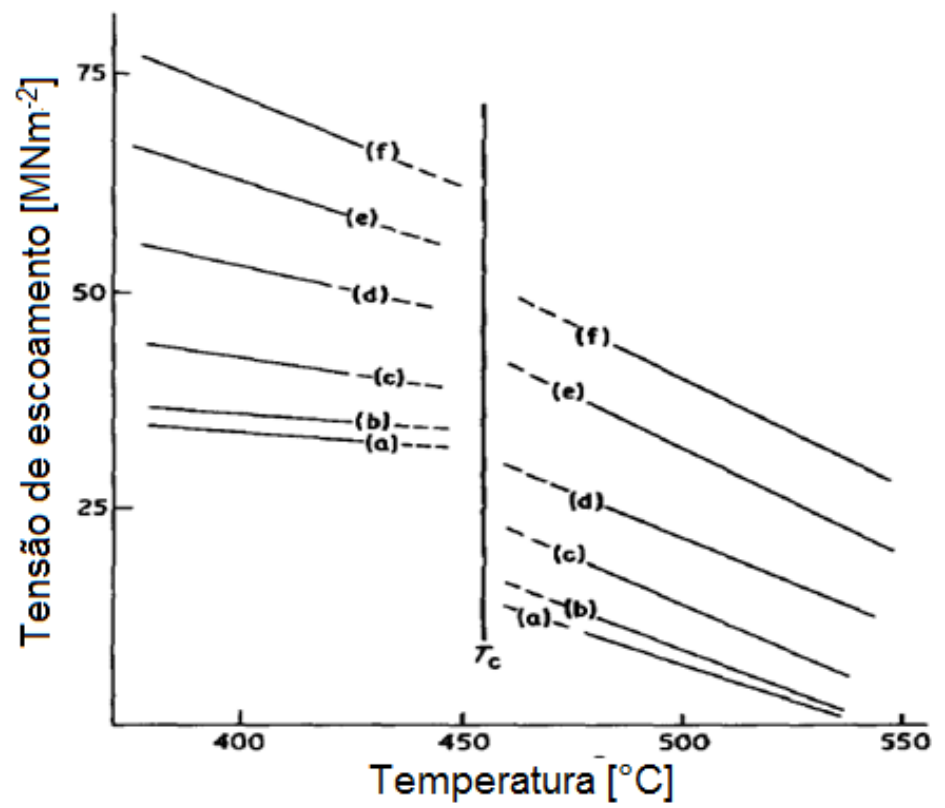

Figura 32 - Tensões de escoamento para latão beta policristalino, testado em elevadas temperaturas e taxas de deformação (a) $0,01 \mathrm{~min}^{-1}$; (b) $0.02 \mathrm{~min}^{-1}$; (c) $0.05 \mathrm{~min}^{-1}$; (d) $0.10 \mathrm{~min}^{-1}$; (e) $0.15 \mathrm{~min}^{-1}$; (f) $0.20 \mathrm{~min}^{-1}$ (KHEZRI-YAZDAN; SUBRAMANIAN, 1984c)

Uma vez que a fase $\beta$ presente nos latões em condições com temperaturas acima da crítica de transformação ordem-desordem conduzem para uma significativa alteração do comportamento mecânico destas ligas, e sabendo que a energia consumida nos processos de usinagem tem uma parcela convertida em calor, é necessário compreender os mecanismos de geração e transferência de calor nos processos de torneamento e nos mecanismos de usinagem anteriormente descritos.

\subsection{CALOR GERADO NO PROCESSO DE USINAGEM}

Maior parte da potência consumida na usinagem dos metais é convertida em calor próximo à aresta cortante, sendo grande parte deste calor contida no cavaco retirado. Esta afirmação corrobora com o indicado por Meyers e Chawla, de que conforme se aumenta a taxa de deformação aplicada ao material, o processo de deformação muda gradualmente de totalmente isotérmico para totalmente adiabático (MACHADO et al, 2011; MEYERS, CHAWLA 2009).

Um estudo conduzido em 1950 comparou as quantidades de calor armazenadas no cavaco, na ferramenta e na peça, cujo resultado está demonstrado na Figura 33, indicando consistência com o exposto acima, pois conforme se aumenta a velocidade de corte, ocorre consequentemente o aumento também da taxa de deformação e o processo se aproxima cada vez mais de um comportamento adiabático. (SCHMIDT, 1950; SHAW, 2005; MACHADO et al, 2011), 


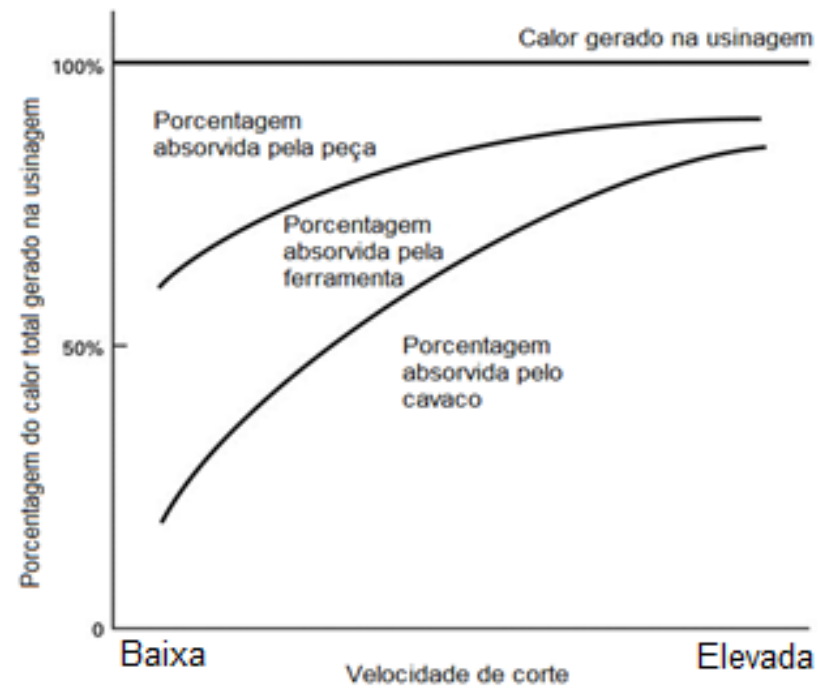

Figura 33 - Distribuição do calor gerado na usinagem distribuído no cavaco, na ferramenta e na peça (Adaptado de SCHMIDT, 1950).

O calor gerado no cavaco, principal parcela do efeito térmico, pode ser analisado sob a influência de três principais fontes geradoras de calor, as quais são responsáveis pelo aumento de temperatura no processo de corte, sendo elas a deformação plástica e cisalhamento do cavaco no plano de cisalhamento primário, atrito do cavaco com a superfície de saída da ferramenta e atrito da superfície de folga da ferramenta com a peça, as quais correspondem respectivamente à zona de cisalhamento primária, secundária e terciária, conforme mostrado na Figura 16. (BOOTHROYD, 1975; TRENT; WRIGHT, 2000; SHAW, 2005; MACHADO et al, 2011)

Existem técnicas experimentais as quais são utilizadas para a medição da temperatura, sendo a principal a inserção de termopares na ferramenta de corte, nas proximidades da região de cisalhamento secundário. Entretanto, os métodos de medição direta acarretam em variações nas observações experimentais em decorrência da dificuldade de acesso à região do corte devido à pequena área disponível para medição, além do elevado gradiente térmico existente nas regiões de geração de calor, como o mostrado na Figura 34, principalmente nas proximidades da zona de cisalhamento primário e da interface entre a ferramenta e o cavaco. (BOOTHROYD, 1975; TAY; 1993; TRENT; WRIGHT, 2000; SHAW, 2005; MACHADO et al, 2011; KLOCKE et al 2012) 


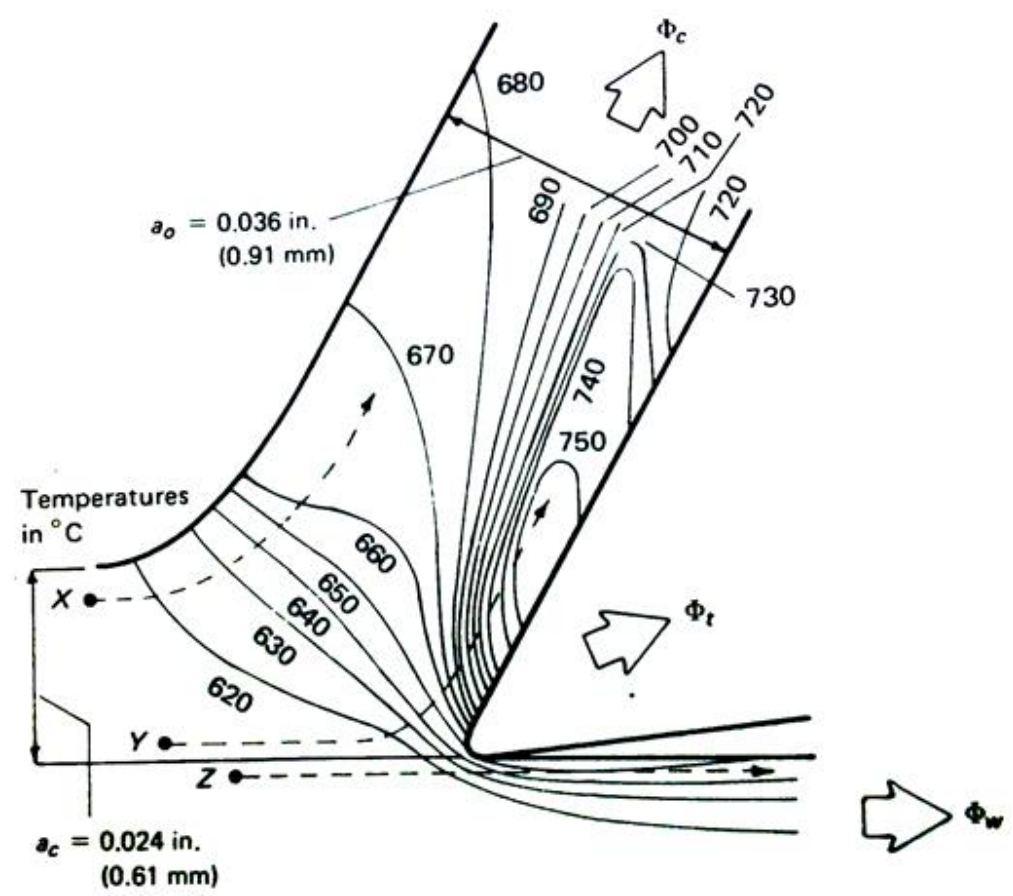

Figura 34 - Gradiente térmico observado por medição por radiação infravermelha do corte ortogonal de aço de corte livre (BOOTHROYD, 1975)

Com isso, as abordagens analíticas, apesar de serem complexas e atribuídas com hipóteses simplificadoras, caracterizam-se como uma importante ferramenta para análise das temperaturas na usinagem. (BOOTHROYD, 1975; TAY; 1993; TRENT; WRIGHT, 2000; MACHADO et al, 2011)

\subsubsection{Modelo analítico para as temperaturas geradas na usinagem}

A abordagem analítica para o efeito térmico da usinagem vem sendo utilizada com base nos modelos concebidos a partir da análise do corte ortogonal, pelo princípio de que o fluxo de calor se dá em regime permanente. A temperatura gerada na interface ferramenta/cavaco está associada à temperatura obtida pelo cisalhamento da zona primária e ao aumento de temperatura causado pelo atrito entre o cavaco e a superfície de saída, sendo desprezado o calor gerado pela zona terciária. (BOOTHROYD, 1975; TAY; 1993; TRENT; WRIGHT, 2000; MACHADO et al, 2011)

Baseando-se em experimentos de furação, Trigger e Chao também assumem que $10 \%$ do calor gerado no processo de corte devido ao cisalhamento no cavaco flui para a peça (Г) e a outra parcela (90\%) é conduzida ao cavaco, o que inevitavelmente se constitui em uma fraca hipótese simplificadora. (TAY; 1993; TRENT; WRIGHT, 2000) 
Boothroyd (1975) apresentou um modelo mais aprofundado para o cálculo das temperaturas de usinagem, o qual levou em consideração outros aspectos importantes da usinagem, tais como a medição das forças de corte, conhecimento dos parâmetros de corte e dados das propriedades térmicas do material a ser usinado. Este modelo vem sendo utilizado como base analítica para vários estudos do ramo e em livros especializados em usinagem, e será utilizado neste trabalho para estimar as temperaturas geradas nos experimentos. (BOOTHROYD, 1975; TAY; 1993; TRENT; WRIGHT, 2000)

\subsubsection{Modelo analítico de Boothroyd (1975)}

A taxa de calor total gerado $\left(P_{m}\right)$, é dado pelo produto da força de corte e a velocidade de corte, a qual está expressa na equação (22) (BOOTHROYD, 1975):

$$
P_{m}=F_{c} \cdot v_{c}
$$

Conforme citado na seção 2.9.1, a transformação da energia de deformação em calor ocorre principalmente em duas regiões: na zona de cisalhamento primária e secundária, sendo $P_{s}$ a taxa de calor gerado na zona de cisalhamento primária e a taxa de calor gerado na zona de cisalhamento secundário definida com $\mathrm{P}_{\mathrm{f}}$. Com isso é possível expressar a taxa de calor total gerado $\left(P_{m}\right)$ pela relação (23) (BOOTHROYD, 1975):

$$
P_{m}=P_{s}+P_{f}
$$

$O$ valor de $P_{f}$ (Equação 24) é obtido pela análise do calor gerado em decorrência da interação entre o cavaco e a ferramenta, e pode ser expressa pelo produto da força de avanço pela velocidade do cavaco $\left(v_{\text {cav }}\right)$, e consequentemente pelo produto do grau de recalcamento do cavaco pela velocidade de corte empregada. (BOOTHROYD, 1975):

$$
P_{f}=F_{f} \cdot \frac{1}{r_{c}} \cdot v_{c}
$$


De toda a taxa de calor gerado na zona de cisalhamento primário $\left(P_{s}\right)$, uma fração deste calor obtido pelo cisalhamento é transferido para a peça (Г), e o restante $(1-\Gamma)$ flui para o cavaco, conforme descrito anteriormente. $O$ aumento de temperatura média na zona de cisalhamento primária $(\theta s)$ é obtido pela equação (25), no qual $\rho$ e c são respectivamente a densidade e o calor específico do material a ser usinado e w é a largura de corte. (BOOTHROYD, 1975; TAY; 1993; TRENT; WRIGHT, 2000):

$$
\theta_{s}=\frac{(1-\Gamma) \cdot P s}{\rho \cdot c \cdot v_{c} \cdot t_{0} \cdot w}
$$

Boothroyd (1975) estimou através de método experimental o valor de $\Gamma$ a partir da relação do número térmico adimensional (Z), o qual é definido em (26) com o valor de tanф, o qual é obtido pelo gráfico experimental da Figura 35, ou pelas equações (27a) e (27b). (BOOTHROYD, 1975; TAY; 1993; TRENT; WRIGHT, 2000; BARBOSA, 2014)

$$
Z=\frac{\rho \cdot c \cdot v_{c} \cdot t_{0}}{k}
$$

$$
\begin{gathered}
\Gamma=0,5-0,3 \cdot \log _{10}(Z \cdot \tan \phi) \rightarrow \operatorname{para} 0,04 \leq Z \cdot \tan \phi \leq 10 \\
\Gamma=0,3-0,15 \cdot \log _{10}(Z \cdot \tan \phi) \rightarrow \operatorname{para} Z \cdot \tan \phi \geq 10
\end{gathered}
$$

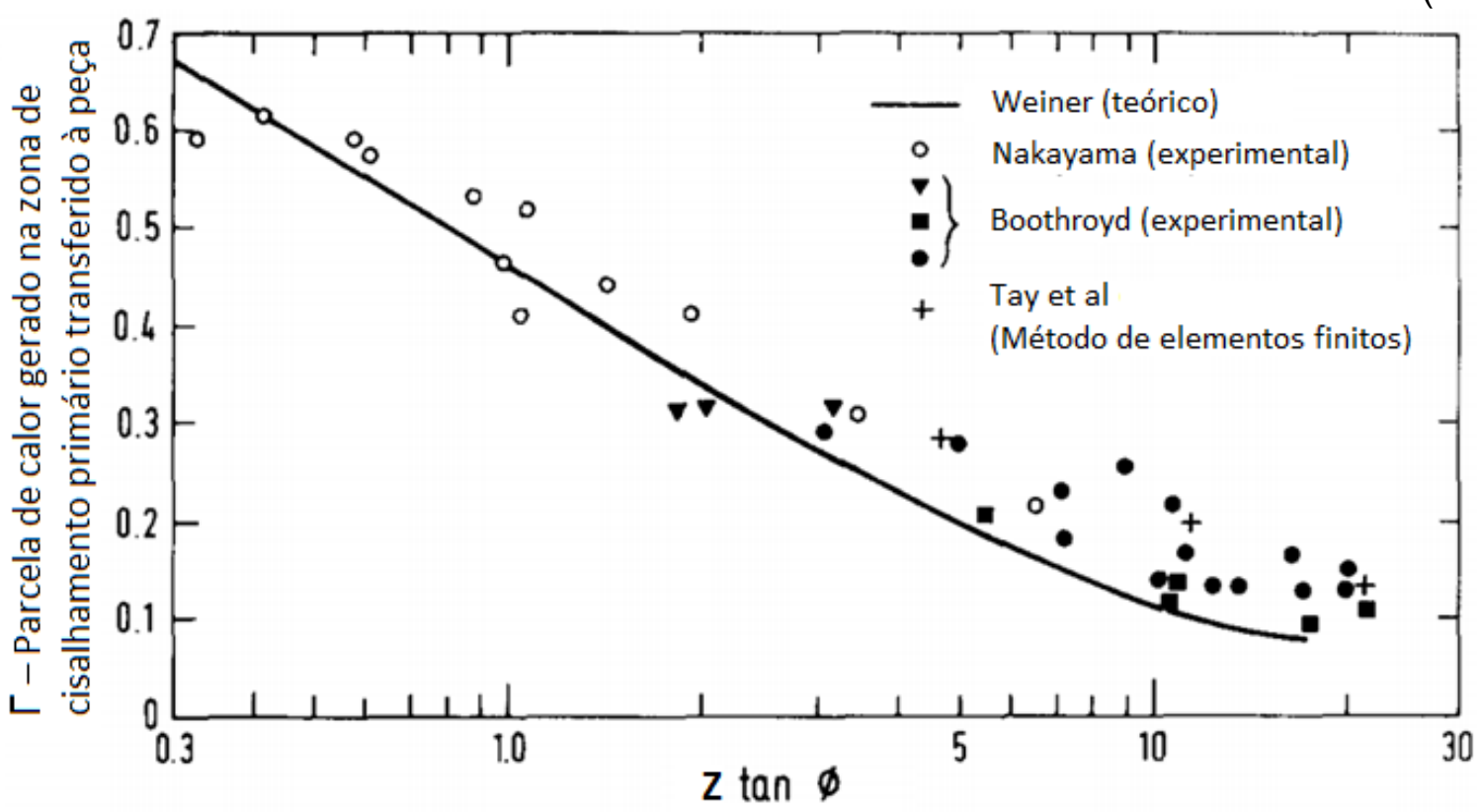

Figura 35 - Curva experimental de Boothroyd para a fração de calor transferida para a peça (BOOTHROYD, 1975; TAY; 1993; TRENT; WRIGHT, 2000) 
A Figura 36 mostra que, após o aumento de temperatura ocorrido na zona de cisalhamento primária, o cavaco atinge sua temperatura máxima ao deixar a zona de cisalhamento secundária, com o acréscimo de uma parcela de temperatura definida como $\theta_{\mathrm{m}}$. Portanto, a temperatura máxima na zona de contato entre a ferramenta e o cavaco $\left(\theta_{\text {máx }}\right)$ pode ser estimada peça equação (28), sendo $\theta_{0}$ a temperatura ambiente (BOOTHROYD, 1975).

$$
\theta_{\text {máx }}=\theta_{m}+\theta_{s}+\theta_{0}
$$

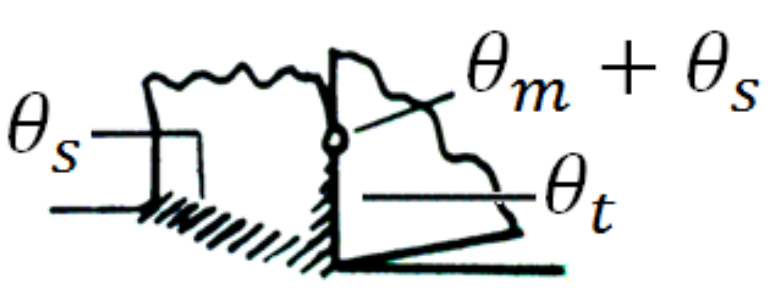

Figura 36 - Temperaturas geradas no processo de corte (Adaptado de BOOTHROYD, 1975)

Entretanto, o aumento de temperatura do cavaco em decorrência da zona de cisalhamento secundária $\left(\theta_{\mathrm{m}}\right)$ é uma das parcelas do aumento de temperatura total ocorrido nesta zona. $O$ aumento total de temperatura na zona de cisalhamento secundária $\left(\theta_{\mathrm{f}}\right)$ é dado pela fonte de calor resultante pelo atrito do cavaco com a ferramenta de corte, e consequentemente também deve levar em consideração a parcela relativa ao aumento de temperatura na ferramenta $\left(\theta_{\mathrm{t}}\right)$. Com estes dados, se calcula pelas relações (29) e (30) o aumento total de temperatura na zona de cisalhamento secundária ( $\theta f)$. (BOOTHROYD, 1975):

$$
\begin{gathered}
\theta_{f}=\theta_{m}+\theta_{t} \\
\theta_{f}=\frac{P_{f}}{\rho \cdot c \cdot v_{c} \cdot t c \cdot w}
\end{gathered}
$$

Boothroyd (1975) mostrou, por meio de trabalhos experimentais, que a relação entre as temperaturas do cavaco e ferramenta na zona de cisalhamento secundária $\left(\theta_{\mathrm{m}} / \theta_{\mathrm{f}}\right)$ poderia ser obtida pela relação matemática (31) abaixo (BOOTHROYD, 1963 apud TAY, 1991):

$$
\log \frac{\theta_{m}}{\theta_{f}}=0,06-0,195 \cdot w_{0} \cdot \sqrt{\frac{Z \cdot t c}{l_{0}}}+0,5 \cdot \log \left(\frac{Z \cdot t c}{l_{0}}\right)
$$


Sendo Ic definido como o comprimento de contato ferramenta/cavaco, o qual para ligas de cobre é definido como $\mathrm{Ic}=2 \cdot \mathrm{t}_{\mathrm{c}}$ (IQBAL et al, 2008; MACHADO et al, 2011), e w $w_{0}$ é definido como a largura da zona de deformação secundária dividida pela espessura do cavaco $t_{c}$. $O$ valor de $w_{0} \cdot t_{c}$ pode ser estimado pela micrografia dos cavacos resultantes, como é mostrado na Figura 37, pela altura da região em que os grãos alongados pelo processo de usinagem apresentam aspecto encurvado próximo à raiz do cavaco, pois é uma evidência de que o cavaco passou através da zona de deformação secundária (BOOTHROYD, 1975).

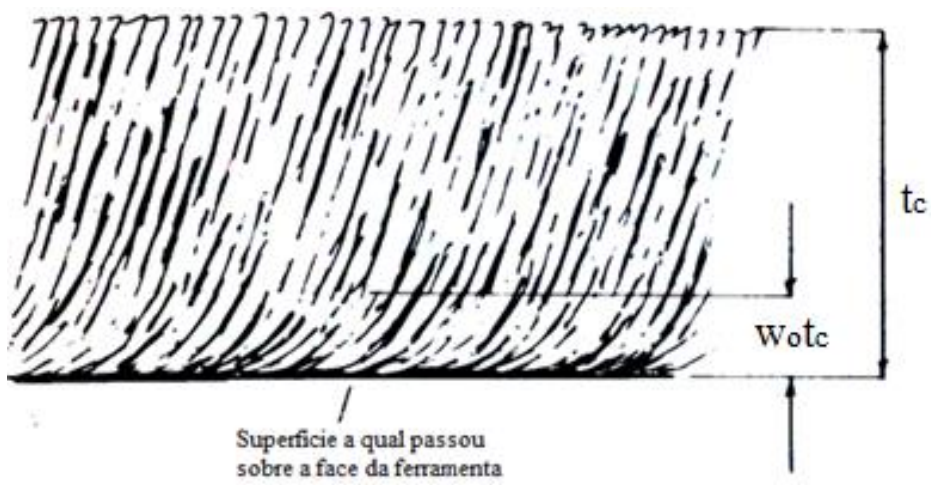

Figura 37 - Deformação microestrutural na seção transversal do cavaco decorrente da zona de cisalhamento secundária (BOOTHROYD, 1975)

\subsection{USINABILIDADE}

A usinabilidade pode ser definida como a facilidade com que um metal pode ser submetido a diferentes operações ou técnicas de usinagem. Entretanto, não existe uma definição única e não ambígua a este termo, uma vez que devido às complexas relações existente nestes processos, não é possível avaliar as operações em termos de um único critério padronizado. (BOOTHROYD, 1975; TRENT; WRIGHT, 2000; GERMAN COPPER INSTITUTE, 2010)

Com isso, a definição do termo depende significativamente da aplicação estudada, e em geral, costuma-se avaliar a usinabilidade sob quatro aspectos principais: desgaste de ferramenta, energia total consumida (forças de corte), acabamento superficial e morfologia dos cavacos. Embora estes critérios sejam mutuamente interdependentes, quando avaliados em conjunto, geram parâmetros importantes para seleção de materiais, pois exercem influência no processo, produtividade, custos de fabricação, precisão dimensional e acabamento superficial. (BOOTHROYD, 1975; TRENT; WRIGHT, 2000; GERMAN COPPER INSTITUTE, 2010; WOBKER et al, 2011) 


\subsubsection{Vida útil da ferramenta}

O critério de vida da ferramenta (Tf) é definido como o tempo mínimo pelo qual uma ferramenta resiste do início do corte até a sua utilização total, relacionada a um determinado critério de fim de vida. Um dos critérios mais utilizados atualmente é o desenvolvido por F.W. Taylor no início do século XX, baseado no conhecimento que a velocidade de corte tem significativa influência no desgaste da ferramenta. Este estudo baseia-se na medição do desgaste de flanco de ferramenta $\left(V_{b}\right)$, sendo este definido na Figura 38, após ensaio prático no qual se fixa a profundidade e avanço de corte, e varia-se a velocidade de corte (BOOTHROYD, 1975; TRENT; WRIGHT, 2000; GERMAN COPPER INSTITUTE, 2010; MACHADO et al, 2011)

Os resultados de desgaste são utilizados para a construção de uma curva como a apresentada na figura 39(a), denominada de "curva de desgaste". Posteriormente fixa-se o valor limite para $V_{b}$ e obtém-se uma curva que correlaciona de forma direta a velocidade de corte com o tempo de vida da ferramenta. A Figura 39(b) mostra esta curva, sendo neste exemplo obtida da Figura 39(a) a partir de um valor limite de $V_{b}$ de 0,8mm. (BOOTHROYD, 1975; MACHADO et al, 2011)
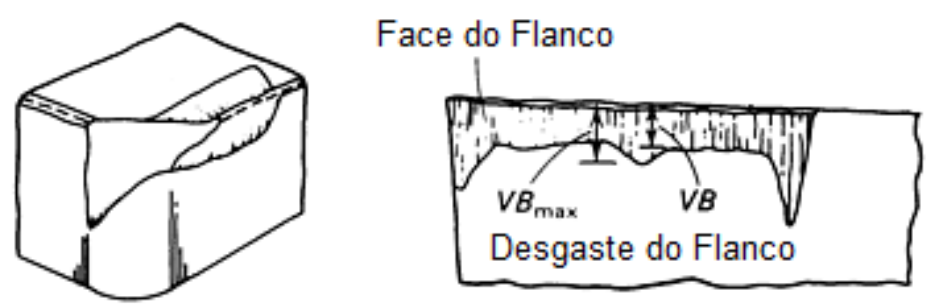

Figura 38 - Definição de desgaste do flanco $V_{b}$ (Adaptado de ASM METALS HANDBOOK, 1995)

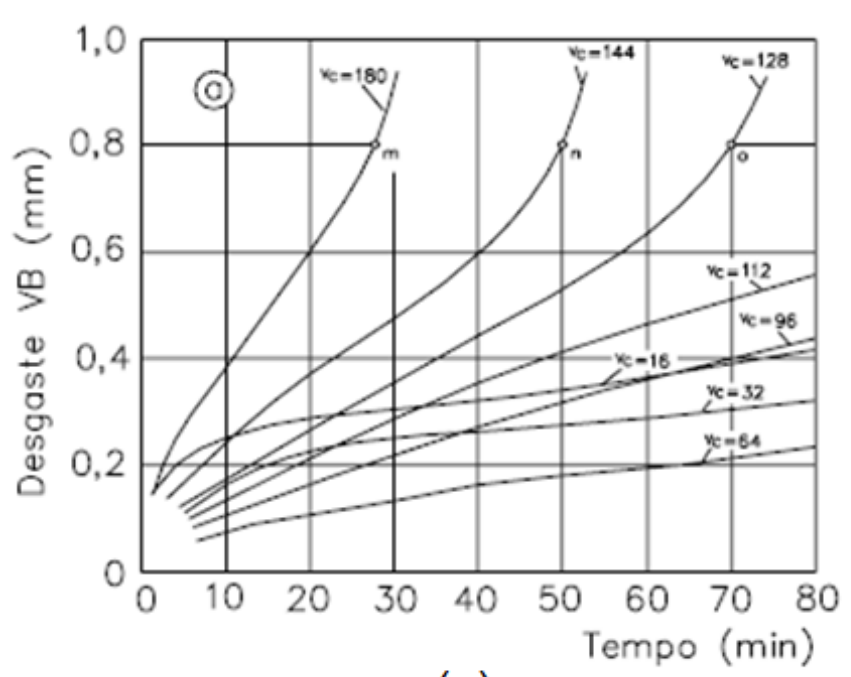

(a)

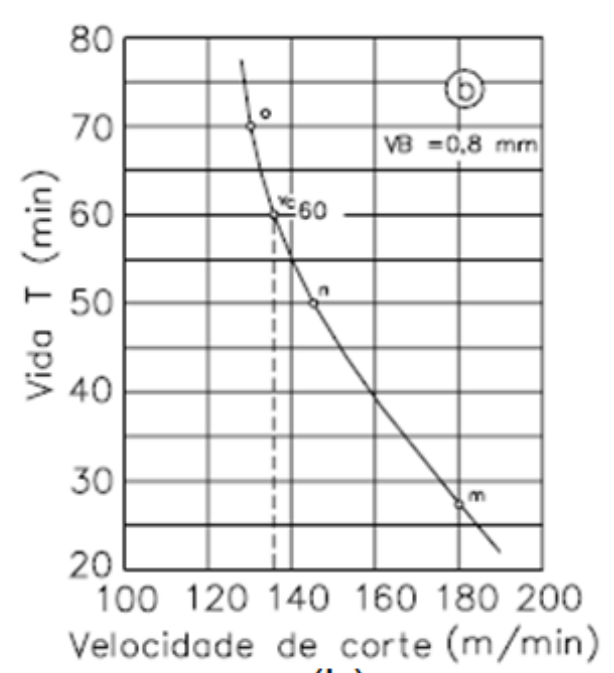

(b)

Figura 39 - Curva de desgaste da Ferramenta e curva de vida para torneamento de aço com ferramentas de metal duro (MACHADO et al, 2011) 


\subsubsection{Critério forças de usinagem}

Para o bom projeto de uma máquina-ferramenta, isto é, para o dimensionamento correto das estruturas, acionamentos, fixação de ferramentas e guias, e consequentemente a determinação do consumo energético da operação de usinagem, é necessário o conhecimento da intensidade e orientação das forças de usinagem. As forças de usinagem são dividas em três forças principais, sendo estas a força de corte $(\mathrm{Fc})$, força de avanço $(\mathrm{Ff})$ e força passiva $(\mathrm{Fp})$. As forças de usinagem caracterizam um importante critério de análise, pois geralmente materiais de baixa usinabilidade apresentam valores maiores para as forças mencionadas (BOOTHROYD, 1975; TRENT; WRIGHT, 2000; GERMAN COPPER INSTITUTE, 2010; MACHADO et al, 2010).

\subsubsection{Critério formação de cavaco}

É de fundamental importância no processo de usinagem avaliar a morfologia dos cavacos formados no processo de usinagem, pois o mesmo tem influência direta em vários aspectos da usinagem, tais como força de corte, temperatura do processo, desgaste de ferramenta, segurança operacional e logística. (BOOTHROYD, 1975; TRENT; WRIGHT, 2000; SHAW, 2005; GERMAN COPPER INSTITUTE, 2010; MACHADO et al, 2011).

Os cavacos podem ser classificados por sua morfologia em contínuos, segmentados e descontínuos, os quais são esquematizados na Figura 40. (BOOTHROYD, 1975; TRENT; WRIGHT, 2000; SHAW, 2005; GERMAN COPPER INSTITUTE, 2010; MACHADO et al, 2011; KLOCKE et al, 2012a).

Os cavacos contínuos são geralmente formados em materiais dúcteis e homogêneos, sendo que estes escoam continuamente ao longo da zona de cisalhamento primário em grandes deformações e permanecem homogêneos, sem fragmentação. Nestes casos, existe um equilíbrio entre a tensão normal e a de cisalhamento no plano de cisalhamento primária, de forma que a trinca gerada na ruptura do cavaco não se propague rapidamente, e o cavaco não é interrompido. (TRENT; WRIGHT, 2000; SHAW, 2005; GERMAN COPPER INSTITUTE, 2010; MACHADO et al, 2011). 


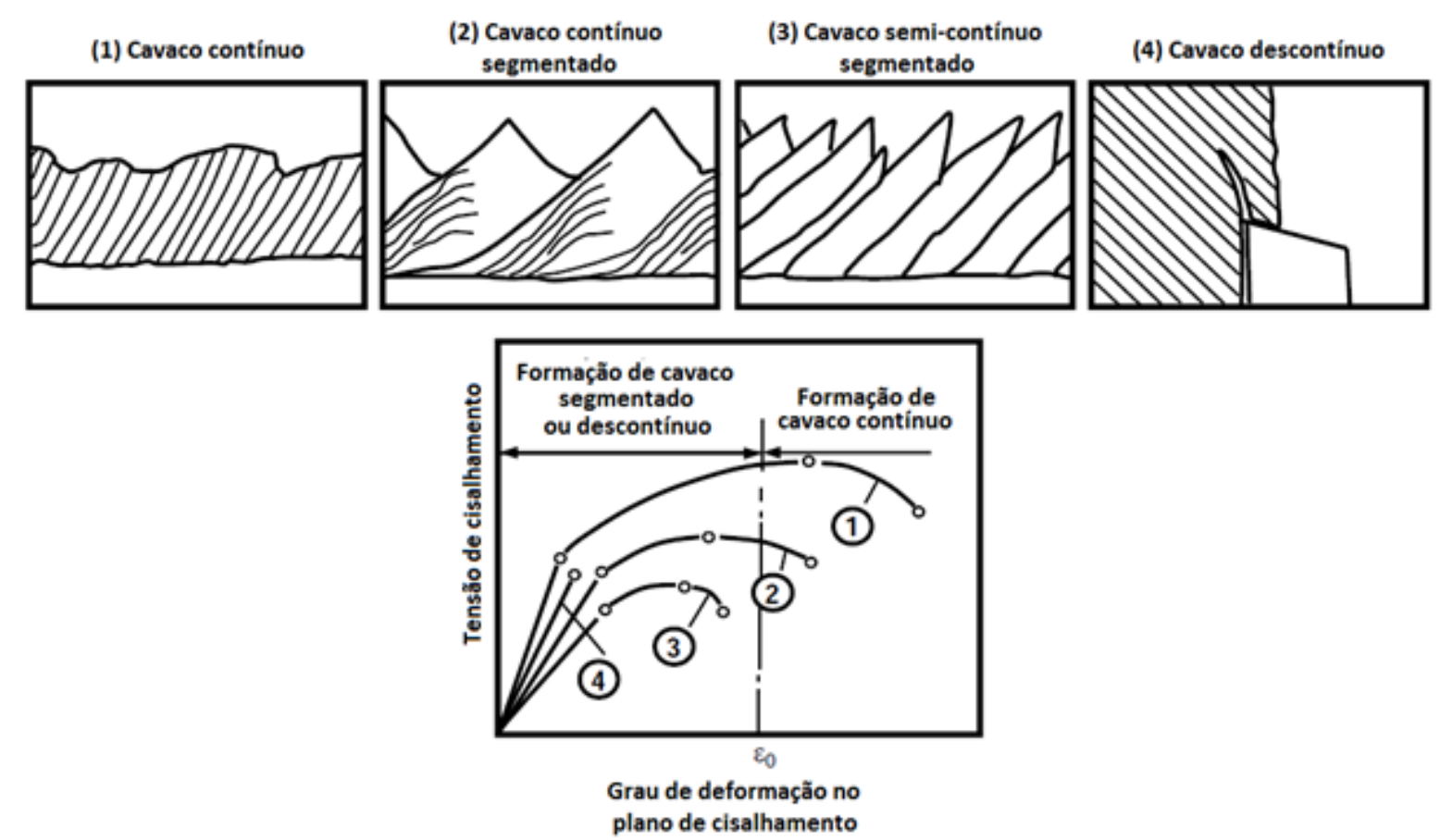

Figura 40 - Tipos comuns de cavacos (Adaptado de GERMAN COPPER INSTITUTE, 2010)

Uma variação dos cavacos contínuos são os relacionados com a formação da aresta postiça de corte, presente em situações de usinagem de materiais altamente dúcteis, tais como o cobre eletrolítico, em baixas velocidades de corte. A aresta postiça é feita a partir da formação de camadas endurecidas pela deformação plástica do material da peça as quais aderem na superfície da ferramenta de forma irregular e impedem o contato direto do cavaco com a ferramenta. Dependendo das condições de corte utilizadas, a aresta postiça pode se quebrar periodicamente e se depositar entre o flanco da ferramenta e a superfície da peça de trabalho, deteriorando a qualidade da superfície da peça, com o aumento do desgaste da ferramenta e redução da precisão dimensional da peça. (TRENT; WRIGHT, 2000; SHAW, 2005; GERMAN COPPER INSTITUTE, 2010; MACHADO et al, 2011).

Se o material da peça de trabalho apresentar menor ductilidade para as condições de processo, microestrutura não homogênea ou se forem submetidas a vibrações externas, a usinagem irá resultar na formação de cavacos contínuos segmentados. Em comparação com os cavacos contínuos, a superfície superior do cavaco apresenta uma estrutura tipo dente de serra pronunciada. Cavacos deste tipo podem ser formados em avanços elevados ou em altas velocidades de corte. Também podem ser observados na usinagem de materiais de baixa condutividade térmica e na presença de cisalhamento adiabático. (TRENT; WRIGHT, 2000; SHAW, 2005; GERMAN COPPER INSTITUTE, 2010; MACHADO et al, 2011). 
Cavacos segmentados semicontínuos, por outro lado, consistem em secções de cavaco os quais foram completamente separados na zona de esforço cortante. Este tipo de cavaco ocorre quando o grau de deformação na zona de cisalhamento primário é superior à ductilidade do material. Isto se aplica não só para materiais frágeis, mas também para materiais nos quais a deformação induziu fragilidade na microestrutura. Estes cavacos podem também se formar em velocidades de corte extremamente baixas. (TRENT; WRIGHT, 2000; SHAW, 2005; GROOVER, 2007; GERMAN COPPER INSTITUTE, 2010; MACHADO et al, 2011).

Cavacos descontínuos normalmente se formam ao se usinar materiais frágeis com uma microestrutura não homogênea. Estes cavacos não são cortados, mas sim rasgados a partir da superfície do material de trabalho, com o resultado de que a superfície da peça de trabalho é frequentemente danificada por estes pequenos fragmentos de cavacos. (TRENT; WRIGHT, 2000; SHAW, 2005; GROOVER, 2007; GERMAN COPPER INSTITUTE, 2010; MACHADO et al, 2011).

\subsubsection{Formas de cavaco}

A Figura 41 indica que as formas mais adequadas para os cavacos são os tubulares curtos (6), enrolados cônicos (7) e espirais (8). Os cavacos descontínuos obtidos da usinagem das ligas de corte livre (9 e 10), entre elas o latão CLA, são aceitáveis desde que não gerem problemas no sistema de esteira ou bloqueie os filtros de óleo das máquinas operatrizes. (TRENT; WRIGHT, 2000; SHAW, 2005; GERMAN COPPER INSTITUTE, 2010; MACHADO et al, 2011).

Os cavacos contínuos (1, 2 e 3) são indesejados, pois dificultam o manuseio das peças em sistemas de produção automáticos devido ao emaranhamento do cavaco à peça, sendo um exemplo mostrado na Figura 42, além de representarem um risco aos operadores devido à suas arestas afiadas, bem como à integridade superficial da peça e durabilidade da ferramenta. (TRENT; WRIGHT, 2000; SHAW, 2005; GERMAN COPPER INSTITUTE, 2010; MACHADO et al, 2011).

Os cavacos helicoidais longos (4) com formato semelhante a um saca-rolhas devem ser cuidadosamente observados, pois podem movimentar-se sobre o flanco da ferramenta de causar danos ao suporte da ferramenta. (TRENT; WRIGHT, 2000; SHAW, 2005; GERMAN COPPER INSTITUTE, 2010; MACHADO et al, 2011). 


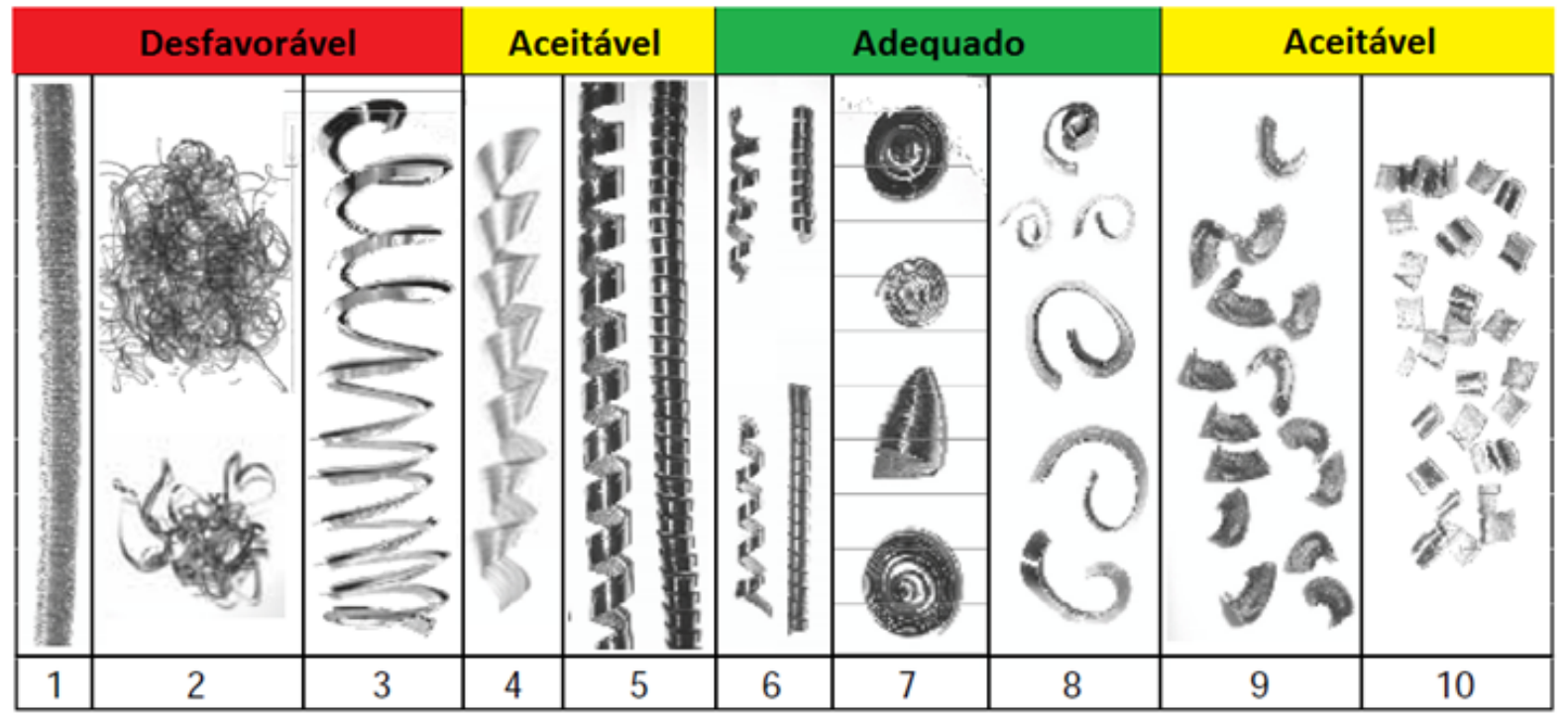

1) Cavacos em fita

6) Cavacos tubulares curtos

2) Cavacos Emaranhado

7) Cavacos cônicos enrolados

3) Cavacos helicoidais tipo arruela)

8) Cavacos espirais

4) Cavacos helicoidais cônicos

9) Cavacos em arco (Cavaco curvado curto)

5) Cavacos tubulares longos 10) Cavaco descontínuo (Fragmentado curto)

Figura 41 - Classificação da forma dos cavacos (Adaptado de GERMAN COPPER INSTITUTE, 2010)

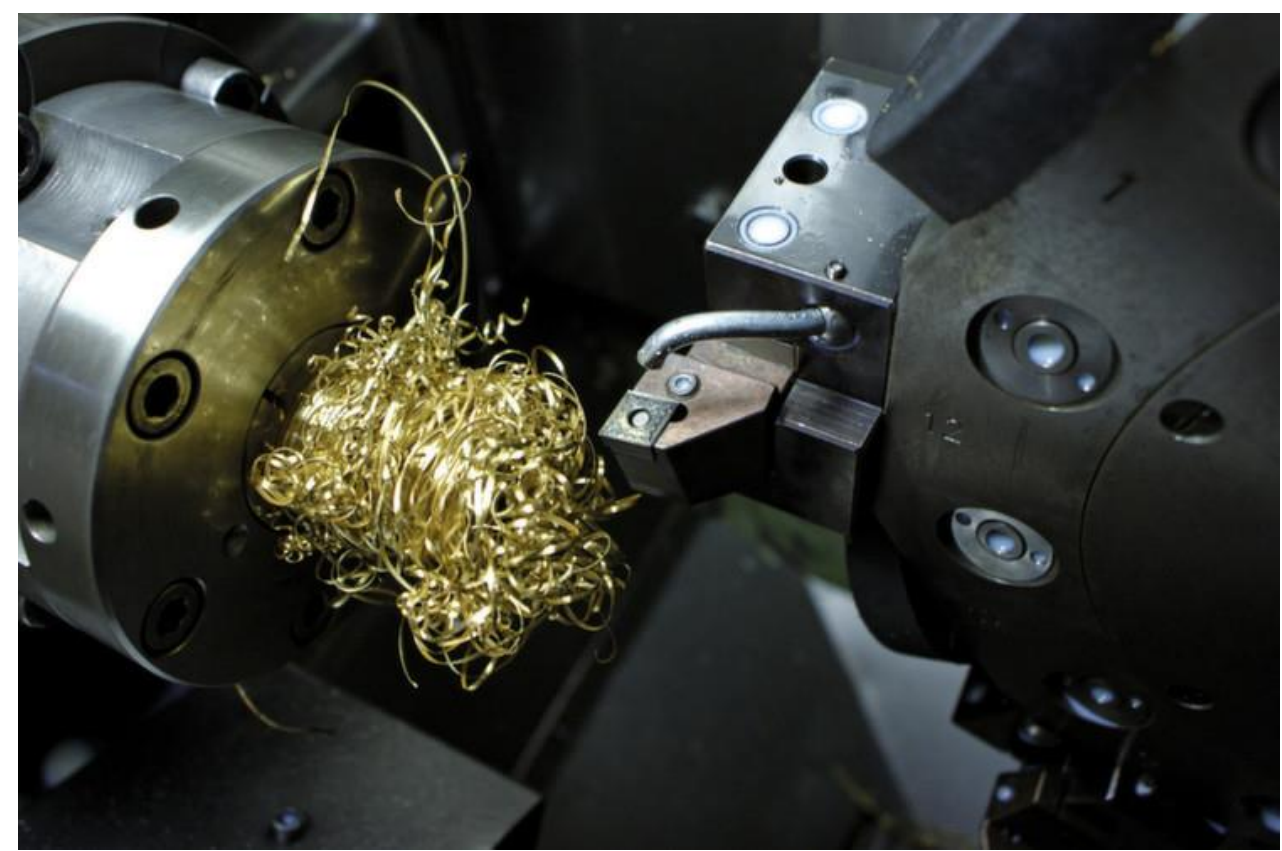

Figura 42 - Cavaco contínuo de latão emaranhado à peça usinada (KLOCKE et al, 2012a)

Os cavacos também podem ser classificados de uma maneira mais detalhada, a qual está prevista na norma ISO 3685 (1993), e apresentada na Figura 43. (ISO 3685, 1993). 


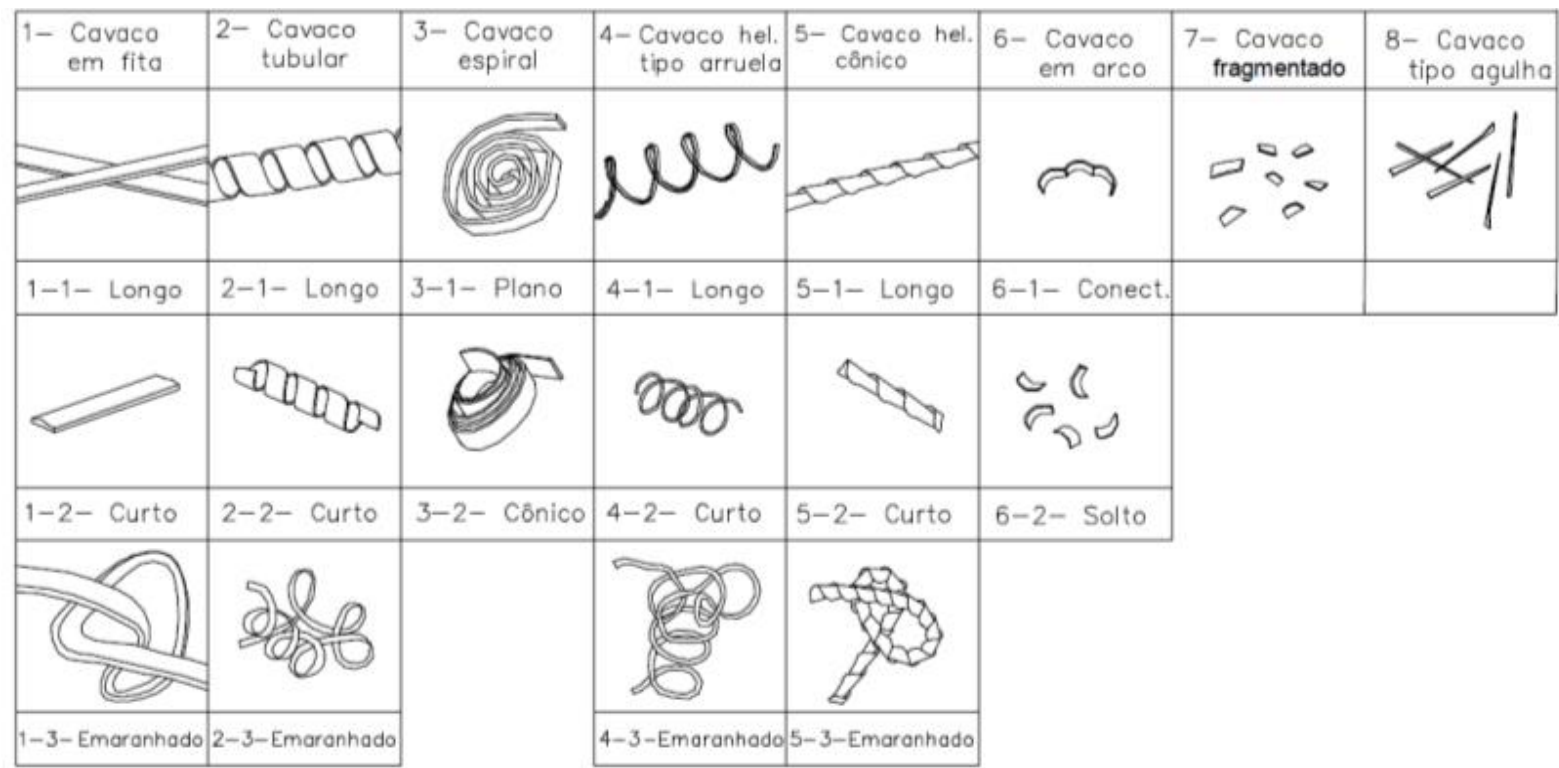

Figura 43 - Tipos mais comuns de cavacos gerados no processo de usinagem (ISO 3685, 1993)

\subsubsection{Critério qualidade superficial}

A condição final de uma superfície usinada é resultado do processo de corte que envolve deformações plásticas, ruptura, recuperação elástica, geração de calor, vibrações, tensões residuais e reações químicas. Todos estes fatores ocasionam efeitos diferentes na superfície e na subsuperfície gerada e definem a integridade superficial. (TRENT; WRIGHT, 2000; SHAW, 2005; MACHADO et al, 2011).

A qualidade da superfície na usinagem de acabamento de cobre e suas ligas de cobre são fundamentais principalmente em superfícies decorativas, sendo empregados muitas vezes os latões de corte livre, pois frequentemente requerem elevada precisão e acabamento satisfatório. A qualidade da superfície é, portanto, considerado como um critério muito importante para avaliar a usinabilidade de ligas de corte livre, tais como CuZn39Pb3, CuZn39Pb2, CuZn40Pb2 e CuZn30Pb3. (TRENT; WRIGHT, 2000; GERMAN COPPER INSTITUTE, 2008).

O parâmetro mais utilizado para medição da qualidade superficial é a rugosidade na direção longitudinal, a qual é medida ao longo da direção do movimento de avanço. Também denominada de rugosidade cinemática, a mesma está relacionada com o raio da ponta da ferramenta e do avanço aplicado, conforme esquema da Figura 44. 


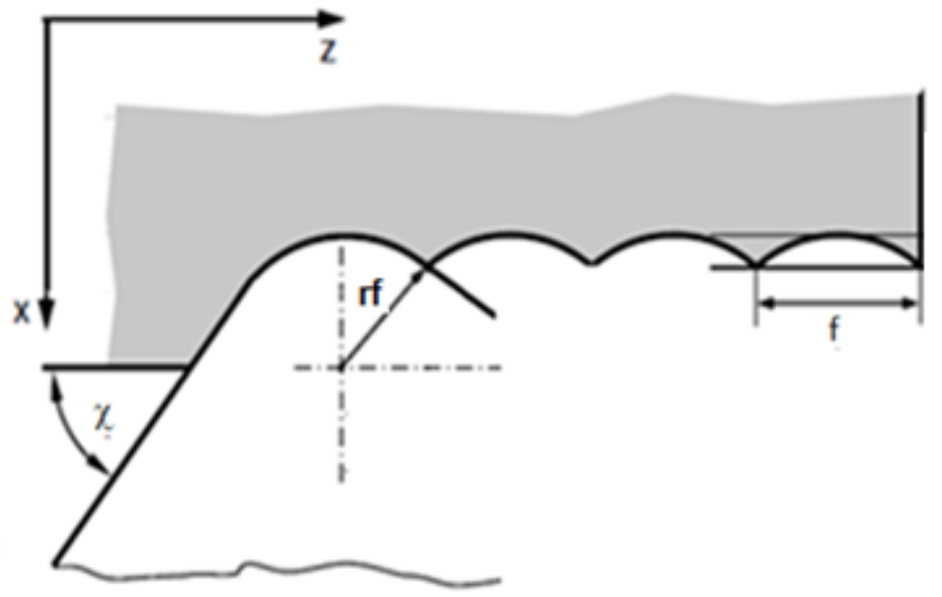

Figura 44 - Rugosidade cinemática (GERMAN COPPER INSTITUTE, 2008)

No entanto, em aplicações práticas esta rugosidade tende a se desviar significativamente do valor teórico, como mostra a figura 45, e ocorre devido a três causas principais: Na utilização de baixos avanços ( $f<0,1 \mathrm{~mm} / \mathrm{rot}$ ), pela ocorrência da ruptura periódica da aresta postiça de corte, as quais atingem a superfície da peça usinada, e provocando uma deterioração da qualidade da superfície usinada. Em baixas velocidades de corte, também podem ser formados fluxos laterais, em função da recuperação elástica dos sulcos formados na usinagem, fato não presente na usinagem de materiais frágeis. Em avanços mais elevados ( $f>0,1 \mathrm{~mm} / \mathrm{rot}$ ), poderá ocorrer um aumento do desgaste de flanco, particularmente no raio de ponta, levando a uma deterioração da qualidade da superfície usinada. (TRENT; WRIGHT, 2000; SHAW, 2005; GERMAN COPPER INSTITUTE, 2008; MACHADO et al, 2011)

a)

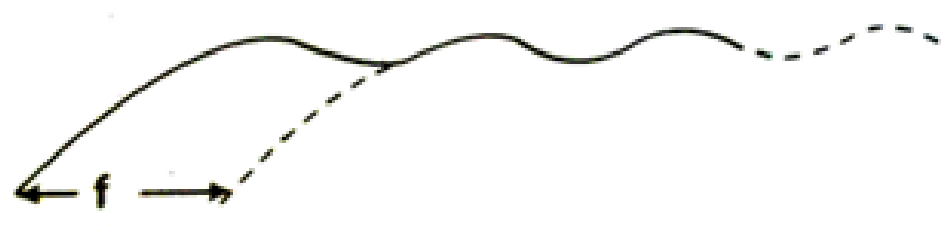

b)

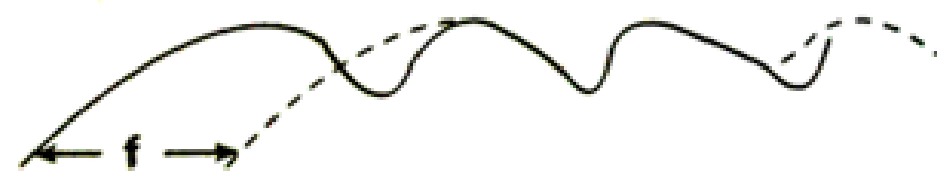

Figura 45 - Perfil usinado: a) Sem fluxo lateral; (b) Com fluxo lateral (MACHADO et al, 2011)

Outro aspecto importante é que a aproximação do modelo de rugosidade cinemática encontra maior precisão para a usinagem de materiais com granulação fina, sendo que para materiais com microestrutura grosseira, o valor da rugosidade será significativamente maior do que o valor calculado. (TRENT; WRIGHT, 2000; GERMAN COPPER INSTITUTE, 2008) 
A rugosidade da superfície transversal da peça de trabalho também depende dos ângulos de ferramenta, em particular o ângulo de saída $(\gamma)$, sendo que seu aumento melhora a qualidade da superficial. Além disso, o processamento de cobre e suas ligas em elevadas velocidades de corte produz uma melhor qualidade da superficial do que na usinagem a velocidades mais baixas, porém cabe ressaltar a necessidade de observar a influência das vibrações do processo, principalmente em maiores velocidade de corte. (TRENT; WRIGHT, 2000; GERMAN COPPER INSTITUTE, 2008; MACHADO et al 2011)

A rugosidade pode ser classificada de várias maneiras diferentes, sendo mais utilizado o Desvio Aritmético Médio (Ra), mostrado na Figura 46 e definido como a média aritmética dos valores absolutos das ordenadas no comprimento de amostragem. Existem metodologias de controle de processo que tomam como referência o valor de $\mathrm{Ra}$, pois as alterações em seu valor indicam alterações no processo, em especial no desgaste de ferramenta (ASM HANDBOOK, 1995; MACHADO et al, 2011).

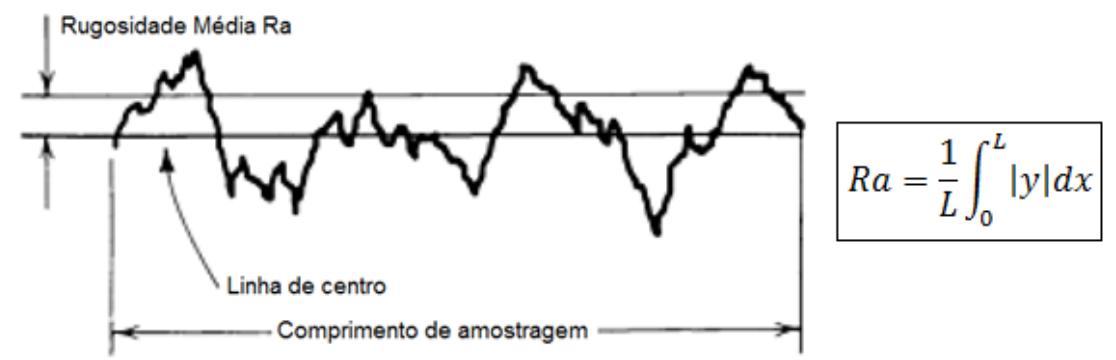

Figura 46 - Definição de Rugosidade média (Ra) (Adaptado de ASM HANDBOOK, 1995)

O parâmetro $R z$, mostrado na Figura 47 , é definido como a distância média entre os 5 maiores picos e os 5 vales mais profundos, através de um comprimento de amostragem medido por uma linha de referência paralela, a qual não intercepta o perfil medido (ASM HANDBOOK, 1995).

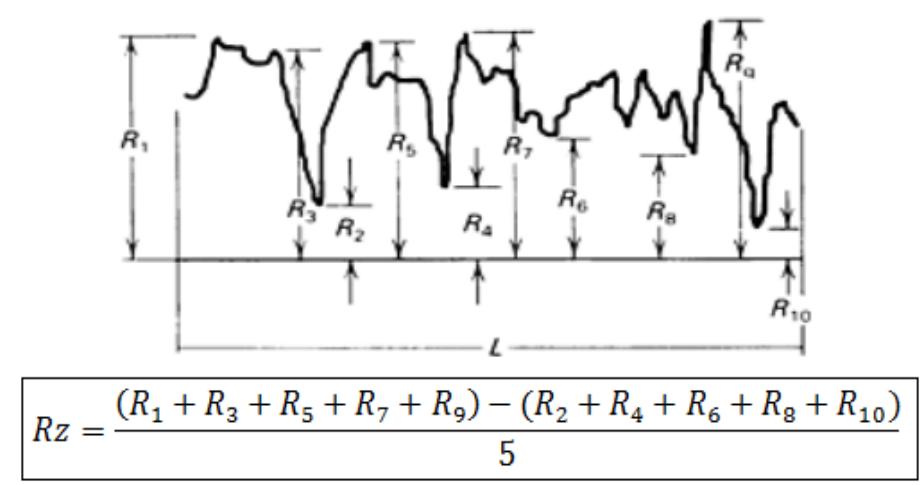

Figura 47 - Definição de Rugosidade de profundidade média (Rz) (ASM HANDBOOK, 1995) 


\subsection{USINABILIDADE DAS LIGAS DE COBRE}

As ligas de cobre de alta condutividade térmica e elétrica (acima de $99 \%$ de cobre) são consideradas como uma das famílias de ligas mais difíceis de usinar. Em operações de furação, por exemplo, as forças são suficientemente altas para ocorrer quebra da broca, principalmente em baixas velocidades. É possível melhorar este desempenho utilizando maiores velocidades de corte, mas os cavacos gerados são contínuos e se emaranham facilmente (TRENT; WRIGHT, 2000; GERMAN COPPER INSTITUTE, 2010; LORENZ et al, 2010; WOBKER et al, 2011; KLOCKE et al, 2012a; KLOCKE et al, 2012b; NOBEL et al, 2014).

Em geral, a usinabilidade destas ligas pode ser melhorada também com o emprego de endurecimento por trabalho a frio e pela adição de elementos de liga. Adições de aproximadamente $0,3 \%$ de enxofre melhoram a usinabilidade de ligas de cobre de alta condutividade, reduzindo de maneira significativa a força de corte com a formação de cavacos quebradiços, e consequentemente reduzindo a temperatura do processo de usinagem, bem como adições de telúrio da ordem de $0,4 \%$ nas ligas de cobre também tem reconhecido efeito benéfico na usinagem de ligas de cobre elevado. (TRENT; WRIGHT, 2000; GERMAN COPPER INSTITUTE, 2010)

\subsection{DESENVOLVIMENTO DE LATÕES DE CORTE LIVRE ISENTOS DE CHUMBO}

O desenvolvimento de ligas de fácil usinagem sem chumbo tem sido discutido com mais intensidade nos últimos anos, principalmente pelas restrições geradas pela legislação e pelos conhecidos efeitos nocivos à saúde humana. Das pesquisas conduzidas no tema, é verificado um enfoque principalmente nos aspectos relacionados à composição química dos latões e aspectos relacionados aos parâmetros de usinagem. Pouca ênfase é dada na influência da microestrutura, sendo os trabalhos relacionados a este aspecto conduzidos na década de 1970, principalmente em operações de microcorte em monocristais. (NAKAYAMA et al, 1970; NAKAYAMA, 1972 apud SHAW, 2005; HOFMANN; MAGD, 2004; VILARINHO et al, 2005; LORENZ et al, 2010; IMAl et al, 2010; WOBKER et al, 2011; TAHA el al, 2012; KLOCKE et al, 2012a; KLOCKE et al, 2012b; ATSUMl et al, 2011; NOBEL et al, 2014) 


\subsubsection{Efeitos da composição química na usinabilidade de latões isentos de chumbo}

Uma das abordagens utilizadas é a de utilização de elementos químicos com nenhuma solubilidade ao cobre, sendo neste aspecto materiais com comportamento similar ao chumbo. (VILARINHO et al, 2005; IMAl et al, 2010; TAHA el al, 2012; ATSUMl et al, 2011; NOBEL et al, 2014). Alguns estudos com ligas de latão com adições de bismuto e selênio, em função da similaridade que o bismuto apresenta com o chumbo, cuja microestrutura é mostrada na Figura 48, caracterizando uma família denominada de "SeBiLoys". (VILARINHO et al, 2005; ATSUMI et al, 2011).

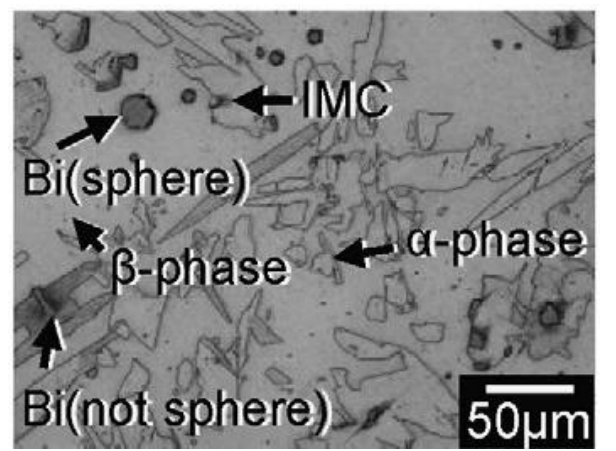

Figura 48 - Microestrutura de latão com adição de bismuto (ATSUMI et al, 2011)

Entretanto, estes elementos apresentam importantes inconvenientes para sua utilização em larga escala, principalmente com relação ao custo de emprego dos mesmos. Por exemplo, o bismuto possui rara disponibilidade na mineração e apresenta custo cerca de 10 vezes maior em comparação ao chumbo. (LORENZ et al, 2010; KLOCKE et al, 2012a; NOBEL et al, 2014).

Além disso, existem pesquisas as quais associam a presença do bismuto a uma maior incidência de fragilização estrutural nos latões no processo de fabricação e no aumento da suscetibilidade a corrosão sob tensão, obrigando a sua utilização em proporções menores das utilizadas para o chumbo, e consequentemente reduzindo a sua efetividade. (FONTAINE; KEAST; 2006; HERNANDEZ et al, 2013)

Outra linha de trabalho é baseada na adição de silício, com variações de 1 a 4\% em massa, caracterizando uma família de latões denominados de "Ecobrass". Os estudos demonstram pontos importantes como a melhora no acabamento superficial em composições de $1 \%$ de silício, e melhoras na morfologia dos cavacos no caso de composições de $4 \%$ de silício. A presença deste elemento forma na 
microestrutura uma fase rica em silício, denominada de fase $\kappa$, a qual atua como elementos de quebra do cavaco, porém diferentemente do chumbo, são de elevada dureza, e consequentemente diminuem a vida útil da ferramenta de corte. (TAHA et al, 2012; NOBEL et al, 2014; KLOCKE et al, 2012b).

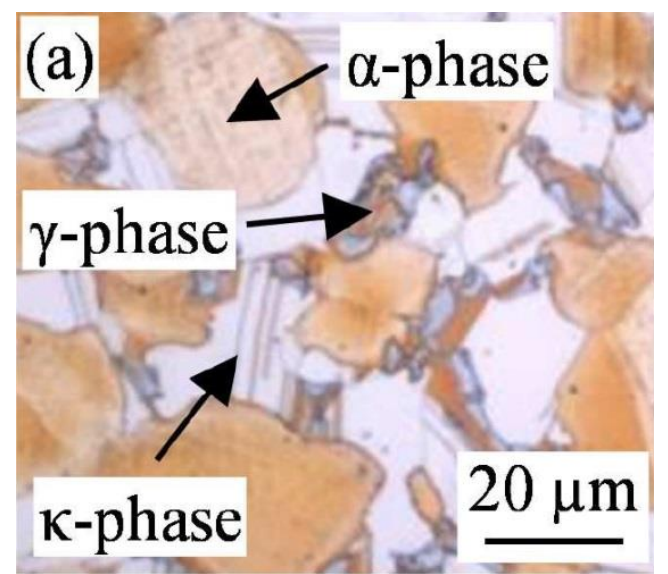

Figura 49 - Microestrutura típica de latões com silício (NOBEL et al, 2014)

Sob o aspecto das forças de corte, as pesquisas conduzidas com este elemento nos latões apresentam dados diferentes, sendo que Taha et al (2012) indica para um invariável aumento na força de corte dos latões com silício em comparação a latões 60/40 isentos de chumbo, como pode ser visto na Figura 50. Por outro lado, Klocke et al, (2012b), mostram em seu trabalho um resultado distinto, o qual é mostrado na Figura 52 da seção 2.12.2, no qual o latão com adições de silício apresenta forças de corte de $550 \mathrm{~N}$ e os latões isentos de chumbo apresentam forças de corte de $750 \mathrm{~N}$.

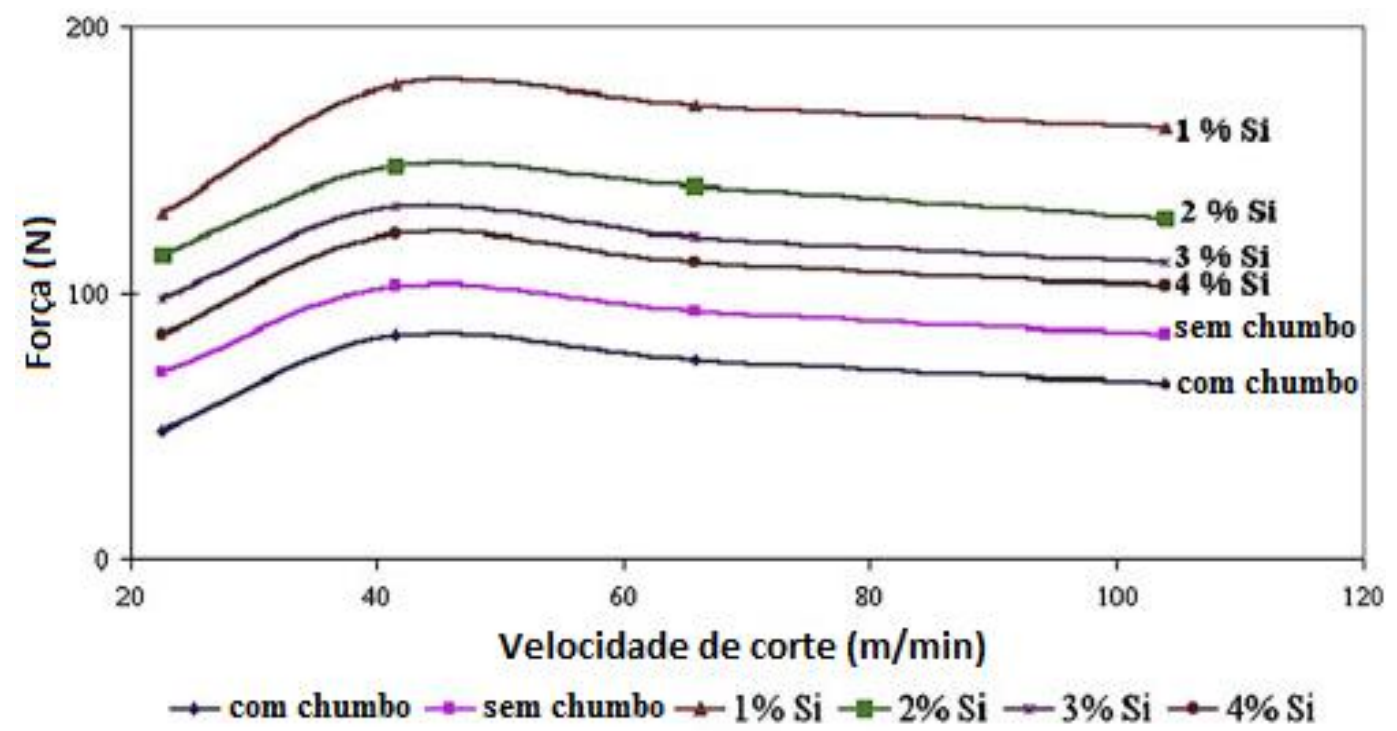

Figura 50 - Efeito da velocidade de corte nas diferentes ligas fundidas de Latão Silício com até $4 \%$ de $\mathrm{Si}$, Latão com chumbo e Latão 60/40 sem chumbo. Parâmetros ap=0,5mm e f=0,08mm/rot.

Ferramenta H123 (Adaptado de TAHA et. al, 2012) 
Outra pesquisa realizou testes de usinabilidade de latões com partículas de grafite dispersas em sua microestrutura, com a observação de ganhos de usinabilidade em testes de furação em comparação às ligas de latão com chumbo. Estes materiais foram obtidos pela metalurgia do pó no processo de Spark Plasma Sintering (SPS), a uma proporção de Carbono de 1\% em massa, e a micrografia resultante é mostrada na Figura 51. (IMAl et al, 2010). Entretanto, alguns autores apontam para a inviabilidade econômica deste processo, associado a maior dificuldade de processamento posterior nestas condições. (LORENZ et al, 2010; KLOCKE et al, 2012a; NOBEL et al, 2014).

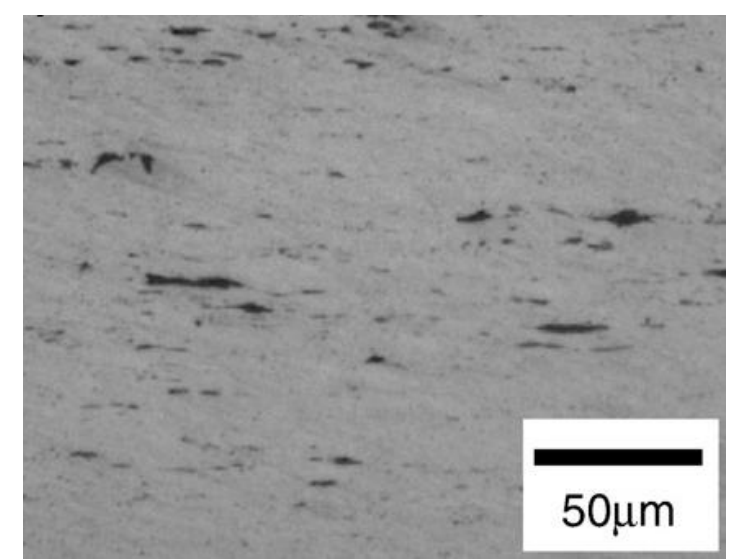

Figura 51 - Fotomicrografia de latão com partículas de grafite, obtidos pela metalurgia do pó (IMAI et al, 2010)

\subsubsection{Melhoria da usinabilidade de latões isentos de chumbo pela alteração dos parâmetros de usinagem}

Estudos de usinabilidade mostram que o chumbo reduz significativamente o grau de recalcamento do cavaco, além de ter importante influência no valor ângulo de cisalhamento $\phi$ por intermédio da alteração do $\omega$, pois o chumbo forma uma película de lubrificante na zona de contato entre a ferramenta e o material, com a consequentemente redução das forças de corte e, portanto, reduzindo a tensão mecânica e térmica sobre a ferramenta e a peça de trabalho. (KLOCKE et al, 2012a; KLOCKE et al, 2012b; NOBEL et al, 2014).

A Figura 52 confirma esta hipótese, sendo que a liga de latão com chumbo (CuZn39Pb3) apresenta menores forças de corte e temperaturas na ferramenta $\left(350 \mathrm{~N}\right.$ e $180^{\circ} \mathrm{C}$ ) em comparação as outras ligas de cobre isentas de chumbo. (KLOCKE et al, 2012a; KLOCKE et al, 2012b; NOBEL et al, 2014). 


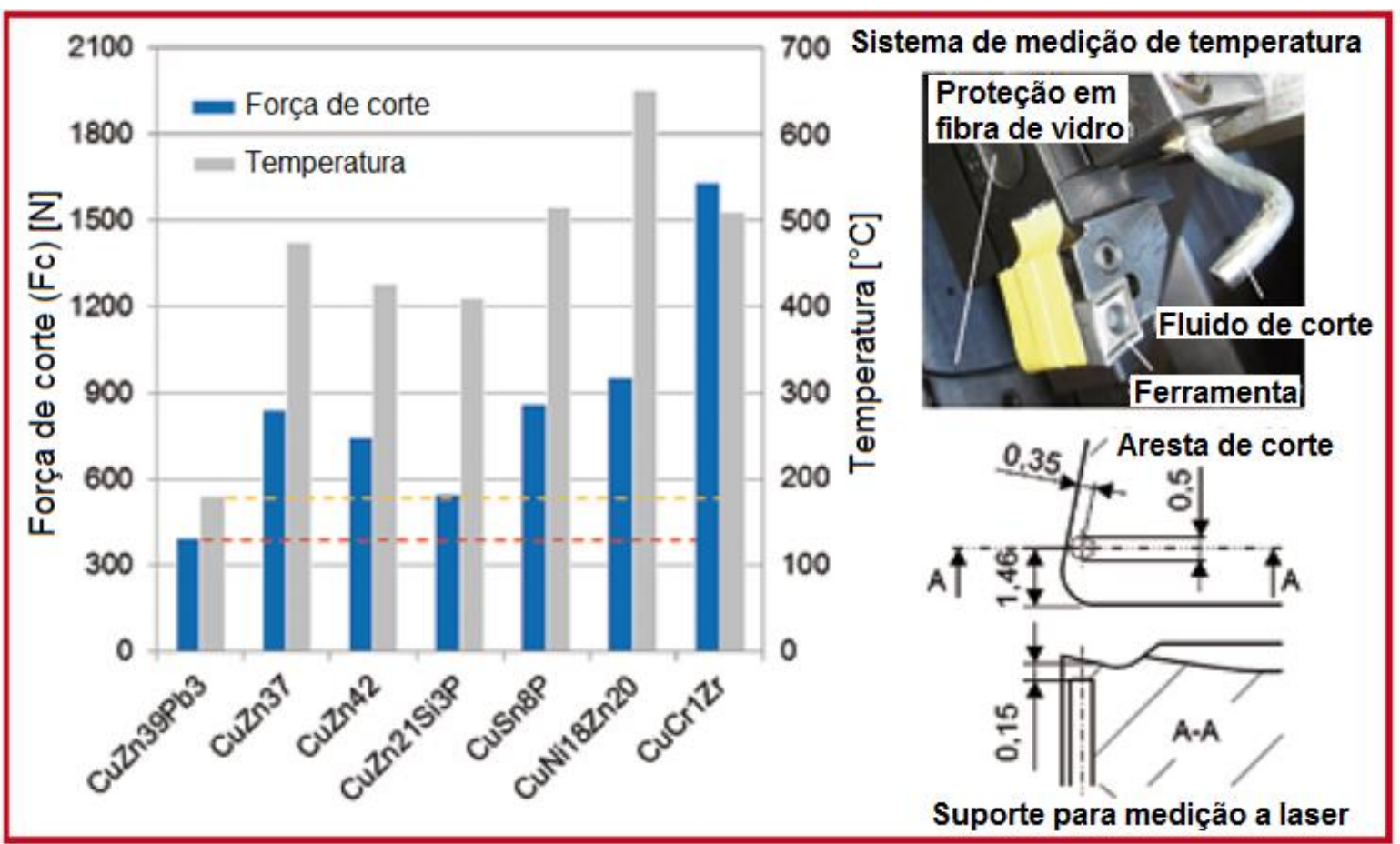

Figura 52 - Força de corte e temperatura de ferramenta no torneamento longitudinal externo em diferentes ligas de cobre. Parâmetro de corte utilizados $\gamma=10^{\circ}, \mathrm{X}=95^{\circ}$, vc $=200 \mathrm{~m} / \mathrm{min}, \mathrm{f}=0,2$ $\mathrm{mm} / \mathrm{rot}$, ap $=3 \mathrm{~mm}$, fluido de corte = emulsão, 7\% (KLOCKE et al, 2012b)

A Figura 53 mostra o comparativo do formato de cavaco e micrografia longitudinal de diferentes ligas de cobre usinadas. Os diferentes graus de recalcamento dos cavacos podem explicar as diferentes forças e temperaturas de corte descritas anteriormente. (KLOCKE et al, 2012b)

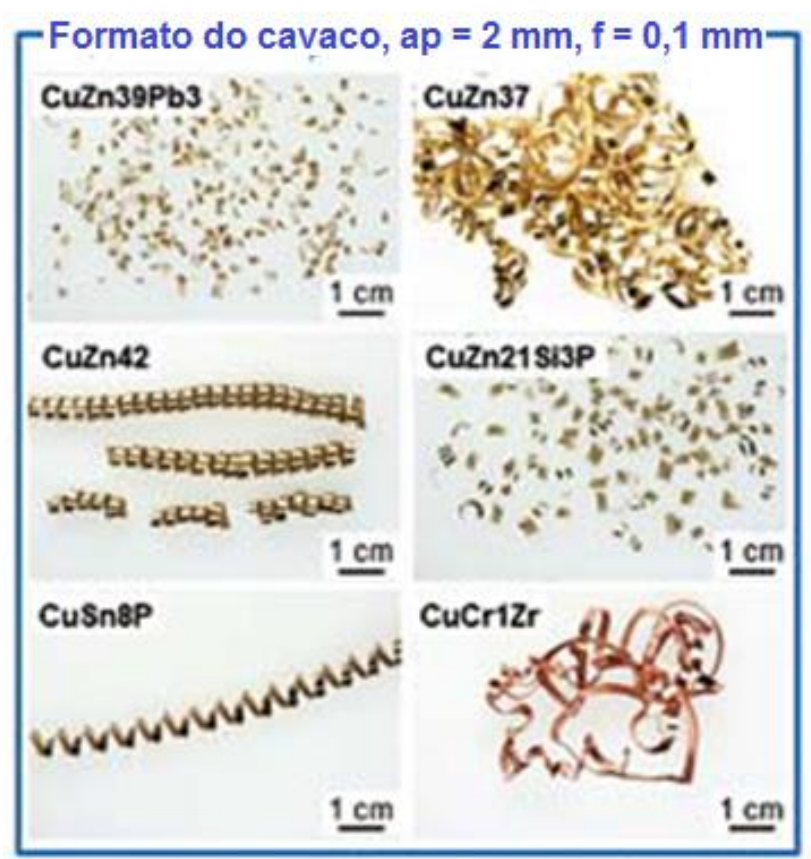

Micrografia longitudinal do cavaco

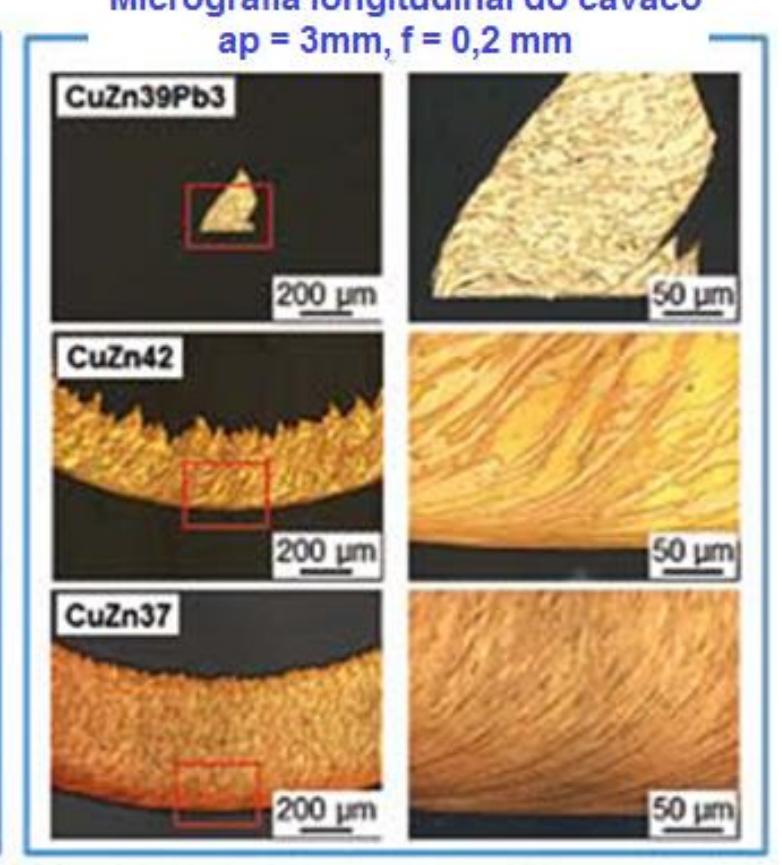

Figura 53 - Formas de cavacos resultantes do torneamento longitudinal externo em várias ligas de cobre. Parâmetro de corte utilizados $\gamma=10^{\circ}, \mathrm{X}=95^{\circ}, \mathrm{vc}=200 \mathrm{~m} / \mathrm{min}$, fluido de corte $=$ emulsão, $7 \%$

(KLOCKE et al, 2012b) 
Para o caso dos latões com chumbo, como o cavaco se fragmenta facilmente, mínima deformação microestrutural é observada na raiz do cavaco, indicando que o material praticamente não tem contato com a zona de cisalhamento secundário, e consequentemente são observadas as menores temperaturas de corte citadas anteriormente. Consequentemente, o grau de recalcamento dos cavacos é cerca de cinco vezes menor do que um cavaco de material isento de chumbo, como o CuZn37. (HOFMANN; MAGD, 2004; LORENZ et al, 2010; WOBKER et al, 2011; KLOCKE et al, 2012a; KLOCKE et al, 2012b; NOBEL et al, 2014).

A Figura 53 também indica que a fase $\beta$ contribui positivamente na redução da espessura do cavaco deformado, e consequentemente no grau de recalcamento do cavaco. A liga CuZn42, para as condições ensaiadas, apresenta uma menor espessura de cavaco, sendo duas vezes menor do que a obtida no material CuZn37. Esta diferença explica as menores forças de corte e temperaturas verificadas na Figura 52. (KLOCKE et al, 2012a; KLOCKE et al, 2012b; NOBEL et al, 2014).

Quanto ao desgaste de ferramenta, o gráfico da Figura 54 indica que as ligas de latão sem chumbo causam um desgaste de flanco ligeiramente maior em comparação aos latões com chumbo. Também se verifica que os latões com adição de silício têm vida de ferramenta geralmente menor em comparação aos latões sem silício, sendo esta diferença atribuída à presença da fase $\kappa$. (KLOCKE et al, 2012a)

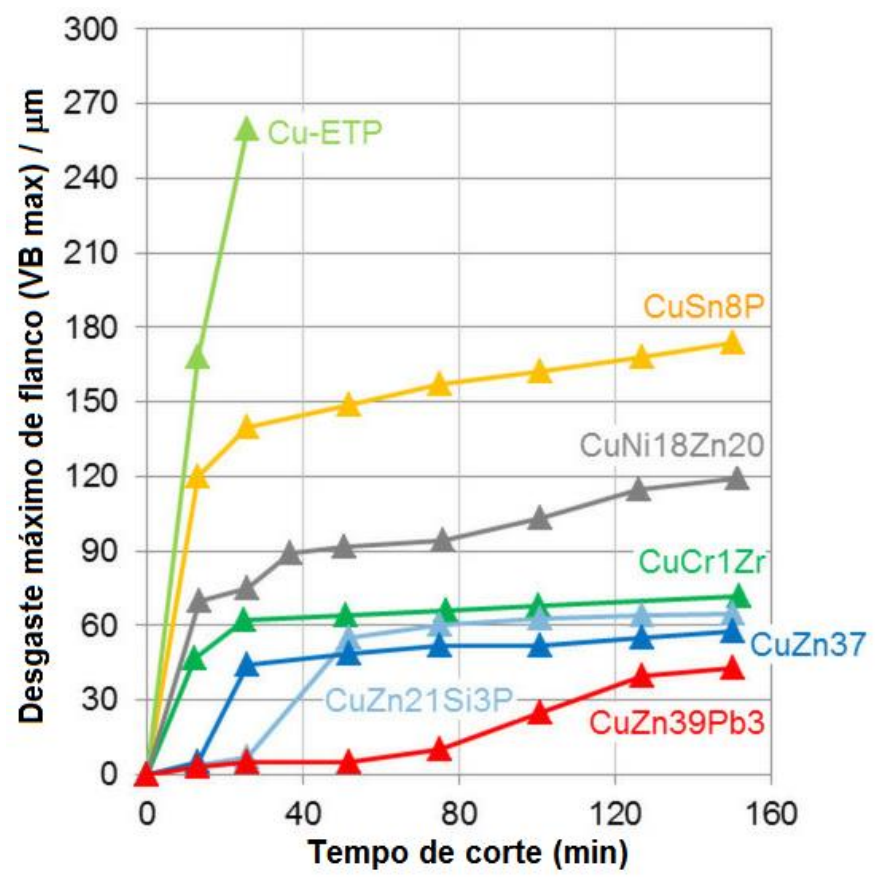

Figura 54 - Desgaste máximo do flanco ao ligar vários materiais de cobre, nas condições: vc $=200$ $\mathrm{m} / \mathrm{min}, \mathrm{ap}=1 \mathrm{~mm}, \mathrm{f}=0,1 \mathrm{~mm}$, emulsão (KLOCKE et al, 2012a) 
Dentre os aspectos tecnológicos, existem pesquisas cujo enfoque foi direcionado ao controle do cavaco, por meio de geometrias específicas de ferramenta. A Figura 55 mostra os resultados para três diferentes ângulos de saída e geometrias, as quais promovem a quebra dos cavacos das ligas de latão isentos de chumbo. (LORENZ et al, 2010; KLOCKE et al, 2012b; NOBEL et al, 2014).
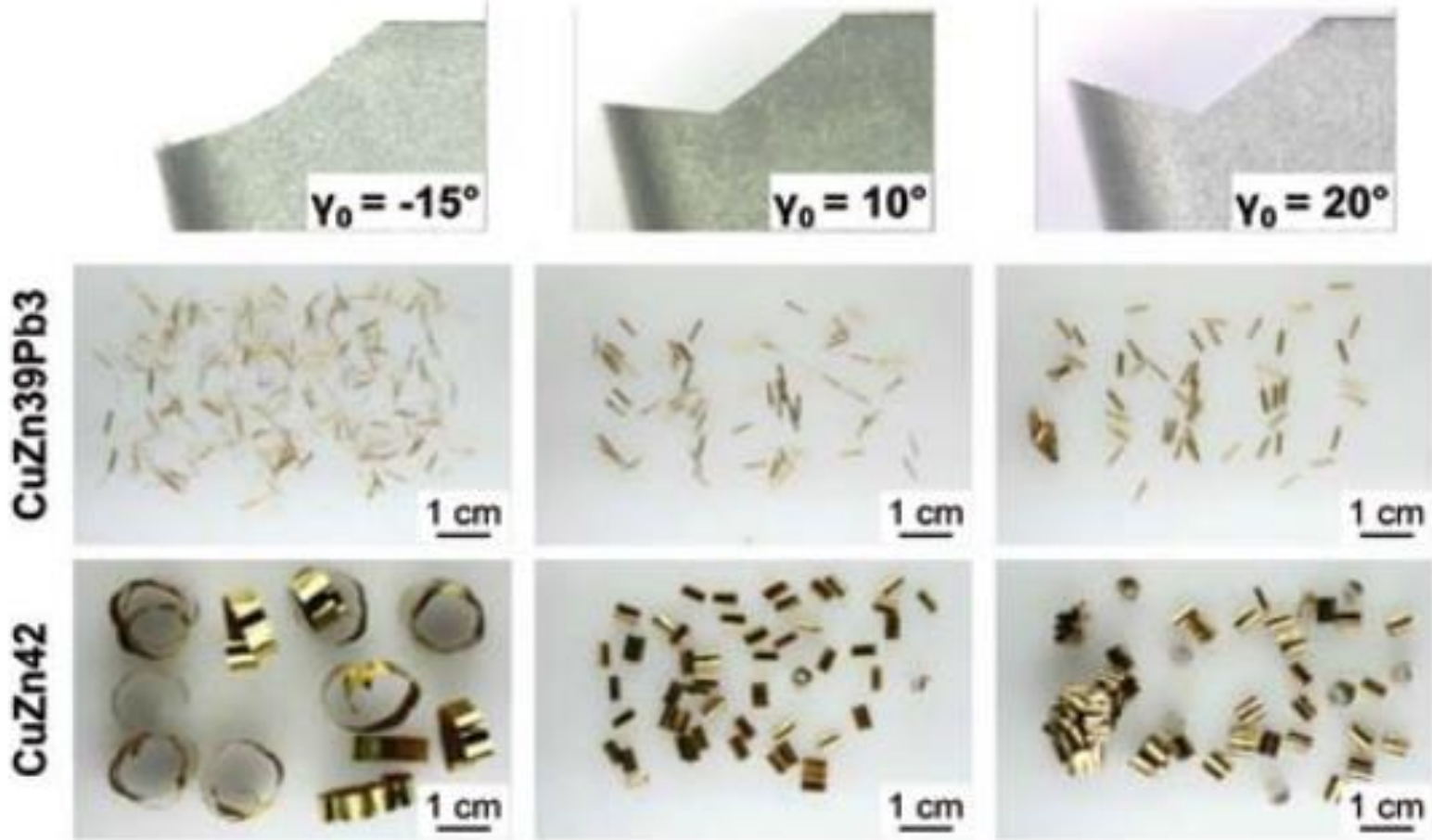

Figura 55 - Cavacos gerados a partir de ferramentas com geometrias de quebra cavaco. Parâmetros utilizados: $v c=300 \mathrm{~m} / \mathrm{min}, \mathrm{f}=0,04 \mathrm{~mm}, \mathrm{p}=0,25 \mathrm{~mm}$ (KLOCKE et al, 2012b)

Outra abordagem para o controle dos cavacos na usinagem de materiais isentos de chumbo está na aplicação direcionada de refrigerante em alta pressão, direcionado na zona de cisalhamento primário, com o uso de ferramentas de diamante policristalino planas, sem qualquer geometria auxiliar para quebra dos cavacos.

A Figura 56 mostra os resultados da utilização deste método, com a possibilidade de obtenção de cavacos fragmentados em avanços inferiores a 0,05 $\mathrm{mm}$, tanto para a liga CuZn37, quanto para a liga CuZn42. A principal diferença observada entre os dois materiais está na pressão necessária para a ocorrência deste comportamento, sendo que para a liga CuZn37 a pressão exigida foi de 40 bar, enquanto que para a Liga CuZn42 a pressão necessária foi de 6 bar. (KLOCKE et al, 2012a) 


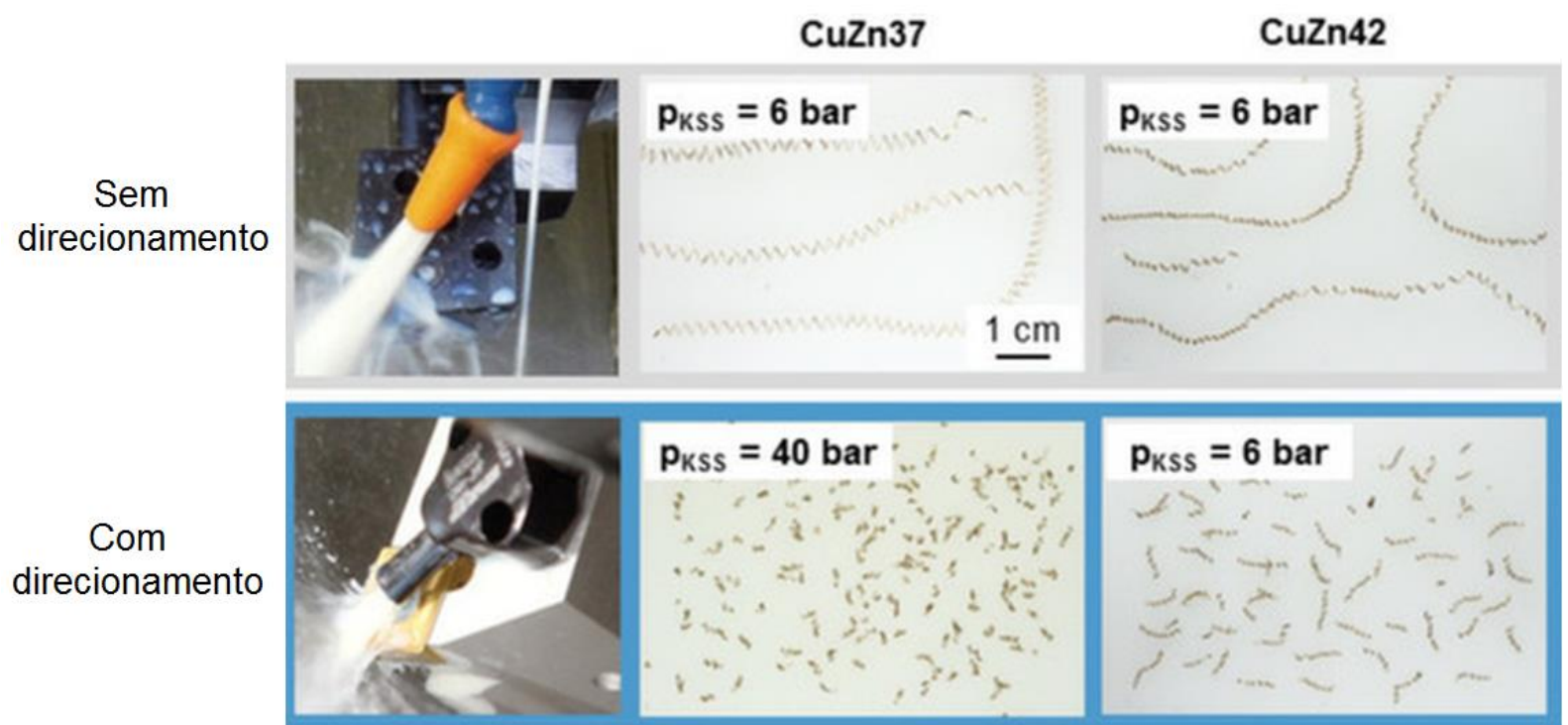

Figura 56 - Comparação das formas de cavaco obtidas pela variação do método de refrigeração. Parâmetros utilizados: $v c=125 \mathrm{~m} / \mathrm{min}, \mathrm{f}=0,03 \mathrm{~mm}, \mathrm{p}=0,25 \mathrm{~mm}$ (Adaptado de KLOCKE et al, 2012a)

É possível observar que as principais pesquisas do ramo enfatizam a alteração da composição química dos latões ou aspectos tecnológicos da usinagem de metais. Porém, as características até então apresentadas para os latões, indicam para uma importante influência do tratamento térmico, taxas de deformação e temperaturas de corte na usinagem de latões, e com isso, decidiu-se trabalhar em um diferente ponto de vista, baseado no desenvolvimento de diferentes características microestruturais de latões binários com $40 \%$ de zinco, com atenção à contribuição das diferentes morfologias da fase $\beta$, obtidas em processos de tratamento térmico industriais, para o processo de usinagem. 


\section{PROCEDIMENTO EXPERIMENTAL}

Para a observação da contribuição da fase $\beta$ nos processos de usinagem, fazse necessária a realização de ensaios experimentais de torneamento com materiais de diferentes frações de fase $\beta$, os quais poderão auxiliar a esclarecer o grau de contribuição da mesma em cada um dos diferentes aspectos de usinagem.

Os materiais e procedimentos escolhidos para este trabalho são baseados em uma abordagem mais próxima possível do contexto industrial, inclusive com a utilização de equipamentos de grande escala, de uma indústria metalúrgica de metais não ferrosos.

\subsection{MATERIAIS}

Para a realização do estudo foram fabricadas barras da liga latão 60/40, mediante o processo de extrusão a quente de billets fundidos com diâmetro de 280 $\mathrm{mm}$ e aquecidos em forno a gás em uma faixa de temperatura para obtenção de microestrutura com predominância de fase $\beta\left(830^{\circ} \mathrm{C}\right)$, seguido de trefilação a frio. Posteriormente os mesmo foram submetidos a diferentes tratamentos térmicos, e foram denominados de A1, A2, A3 e A4. O processo de fabricação padrão dos mesmos está representado esquematicamente pela Figura 57.

Quanto aos tratamentos térmicos empregados, o material A1 é isento de tratamento térmico (extrudado), A2 foi recozido em forno de recozimento contínuo a $550^{\circ} \mathrm{C}$ por 2 horas e $\mathrm{A} 3$ recozido em forno contínuo a $650^{\circ} \mathrm{C}$ por 2 horas, e A4 submetido ao processo de alívio de tensões em forno estático, na temperatura de $460^{\circ} \mathrm{C}$ por 10 horas.

Observando a Figura 58, verifica-se para as temperaturas empregadas existe uma tendência de redução percentual de fase $\beta$, sendo que na temperatura de $460^{\circ} \mathrm{C}$ observa-se o ponto de máxima solubilidade do zinco ao cobre. Neste ponto se espera a menor fração volumétrica fase $\beta$ possível para esta liga, além da obtenção de distintas propriedades mecânicas entre os materiais. É fundamental ressaltar que a referência proposta é baseada no diagrama de fases, sendo este válido apenas para condições de equilíbrio, o que não ocorre em tratamentos térmicos industriais. 


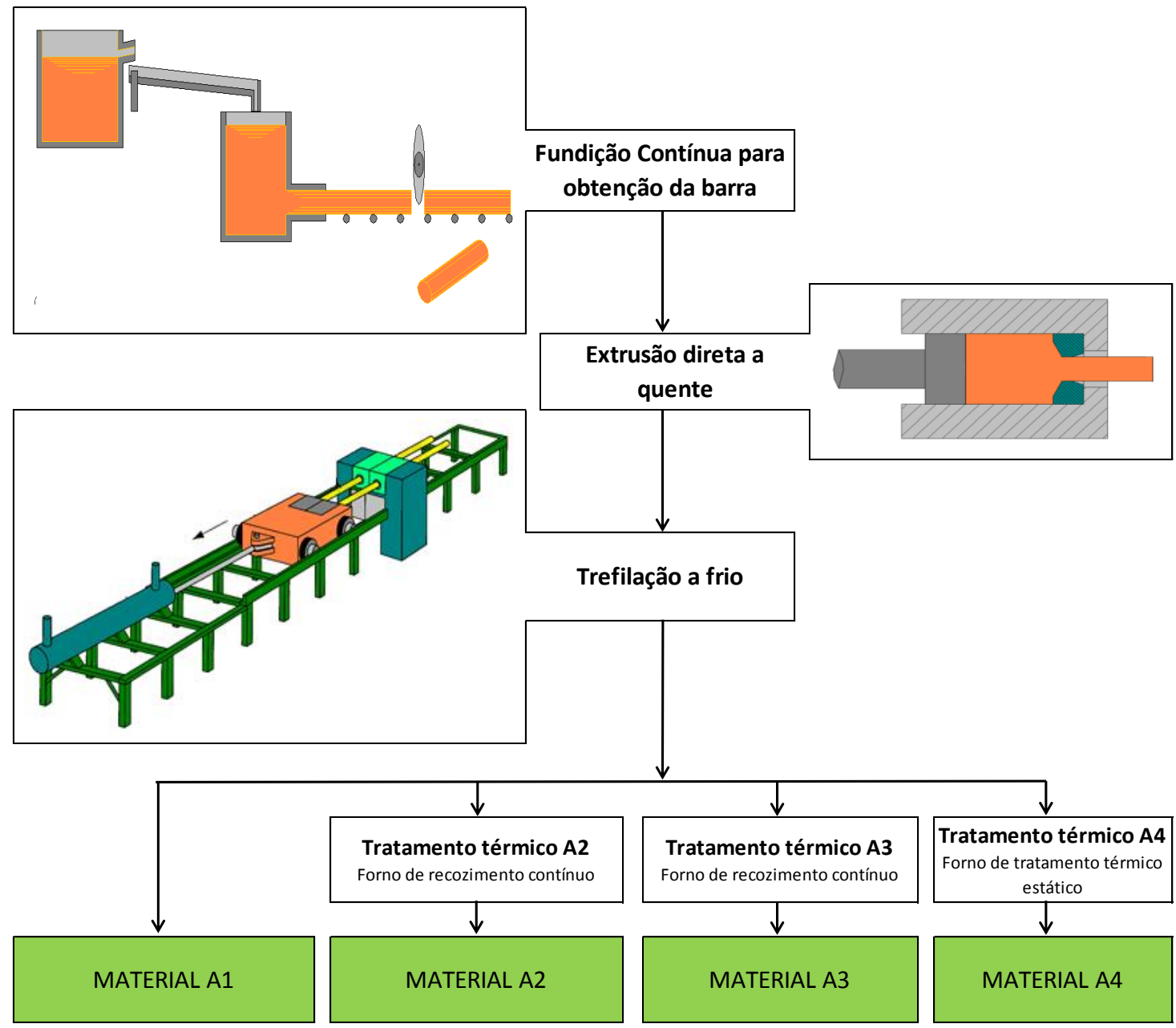

Figura 57 - Representação esquemática dos processos de fabricação dos materiais A1, A2, A3 e A4

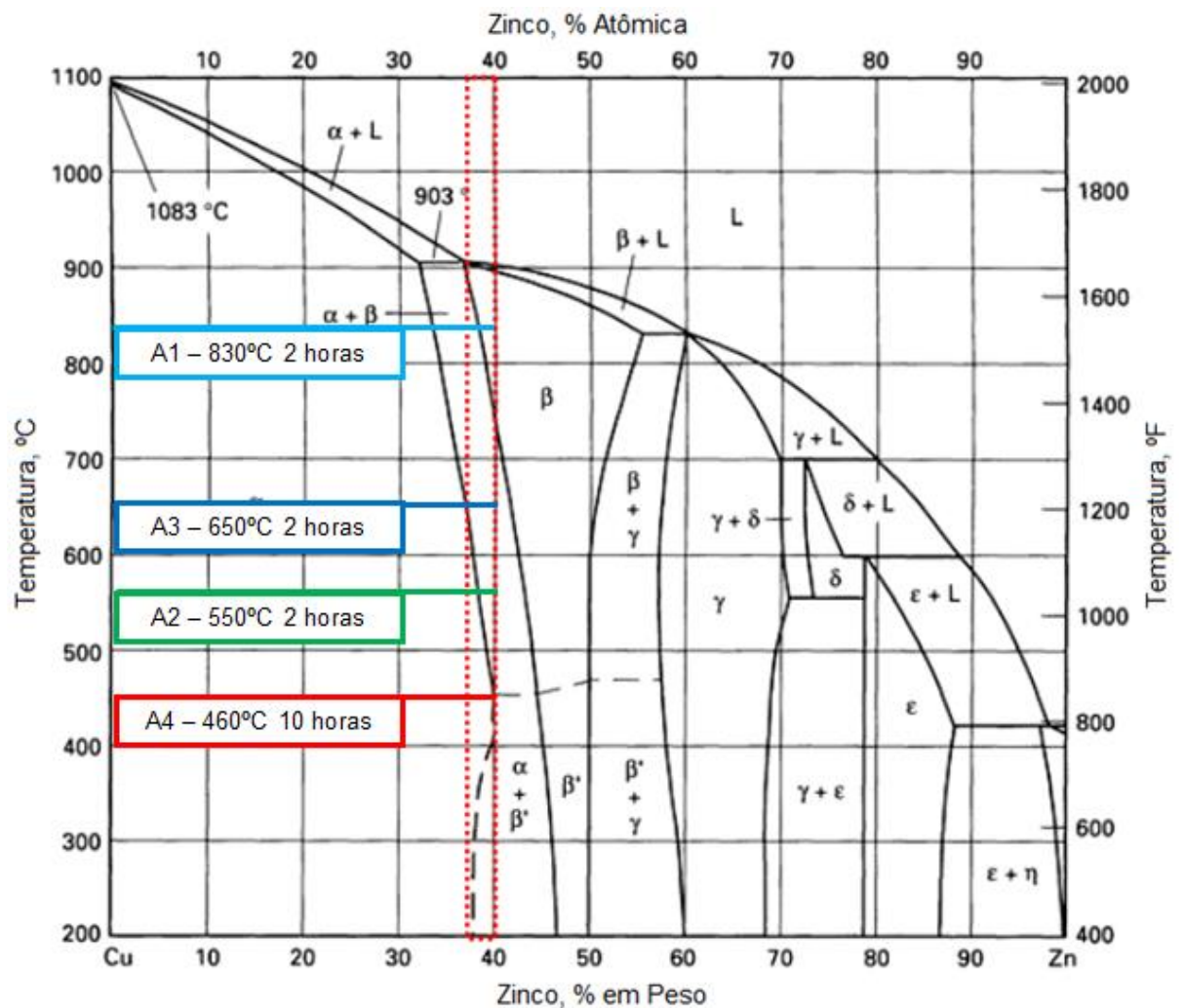

Figura 58 - Referência para utilização das temperaturas de processo e tratamento térmico 
Para os ensaios comparativos, foram fabricados pelos mesmos processos industriais descritos anteriormente dois materiais de referência, sendo um nomeado como grupo B1, da liga Latão cartucho 70/30 (UNS-C26000), o qual se caracteriza por ser um material monofásico, com $70 \%$ de cobre e isento de fase $\beta$, e o grupo denominado de $\mathrm{C} 1$, referente à liga de Latão de Corte Livre Americano, (CLA), reconhecida como a liga mais indicada no mercado para operações de usinagem (Usinabilidade 100\%), sendo a principal diferença entre ambas a presença ou não de chumbo respectivamente. As composições químicas dos materiais estão na Tabela 1.

Tabela 1 - Composição química dos materiais estudados

\begin{tabular}{|c|c|c|c|c|c|c|c|}
\hline \multirow{2}{*}{ Grupo } & \multirow{2}{*}{ Liga } & \multicolumn{6}{|c|}{ Elemento } \\
\hline & & Zn & $\mathbf{P b}$ & $\mathrm{Fe}$ & $\mathbf{N i}$ & As & $\mathrm{Cu}$ \\
\hline A1 & Latão 60/40 & $40,10 \%$ & $0,01 \%$ & $0,00 \%$ & $0,01 \%$ & $0,00 \%$ & Restante \\
\hline $\mathrm{A} 2$ & Latão 60/40 & $40,10 \%$ & $0,01 \%$ & $0,00 \%$ & $0,01 \%$ & $0,00 \%$ & Restante \\
\hline A3 & Latão 60/40 & $40,10 \%$ & $0,01 \%$ & $0,00 \%$ & $0,01 \%$ & $0,00 \%$ & Restante \\
\hline A4 & Latão 60/40 & $40,10 \%$ & $0,01 \%$ & $0,00 \%$ & $0,01 \%$ & $0,00 \%$ & Restante \\
\hline B1 & Latão 70/30 & $30,50 \%$ & $0,01 \%$ & $0,02 \%$ & $0,01 \%$ & $0,00 \%$ & Restante \\
\hline C1 & CLA com $\mathrm{Pb}$ & $36,80 \%$ & $3,40 \%$ & $0,02 \%$ & $0,01 \%$ & $0,00 \%$ & Restante \\
\hline
\end{tabular}

\subsection{MÉTODOS}

\subsubsection{Caracterização mecânica}

A caracterização mecânica dos materiais estudados foi realizada utilizando-se dos ensaios de tração, dureza e microdureza, sendo os ensaios de tração realizados com a máquina de tração Instron 3387, com capacidade de 29,4 KN de carga, com corpos de prova cilíndricos de diâmetro de $8 \mathrm{~mm}$ e procedimentos em conformidade com a norma ASTM E8 M.

O ensaio de dureza foi realizado com os parâmetros previstos na norma ASTM E92, sendo escolhida a escala Vickers com carga de 10 kgf, no durômetro universal Wilson UH-930. Para o ensaio de microdureza Vickers, foi utilizado microdurômetro Buehler com carga de 0,01 kgf, a qual permite a caracterização dos microconstituintes de forma individualizada. Em ambos os casos, foram realizadas 10 medições de cada condição. 


\subsubsection{Caracterização microestrutural}

As amostras metalográficas foram preparadas em conformidade com a norma ASTM E3, mediante sucessivo polimento em lixadeira metalográfica, e imergindo o corpo de prova em reagente composto por $5 \mathrm{~g}$ de $\mathrm{FeCl}_{3}, 100 \mathrm{ml}$ de etanol e $7 \mathrm{ml}$ de $\mathrm{HCl}$ por 30 segundos. A microestrutura revelada foi analisada em 3 diferentes campos amostrais via microscopia óptica utilizando o microscópio Leica DM2700 M, sendo que foram avaliadas as seções transversais e longitudinais das barras fabricadas.

O microscópio é associado ao software Leica QPhase, o qual permite quantificar através de análise das áreas escuras das imagens monocromáticas, a fração volumétrica da fase $\beta$ dos materiais analisados.

\subsubsection{Ensaios de usinagem}

Os ensaios de usinagem foram realizados em torno CNC Romi Multiplic 30D, com montagem da ferramenta TNMA160408 IC20 (ISO 513) de acordo com a Figura 59, e suas dimensões e geometrias de corte indicadas na Figura 60 e Tabela 2.

É importante ressaltar que foi escolhido um inserto de usinagem com superfície plana e isenta de geometrias auxiliares na quebra de cavaco, pois a proposta da pesquisa é avaliar a contribuição das diferentes frações de fase $\beta$ contidas nos materiais, e uma geometria de quebra cavacos prejudicaria a análise desta variável.
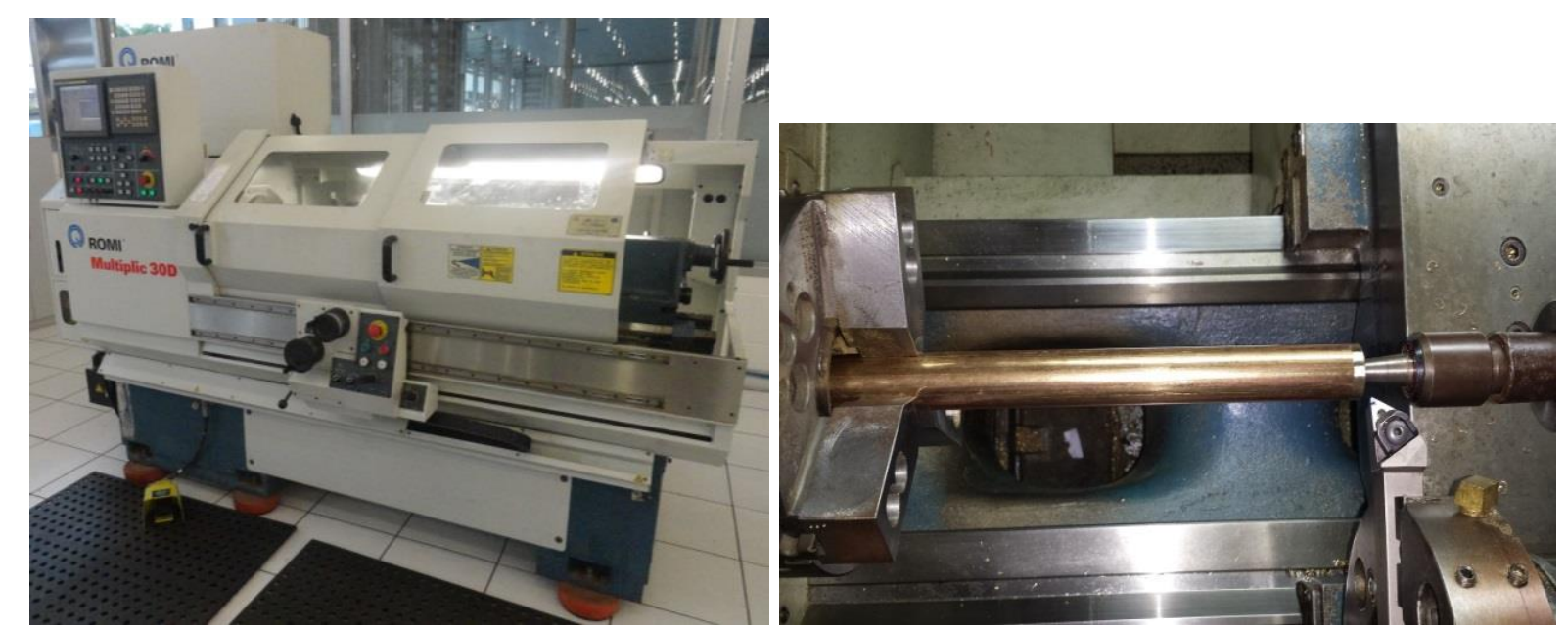

Figura 59 - Torno utilizado no experimento com a respectiva montagem da ferramenta 

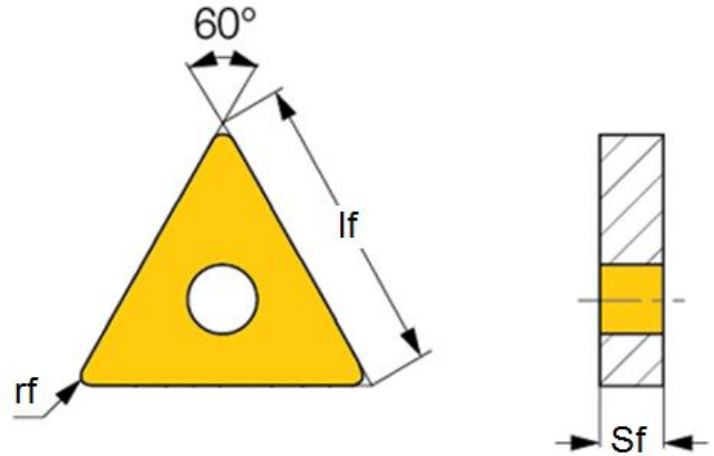

Figura 60 - Representação esquemática da ferramenta utilizada (ISCAR, 2015)

Tabela 2 - Dimensões do inserto utilizado no ensaio (ISCAR, 2015)

\begin{tabular}{cc}
\hline Dimensão & Valor \\
\hline If & $0,8 \mathrm{~mm}$ \\
દf & $60^{\circ}$ \\
If & $16,50 \mathrm{~mm}$ \\
Sf & $4,76 \mathrm{~mm}$ \\
\hline
\end{tabular}

O suporte utilizado para apoio e posicionamento da ferramenta é o MTJNR2020K-16W, do fornecedor Iscar, gerando as geometrias de corte representadas na Figura 61 e Tabela 3:
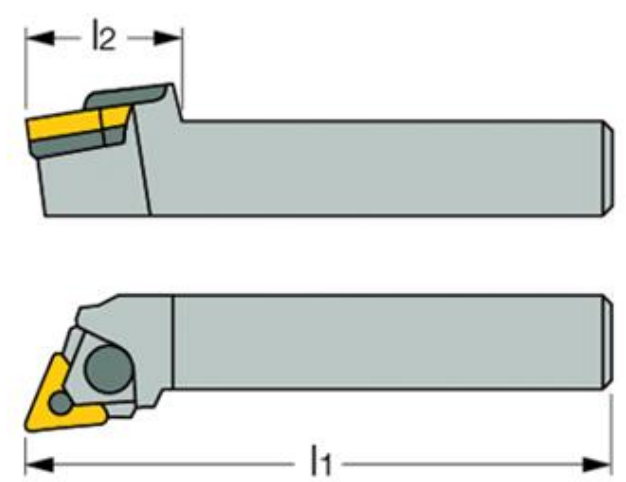

Figura 61 - Representação esquemática da ferramenta de corte (ISCAR, 2015)

Tabela 3 - Principais dimensões e ângulos da ferramenta utilizada (ISCAR, 2015)

\begin{tabular}{cc}
\hline Dimensão & Valor \\
\hline af & $6^{\circ}$ \\
$\beta f$ & $90^{\circ}$ \\
$Y$ & $-6^{\circ}$ \\
$X$ & $93^{\circ}$ \\
I1 & $125 \mathrm{~mm}$ \\
I2 & $32 \mathrm{~mm}$ \\
\hline
\end{tabular}

Foram utilizados quatro parâmetros de corte, descritos na Tabela 4, e baseados nas recomendações previstas pela German Copper Institute (2010). A diferença consiste no uso de quatro diferentes velocidades de corte, sendo mantida a profundidade de corte e a velocidade de avanço, e não foram utilizados fluidos de corte. 
Tabela 4 - Parâmetros de corte utilizados nos experimentos

\begin{tabular}{ccccc}
\hline Parâmetro & Processo 1 & Processo 2 & Processo 3 & Processo 4 \\
\hline Passe (ap) & $2 \mathrm{~mm}$ & $2 \mathrm{~mm}$ & $2 \mathrm{~mm}$ & $2 \mathrm{~mm}$ \\
Avanço (f) & $0,2 \mathrm{~mm} / \mathrm{rot}$ & $0,2 \mathrm{~mm} / \mathrm{rot}$ & $0,2 \mathrm{~mm} / \mathrm{rot}$ & $0,2 \mathrm{~mm} / \mathrm{rot}$ \\
Velocidade de Corte $(\mathrm{vc})$ & $60 \mathrm{~m} / \mathrm{min}$ & $100 \mathrm{~m} / \mathrm{min}$ & $140 \mathrm{~m} / \mathrm{min}$ & $180 \mathrm{~m} / \mathrm{min}$ \\
\hline
\end{tabular}

\subsubsection{Análise da rugosidade das peças usinadas}

As peças depois de usinadas foram submetidas à medição de rugosidade $\mathrm{Ra}$ e $R z$ utilizando o rugosímetro Mitutoyo Surftest SJ-201, na montagem da Figura 62, sendo realizadas 10 repetições para cada medida, com parâmetro de cutoff de $2,5 \mathrm{~mm}$, adequado para os valores de rugosidade identificados nos materiais.

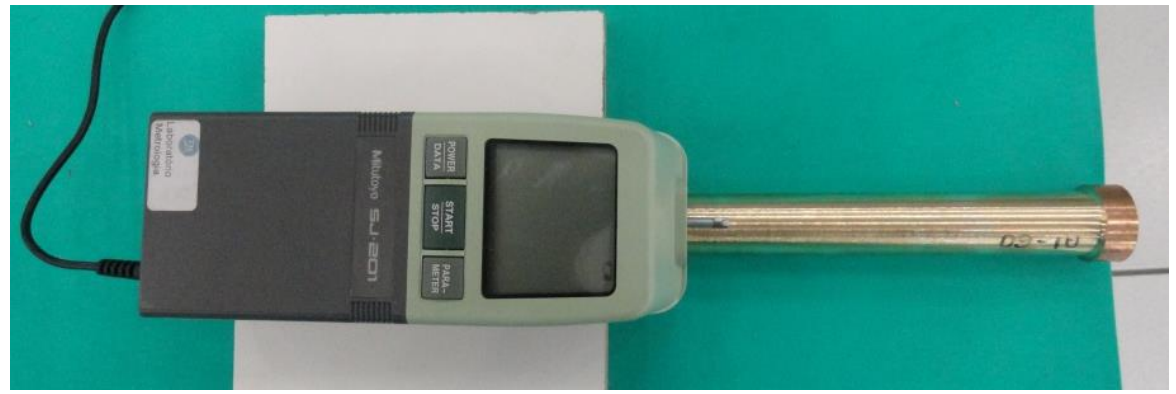

Figura 62 - Ensaio de rugosidade

\subsubsection{Caracterização dos cavacos}

A morfologia dos cavacos gerados neste processo de usinagem foi analisada de acordo com o padrão previsto na norma ISO 3685. Além disso, as amostras dos cavacos foram analisadas através de microscopia eletrônica de varredura (MEV), no equipamento Phenom Pro $X$, no intuito de identificar possíveis mecanismos de fratura dos cavacos nos contornos de interface $\alpha / \beta$ '. Além disso, foi utilizado o recurso da análise química por elétrons retro espalhados (BSC), para análise da composição química qualitativa na região de segunda fase nos materiais e nos cavacos usinados.

Para avaliação do grau de recalcamento dos cavacos e análise das temperaturas de corte, foram medidas as espessuras dos cavacos, bem como a altura da curvatura da microestrutura na superfície inferior com auxílio do software Leica MW, com base nas amostras metalográficas da seção longitudinal dos cavacos, as quais foram preparadas em conformidade com a norma ASTM E3, conforme descrito na seção 3.2.2. 


\subsubsection{Avaliação das forças de corte}

Para avaliação dos esforços de usinagem em cada um dos parâmetros de usinagens, sendo estes a força de corte $(\mathrm{Fc})$, Força de avanço $(\mathrm{Ff})$ e a Força passiva $(\mathrm{Fp})$, foram realizados dois ensaios para cada parâmetro utilizando o aparato experimental da Figura 63, o qual consiste de um dinamômetro piezoelétrico Kistler modelo 9265B/ 9441B, e software analisador de sinais DynoWare 2825A1-2.

Dada a condição de que a máquina utilizada neste ensaio é um torno mecânico convencional, e consequentemente diferente do equipamento descrito na seção 3.2.3, foram considerados os parâmetros de usinagem com profundidade de corte de $2 \mathrm{~mm}$, avanço de $0,205 \mathrm{~mm} /$ rotação e velocidade de corte de $132 \mathrm{~m} / \mathrm{min}$.

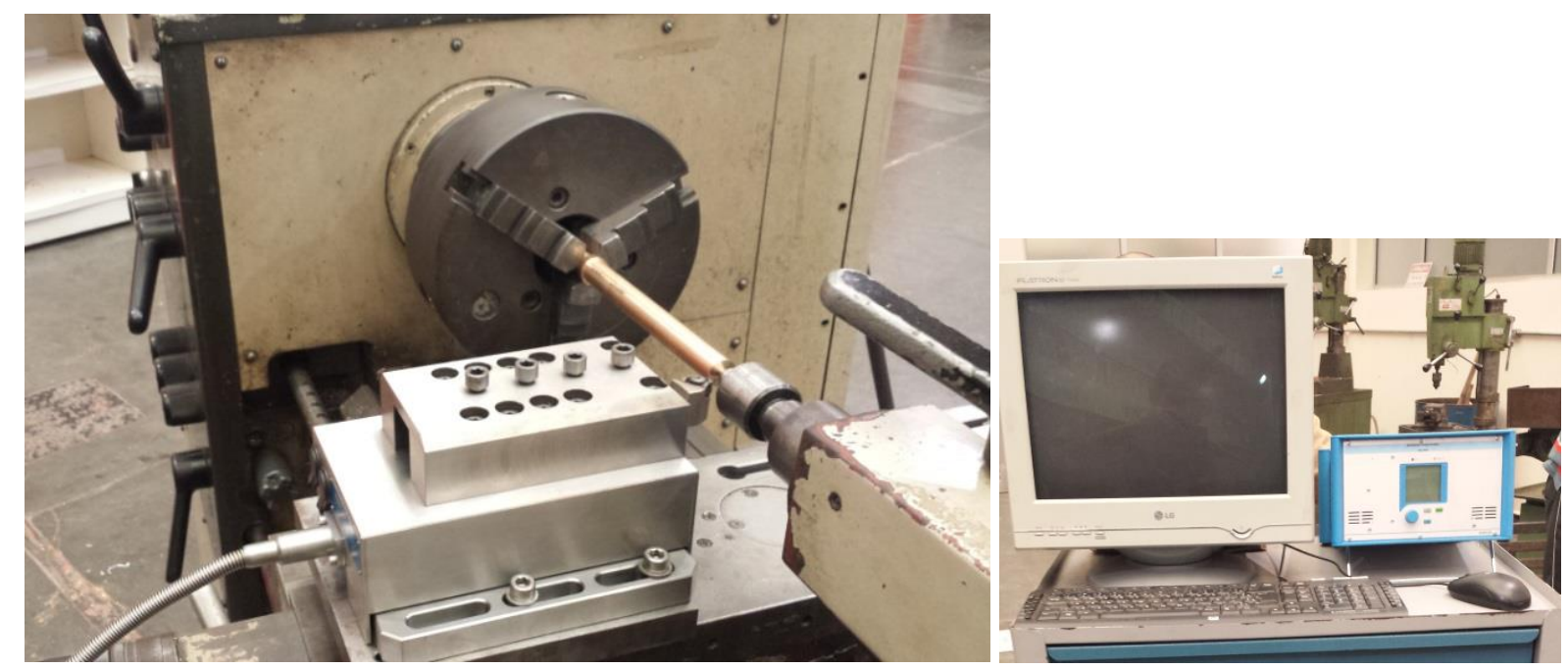

Figura 63 - Dinamômetro piezoelétrico Kistler utilizado nos experimentos

\subsubsection{Análise do desgaste da ferramenta}

Os ensaios de desgaste de ferramenta foram baseados na observação do desgaste de flanco, tanto em microscópio estereoscópico Olympus SZX10 quanto em microscópio eletrônico de varredura Phenon Pro X.

Dado ao elevado volume amostral que este ensaio demanda, e visando reduzir o tempo de preparação do equipamento, foi escolhida uma diferente estratégia experimental, a qual consiste de usinar com a mesma ferramenta uma série de peças em um tempo acumulado de processo de 60 minutos na velocidade de corte de $140 \mathrm{~m} / \mathrm{min}$, profundidade de corte de $1 \mathrm{~mm}$ e avanço de $0,08 \mathrm{~mm} / \mathrm{rot}$ no torno CNC Romi Multiplic 30D, utilizando ferramenta TNMA160408 IC20 (ISO 513) com suporte MTJNR2020K-16W. 


\subsection{ABORDAGENS ANALÍTICAS}

\subsubsection{Determinação analítica das temperaturas geradas na usinagem}

As temperaturas obtidas no processo de usinagem foram estimadas pelo modelo de Boothroyd (1975), equações (25), (28), (30) e (31), descritas na seção 2.9.2 e foram baseadas nos dados extraídos das forças de corte da seção 3.2.6 na velocidade de $132 \mathrm{~mm} / \mathrm{min}$, bem como a respectiva análise das micrografias dos cavacos gerados. As propriedades físicas dos materiais necessárias para os cálculos, sendo elas a densidade ( $\rho)$, calor específico (c) e condutividade térmica são apresentadas na Tabela 5:

Tabela 5 - Propriedades físicas dos latões utilizados nos experimento. (LOCONSOLO; NOBILI, 1995)

\begin{tabular}{ccccc}
\hline \multirow{2}{*}{ Liga UNS } & Referência & \multicolumn{3}{c}{ Propriedades físicas } \\
\cline { 3 - 5 } & & $\mathbf{\rho}$ & $\mathbf{c}$ & $\mathbf{k}$ \\
{$[\mathbf{k g} / \mathbf{m} 3]$} & {$[\mathbf{J} / \mathbf{k g k}]$} & {$[\mathbf{W} / \mathbf{m K}]$} \\
\hline Latão UNS-C 28000 & Materiais A1-A4 & 8,39 & 375 & 123 \\
Latão UNS-C26000 & Material B1 & 8,53 & 375 & 120 \\
Latão UNS-C36000 & Material C1 & 8,5 & 380 & 115 \\
\hline
\end{tabular}

\subsubsection{Determinação analítica das taxas de deformação existentes}

As taxas de deformação foram estimadas conforme equação (18) mostrada na seção 2.7.5. Foi medida a espessura elementar do cavaco $(\Delta y)$, nas condições em que apresentaram aspectos segmentados, e comparados com o valor de literatura (GANE 1981 apud HOFMANN; MAGD, 2004).

\subsubsection{Análise estatística dos resultados}

Os resultados obtidos para a microdureza da fase $\beta$ e rugosidades foram analisados pela ferramenta estatística ANOVA: fator único, para um nível de significância $\alpha_{e}=0,05$. Foi utilizado o teste de hipóteses $F$, sendo os parâmetros de interesse: O quadrado das somas (SS), número de graus de liberdade (GL), quadrado das médias (MS), valor do teste de hipóteses $F$ observado $\left(F_{0}\right)$, valor do teste de hipóteses $F$ crítico $\left(F_{c}\right)$. Para que uma amostragem obtida seja significativamente diferente de outra, o valor de $F_{0}$ deverá ser maior do que o valor de $F_{c .,}$ e o valor $p$ ( $p$-value) obtido deverá ser menor do que o valor do nível de significância $\alpha_{e}$. 


\section{RESUltados E discussão}

Nesta seção serão apresentados os resultados obtidos a partir da metodologia experimental e analítica, na ordem em que foram descritas nas seções 3.2 e 3.3 respectivamente.

\subsection{CARACTERIZAÇÃO MICROESTRUTURAL DOS MATERIAIS}

As microestruturas obtidas para os materiais, vistas em aumento de 200x, são mostradas nas Figuras 64,65, 66, 67, 68 e 69 a seguir, sendo as áreas escuras correspondentes à fase $\beta$, e a fase $\alpha$ é representada em tons de amarelo.

O material A1 (Figura 64) apresentou microestrutura similar à figura 7 (LEE et al 2003), pois a temperatura de extrusão empregada permitiu o material ser conformado em uma microestrutura predominante de fase $\beta$. $O$ aspecto lamelar da microestrutura ocorreu devido ao resfriamento lento do processo, e pelo mecanismo de difusão, a fase $\alpha$ precipitou a partir da fase $\beta$.

O material A2 (Figura 65), em função das temperaturas e tempo utilizados, apresenta uma microestrutura com tendência de esferoidização das fases $\alpha$ e $\beta$, porém incompleta devido ao tempo de tratamento utilizado. Esta microestrutura preserva uma distribuição lamelar, semelhante à observada no material A1.

O material A3 (Figura 66), devido ao fato de ter sido submetido a uma maior temperatura de recozimento, apresentou uma microestrutura mais grosseira em comparação aos materiais A2 e A4, sendo possível verificar um maior tamanho médio dos grãos de fase $\alpha$ e $\beta$, sendo que esta microestrutura apresenta menor semelhança em comparação à microestrutura $A 1$, oriunda do processo de extrusão.

O material A4 (Figura 67), em função da menor temperatura utilizada, apresentou menor tamanho médio dos grãos das fases $\alpha$ e $\beta$, e consequentemente preservou uma semelhança na distribuição lamelar observada no material A1.

O material B1 (Figura 68) apresentou microestrutura monofásica com grãos de estrutura a maclados. Pelo método comparativo, foi determinado um tamanho de grão médio de $100 \mu \mathrm{m}$. Quanto ao material C1 (Figura 69), o mesmo apresentou a presença de fase $\beta$, com nódulos de chumbo finamente dispersos, os quais estão localizados próximos aos contornos de grão da fase $\beta$. 


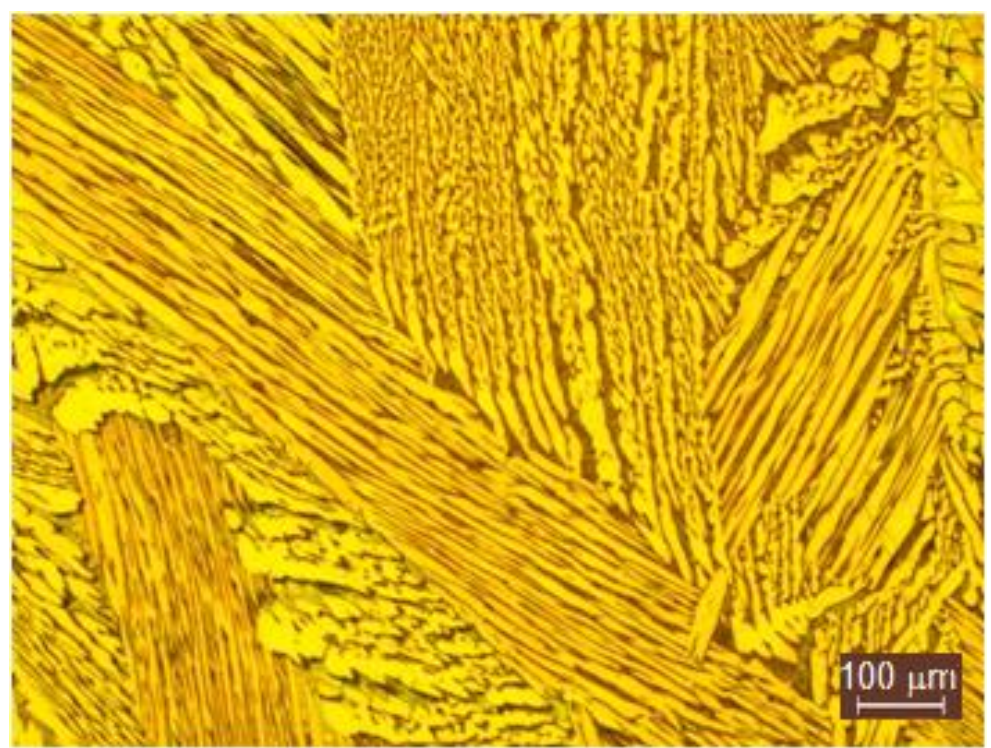

Figura 64 - Microestrutura do material relativo ao grupo A1 (x200, Reagente $\mathrm{FeCl}_{3}+$ Etanol $+\mathrm{HCl}$ )

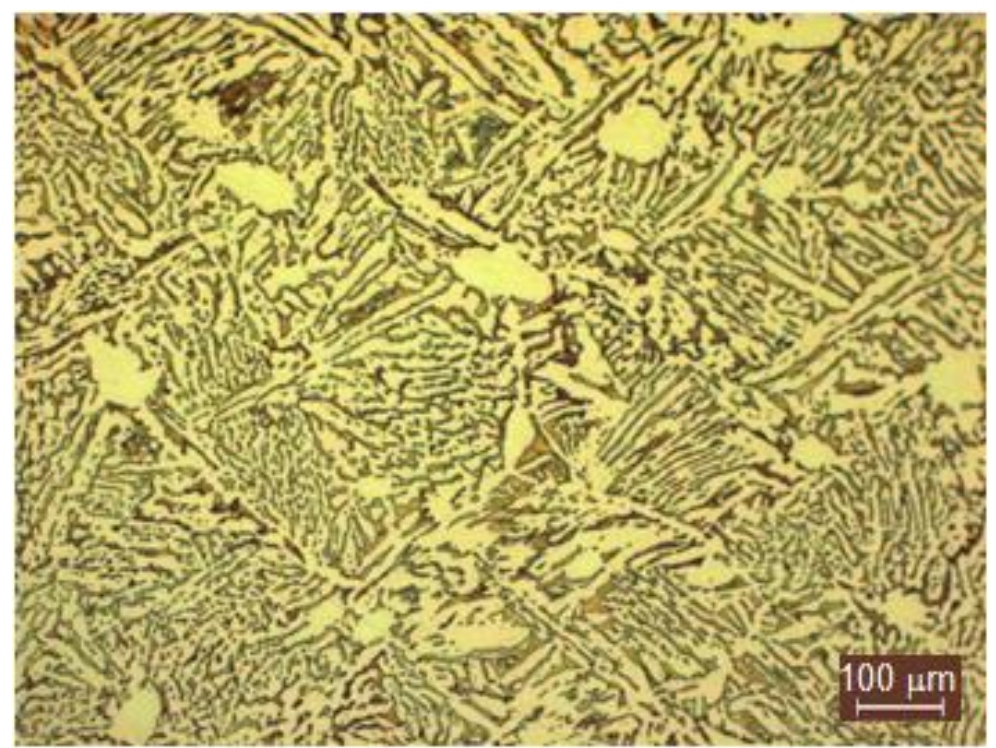

Figura 65 - Microestrutura do material relativo ao grupo A2 (x200, Reagente $\left.\mathrm{FeCl}_{3}+\mathrm{Etanol} \mathrm{HCl}\right)$

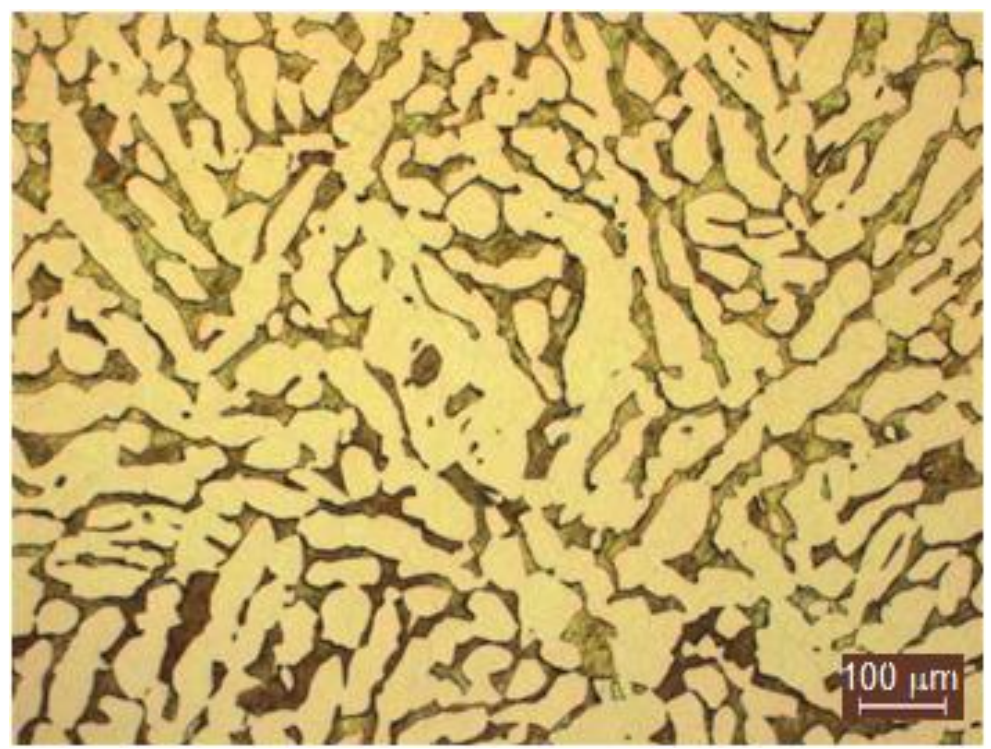

Figura 66 - Microestrutura do material relativo ao grupo A3 (x200, Reagente $\mathrm{FeCl}_{3}+$ Etanol $\left.+\mathrm{HCl}\right)$ 


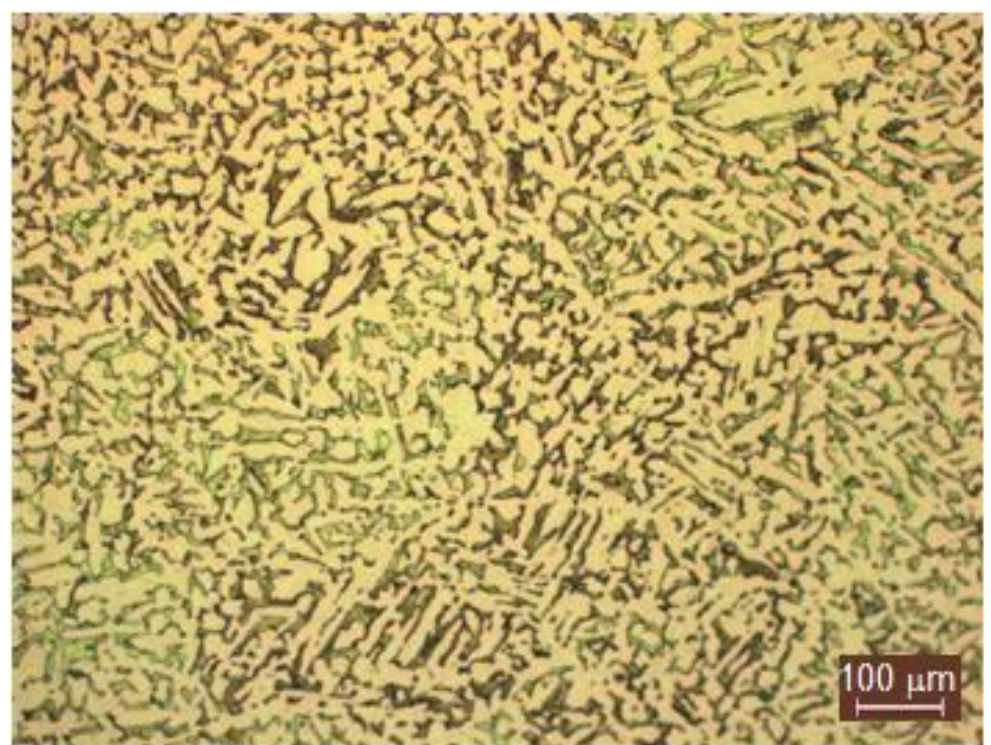

Figura 67 - Microestrutura do material relativo ao grupo A4 (x200, Reagente $\mathrm{FeCl}_{3}+$ Etanol $+\mathrm{HCl}$ )

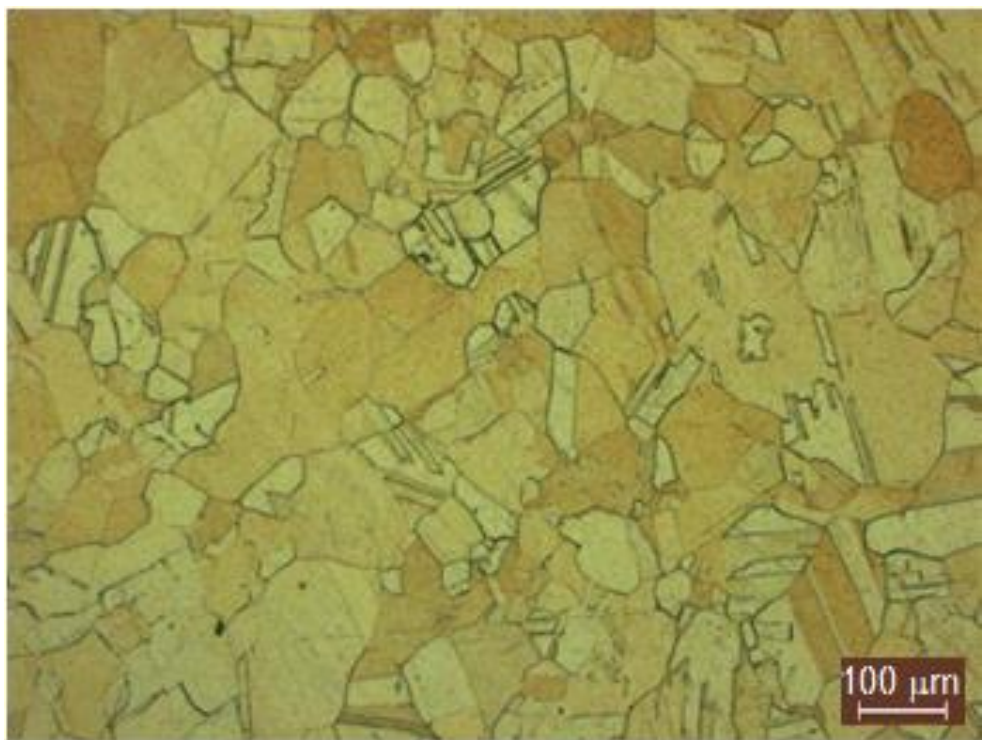

Figura 68 - Microestrutura do material relativo ao grupo B1 (x200, Reagente $\mathrm{FeCl}_{3}+\mathrm{Etanol}_{+} \mathrm{HCl}$ )

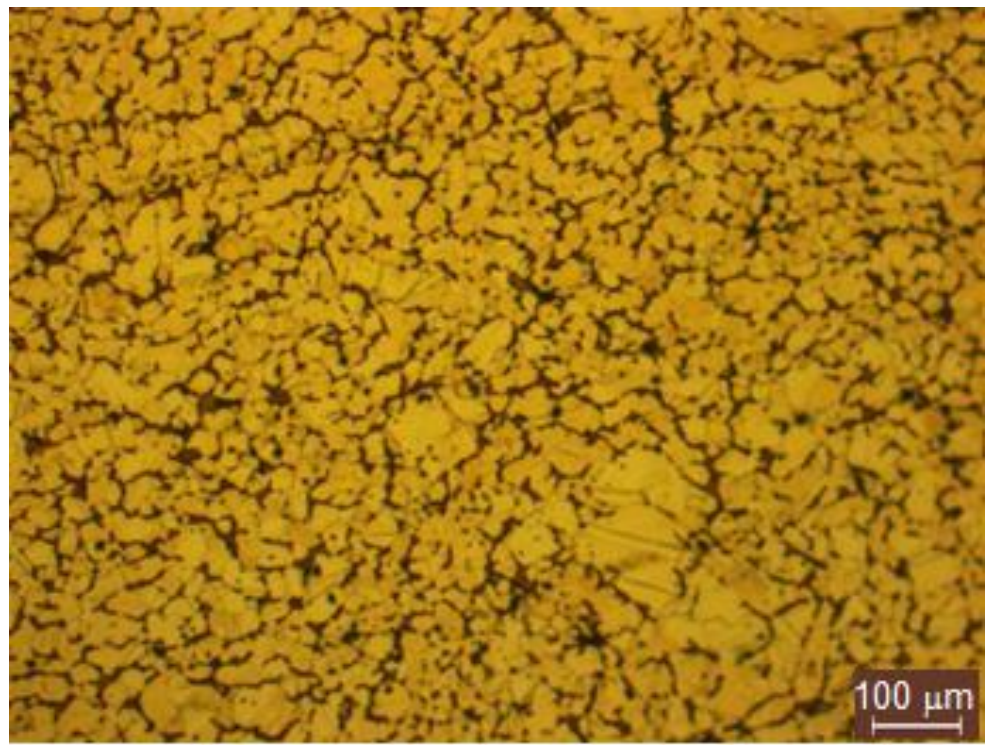

Figura 69 - Microestrutura do material relativo ao grupo C1 (x200, Reagente $\left.\mathrm{FeCl}_{3}+\mathrm{Etanol}_{+} \mathrm{HCl}\right)$ 


\subsubsection{Quantificação da fase $\beta$}

Para a quantificação da fase $\beta$, foram realizados ensaios metalográficos das seções longitudinal e transversal das amostras, de acordo com o método experimental descrito na seção 3.2.2., e apresentaram resultados expostos na Tabela 6 e nas Figuras 70, 71, 72, 73 e 74.

O material A1, devido ao processo de fabricação, apresentou maior fração de fase $\beta$ do que os outros materiais. Quanto aos materiais $A 2$ e A3, uma observação importante deve ser feita, pois ao se analisar o diagrama de fases da Figura 58 pela regra das alavancas, se esperaria para o material $A 3$ uma maior quantidade de fase $\beta$ do que para o material A2. Entretanto ocorreram resultados opostos, que pode ser explicado por condições fora do equilíbrio durante o tratamento térmico.

Quanto ao tratamento térmico $A 4$, em função da temperatura empregada $\left(460^{\circ} \mathrm{C}\right)$, esperava-se a menor fração de fase $\beta$ entre os materiais tratados termicamente. Embora concretizada a expectativa, o valor medido se afastou do esperado teoricamente. Esta diferença pode ser explicada por variações de homogeneidade da temperatura das barras tratadas termicamente, uma vez que foram utilizados fornos industriais para o processo de tratamento térmico.

Em função do ataque metalográfico, não foi possível distinguir no material C1 as frações volumétricas de chumbo e fase $\beta$ utilizando o software de análise. Com isso, foi realizada uma segunda análise, na qual se determinou o percentual de chumbo na amostra sem ataque metalográfico, mostrado na Figura 75 , sendo obtido um valor de $1,4 \%$, o qual foi devidamente subtraído do resultado obtido para a fase $\beta$ no primeiro procedimento.

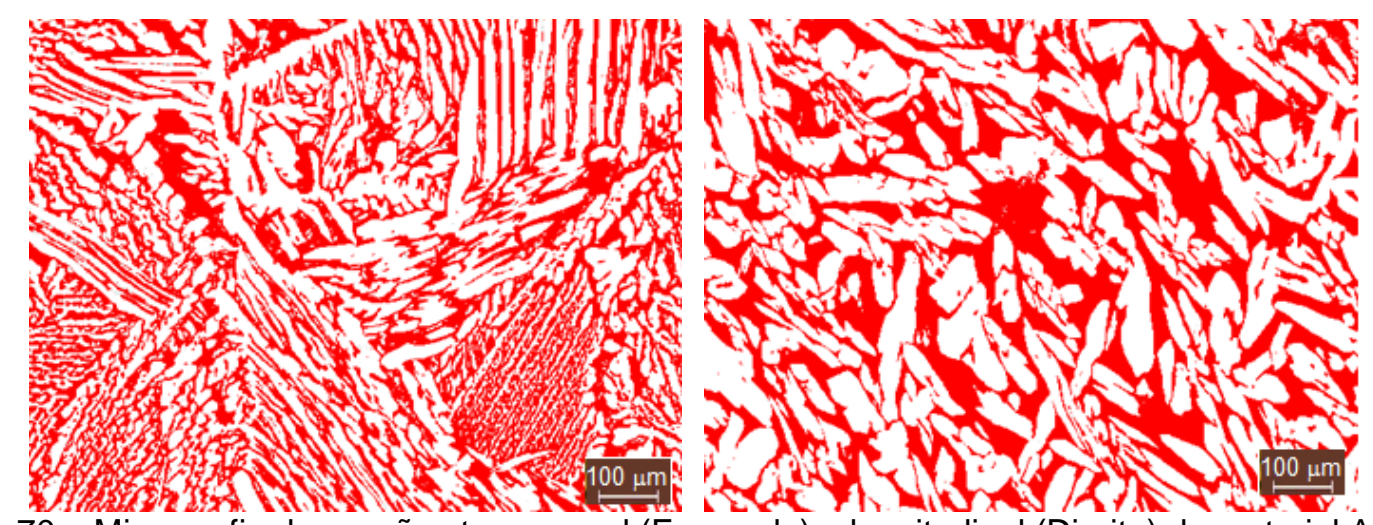

Figura 70 - Micrografia das seções transversal (Esquerda) e longitudinal (Direita) do material A1, para quantificação da fração de fase $\beta$ (200X) 

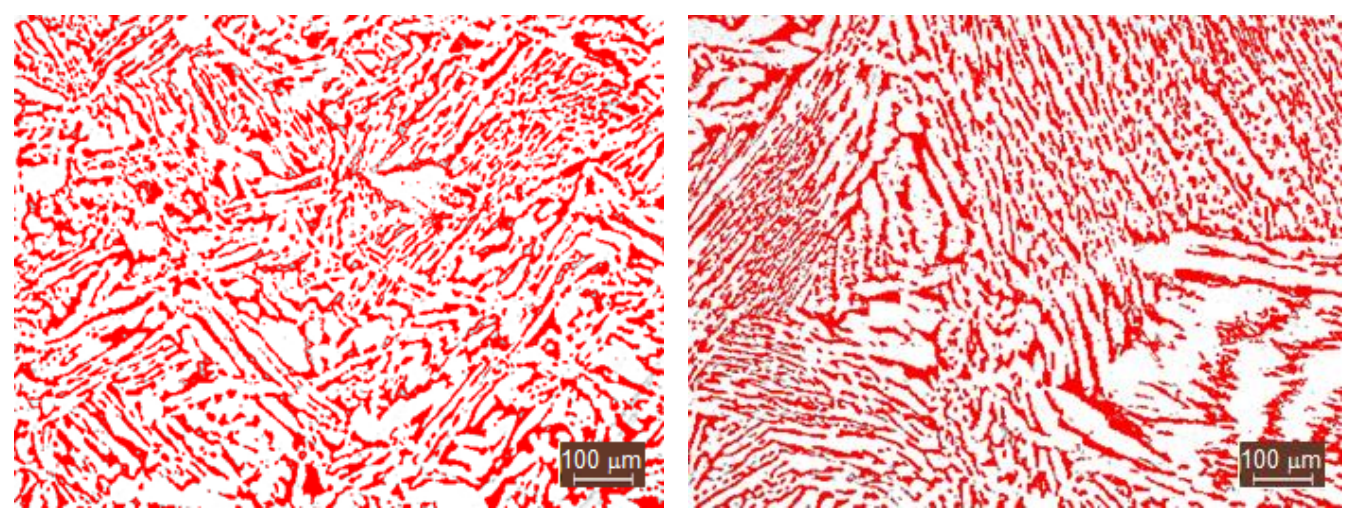

Figura 71 - Micrografia das seções transversal (Esquerda) e longitudinal (Direita) do material A2, para quantificação da fração de fase $\beta$ (200X)

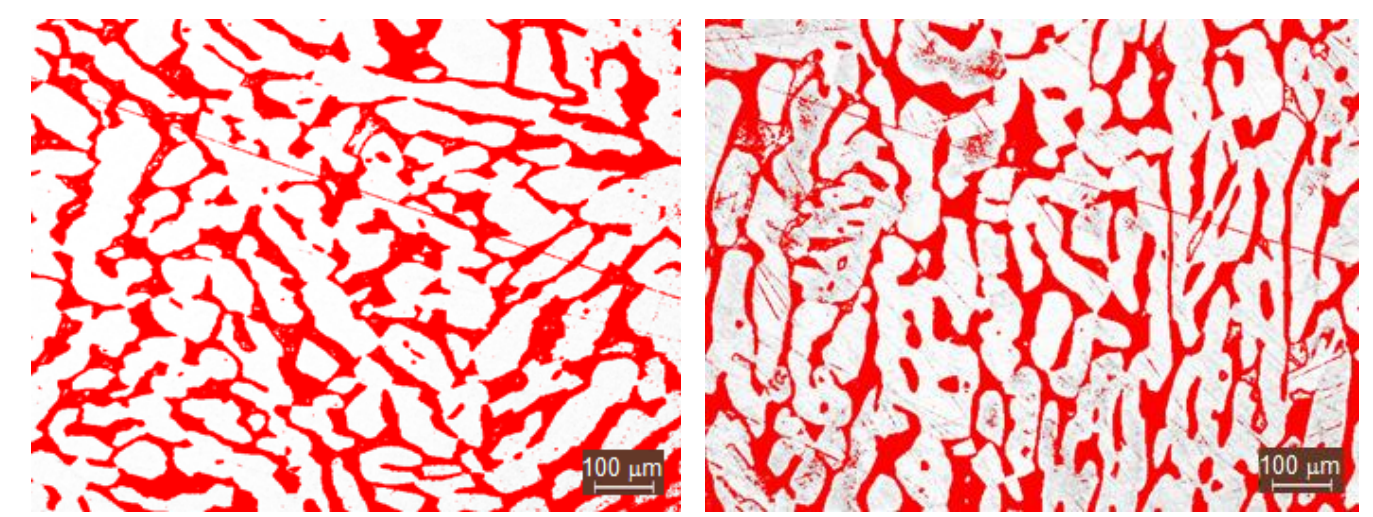

Figura 72 - Micrografia das seções transversal (Esquerda) e longitudinal (Direita) do material A3, para quantificação da fração de fase $\beta$ (200X)
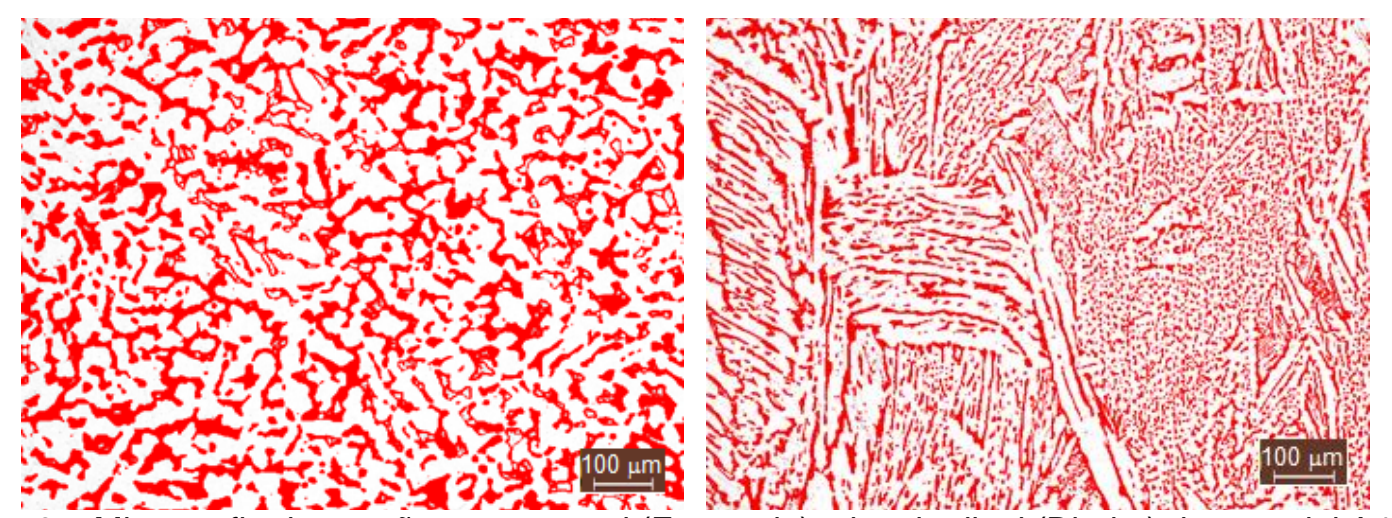

Figura 73 - Micrografia das seçõ̃es transversal (Esquerda) e longitudinal (Direita) do material A4, para quantificação da fração de fase $\beta$ (200X)
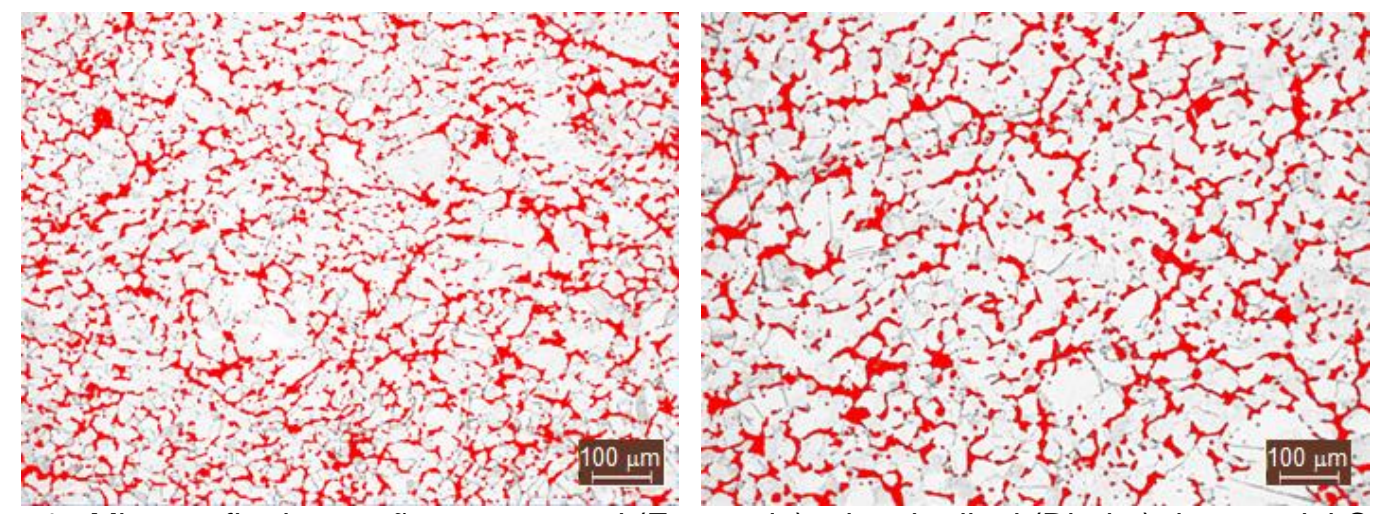

Figura 74 - Micrografia das seções transversal (Esquerda) e longitudinal (Direita) do material C1, para quantificação da fração de fase $\beta$ (200X) 


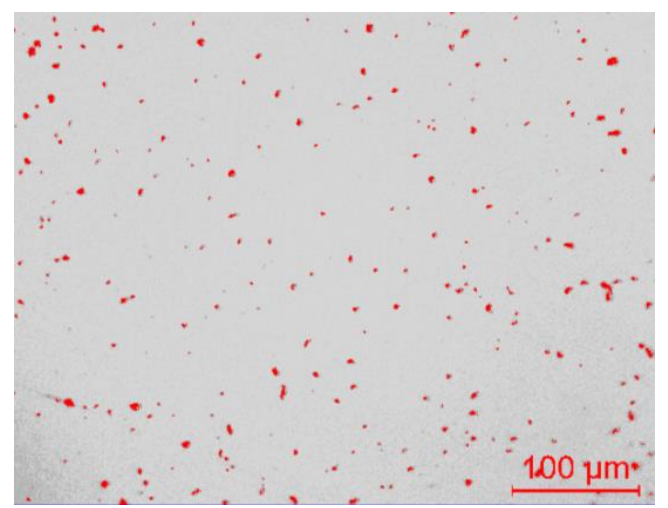

Figura 75 - Quantificação de chumbo do material C1, em amostra sem ataque metalográfico (500X)

Tabela 6 - Frações volumétricas de fase $\beta$ e caminhos livres médio dos materiais analisados

\begin{tabular}{ccccccc}
\hline & \multicolumn{2}{c}{ Transversal } & \multicolumn{2}{c}{ Longitudinal } & \multicolumn{2}{c}{ Média } \\
\cline { 2 - 7 } Grupo & Fração de $\boldsymbol{\beta}$ & $\begin{array}{c}\text { Desvio } \\
\text { Padrão }\end{array}$ & Fração de $\boldsymbol{\beta}$ & $\begin{array}{c}\text { Desvio } \\
\text { Padrão }\end{array}$ & Fração de $\boldsymbol{\beta}$ & $\begin{array}{c}\text { Desvio } \\
\text { Padrão }\end{array}$ \\
\hline A1 & $33,00 \%$ & 0,020 & $36,50 \%$ & 0,005 & $34,80 \%$ & 0,020 \\
A2 & $30,70 \%$ & 0,007 & $31,70 \%$ & 0,009 & $31,20 \%$ & 0,009 \\
A3 & $29,50 \%$ & 0,001 & $27,40 \%$ & 0,010 & $28,50 \%$ & 0,015 \\
A4 & $25,50 \%$ & 0,02 & $25,40 \%$ & 0,013 & $25,50 \%$ & 0,016 \\
B1 & - & - & - & - & - & - \\
C1 & $17,3 \%{ }^{*}$ & 0,001 & $17,3 \%{ }^{*}$ & 0,001 & $17,3 \%{ }^{*}$ & 0,0009 \\
\hline \multicolumn{3}{c}{${ }^{*}$ Descontado 1,4\% do elemento Pb } \\
\hline
\end{tabular}

A análise de variância indica para uma diferença estatística entre as amostras analisadas, sendo a análise de variância apresentada na Figura 76 e Tabela 7 :

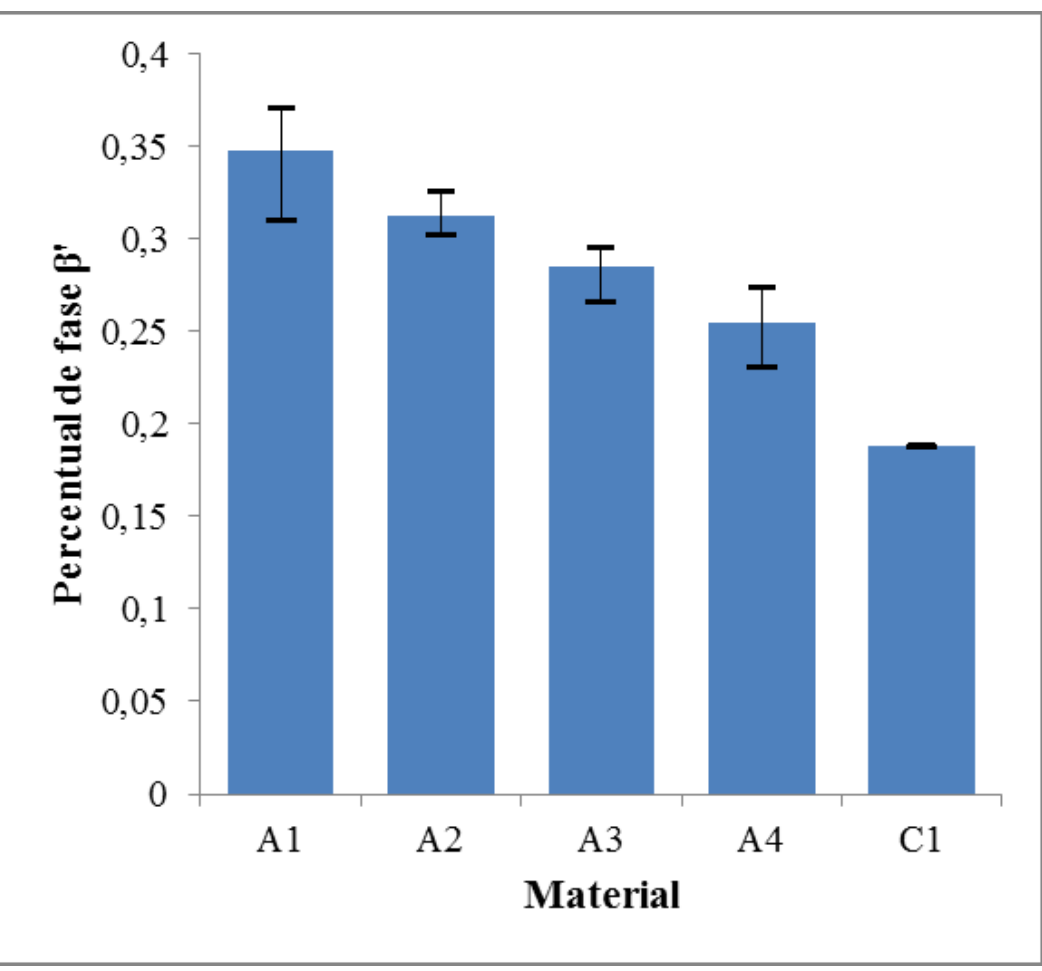

Figura 76 - Análise de variância para a fração volumétrica de fase $\beta^{\prime}$ nos diferentes materiais 
Tabela 7 - Análise de variância do percentual de fase $\beta^{\prime}$ (SS - Quadrado das Somas, GL - Graus de Liberdade e MS - Quadrado das médias)

\begin{tabular}{ccccccc}
\hline $\begin{array}{c}\text { Fonte da } \\
\text { Variação }\end{array}$ & $\begin{array}{c}\text { Entre } \\
\text { grupos }\end{array}$ & $\begin{array}{c}\text { Dentro dos } \\
\text { Grupos }\end{array}$ & Total & Fo & Fc & p-value \\
\hline SS & 0,03 & 1,61 & 1,64 & & & \\
GL & 4,00 & 25,00 & 29,00 & 0,12 & 2,76 & 0,98 \\
MS & 0,01 & 0,06 & - & & & \\
\hline
\end{tabular}

\subsection{CARACTERIZAÇÃO MECÂNICA DOS MATERIAIS}

As Tabela 8 e 9 mostram os valores obtidos para os ensaios de tração uniaxial, dureza com carga de $10 \mathrm{kgf}$ e microdureza Vickers com carga de 0,01 kgf respectivamente. Com a carga maior obtém-se uma dureza média e com a carga menor, se obteve as microdurezas individuais das fases $\alpha$ e $\beta$.

Tabela 8 - Valores obtidos nos ensaios de tração uniaxial e dureza Vickers

\begin{tabular}{ccccc}
\hline Grupo Liga & $\begin{array}{c}\text { Limite de } \\
\text { resistência } \\
\text { a tração } \\
\text { [MPa] }\end{array}$ & $\begin{array}{c}\text { Limite de } \\
\text { escoamento } \\
\text { [MPa] }\end{array}$ & $\begin{array}{c}\text { Alongamento } \\
\text { [\%] }\end{array}$ \\
\hline A1 & $60 / 40$ & 573 & 553 & 20 \\
A2 & $60 / 40$ & 437 & 259 & 46 \\
A3 & $60 / 40$ & 391 & 177 & 50 \\
A4 & $60 / 40$ & 425 & 243 & 43 \\
B1 & $70 / 30$ & 332 & 165 & 66 \\
C1 & CLA & 388 & 305 & 36 \\
\hline
\end{tabular}

Tabela 9 - Valores obtidos nos ensaios de dureza e microdureza Vickers

\begin{tabular}{cccccccc}
\hline \multirow{2}{*}{ Grupo } & \multirow{2}{*}{ Liga } & \multicolumn{2}{c}{ Dureza [HV 10] } & \multicolumn{3}{c}{ Microdureza [HV 0,01] } \\
\cline { 3 - 8 } & & Média & $\begin{array}{c}\text { Desvio } \\
\text { Padrão }\end{array}$ & Média & $\begin{array}{c}\text { Desvio } \\
\text { Padrão }\end{array}$ & Média & $\begin{array}{c}\text { Desvio } \\
\text { Padrão }\end{array}$ \\
\cline { 3 - 8 } & & 186 & 5 & 189 & 3 & 214 & 18 \\
A1 & $60 / 40$ & 185 & 6 & 185 & 8 & 198 & 3 \\
A2 & $60 / 40$ & 125 & 14 & 138 & 9 & 195 & 6 \\
A3 & $60 / 40$ & 102 & 6 & 172 & 10 & 199 & 3 \\
A4 & $60 / 40$ & 116 & 6 & 127 & 15 & - & 0 \\
B1 & $70 / 30$ & 86 & 5 & 136 & 18 & 194 & 7 \\
C1 & CLA & 122 & 6 & 136 & \\
\hline
\end{tabular}

As diferenças observadas entre a fase $\alpha$ e $\beta$ estão de acordo com o previsto (CULLITY, 1956; KHEZRI-YAZDAN; SUBRAMANIAN, 1984a), pois o ensaio foi realizado em temperatura ambiente, condição onde se detecta somente a presença da fase $\beta$ ' ordenada, com maior dureza do que a fase $\alpha$. 
Outro aspecto importante são os diferentes percentuais de redução de dureza entre as fases $\alpha$ e $\beta$. Os resultados expostos na Tabela 10 indicam que as reduções de dureza da fase a são mais pronunciadas dos que as observadas para a fase $\beta$. Este comportamento tem consistência com o exposto na revisão bibliográfica (KHEZRI-YAZDAN; SUBRAMANIAN, 1984a; KHEZRI-YAZDAN; SUBRAMANIAN, 1984b). Materiais de latão bifásicos submetidos ao trabalho a frio tendem a apresentar início da deformação plástica nas regiões de fase $\alpha$, através do mecanismo de escorregamento e movimentação de discordâncias, e diante deste fato tendem a acumular maior energia de deformação nestas condições. Consequentemente, possuem menor energia de ativação, permitindo uma maior recuperação e redução da densidade de discordâncias para o tratamento térmico empregado. Este efeito se torna mais evidente com o aumento da temperatura empregada, como no material A3.

\begin{tabular}{cccccc}
\multicolumn{2}{c}{ Tabela 10 - Comparativo de redução das durezas da fase $\alpha$ e $\beta$ nos materiais de Latão 60/40 } \\
\hline \multirow{2}{*}{ Grupo } & \multirow{2}{*}{ Liga } & \multicolumn{2}{c}{ Fase Alfa } & \multicolumn{2}{c}{ Fase Beta } \\
\cline { 3 - 6 } & & Dureza & Redução & Dureza & Redução \\
\hline A1 & $60 / 40$ & 189 & - & 214 & - \\
A2 & $60 / 40$ & 172 & $-8,7 \%$ & 199 & $-6,9 \%$ \\
A3 & $60 / 40$ & 138 & $-27,2 \%$ & 195 & $-8,9 \%$ \\
A4 & $60 / 40$ & 185 & $-1,9 \%$ & 198 & $-7,6 \%$ \\
\hline
\end{tabular}

Na Figura 77 são mostrados os valores obtidos para a dureza dos materiais, com a respectiva análise estatística, a qual indica em significativa diferença de resultado entre eles, uma vez que o valor obtido no teste de hipóteses $F$ é maior do que o valor de Fc (crítico) de 2,53, mostrado na Tabela 11.

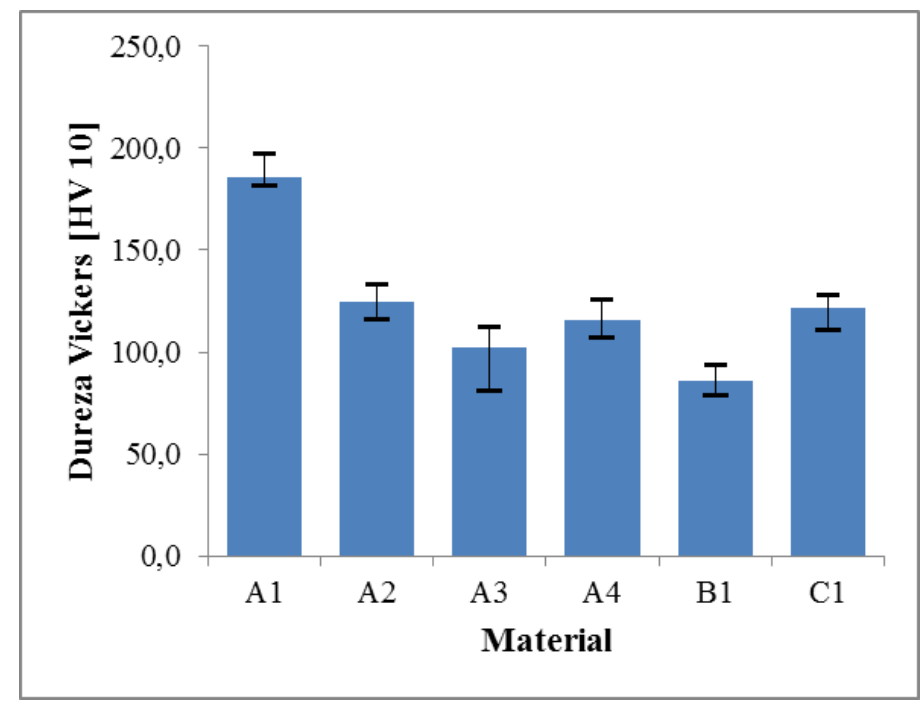

Figura 77 - Análise dos dados de dureza Vickers 
Tabela 11 - Análise de variância da dureza (SS - Quadrado das Somas, GL - Graus de Liberdade e MS - Quadrado das médias)

\begin{tabular}{ccccccc}
\hline $\begin{array}{c}\text { Fonte da } \\
\text { Variação }\end{array}$ & $\begin{array}{c}\text { Entre } \\
\text { grupos }\end{array}$ & $\begin{array}{c}\text { Dentro } \\
\text { dos } \\
\text { Grupos }\end{array}$ & Total & Fo & Fc & p-value \\
\hline SS & 35374,1 & 2148,38 & 37523 & & & \\
GL & 5 & 36 & 41 & 118,55 & 2,4772 & $2,55 E-21$ \\
MS & 7074,83 & 59,6772 & & & & \\
\hline
\end{tabular}

Com relação à microdureza da fase $\beta$, a análise estatística dos dados indicados na Figura 78 mostra que os valores obtidos são próximos entre os diferentes materiais, com exceção do material $A 1$ isento de tratamento térmico, uma vez que o valor obtido no teste de hipóteses $\mathrm{F}$ é menor do que o valor de $\mathrm{F}$ crítico (Fc) de 3,49 (Tabela 12).

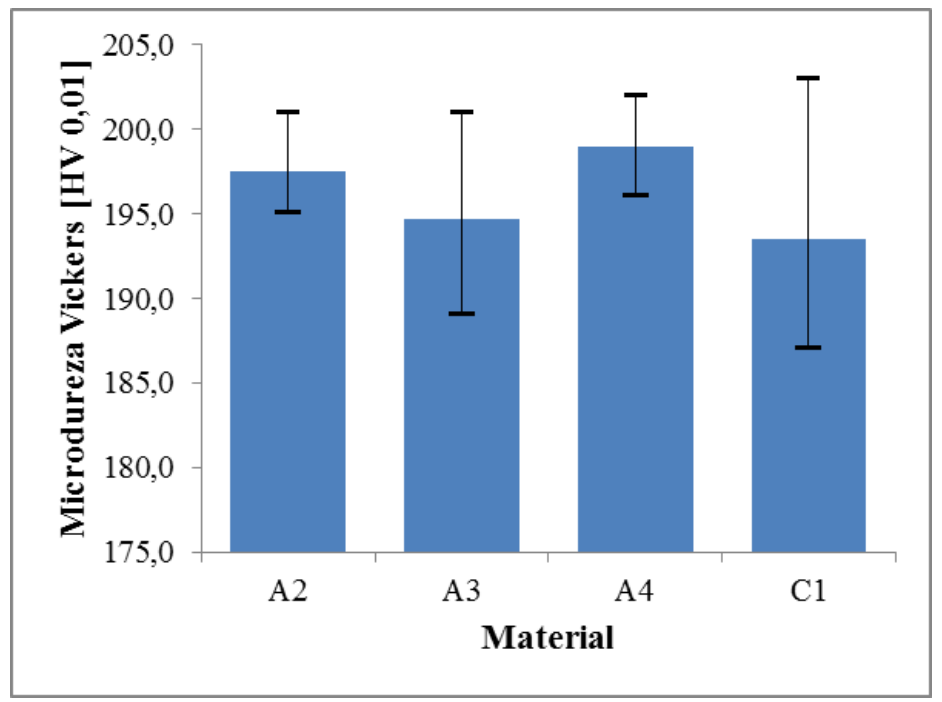

Figura 78 - Análise dos dados de microdureza Vickers para a fase $\beta$

Tabela 12 - Analise de variância da microdureza da fase $\beta$ (SS - Quadrado das Somas, GL - Graus de Liberdade e MS - Quadrado das médias)

\begin{tabular}{ccccccc}
\hline $\begin{array}{c}\text { Fonte da } \\
\text { Variação }\end{array}$ & $\begin{array}{c}\text { Entre } \\
\text { grupos }\end{array}$ & $\begin{array}{c}\text { Dentro } \\
\text { dos } \\
\text { Grupos }\end{array}$ & Total & Fo & Fc & p-value \\
\hline SS & 75,69 & 298,75 & 374,44 & & & \\
GL & 3 & 12 & 15 & 1,01 & 3,49 & 0,42073 \\
MS & 25,23 & 24,9 & - & & & \\
\hline
\end{tabular}

A presença da fase $\beta$ influencia nas propriedades mecânicas das amostras utilizadas, sendo observado o aumento de resistência mecânica devido à solução sólida, bem como pelos campos de tensão gerados pelos contornos de antifase, entretanto existem dois pontos importantes a serem observados: 
i) Os materiais A2 e A4, apesar de apresentarem diferentes frações volumétricas de fase $\beta(31,2 \%$ e $25,5 \%$ respectivamente), apresentam limite de resistência muito próximos (437 MPa e $425 \mathrm{MPa}$, respectivamente), além de indicar para uma semelhança estatística para os valores de microdureza da fase $\beta$.

ii) Os materiais $A 3$ e B1 apesar de apresentarem frações diferentes de fase $\beta$ (28,5\% e zero), apresentam valores próximos de limite de resistência (391 MPa e $332 \mathrm{MPa}$, respectivamente). Com isso, pode-se afirmar que as durezas médias dos materiais são diferentes em função do tamanho médio de grão e das frações de fase $\beta$, pois a análise de microdureza indica para valores similares dureza para os materiais testados.

\subsection{ANÁLISE DA MORFOLOGIA DOS CAVACOS}

Após a realização da operação de torneamento nas quatro velocidades de corte, nos parâmetros descritos anteriormente na seção 3.2.3, o cavaco foi analisado em suas morfologias, de acordo com a tabela do German Copper Institute (2008) e da norma ISO 3685, e os resultados são mostrados nas Figuras 79, 80, 81 e 82.

O cavaco relativo aos materiais $\mathrm{A} 1, \mathrm{~A} 2, \mathrm{~A} 3, \mathrm{~A} 4$ e $\mathrm{B} 1$ apresentaram classificação dos cavacos índice 2 (Emaranhado) conforme a German Copper Institute e 1-3 pela classificação da ISO-3685, sendo classificados como desfavoráveis. Já os cavacos do material $\mathrm{C} 1$ foram classificados como índice 9 pela German Copper Institute e 7 (Cavaco fragmentado) pela ISO-3685, considerado aceitável pelos critérios expostos na revisão bibliográfica (TRENT; WRIGHT, 2000; SHAW, 2005; GERMAN COPPER INSTITUTE, 2010; MACHADO et al, 2011).

É importante ressaltar que, para estes experimentos, foram utilizadas ferramentas isentas de geometria de quebra cavacos, com o intuito de avaliar a contribuição das diferentes formas da microestrutura de segunda fase no processo de usinagem. Neste aspecto, a segunda fase parece não ter contribuído significativamente para a alteração destas morfologias. Entretanto, conforme exposto no item 2.12.2 (LORENZ et al, 2010; KLOCKE et al, 2012a; KLOCKE et al, 2012b; NOBEL et al, 2014), o uso de estratégias diferenciadas, tais como ferramentas com geometrias auxiliares e refrigeração sob alta pressão para a 
quebra de cavacos, são recursos importantes para viabilizar este aspecto, mas estas não foram alvo deste trabalho.

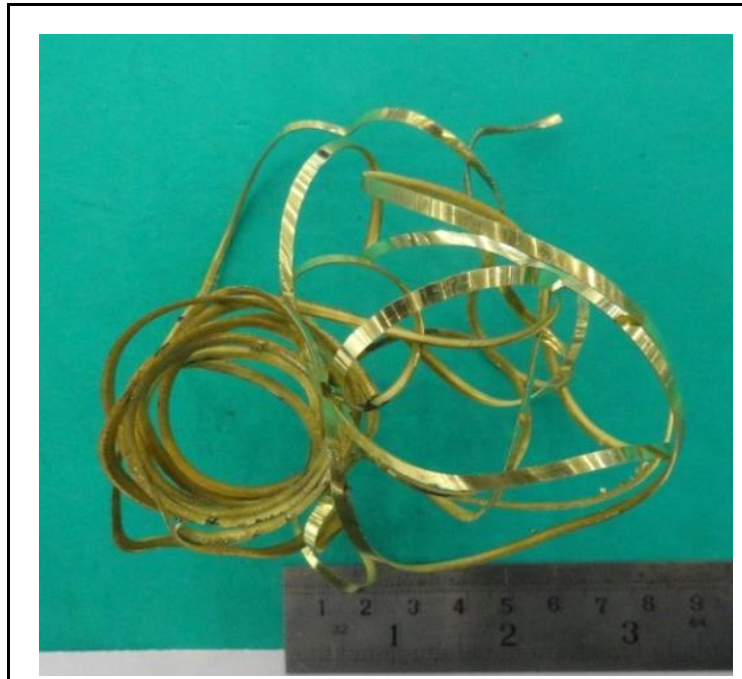

Material A1

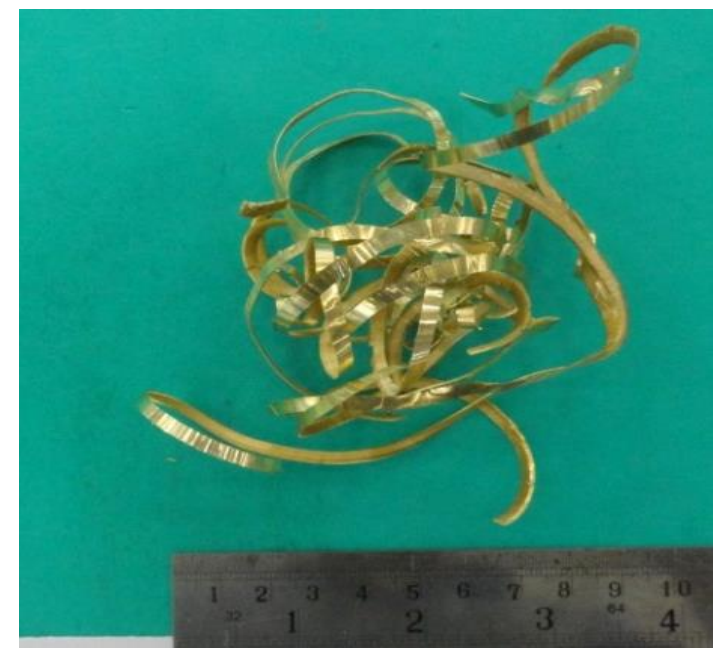

Material A3

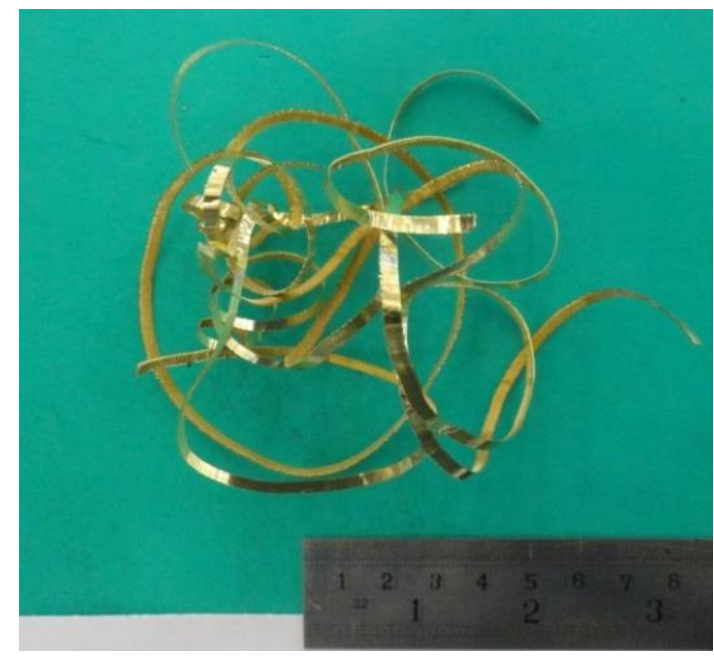

Material B1

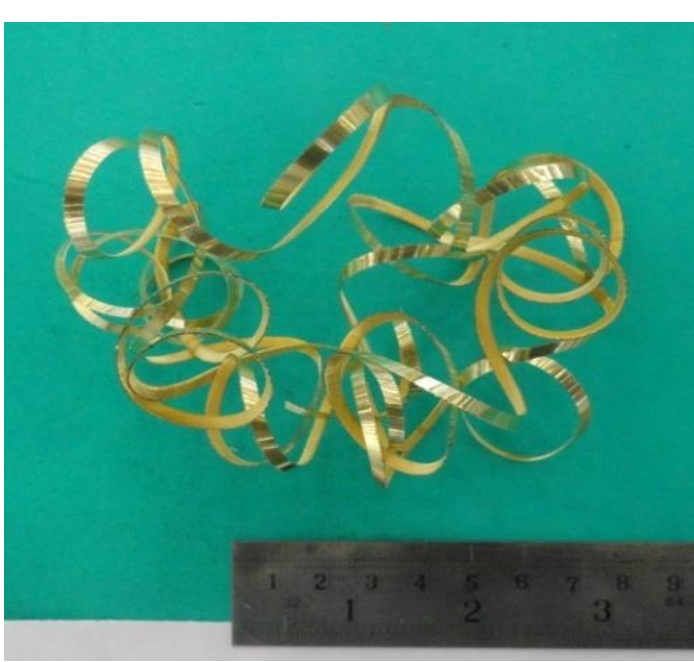

Material A2

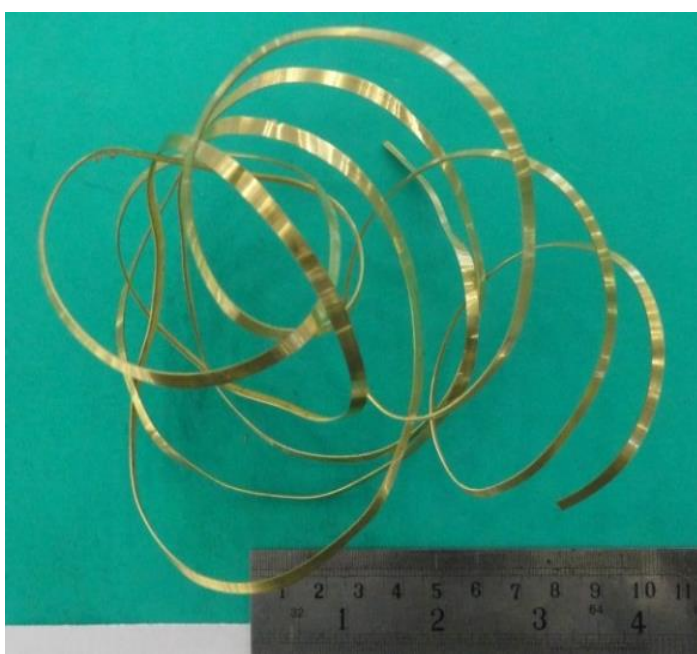

Material A4

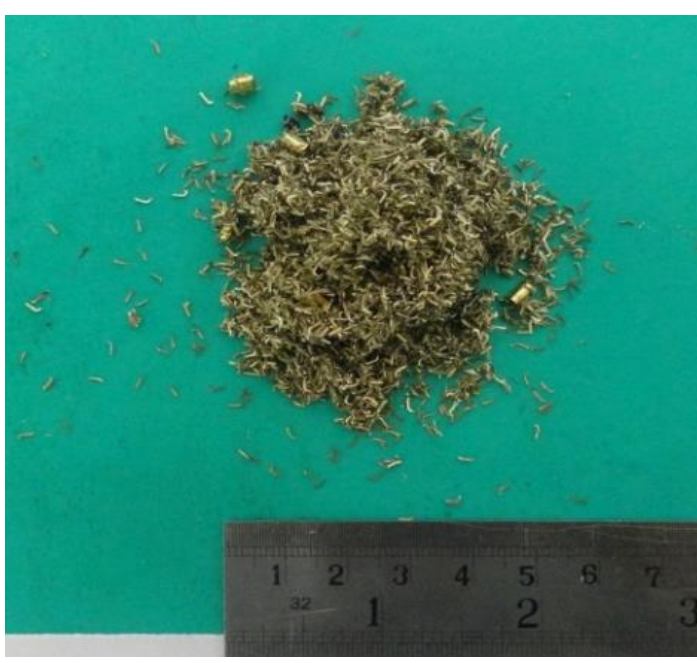

Material C1

Figura 79 - Cavacos obtidos para a velocidade de corte de $60 \mathrm{~m} / \mathrm{min}$ 


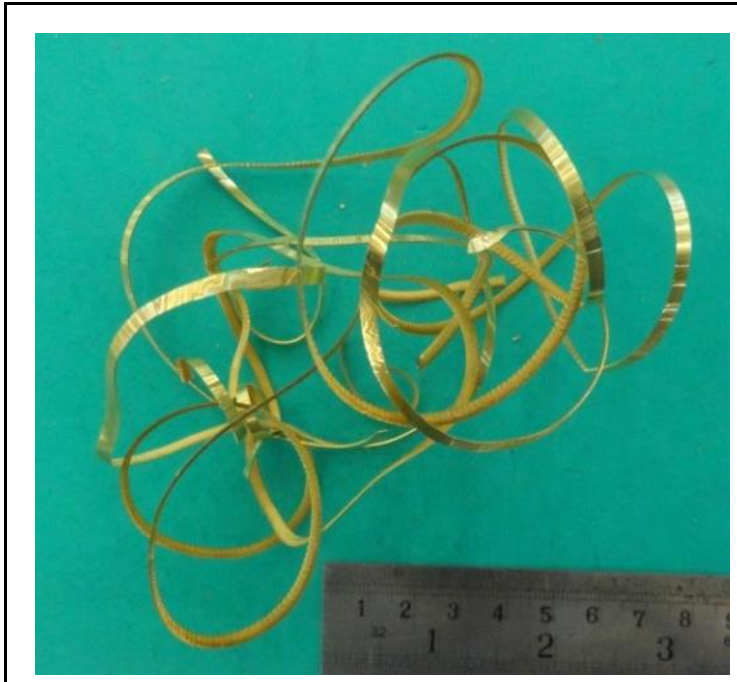

Material A1

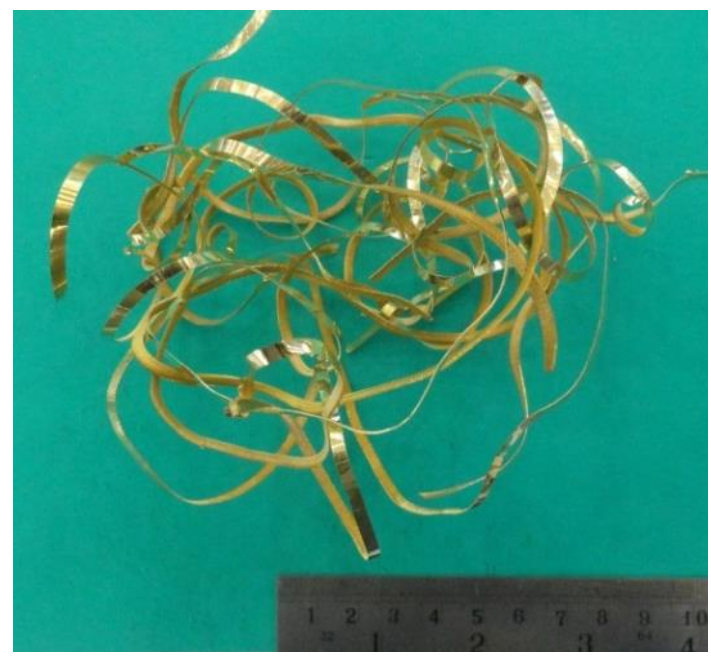

Material A3

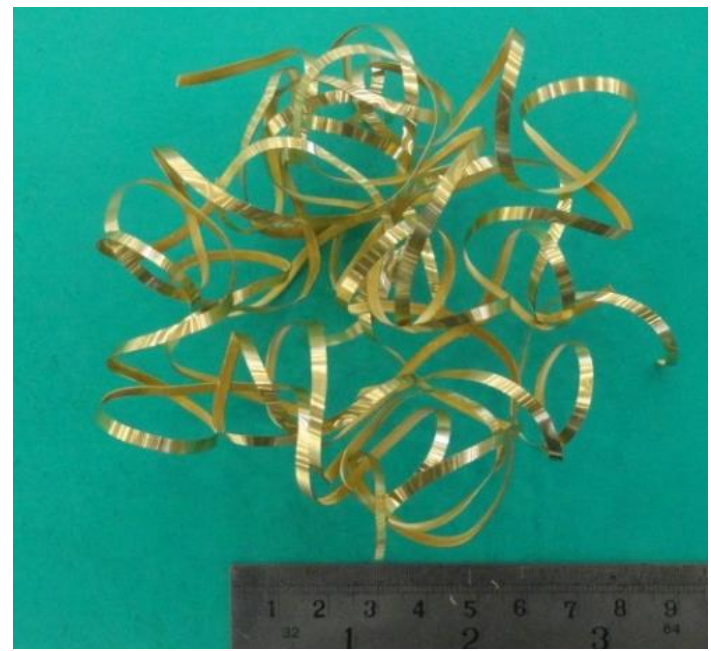

Material B1

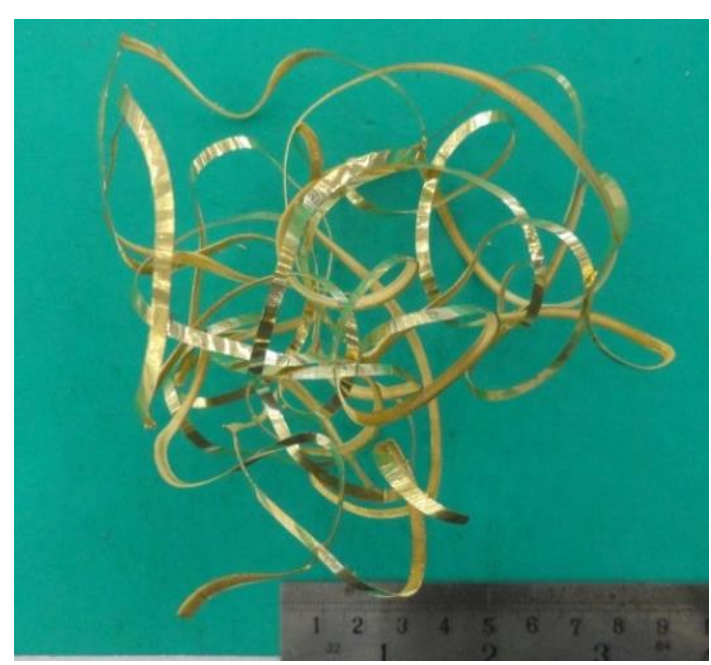

Material A2

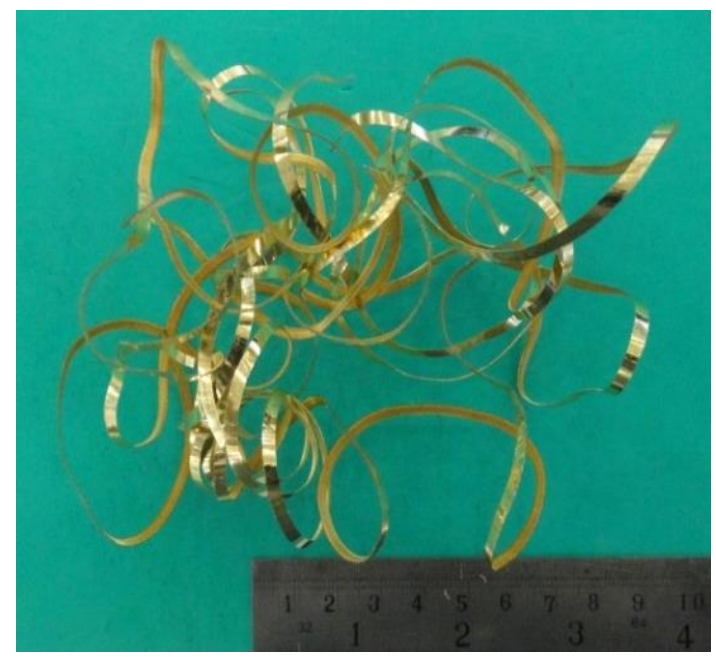

Material A4

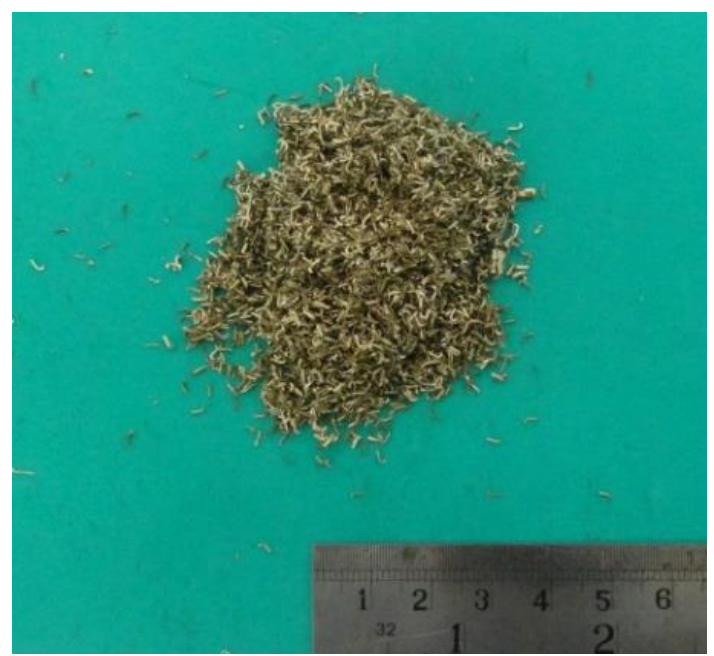

Material C1

Figura 80 - Cavacos obtidos para a velocidade de corte de $100 \mathrm{~m} / \mathrm{min}$ 


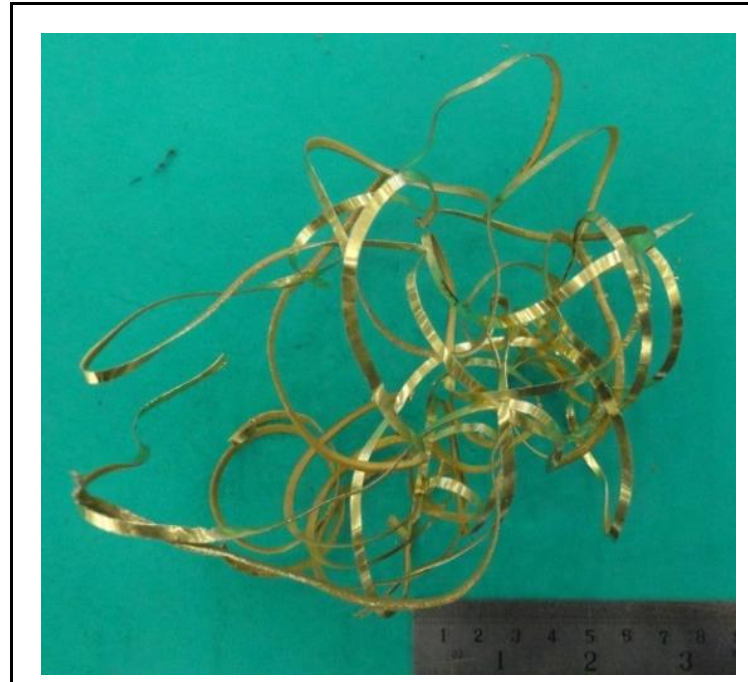

Material A1

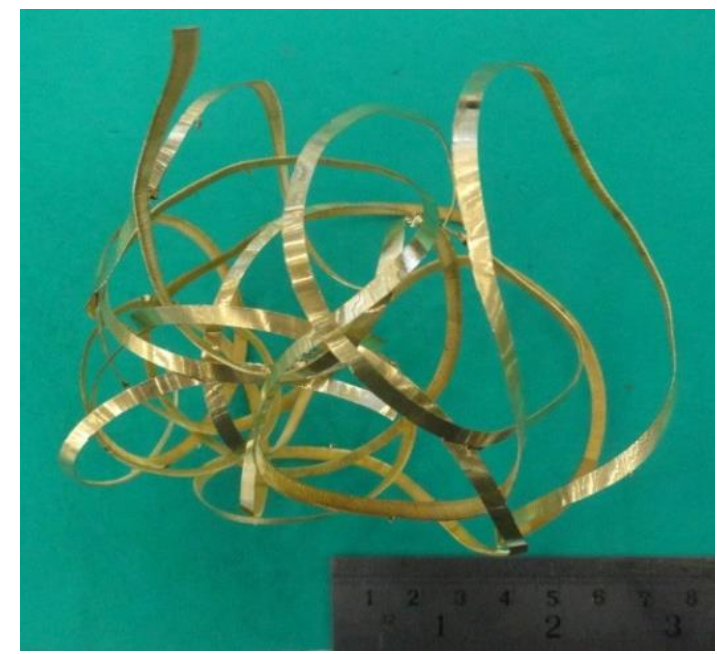

Material A3

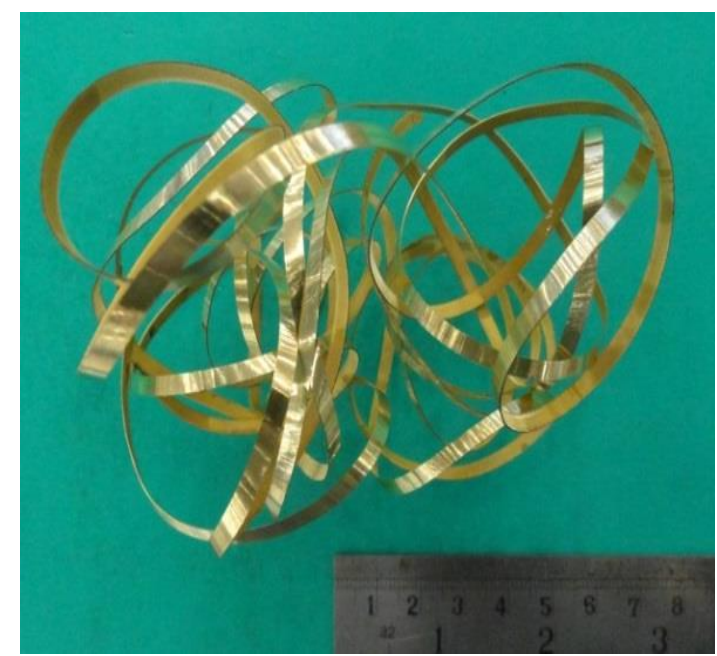

Material B1

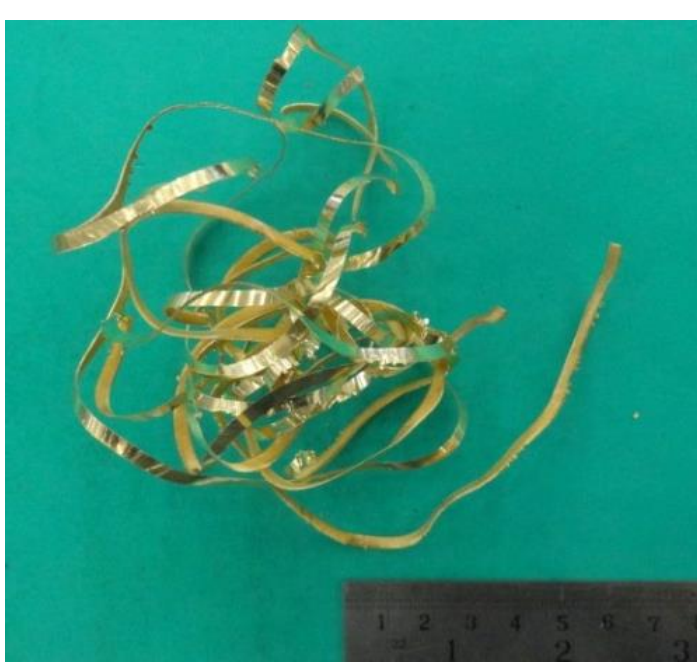

Material A2

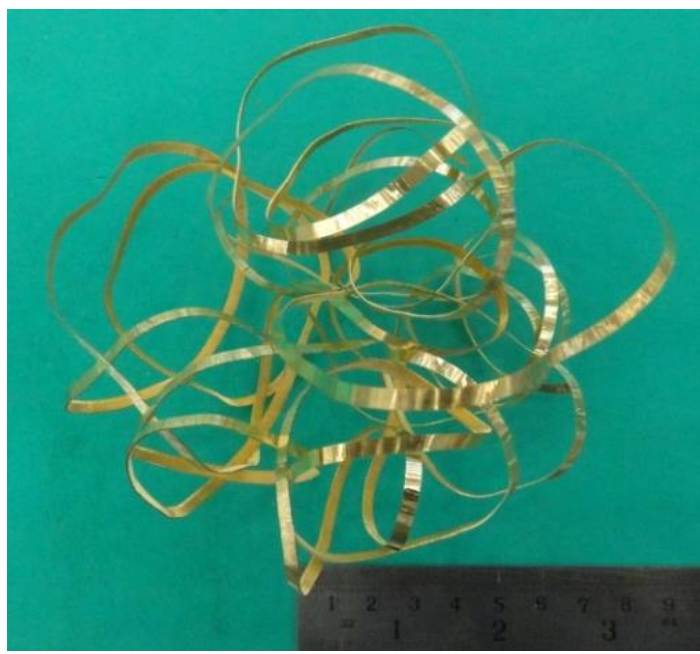

Material A4

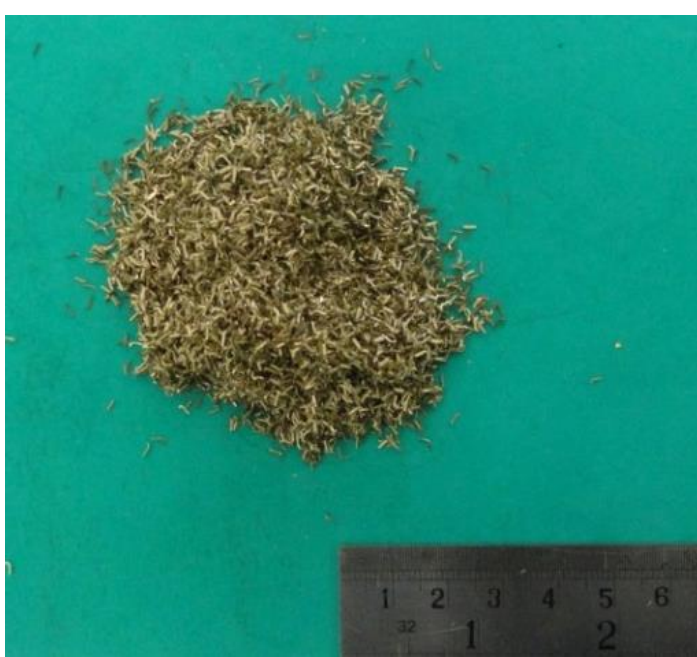

Material C1

Figura 81 - Cavacos obtidos para a velocidade de corte de $140 \mathrm{~m} / \mathrm{min}$ 


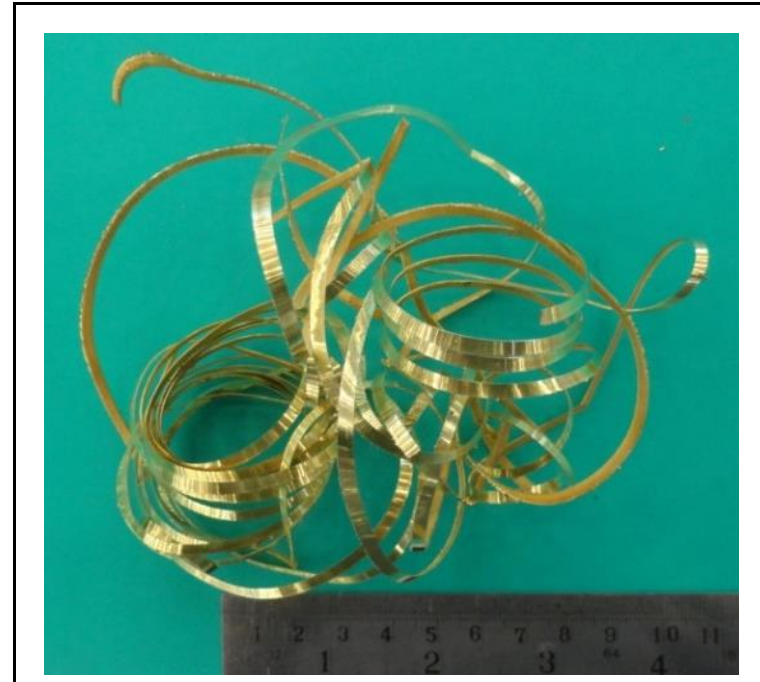

Material A1

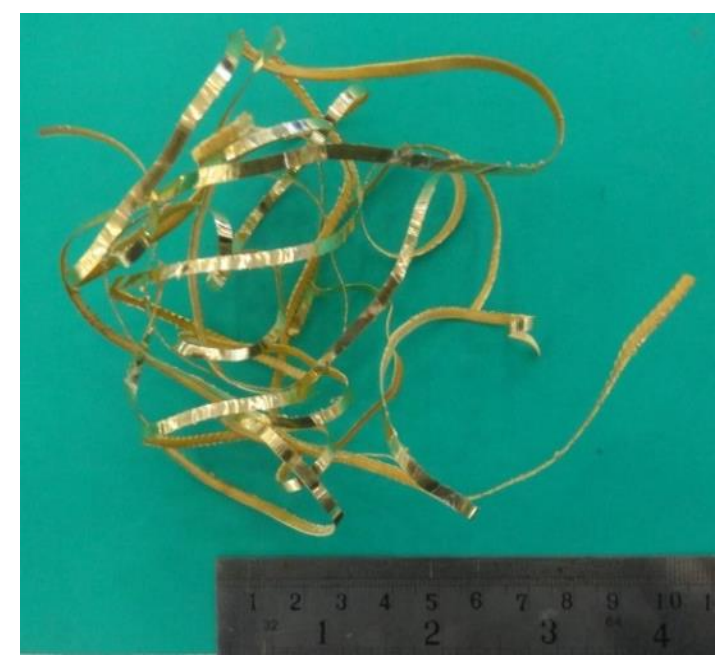

Material A3

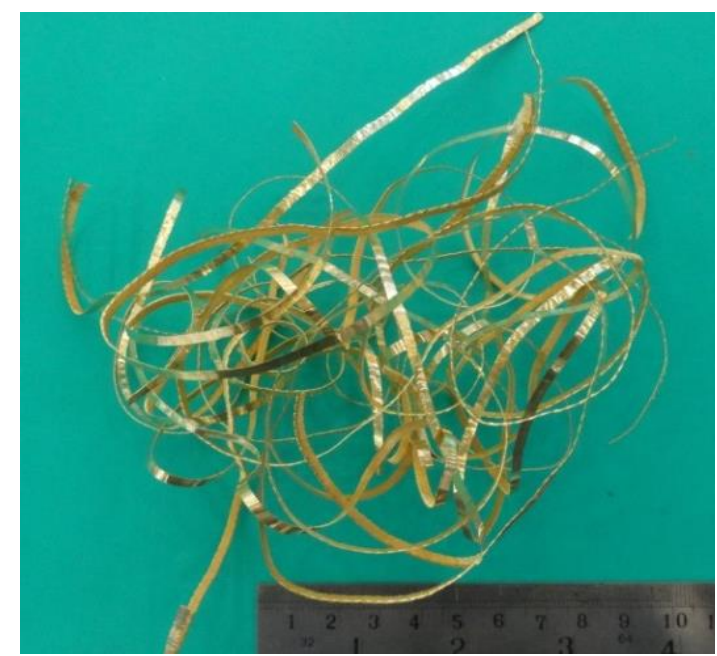

Material B1

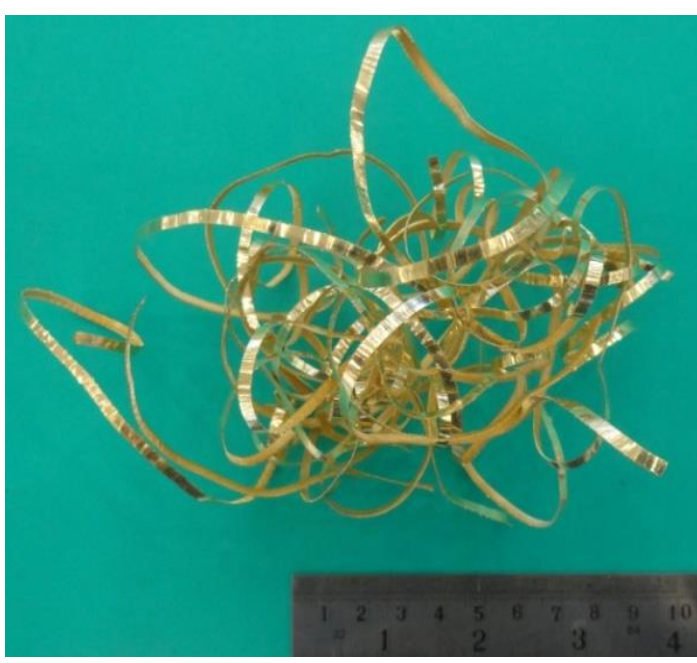

Material A2

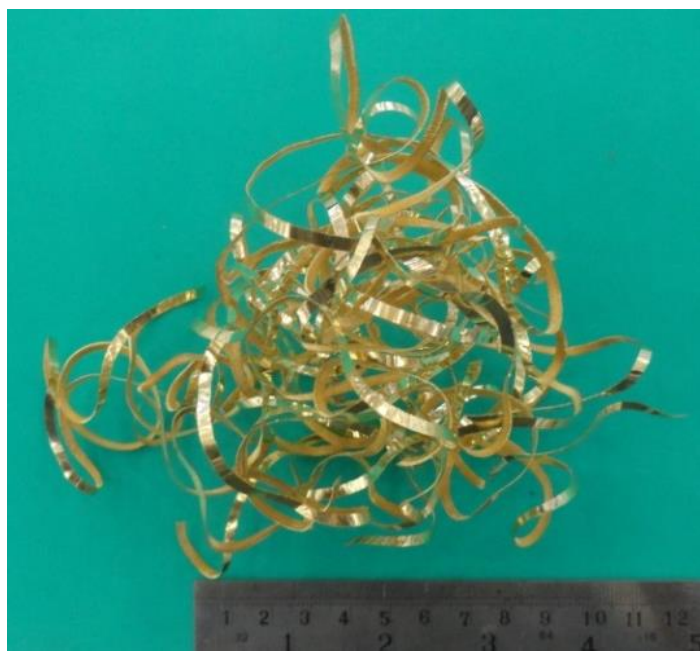

Material A4

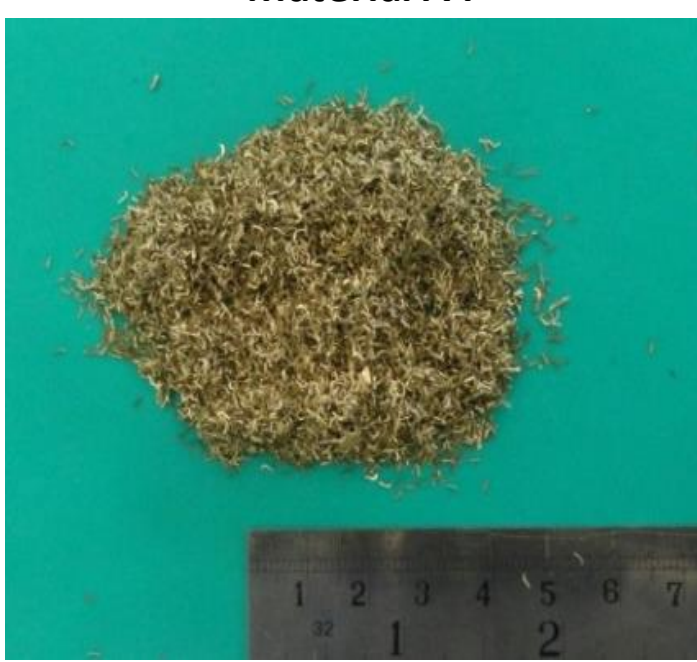

Material C1

Figura 82 - Cavacos obtidos para a velocidade de corte de $180 \mathrm{~m} / \mathrm{min}$ 


\subsubsection{Análise microscópica dos cavacos}

Não foram observados na análise da micrografia dos cavacos, tanto na microscopia óptica (Figuras 83, 84, 85 e 86) quanto na microscopia eletrônica de varredura, exemplificados nas Figuras 87, 88 e 89, mecanismos ou características nas microestruturas que pudessem caracterizar o processo de fratura dos cavacos na interface entre as fases $\alpha$ e $\beta$.

O cavaco gerado na usinagem do material $A 1$, a uma velocidade de $60 \mathrm{~m} / \mathrm{min}$ apresentou características de cavaco segmentado semicontínuo. O resultado está de acordo com o descrito na seção 2.10.3. (TRENT; WRIGHT, 2000; SHAW, 2005; GROOVER, 2007; GERMAN COPPER INSTITUTE, 2010; MACHADO et al, 2011). Como material apresenta menor ductilidade, se comparado aos outros materiais, 0 grau de deformação na zona de cisalhamento primário é superior à ductilidade do material. O aumento da velocidade de corte deste material alterou a morfologia do cavaco para contínuo, confirmando que este efeito é mais frequente na utilização de baixas velocidades de corte.

Os cavacos gerados na usinagem dos materiais $A 2, A 3, A 4$ e $C 1$ permaneceram sem significativa alteração de morfologia, sendo mantido o aspecto contínuo, independentemente da velocidade de corte utilizada. Exceção é feita aos cavacos dos materiais $\mathrm{A} 3$ e $\mathrm{C} 1$, os quais na velocidade de $180 \mathrm{~m} / \mathrm{min}$ passaram a apresentar morfologia contínua segmentada. Este resultado é similar aos estudos até então apresentados, pois indicam para a formação de cavacos deste tipo a partir de velocidades de corte elevadas. (TRENT; WRIGHT, 2000; SHAW, 2005; GERMAN COPPER INSTITUTE, 2010; MACHADO et al, 2011). 


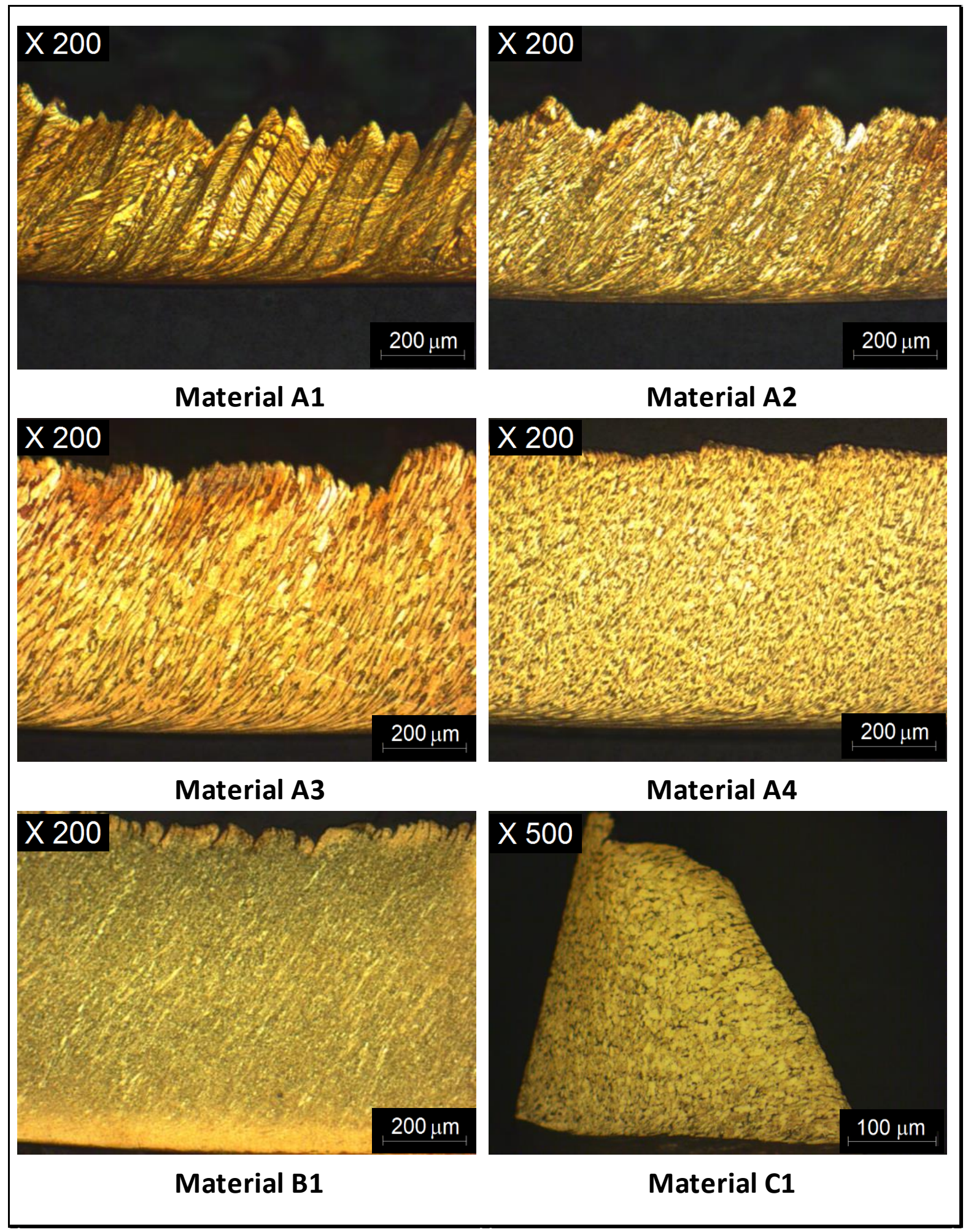

Figura 83 - Micrografias dos cavacos obtidos para a velocidade de corte de $60 \mathrm{~m} / \mathrm{min}$ 


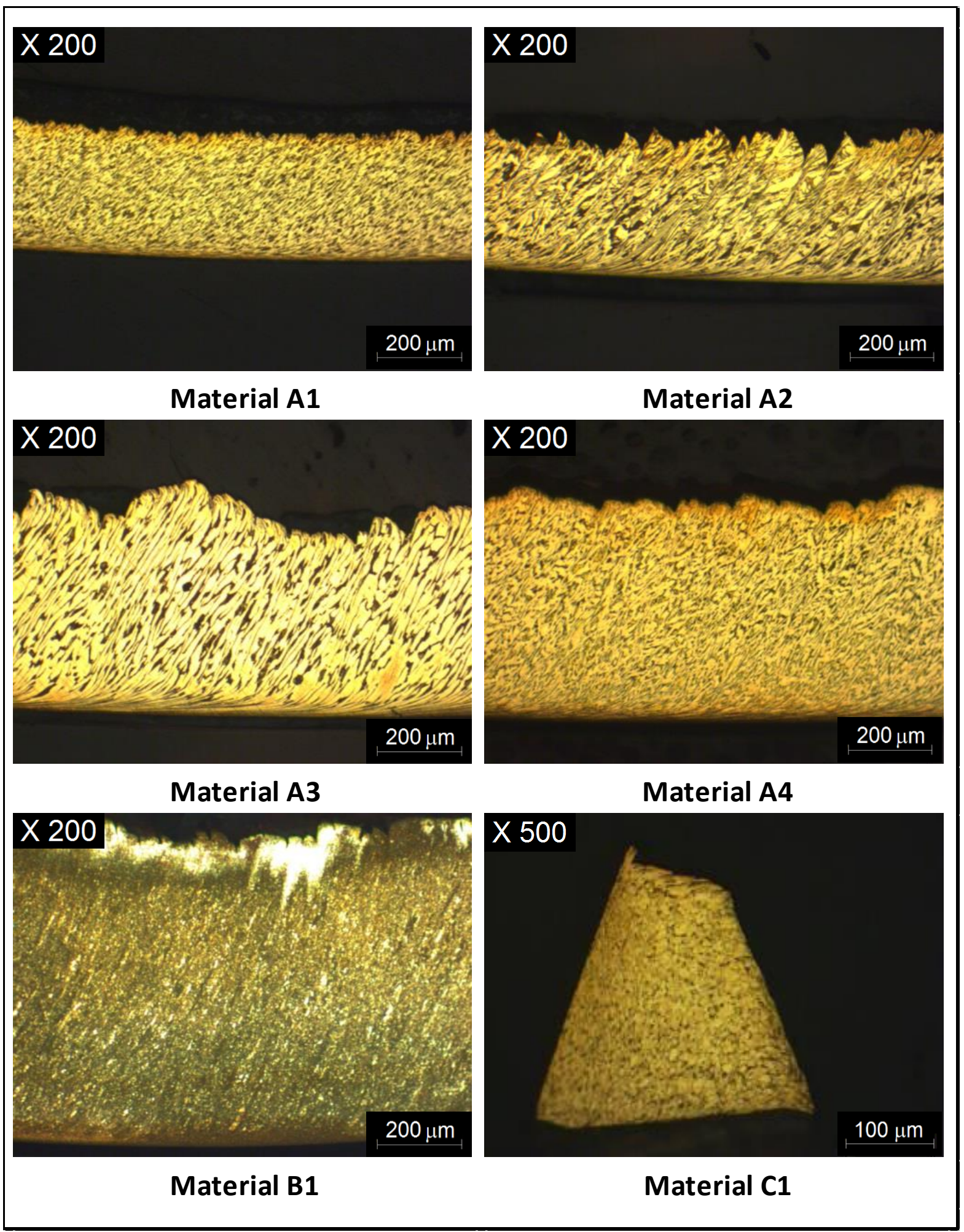

Figura 84 - Micrografias dos cavacos obtidos para a velocidade de corte de $100 \mathrm{~m} / \mathrm{min}$ 


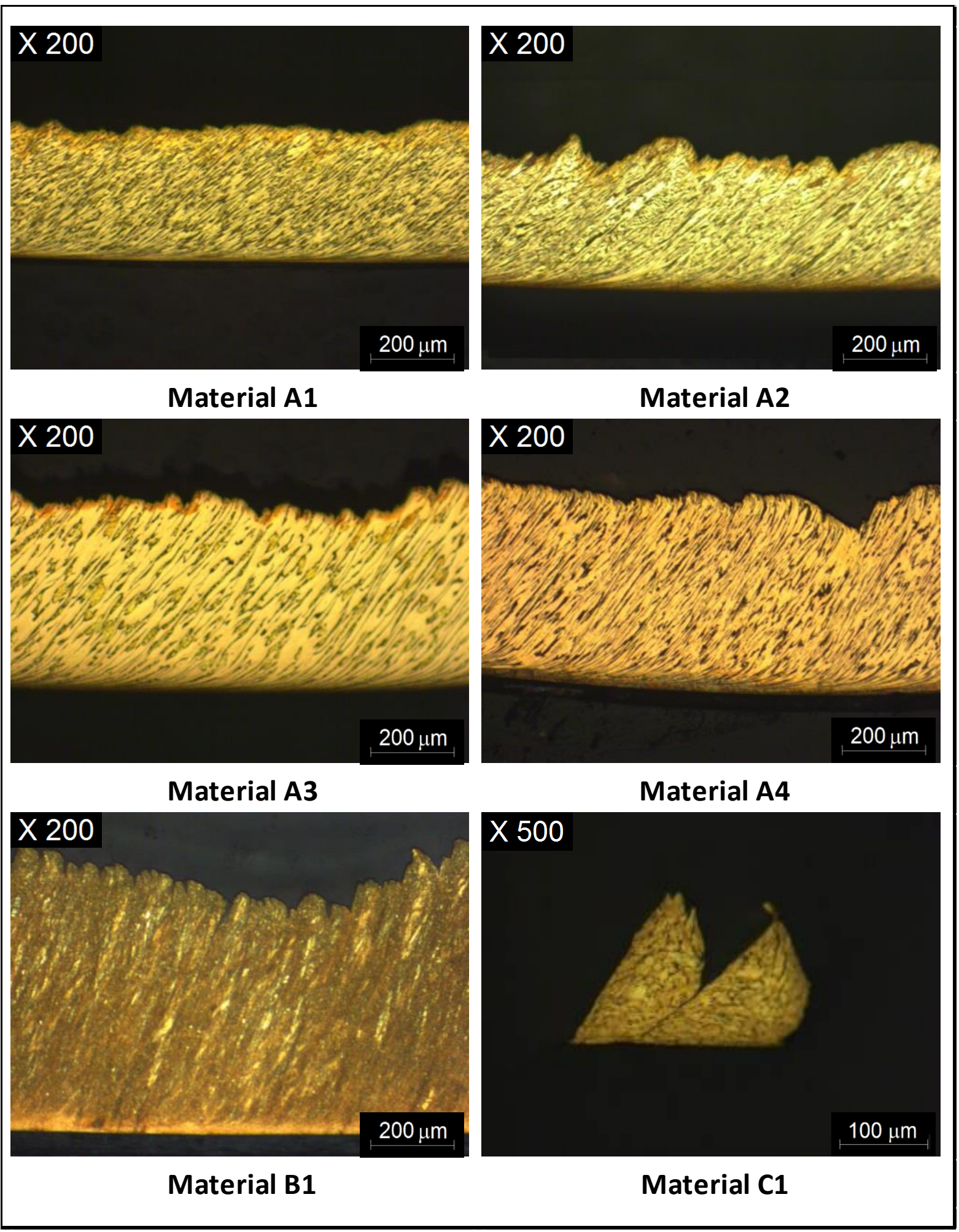

Figura 85 - Micrografias dos cavacos obtidos para a velocidade de corte de $140 \mathrm{~m} / \mathrm{min}$ 


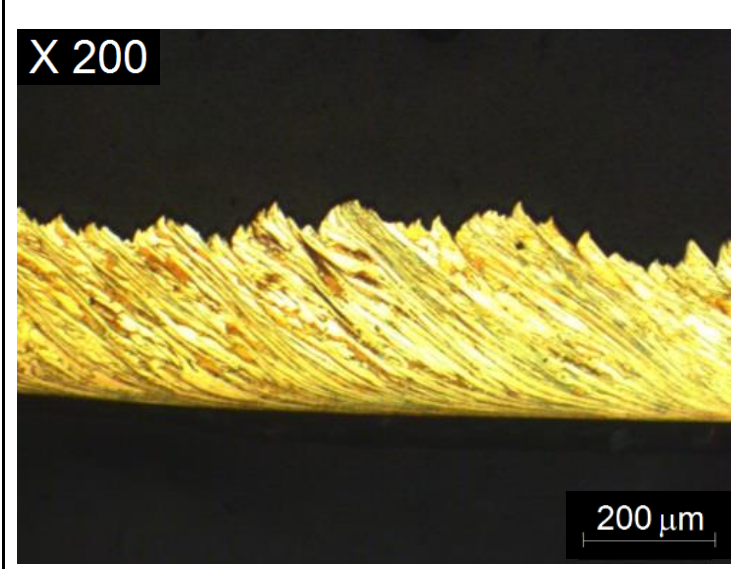

Material A1

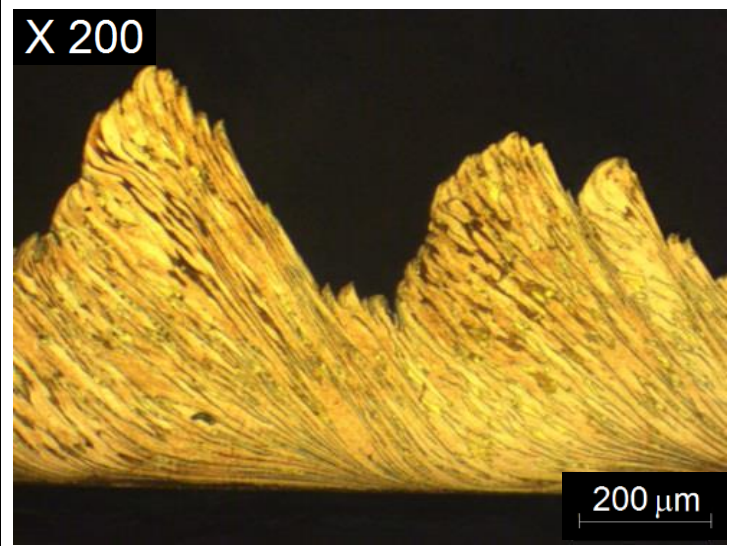

Material A3

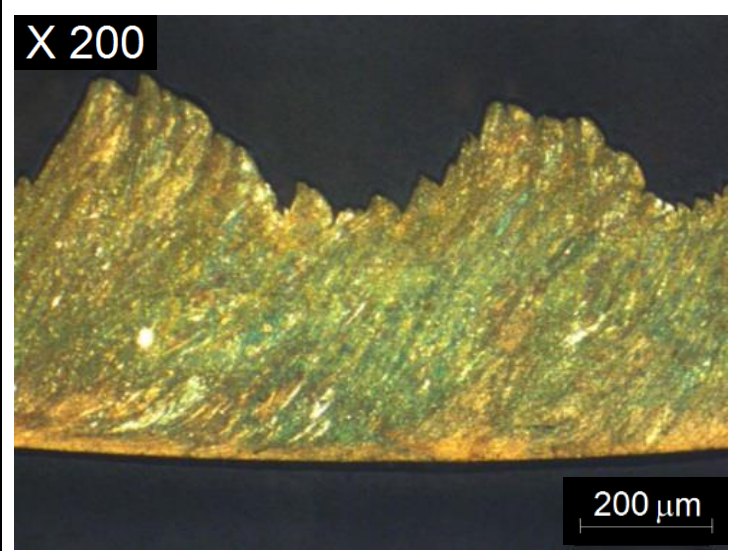

Material B1

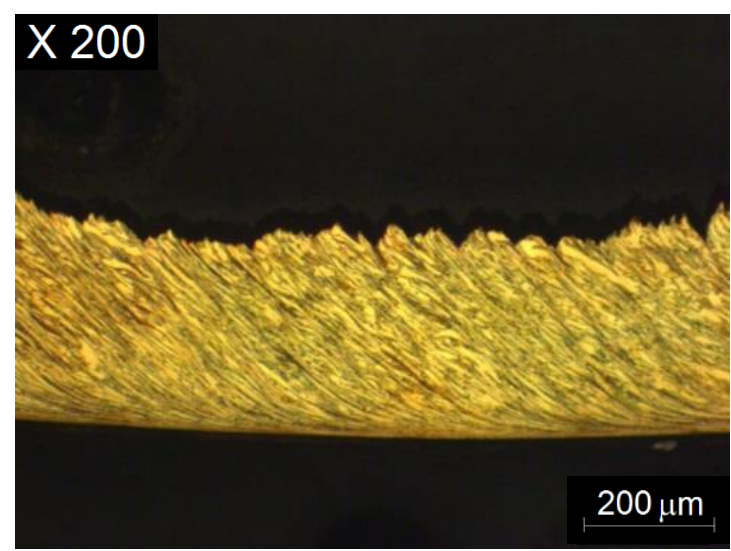

Material A2

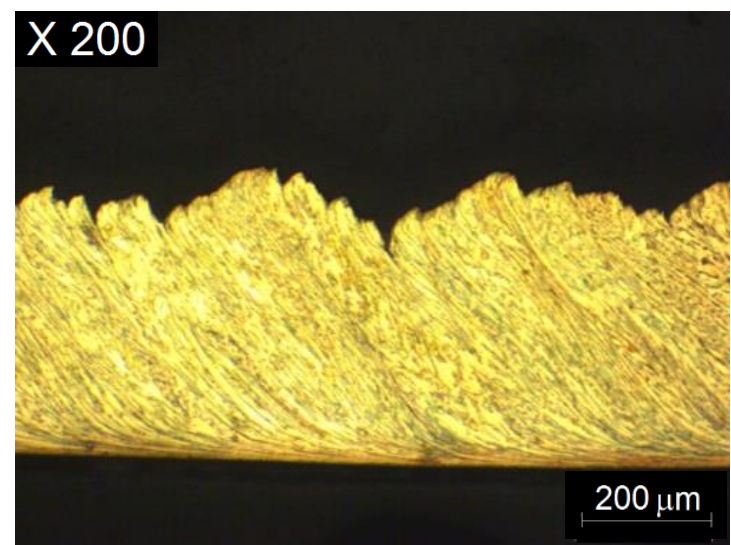

Material A4

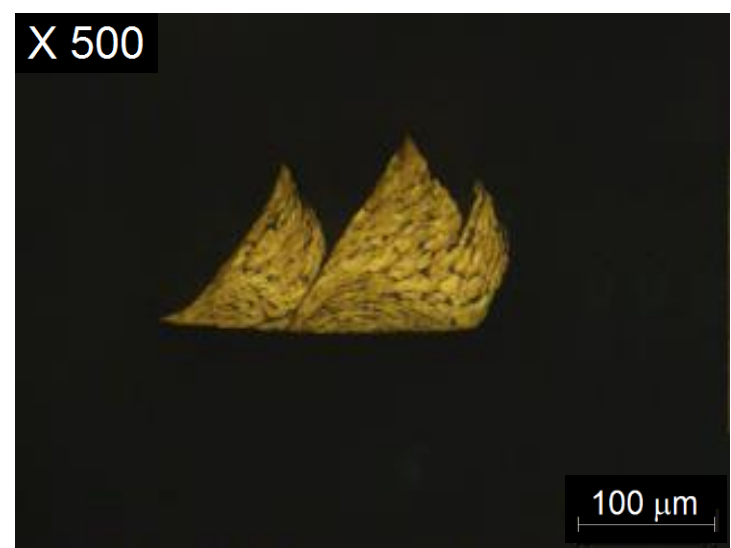

Material C1

Figura 86 - Micrografias dos cavacos obtidos para a velocidade de corte de $180 \mathrm{~m} / \mathrm{min}$ 


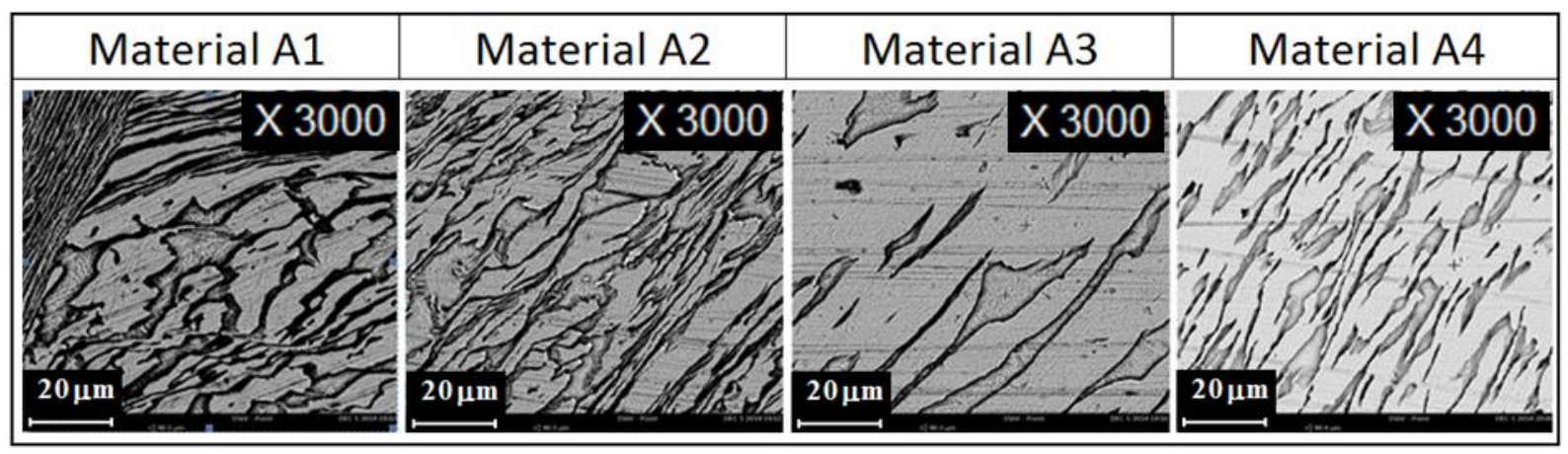

Figura 87 - Análise em microscópio eletrônico de varredura dos cavacos gerados na velocidade de corte de $60 \mathrm{~m} / \mathrm{min}$

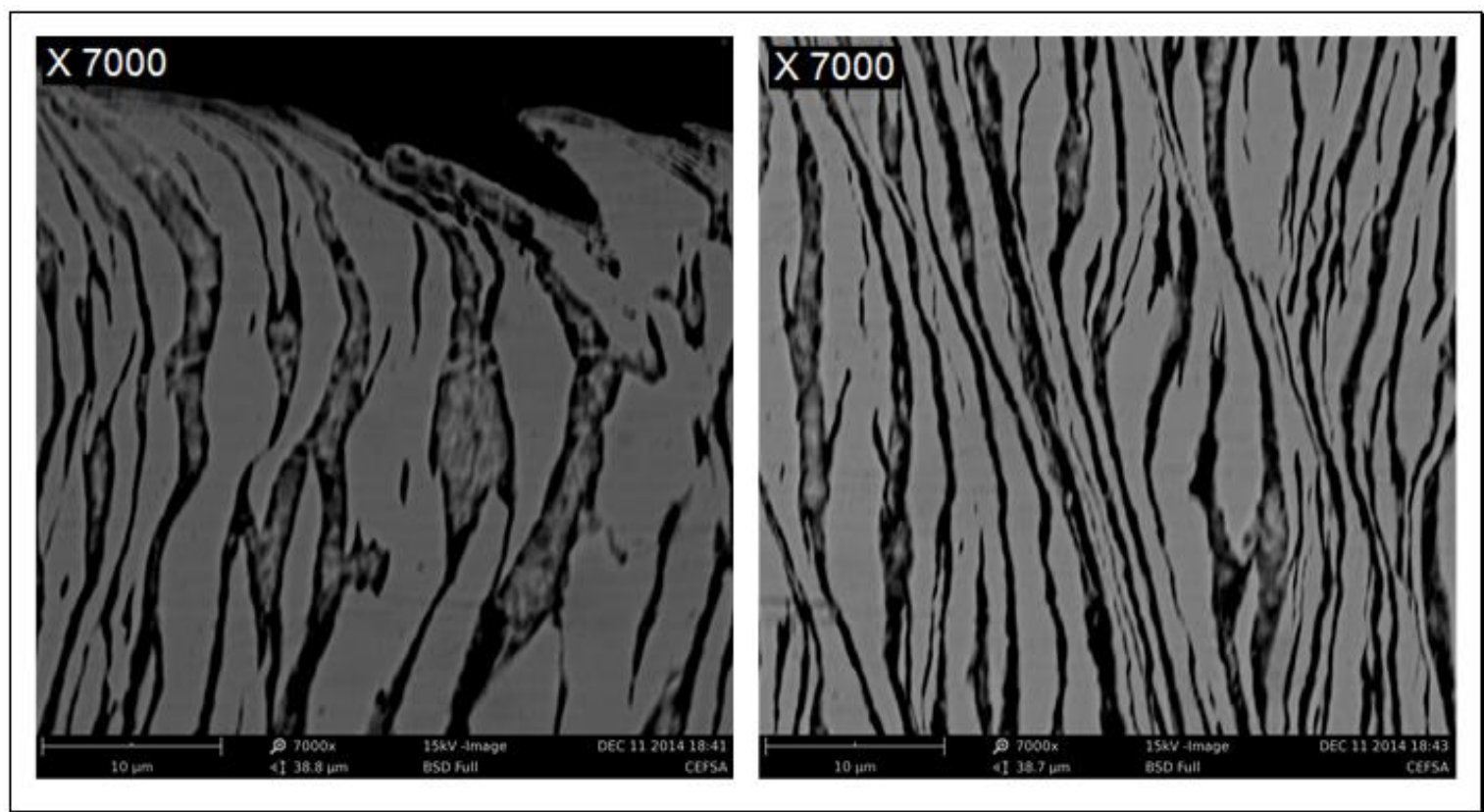

Figura 88 - Análise em microscópio eletrônico de varredura dos cavacos gerados na velocidade de corte de $180 \mathrm{~m} / \mathrm{min}$, para o material $\mathrm{A} 1$

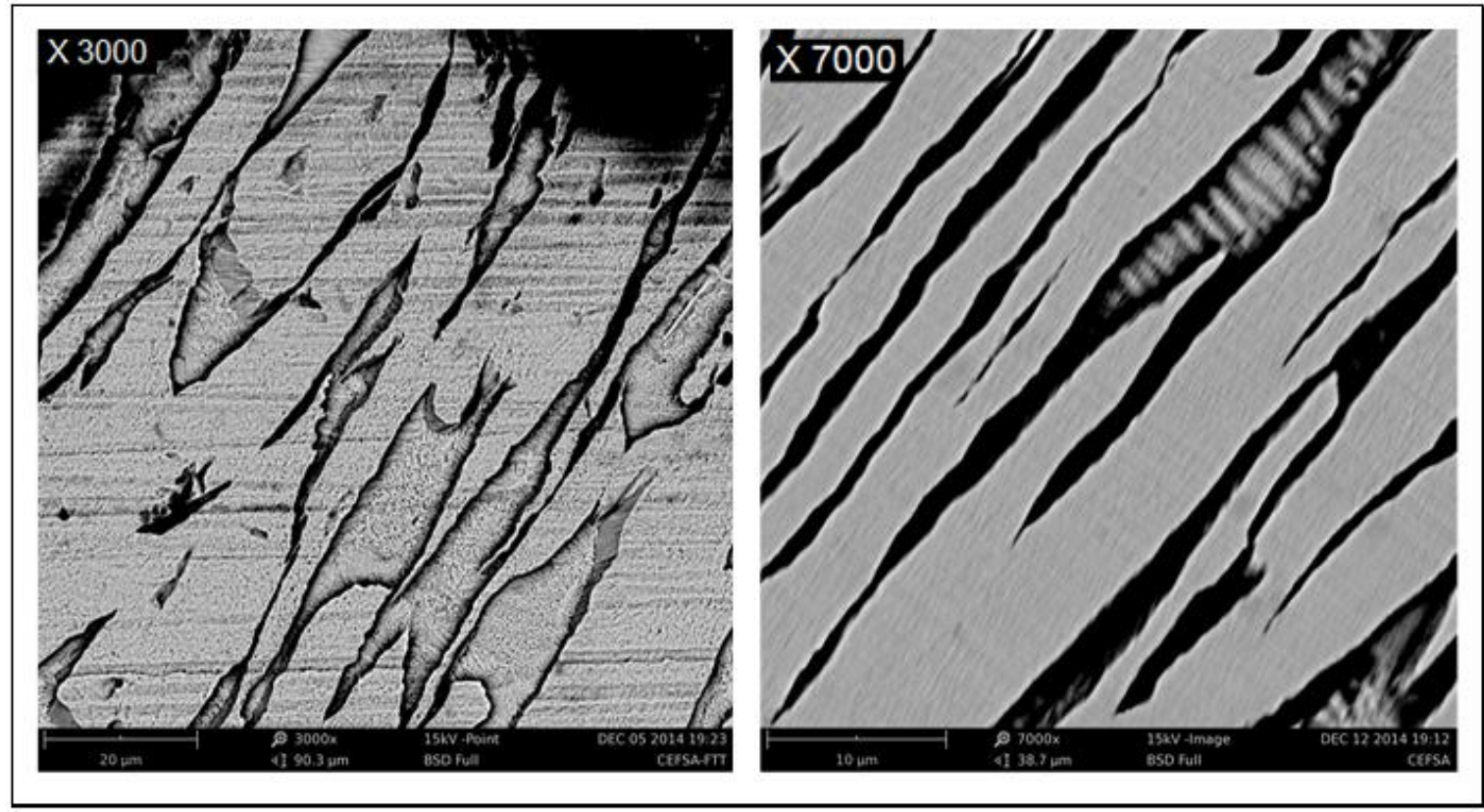

Figura 89 - Análise em microscópio eletrônico de varredura dos cavacos gerados na velocidade de corte de $180 \mathrm{~m} / \mathrm{min}$, para o material A3 
Foram observadas significativas diferenças no grau de recalcamento do cavaco entre os diferentes materiais. Os resultados apresentados na Figura 90 indicam que não só o aumento de zinco descrito na revisão bibliográfica, mas sim as diferentes frações volumétricas de fase $\beta$ contribuem na redução dos valores. (TRENT; WRIGHT, 2000; KLOCKE et al, 2012a; KLOCKE et al, 2012b; NOBEL et al, 2014).

Outro aspecto importante, são os resultados comparativos de $r_{c}$ ao se tomar como referência o material $C 1$ (índice), mostrado na Tabela 13. Os resultados indicam graus de recalcamento do cavaco do latão isento de fase $\beta$ (Material B1) na ordem 2 a 3 vezes maior do que o valor observado ao latão com chumbo (Material C1). Apesar de não coincidirem numericamente com a diferença de 5 vezes descrita na revisão bibliográfica (KLOCKE et al, 2012b; NOBEL et al, 2014), os valores são próximos e preservam a mesma tendência.

Observando os valores de $r_{c}$ mostrados na Figura 90, mais especificamente os atribuídos ao material A3, verifica-se que o aumento da velocidade de corte induz uma mudança de comportamento, o qual está associado à alteração da forma do cavaco de contínuo para serrilhado semicontínuo. Provavelmente, este comportamento tenha sido evidenciado devido ao comportamento mecânico similar do material $A 3$ em comparação ao material $B 1$, e consequentemente quanto às respostas das diferentes microestruturas quanto às maiores taxas de deformação.

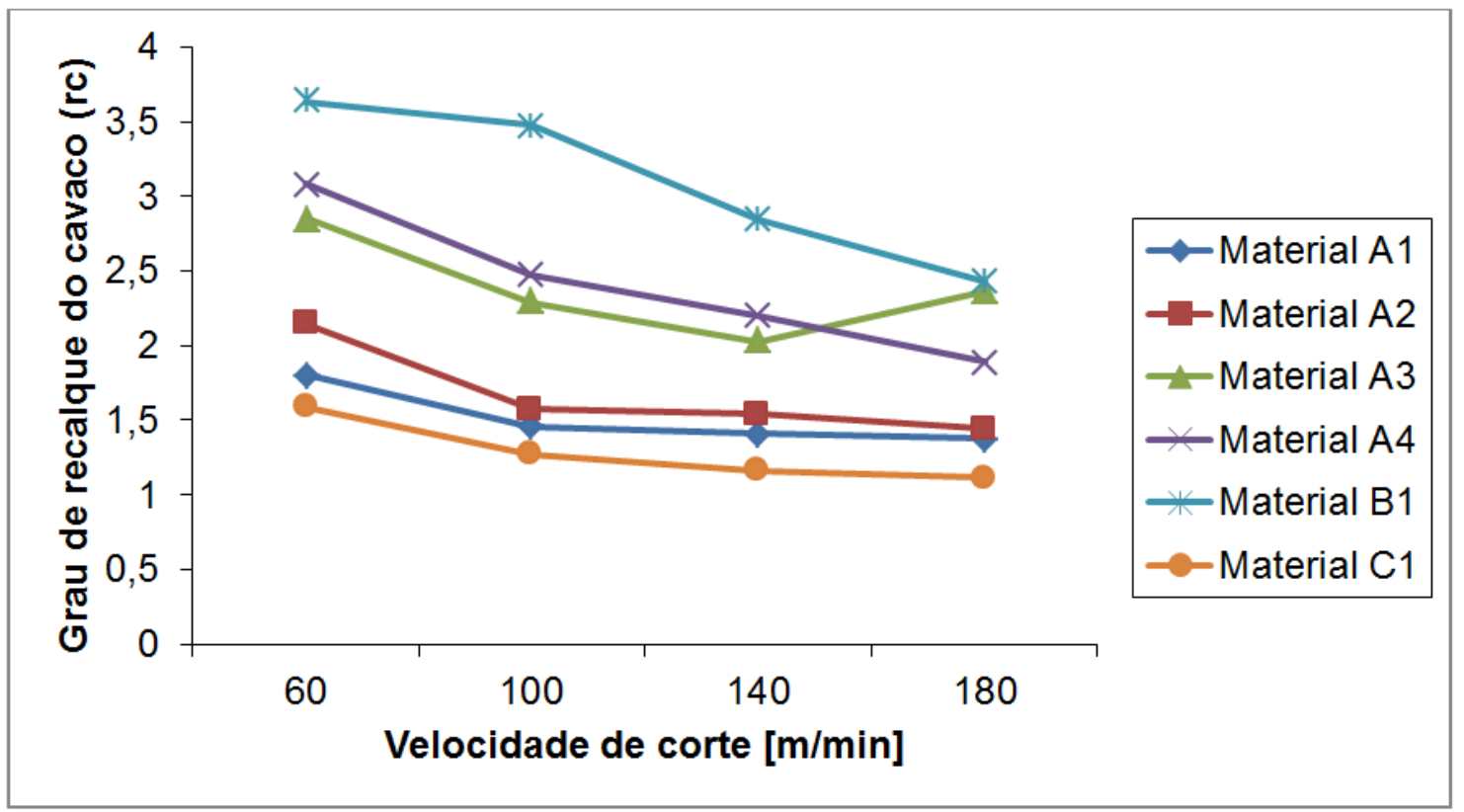

Figura 90 - Comparativo entre o grau de recalcamento dos cavacos usinados 
Tabela 13 - Comparativo do grau de recalcamento dos cavacos em referência ao material C1

\begin{tabular}{ccccccccc}
\hline \multirow{2}{*}{ Material } & \multicolumn{2}{c}{$\mathbf{6 0} \mathbf{~} \mathbf{m i n}$} & \multicolumn{2}{c}{$\mathbf{1 0 0} \mathbf{~} \mathbf{m i n}$} & \multicolumn{2}{c}{$\mathbf{1 4 0} \mathbf{~} \mathbf{m i n}$} & \multicolumn{2}{c}{$\mathbf{1 8 0} \mathbf{~} \mathbf{m i n}$} \\
\cline { 2 - 9 } & $\mathbf{r}_{\mathbf{c}}$ & índice & $\mathbf{r}_{\mathbf{c}}$ & índice & $\mathbf{r}_{\mathbf{c}}$ & índice & $\mathbf{r}_{\mathbf{c}}$ & índice \\
\hline C1 & 1,59 & & 1,27 & & 1,16 & & 1,12 & \\
A1 & 1,81 & 1,1 & 1,46 & 1,1 & 1,41 & 1,2 & 1,38 & 1,2 \\
A2 & 2,15 & 1,4 & 1,58 & 1,2 & 1,54 & 1,3 & 1,44 & 1,3 \\
A3 & 2,86 & 1,8 & 2,29 & 1,8 & 2,03 & 1,8 & 2,37 & 2,1 \\
A4 & 3,09 & 1,9 & 2,48 & 1,9 & 2,20 & 1,9 & 1,89 & 1,7 \\
B1 & 3,64 & 2,3 & 3,48 & 2,7 & 2,85 & 2,5 & 2,43 & 2,2 \\
\hline
\end{tabular}

Ao comparar os resultados de $r_{c}$, entre os materiais $A 2$ e $A 4$, considerados equivalentes em propriedades mecânicas, verifica-se que independentemente das velocidades de cortes utilizadas, o grau de recalcamento no material A4 é de 1,31 a 1,57 maior do que o observado para o material A2. Este resultado indica para a direta influência da fase $\beta$ nesta variável.

\subsubsection{Análise microestrutural dos cavacos}

\subsubsection{Avaliação da espessura elementar de cavaco ( $\Delta y)$}

Das micrografias analisadas, foi possível estimar o valor da espessura elementar de cavaco $\Delta y$ em apenas duas situações, as quais são mostradas nas Figura 91 e Figura 92.

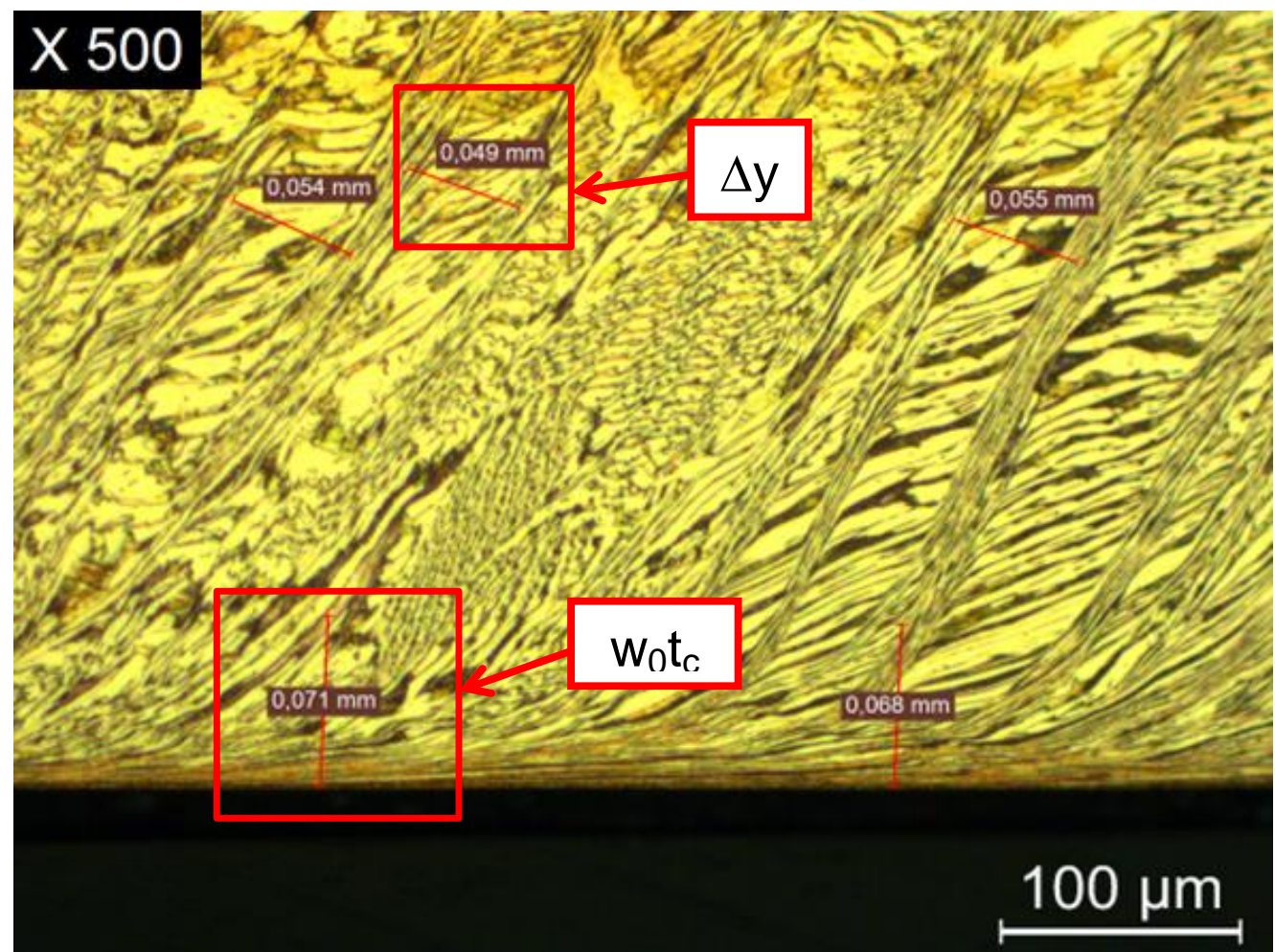

Figura 91 - Medição da espessura elementar de cavaco para o material A1, usinado a $60 \mathrm{~m} / \mathrm{min}$ 


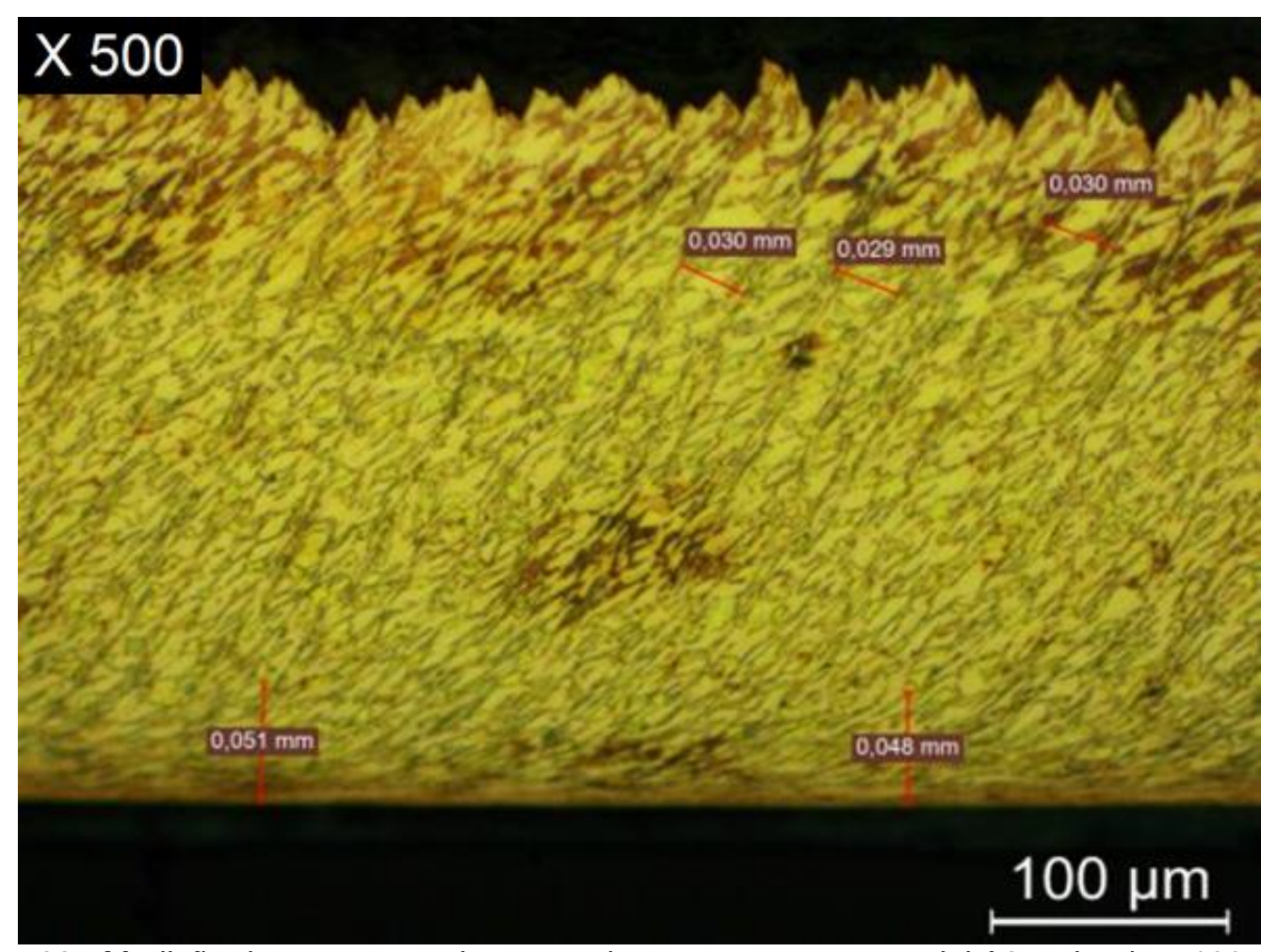

Figura 92 - Medição da espessura elementar de cavaco para o material A2, usinado a $100 \mathrm{~m} / \mathrm{min}$

Os valores obtidos (29 a $55 \mu \mathrm{m}$ ) são maiores do que os valores de 10 a 25 $\mu \mathrm{m}$ descritos na literatura (GANE 1981 apud HOFMANN; MAGD, 2004). As diferenças identificadas podem estar associadas a heterogeneidade microestrutural das amostras, bem como variações no processo de corte. Também deve ser levado em consideração que o método empregado para a medição apresenta imprecisão estatística, dado pela pequena quantidade de amostras avaliadas.

\subsubsection{Avaliação da área afetada pela zona de cisalhamento secundário}

A curvatura da raiz do cavaco, descrita na seção 2.9.2 (Figura 37) fornece um indicativo da interação da superfície inferior do cavaco com a face da ferramenta. (BOOTHROYD, 1975). Dois exemplos das medições são mostrados na Figura 91 e Figura 92.

O comparativo dos resultados obtidos está na Figura 93, sendo possível observar uma tendência de comportamento similar desta variável para os diferentes materiais, sendo que, os maiores valores verificados em menores velocidades são atribuídos à tendência de formação de cavacos segmentados contínuos e a tendência de aumento desta curvatura em maiores velocidades de corte atribuída à formação de cavacos segmentados semicontínuos. 
Em valores intermediários de velocidade, observa-se uma redução nos valores obtidos, e estão associados à formação de cavacos contínuos, os quais tendem a estabilizar o fluxo de massa na superfície do cavaco, reduzindo as temperaturas e minimizando a ocorrência de esforços cíclicos na ferramenta. Os valores de $w_{0} t_{c}$ são influenciados pela fração volumétrica de fase $\beta$, sendo que os materiais A1 e A2 apresentaram menores valores, e estão coerentes com os menores graus de recalcamento do cavaco observado nestes materiais.

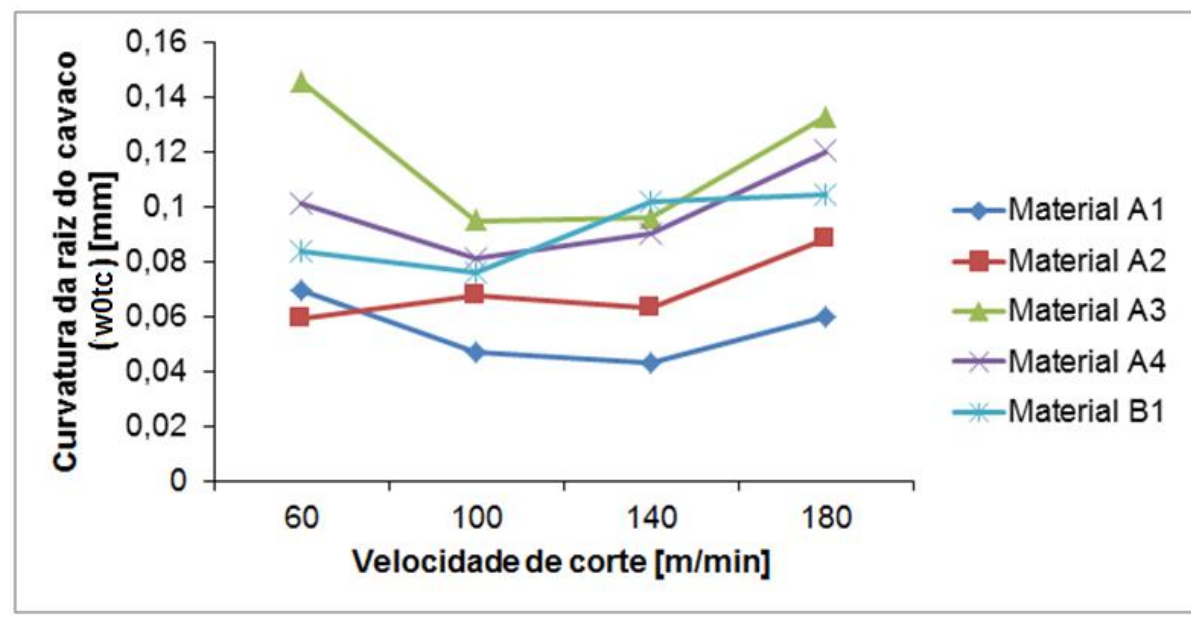

Figura 93 - Resultados da avaliação da curvatura da raiz do cavaco $\left(\mathrm{w}_{0} \mathrm{t}_{\mathrm{c}}\right)$, para as diferentes velocidades de corte

\subsubsection{Avaliação das transformações microestruturais nos cavacos}

A Figura 94, mostra os resultados das observações das frações volumétricas $\beta$ nos cavacos usinados nas diferentes velocidades de corte utilizadas, sendo que estes dados foram obtidos através da metodologia descrita na seção 3.2.5, e as respectivas micrografias são mostradas nas Figuras 95, 96, 97 e 98.

Os resultados indicam para uma significativa alteração microestrutural, a qual está diretamente relacionada com as elevadas taxas de deformação e temperaturas. Os resultados obtidos são similares aos descritos nos estudos de comportamento mecânico de latões bifásicos (KHEZRI-YAZDAN; SUBRAMANIAN, 1984a), com características de lamelas de fase $\alpha$ acomodadas sobre uma matriz de uma fase $\beta$ dúctil, e temperaturas acima da transformação $\beta^{\prime} \rightarrow \beta$.

Os resultados obtidos apontam para um aumento mais evidente desta fração volumétrica de fase $\beta$ em menores velocidades de corte. Esta diferença provavelmente é atribuída ao maior grau de recalcamento do cavaco existente nesta velocidade, a qual consequentemente aumenta o comprimento de contato com o 
flanco da ferramenta, e a concentração de maiores temperaturas nas bandas de deformação formadas nos cavacos. Com isso, embora a taxa de deformação seja menor em menores velocidades de corte, o calor pode se distribuir melhor pela região do corte e do cavaco, e com isso possibilite observar maiores temperaturas de corte nestes casos.

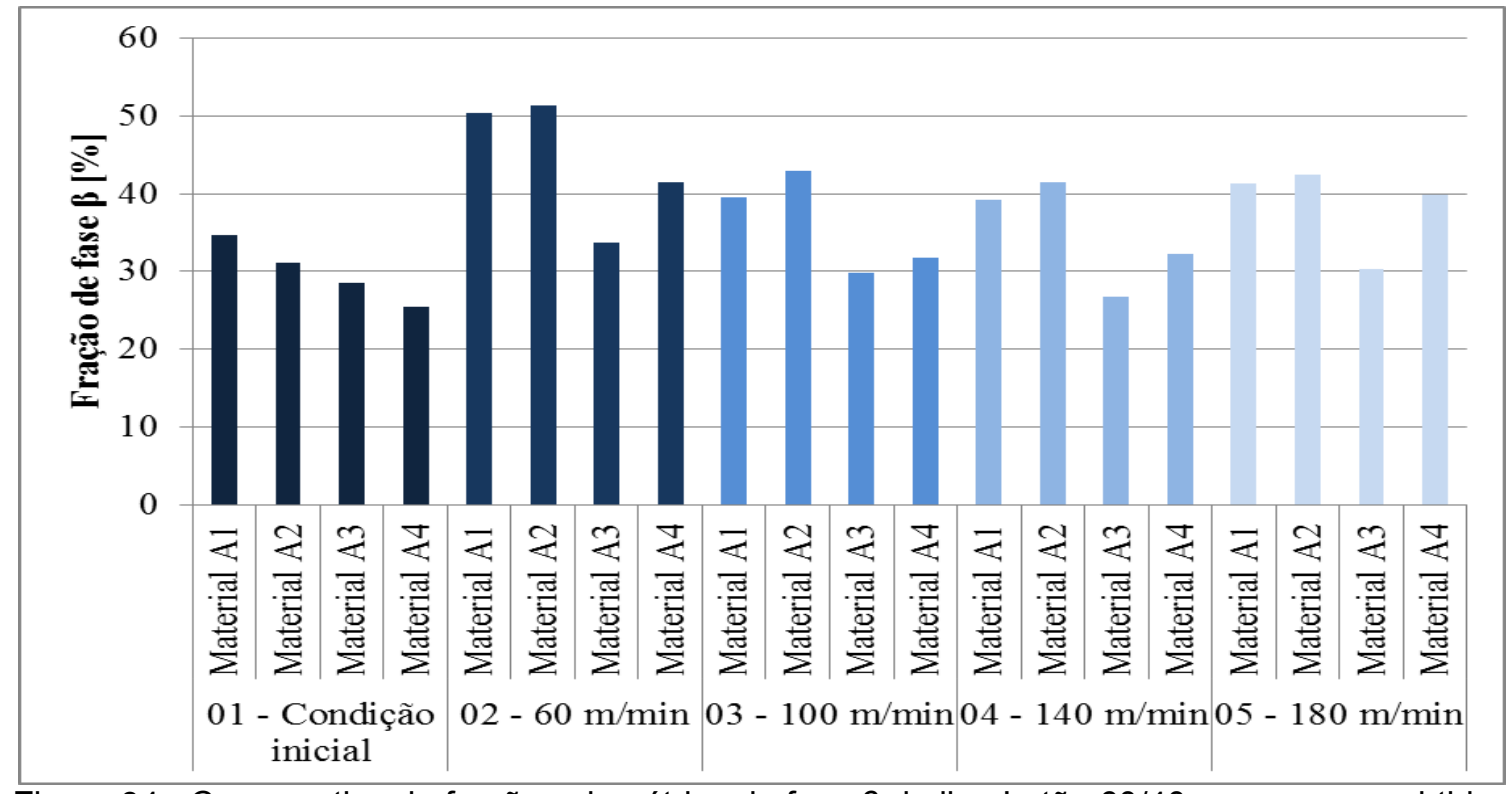

Figura 94 - Comparativo da fração volumétrica de fase $\beta$ da liga Latão 60/40 nos cavacos obtidos
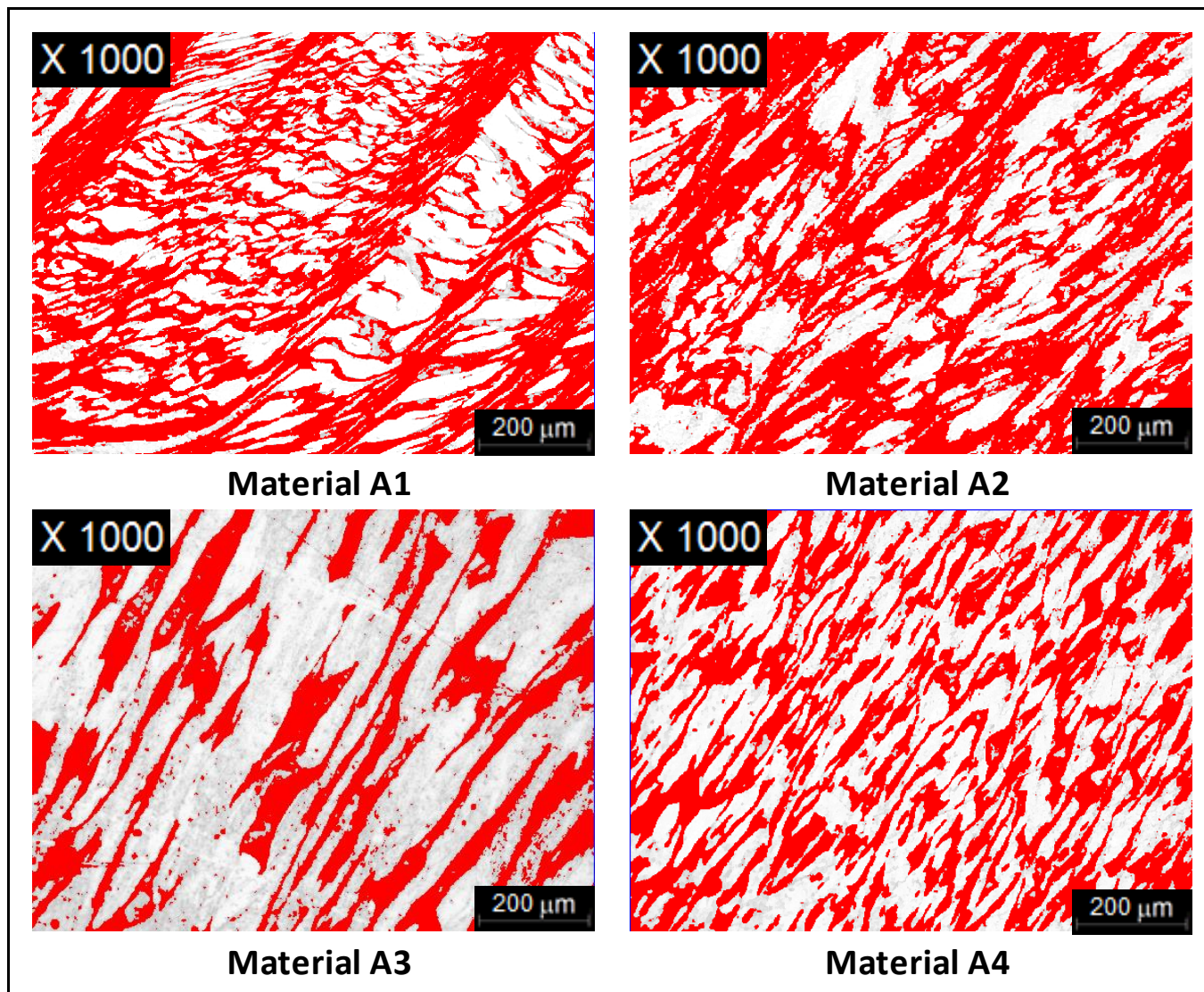

Figura 95 - Medição da Fase $\beta$ nos cavacos obtidos para a velocidade de corte de $60 \mathrm{~m} / \mathrm{min}$ 

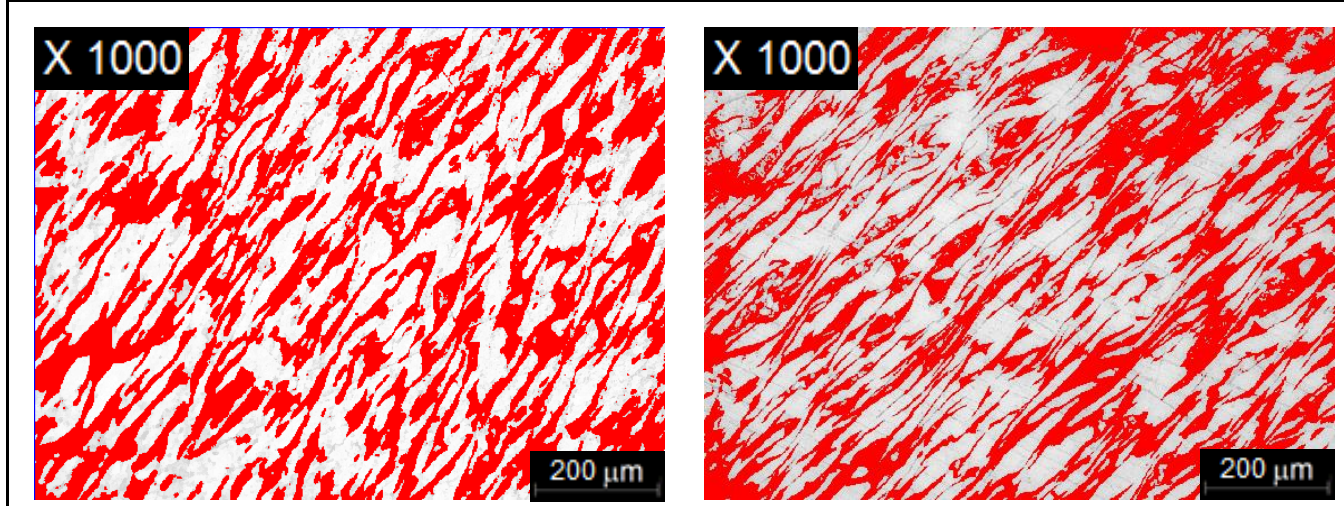

Material A1

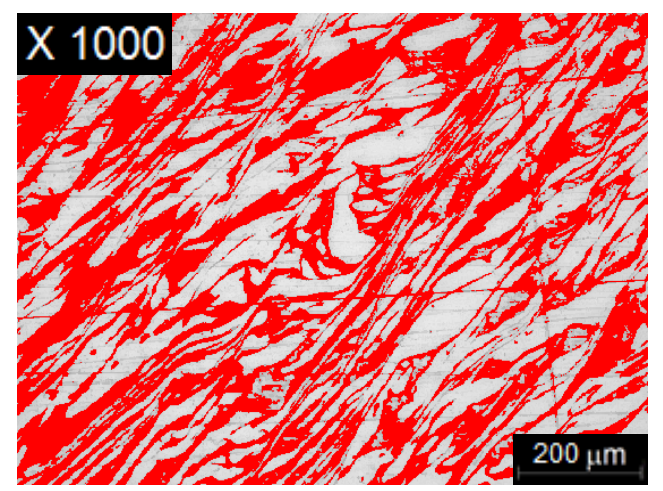

Material A3

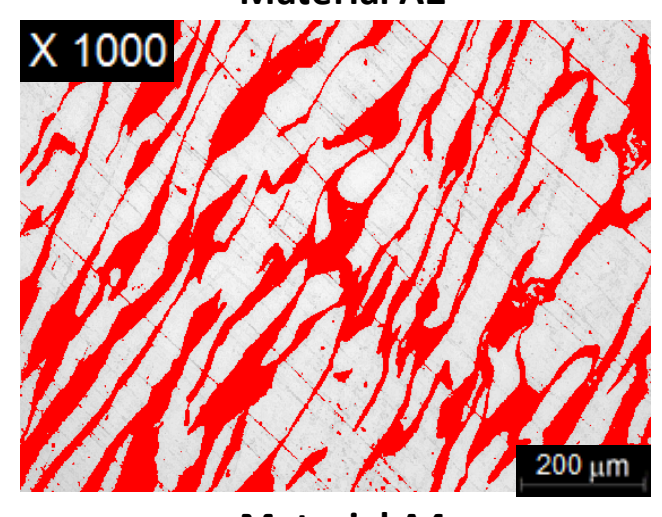

Figura 96 - Medição da Fase $\beta$ nos cavacos obtidos para a velocidade de corte de $100 \mathrm{~m} / \mathrm{min}$

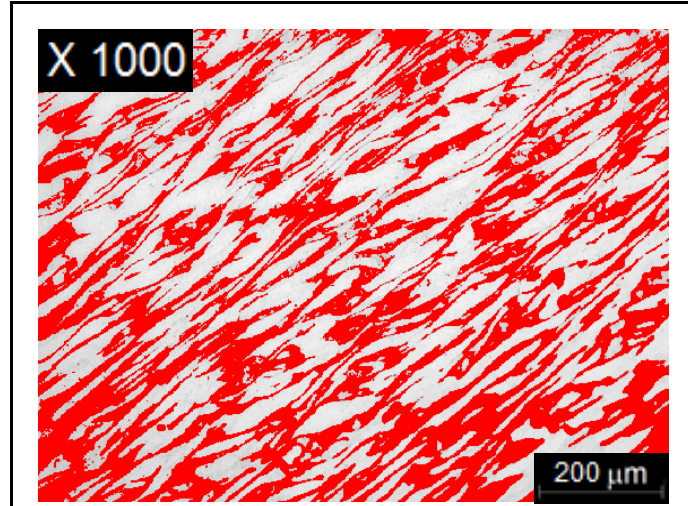

Material A1

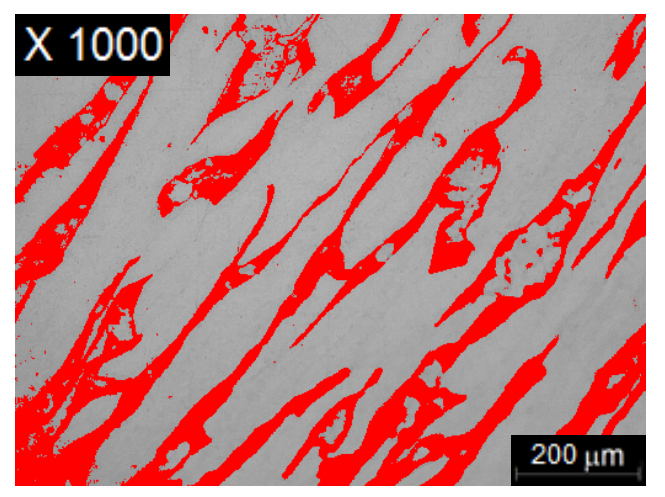

Material A3

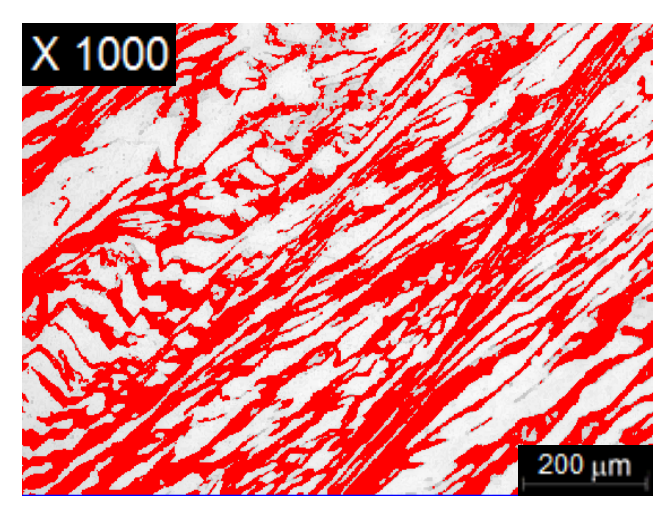

Material A2

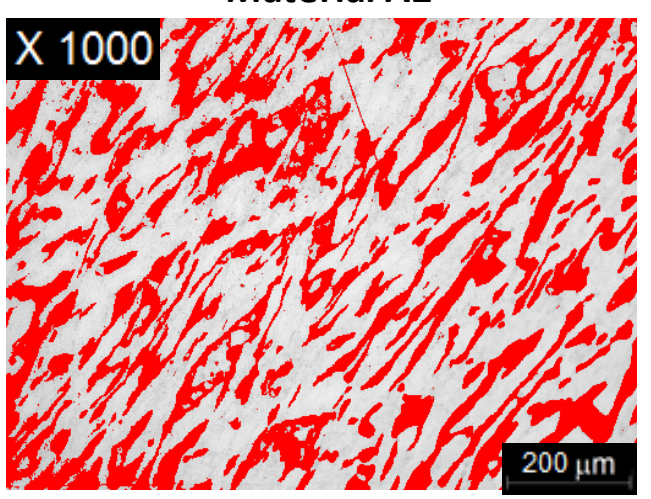

Material A4

Figura 97 - Medição da Fase $\beta$ nos cavacos obtidos para a velocidade de corte de $140 \mathrm{~m} / \mathrm{min}$ 


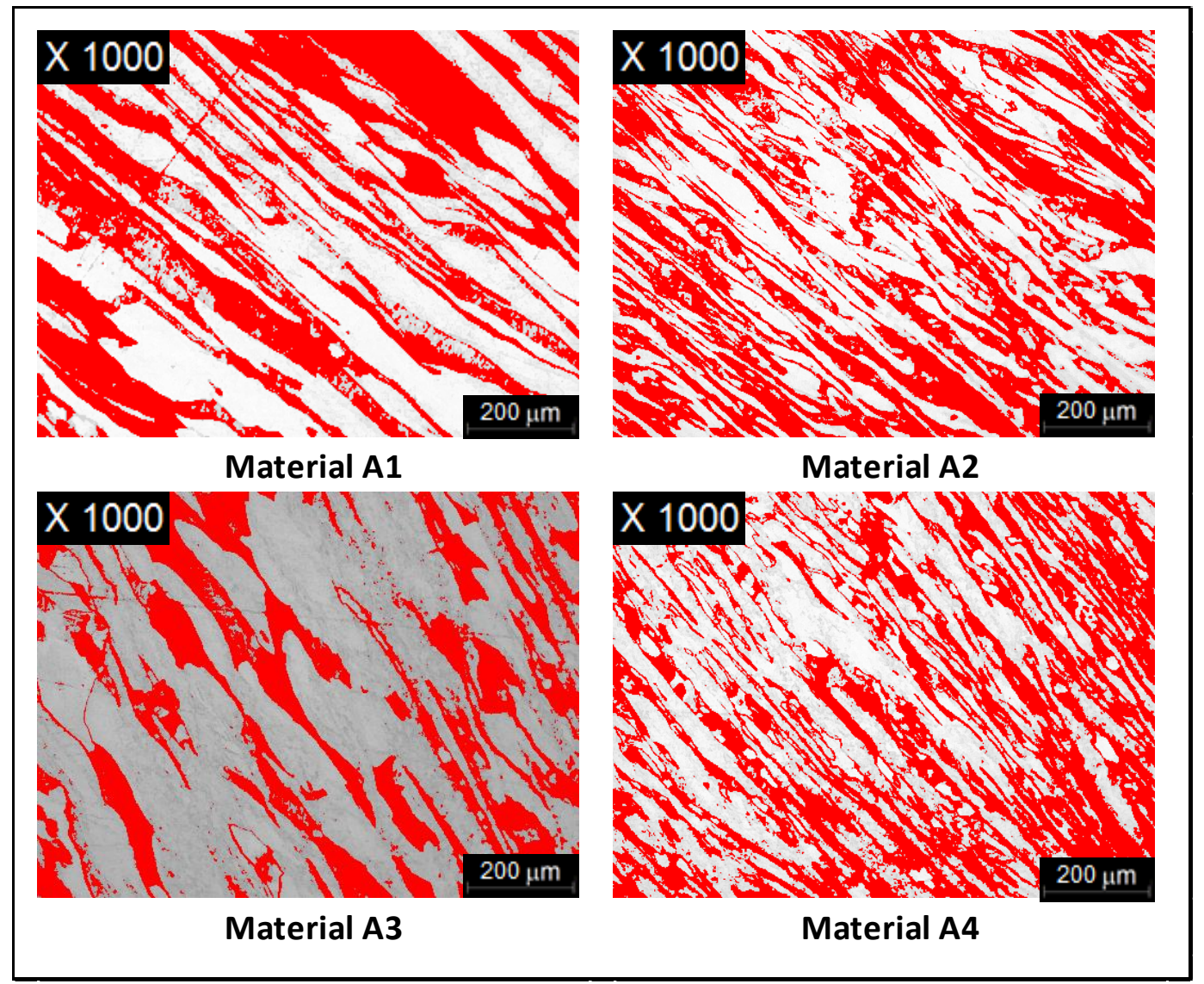

Figura 98 - Medição da Fase $\beta$ nos cavacos obtidos para a velocidade de corte de $180 \mathrm{~m} / \mathrm{min}$

A Figura 99, obtida a partir dos resultados das análises de EDS do microscópio eletrônico de varredura, mostram uma variação na composição química das fases $\alpha$ e $\beta$, em um padrão constante no qual a quantidade de cobre da fase $\beta$ aumenta em comparação a fase $\alpha$, sendo este aspecto uma importante evidência da ocorrência de difusão atômica entre as fases, propiciada pelo calor gerado no processo de corte.

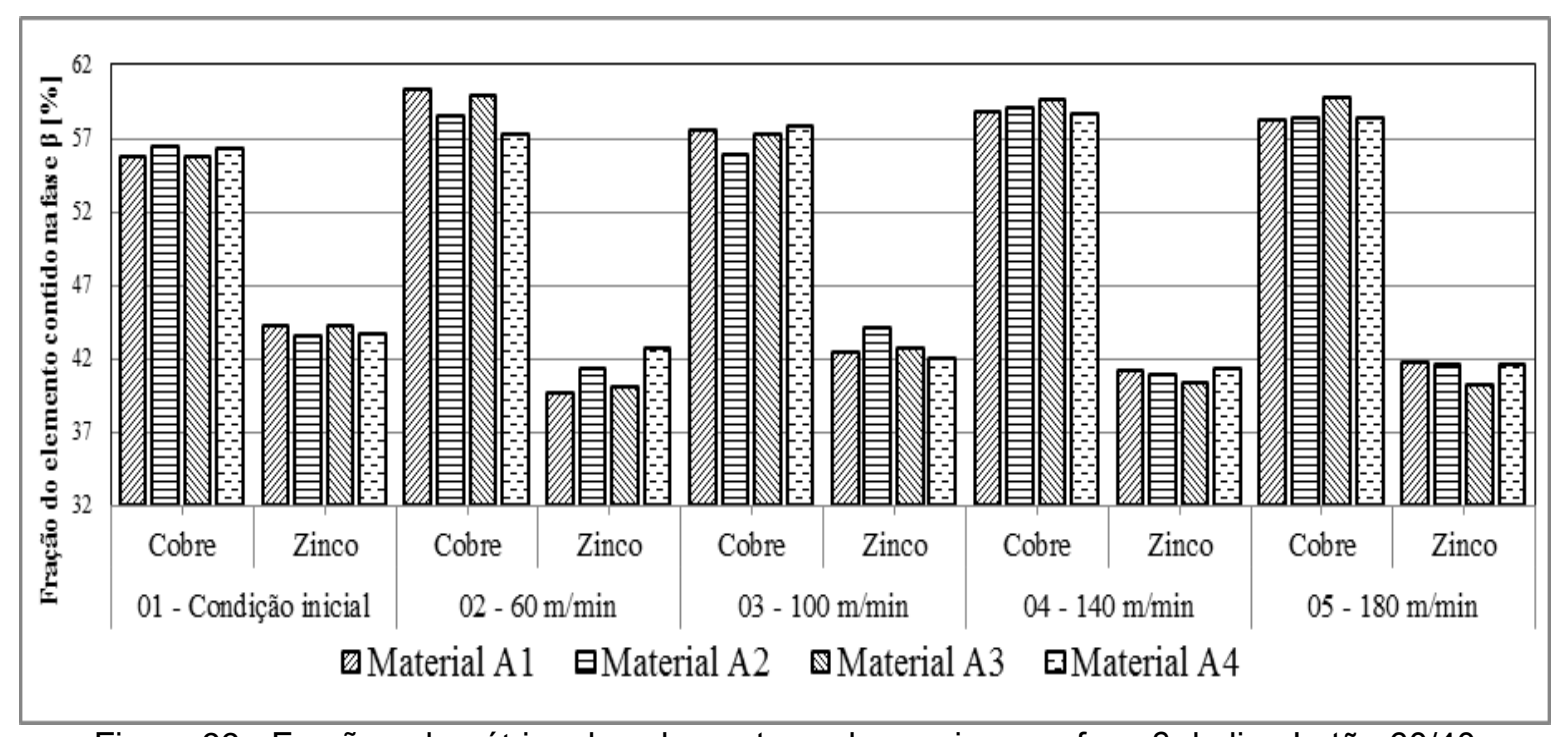

Figura 99 - Fração volumétrica dos elementos cobre e zinco na fase $\beta$ da liga Latão 60/40 


\subsection{ANÁLISE DAS FORÇAS DE CORTE}

Os ensaios de medição das forças de corte, no parâmetro escolhido, são apresentados na Tabela 14. A Figura 100 evidencia uma importante tendência de redução da Força de Corte $(\mathrm{Fc})$ e da Força de Avanço $(\mathrm{Ff})$ com o aumento da fração de fase $\beta$. Com relação à força passiva, os valores obtidos para o material $\mathrm{C} 1$ foram muito menores que os outros valores de força e desconsiderados nesta análise, e os outros materiais apresentaram valores próximos.

Tabela 14 - Comparativo das forças de corte

\begin{tabular}{lccccccc}
\hline Material & $\begin{array}{c}\text { Fase } \boldsymbol{\beta} \\
{[\%]}\end{array}$ & $\begin{array}{c}\text { Força } \\
\text { de } \\
\text { avanço } \\
{[\mathbf{N}]}\end{array}$ & $\begin{array}{c}\text { Desvio } \\
\text { Padrão }\end{array}$ & $\begin{array}{c}\text { Força } \\
\text { de corte } \\
\text { [N] }\end{array}$ & $\begin{array}{c}\text { Desvio } \\
\text { Padrão }\end{array}$ & $\begin{array}{c}\text { Força } \\
\text { passiva } \\
{[\mathbf{N}]}\end{array}$ & $\begin{array}{c}\text { Desvio } \\
\text { Padrão }\end{array}$ \\
\hline Material B1 & 0 & 534,1 & 3,4 & 869,9 & 2,8 & 175,7 & 5,6 \\
Material A4 & 25,5 & 419,2 & 25,5 & 799,8 & 38,1 & 174,1 & 22,3 \\
Material A3 & 28,5 & 443,5 & 14,6 & 782,3 & 12,1 & 176,9 & 26,0 \\
Material A2 & 31,2 & 413,8 & 9,8 & 765,6 & 18,9 & 158,7 & 5,2 \\
Material A1 & 34,7 & 365,9 & 8,6 & 705,7 & 22,6 & 147,3 & 1,9 \\
Material C1 & 17,3 & 171,7 & 14,0 & 393,2 & 16,1 & - & - \\
\hline
\end{tabular}

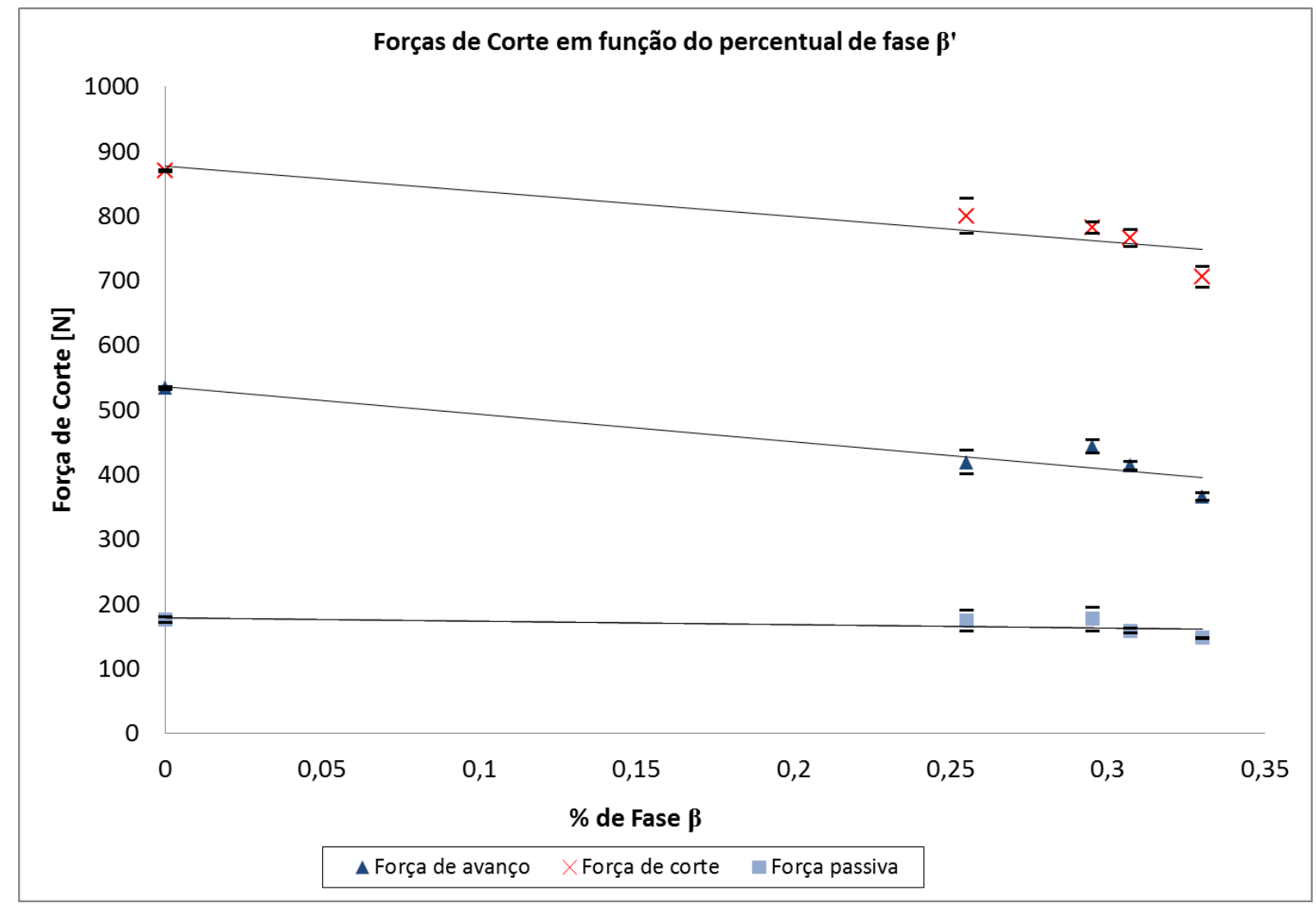

Figura 100 - Forças de corte obtidas nos ensaio de torneamento 
Os resultados têm considerável proximidade com os valores descritos por outros autores, e mostrado neste presente trabalho na Figura 52 (KLOCKE et al, 2012b). Os resultados mostrados na figura 100 indicam para importante redução das forças de corte com a utilização do chumbo na liga, sendo que o material A1 apresentou valor de força $79,5 \%$ maior do que o observado ao material $\mathrm{C} 1$, com Fc de $393 \mathrm{~N}$.

Entretanto, as diferentes frações de fase $\beta$ proporcionaram considerável redução das forças de corte e avanço, sendo que a Tabela 15 , baseada na análise comparativa aos materiais isentos de chumbo, indica que o material A1 apresentou o melhor resultado, representando uma redução de 18,9\% da força de corte em comparação com o material B1, maior valor observado. Mesma observação é feita a força de avanço, com redução de 31,5\%. Outro aspecto o qual evidencia esta contribuição está ao avaliarmos os materiais B1 e A3, cujas características mecânicas foram consideradas similares, entretanto as reduções dos valores de força de corte e de avanço foram de $17 \%$ e $10,1 \%$ respectivamente.

Tabela 15 - Comparativo de redução das forças de corte

\begin{tabular}{cccccccc}
\hline Material & $\begin{array}{c}\text { Fase } \boldsymbol{\beta} \\
{[\%]}\end{array}$ & $\begin{array}{c}\text { Força de } \\
\text { avanço } \\
{[\mathbf{N}]}\end{array}$ & $\begin{array}{c}\text { Desvio } \\
\text { Padrão }\end{array}$ & Redução & $\begin{array}{c}\text { Força de } \\
\text { corte [N] }\end{array}$ & $\begin{array}{c}\text { Desvio } \\
\text { Padrão }\end{array}$ & Redução \\
\hline B1 & 0 & 534,1 & 2,8 & - & 869,9 & 3,4 & - \\
A4 & 25,5 & 419,2 & 38,2 & $-21,50 \%$ & 799,8 & 25,6 & $-8,10 \%$ \\
A3 & 28,5 & 443,5 & 12,2 & $-17,00 \%$ & 782,3 & 14,6 & $-10,10 \%$ \\
A2 & 31,2 & 413,8 & 18,9 & $-22,50 \%$ & 765,6 & 9,8 & $-12,00 \%$ \\
A1 & 34,7 & 365,9 & 22,6 & $-31,50 \%$ & 705,7 & 8,6 & $-18,90 \%$ \\
\hline
\end{tabular}

Dentre os fatores os quais contribuem para as diferenças observadas, estão os diferentes graus de grau de recalcamento dos cavacos obtidos. A análise do $r_{c}$ indica que a energia necessária para realização do corte é dissipada em duas formas principais: uma relativa ao trabalho de compressão dos cavacos, e outra em energia térmica, a qual promoveu a difusão dos contornos de fase descritos na seção anterior.

A observação da relação direta do grau de recalcamento dos cavacos com as forças de corte apresentadas tem consistência com os resultados de trabalhos anteriores (KLOCKE et al, 2012b), sendo que os maiores grau de recalcamento 
aumentam o comprimento de contato cavaco - ferramenta, e consequentemente as cargas mecânicas sobre a mesma.

\subsection{TEMPERATURA MÁXIMA ATINGIDA NO PROCESSO DE CORTE}

\subsubsection{Abordagem analítica}

Os resultados analíticos das máximas temperaturas atingidas no processo de corte (Өmáx) são apresentados na Tabela 16, sendo identificada uma considerável redução dos valores, associado ao aumento da fase $\beta$, com exceção ao material A3. Observação similar é feita para os aumentos de temperatura na zona de cisalhamento primária e secundária.

As principais variáveis que contribuem para a redução das temperaturas são as forças de corte e avanço. Estas duas variáveis estão diretamente relacionadas com os menores graus de recalcamento dos cavacos e, consequentemente, com a redução do comprimento de contato entre o cavaco e a ferramenta. Tal diferença resulta na redução do atrito na zona de cisalhamento secundário e da carga térmica sobre a ferramenta. A exceção descrita acima está associada com as maiores forças de avanço e temperaturas observadas no material $A 3$, em comparação ao material A4, mostradas na seção 4.4 .

Outro aspecto importante é o relacionado com a fração de calor transferida para a peça $(\Gamma)$, e a transferida para o cavaco $(\Gamma-1)$. Os materiais com maior quantidade de fase $\beta$ apresentaram maiores frações de calor transferidas ao cavaco, pelas mesmas razões descritas anteriormente. Porém, como a carga térmica total destes materiais é menor, observa-se que mesmo com uma maior transferência de calor para o cavaco, a sua temperatura máxima permanece menor em comparação às outras situações.

Dentro deste contexto, uma vez que o aumento de fase $\beta$ contribui para a redução do fluxo de calor para a peça $(Г)$, também se espera maior confiabilidade e precisão dimensional do uso destes materiais em sistemas de produção seriada, pois estarão menos sujeitos aos efeitos de distorção e danos superficiais causados pela dilatação térmica volumétrica e pelo amolecimento localizado, em decorrência do aumento de temperatura na região de corte. 
Tabela 16 - Resultados analíticos das temperaturas máximas atingidas no processo de corte

\begin{tabular}{ccccccccccc}
\hline Material & $\mathbf{P}_{\mathbf{m}}[\mathbf{J} / \mathbf{s}]$ & $\begin{array}{c}\mathbf{P}_{\mathbf{f}} \\
{[\mathbf{J} / \mathbf{s}]}\end{array}$ & $\mathbf{P}_{\mathbf{s}}[\mathbf{J} / \mathbf{s}]$ & $\mathbf{Z}$ & $\mathbf{\Gamma}$ & $\boldsymbol{\theta} \mathbf{s}\left[{ }^{\circ} \mathbf{C}\right]$ & $\boldsymbol{\theta m} / \boldsymbol{\theta f}$ & $\boldsymbol{\theta} \mathbf{[}\left[{ }^{\circ} \mathbf{C}\right]$ & $\begin{array}{c}\boldsymbol{\theta} \mathbf{m} \\
{\left[{ }^{\circ} \mathbf{C}\right]}\end{array}$ & $\begin{array}{c}\boldsymbol{\theta} \text { máx } \\
{\left[{ }^{\circ} \mathbf{C}\right]}\end{array}$ \\
\hline B1 & 1913,8 & 413,0 & 1500,8 & 12,01 & 0,31 & 356,4 & 3,10 & 143,1 & 443,8 & 820,2 \\
A4 & 1759,6 & 419,2 & 1340,4 & 11,52 & 0,29 & 336,2 & 2,25 & 147,7 & 331,7 & 687,9 \\
A3 & 1721,1 & 480,6 & 1240,4 & 11,52 & 0,29 & 309,0 & 2,32 & 169,4 & 392,7 & 721,7 \\
A2 & 1684,3 & 591,1 & 1093,2 & 11,52 & 0,25 & 290,1 & 1,64 & 208,3 & 341,5 & 651,6 \\
A1 & 1552,5 & 570,9 & 981,6 & 11,52 & 0,23 & 266,2 & 1,48 & 201,2 & 298 & 584,2 \\
\hline
\end{tabular}

\subsubsection{Análise metalúrgica}

Uma abordagem possível para estimar as temperaturas máximas atingidas no processo de corte é apresentada na Figura 101 abaixo, através da análise do diagrama de fases do sistema cobre e zinco, no qual se observa que, para a obtenção de uma fração de $50 \%$ de fase $\alpha$ e $50 \%$ de fase $\beta$ pela regra das alavancas, o maior valor verificado nos testes, é necessário o aquecimento da liga a uma temperatura de aproximadamente $600^{\circ} \mathrm{C}$.

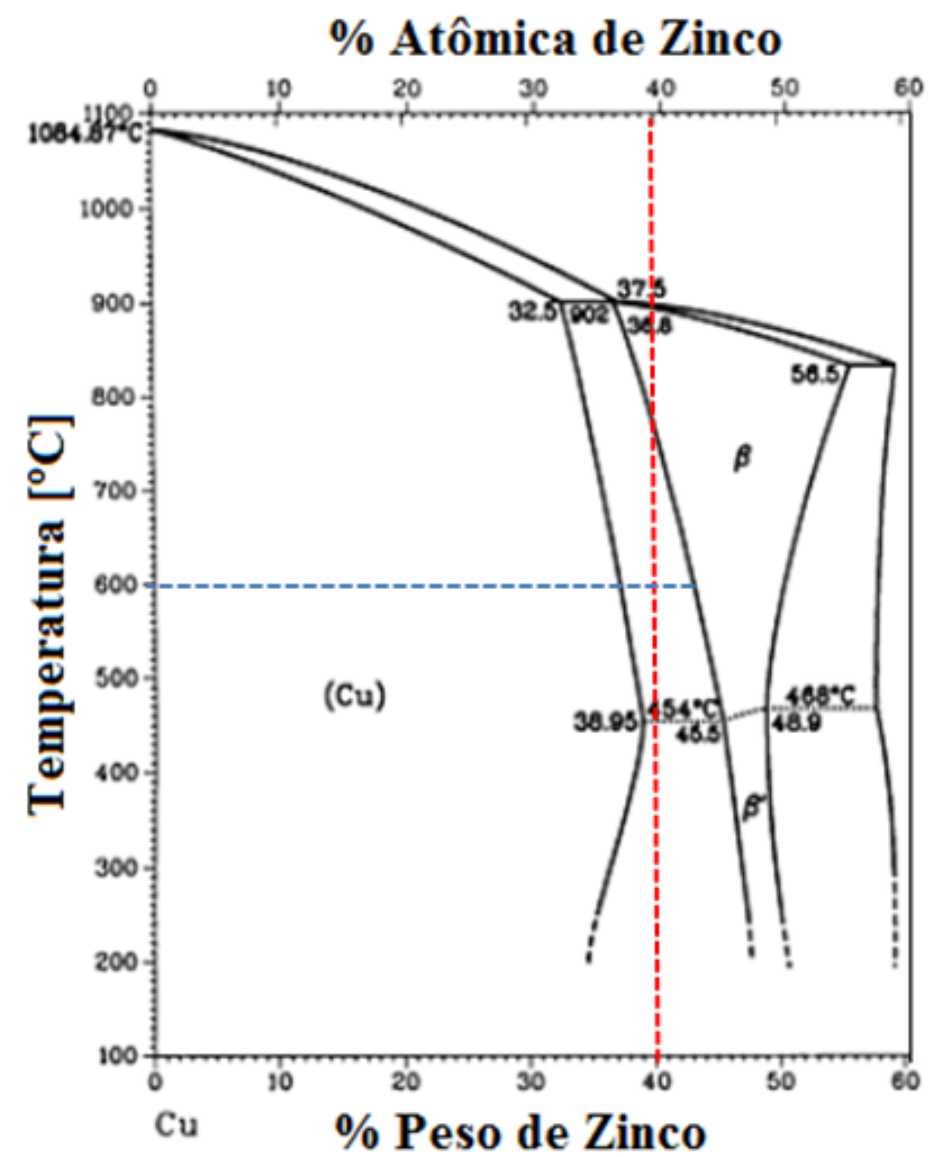

Figura 101 - Análise do diagrama de fases binário cobre-zinco 
Ambas as abordagens descritas anteriormente, permitem afirmar que toda a fase $\beta$ presente no material sofreu transformação de ordem-desordem. Desta forma, o material deixa de apresentar comportamento frágil e passa a exibir comportamento de elevada ductilidade.

A confirmação deste dado explica 0 fato do cavaco apresentar comportamento contínuo, mesmo com o aumento das tensões atuantes no plano de cisalhamento primário, uma vez que as elevadas taxas de deformação e aumento da temperatura de corte alteram significativamente as propriedades mecânicas do material processado.

\subsection{ANÁLISE DAS TAXAS DE DEFORMAÇÃO}

Foram calculadas as taxas de deformação, para os dois casos descritos na seção 4.3.2.2, os quais permitiram a leitura dos valores da espessura elementar do cavaco $(\Delta y)$. Os resultados estão na Tabela 17, e estão coerentes com os resultados descritos na literatura relacionada ao tema. (DIETER, 1981; SHAW, 2003; HOFMANN; MAGD, 2004; DENKENA, 2007; DAVIM E MARANHÃO, 2008; MACHADO et al, 2011).

Em face da coerência dos resultados obtidos nas duas análises propostas, entende-se que, mesmo sem a validação dos valores de $\Delta y$ para os outros casos ensaiados, espera-se valores de taxa de deformação próximos aos relatados neste trabalho.

Tabela 17 - Taxas de deformação avaliadas

\begin{tabular}{cccccc}
\hline Material & $\begin{array}{c}\text { Velocidade } \\
{[\mathbf{m} / \mathbf{m i n}]}\end{array}$ & $\begin{array}{c}\mathbf{r}_{\mathbf{c}} \\
{[\mathbf{m m}]}\end{array}$ & $\boldsymbol{\varphi}\left({ }^{\circ}\right)$ & $\Delta \mathbf{y}[\boldsymbol{\mu m}]$ & $\varepsilon\left[\mathbf{s}^{-1}\right]$ \\
\hline Material A1 & 60 & 1,8 & 27,51 & 0,055 & $9,15 \times 10^{5}$ \\
Material A2 & 100 & 1,6 & 30,63 & 0,029 & $2,78 \times 10^{6}$ \\
\hline
\end{tabular}

\subsection{ANÁLISE DA VIDA DA FERRAMENTA}

As Figuras 102, 103, 104, 105, 106 e 107 são relativas à análise do flanco das ferramentas, nas condições de ensaio descritas na seção 2.3.7, sendo verificada a não ocorrência de diferenças significativas quanto ao desgaste de flanco, seja com a presença ou não de chumbo ou fase $\beta$. 
Os dados são similares aos obtidos na literatura (KLOCKE et al, 2012a), porém este trabalho empregou maiores tempos de usinagem do que os propostos neste estudo. Consequentemente foram apontadas diferenças mais evidentes, com ligeira vantagem aos materiais com chumbo e com a gradativa redução da vida da ferramenta com a redução do percentual de fase $\beta$.

As condições até então apresentadas nas seções anteriores, indicam para um aumento das cargas térmicas e mecânicas nas ferramentas em função da redução do volume de fase $\beta$, mostrando uma maior tendência de desgaste das ferramentas pelos mecanismos de difusão e adesão nestas condições. Com base nisso, afirmase que a possibilidade de falha das ferramentas submetidas a este processo são maiores do que as envolvidas na usinagem dos materiais com maiores percentuais de fase $\beta$, ou com a adição do chumbo, face as menores cargas térmicas e mecânicas apresentadas.

Para as condições ensaiadas, existem indícios da formação de aresta postiça de corte nas ferramentas utilizadas para os materiais A4 e B1, sendo evidenciada nas Figuras 105 e 106, pequena adesão de latão na superfície de saída das ferramentas.
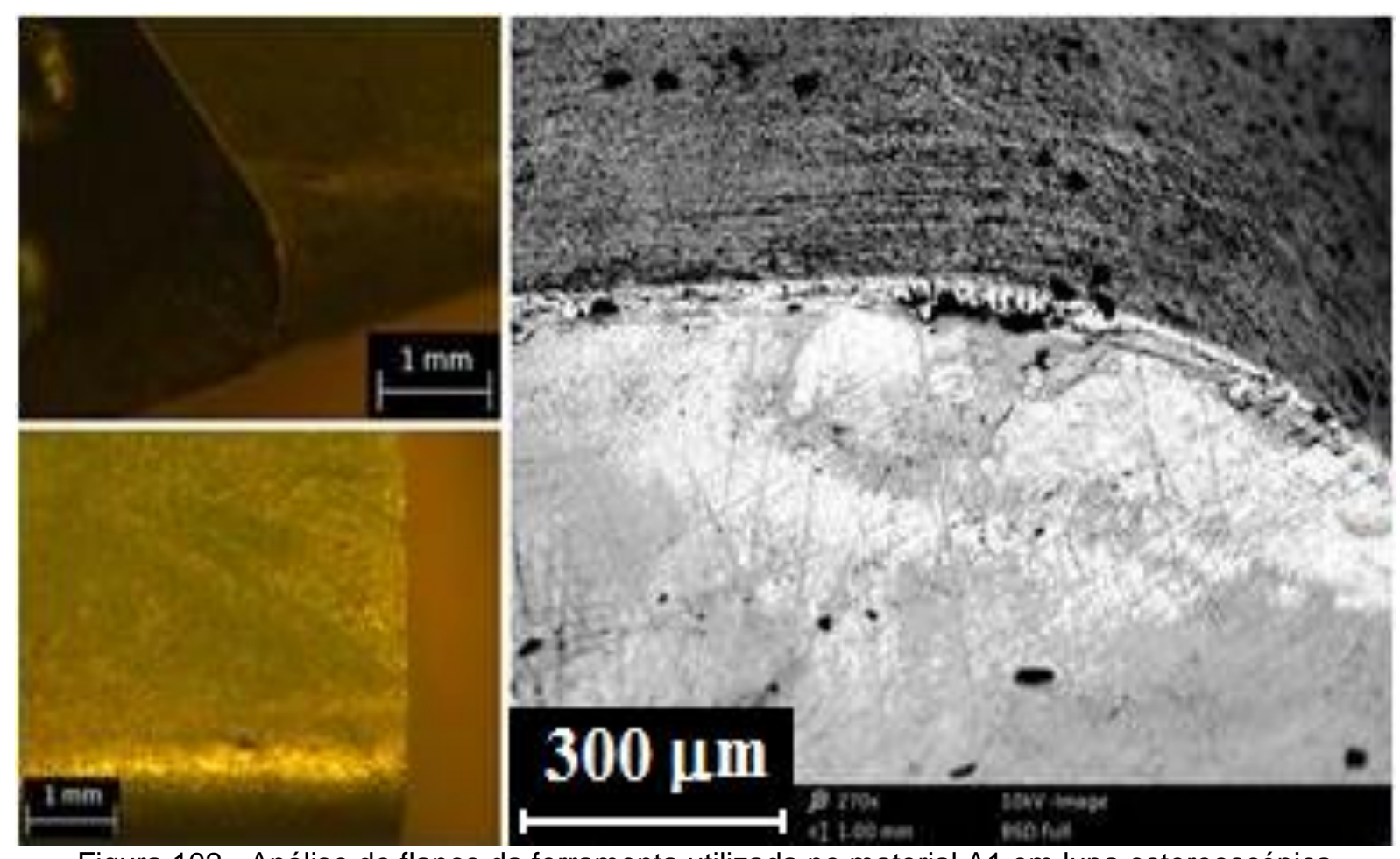

Figura 102 - Análise do flanco da ferramenta utilizada no material A1 em lupa estereoscópica (Aumento 20X) e MEV (Aumento 290x) 

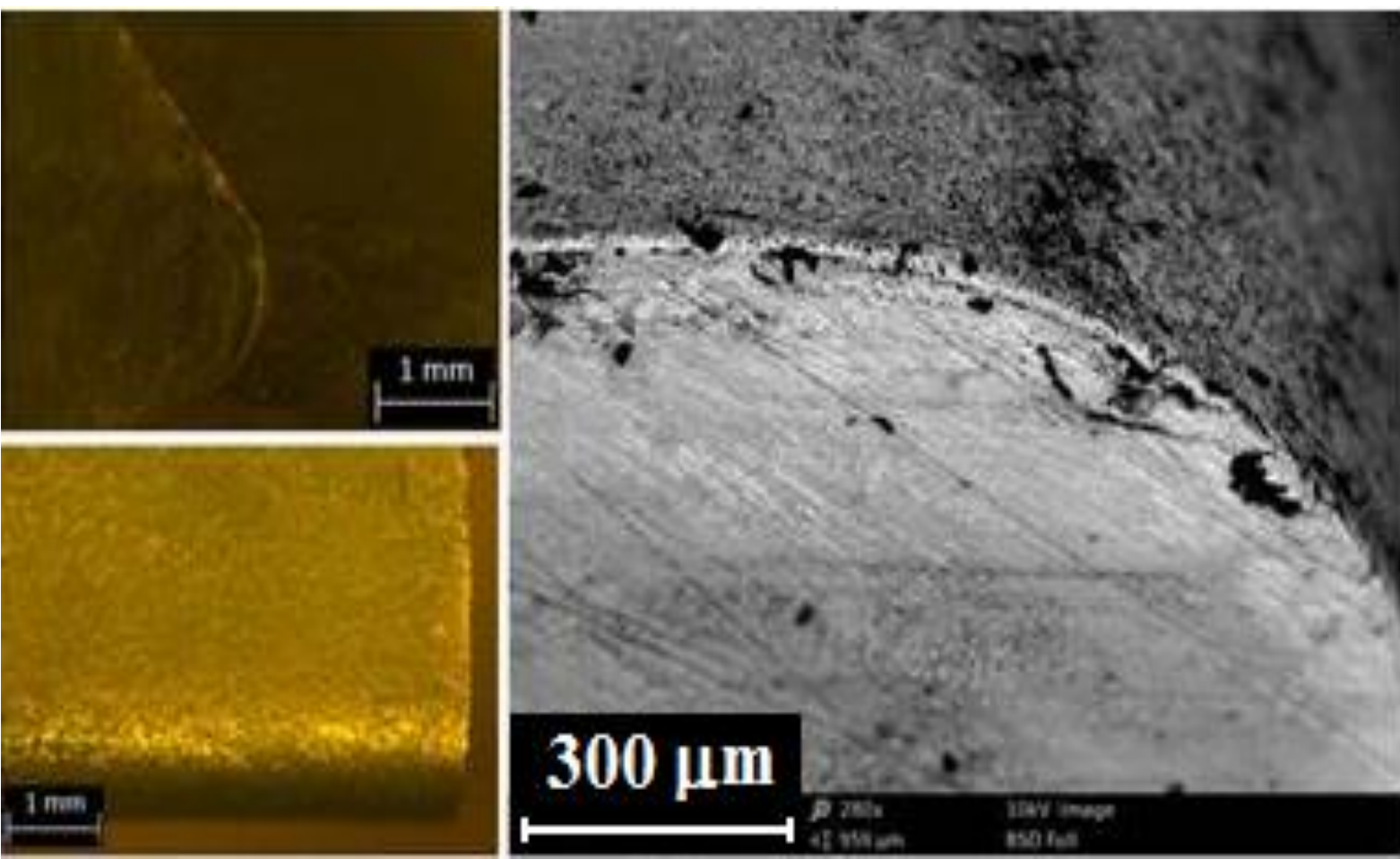

Figura 103- Análise do flanco da ferramenta utilizada no material A2 em lupa estereoscópica (Aumento 20X) e MEV (Aumento 290x)
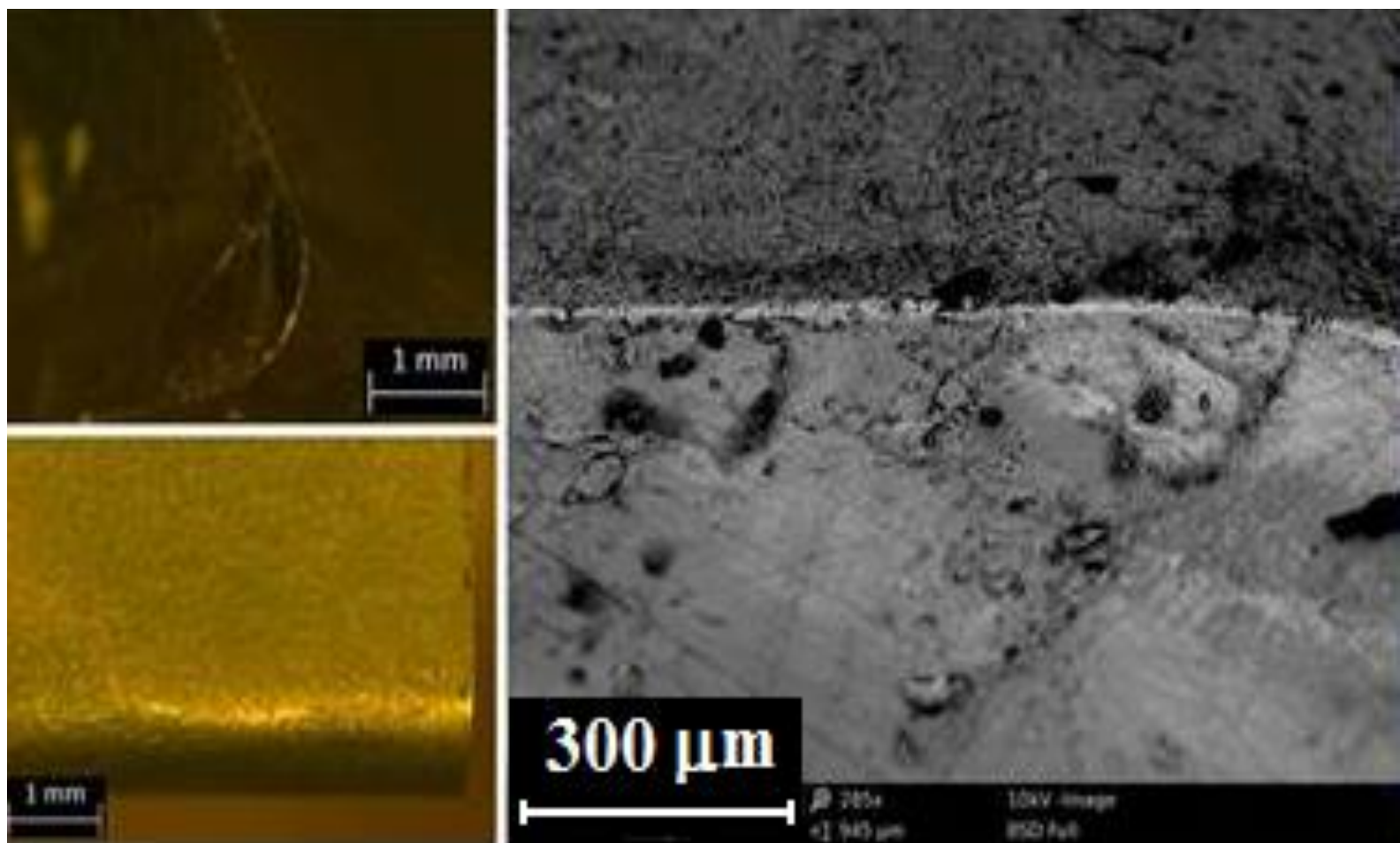

Figura 104- Análise do flanco da ferramenta utilizada no material A3 em lupa estereoscópica (Aumento 20X) e MEV (Aumento 290x) 

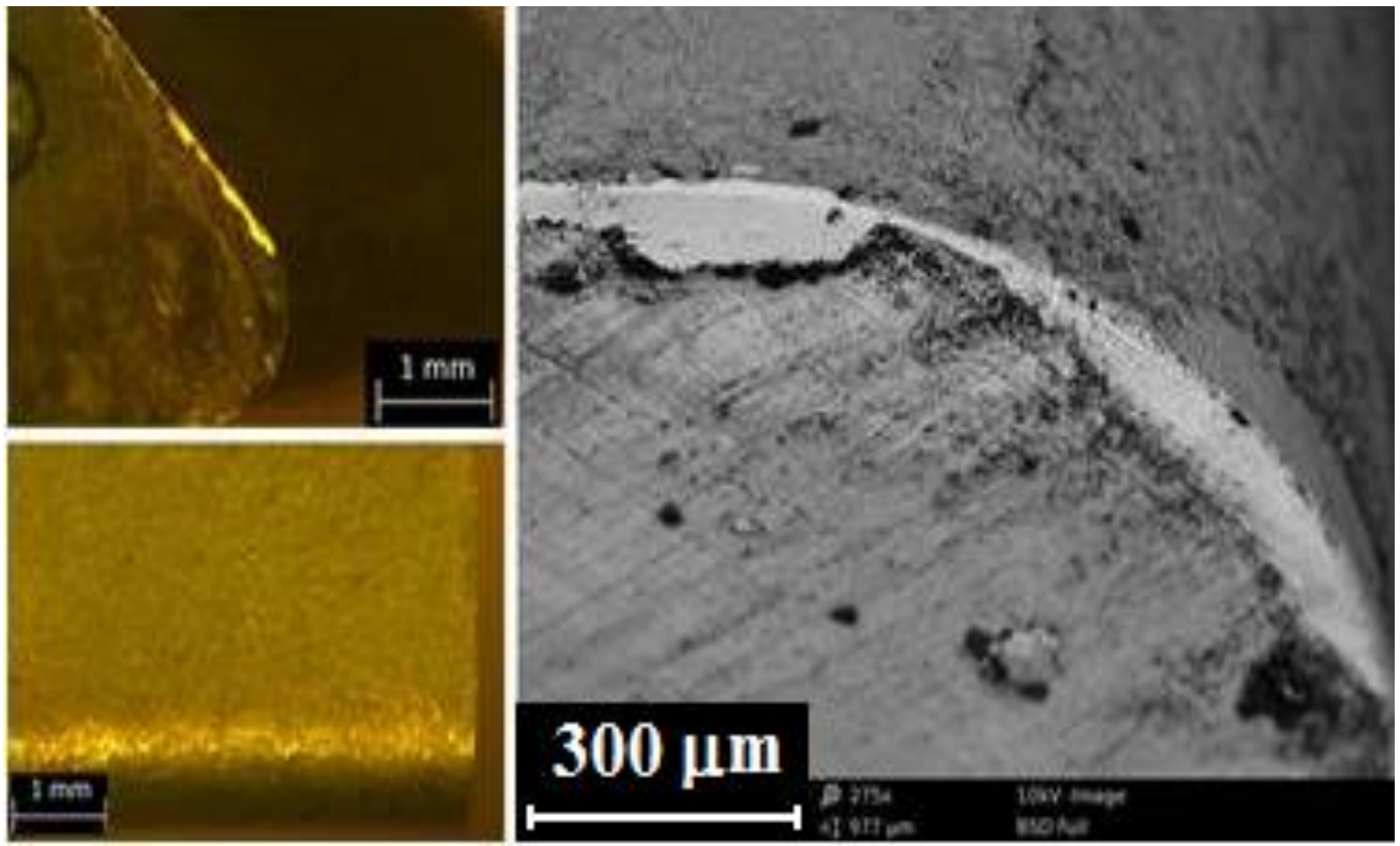

Figura 105 - Análise do flanco da ferramenta utilizada no material A4 em lupa estereoscópica (Aumento 20X) e MEV (Aumento 290x)
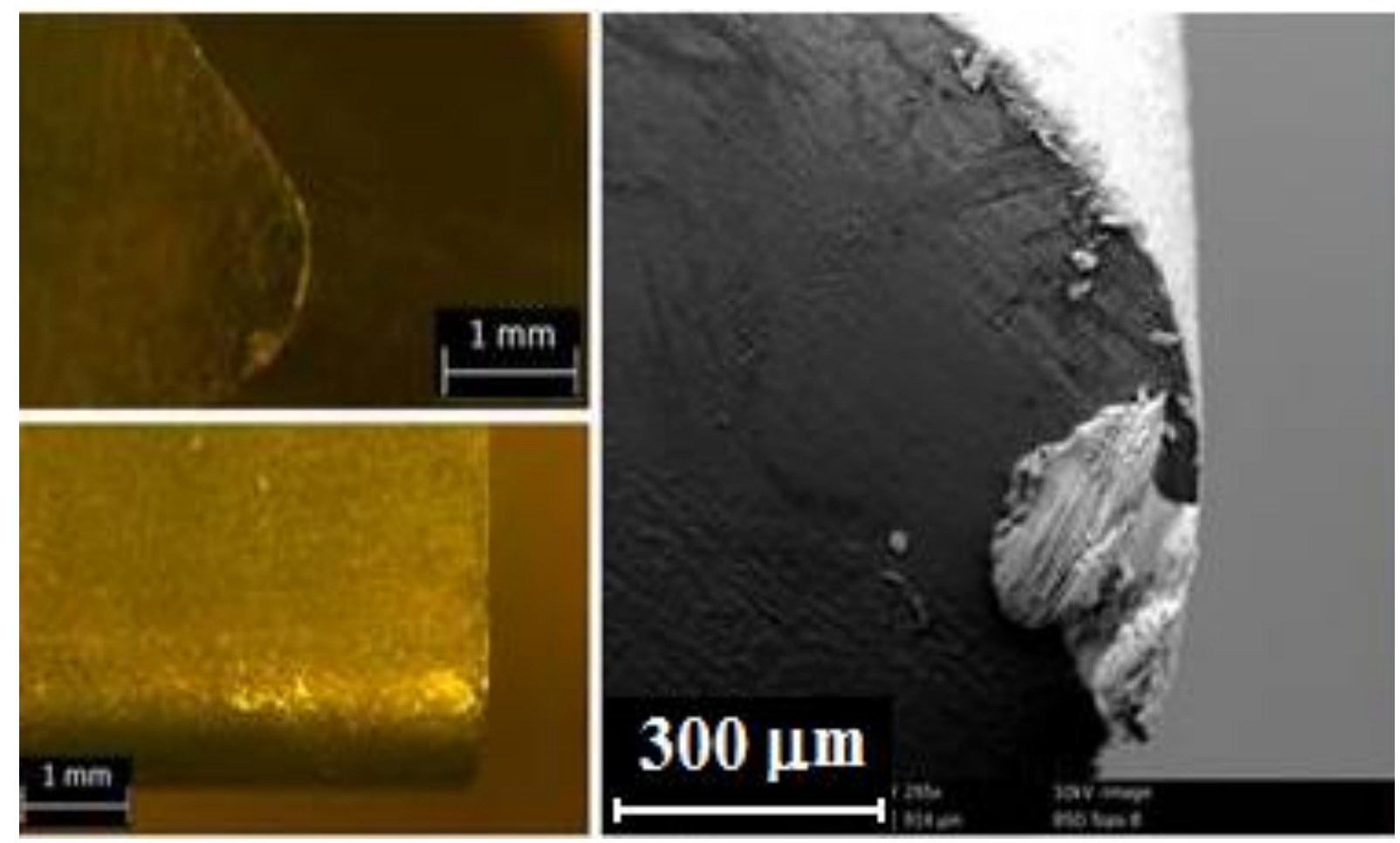

Figura 106 - Análise do flanco da ferramenta utilizada no material B1 em lupa estereoscópica (Aumento 20X) e MEV (Aumento 290x) 


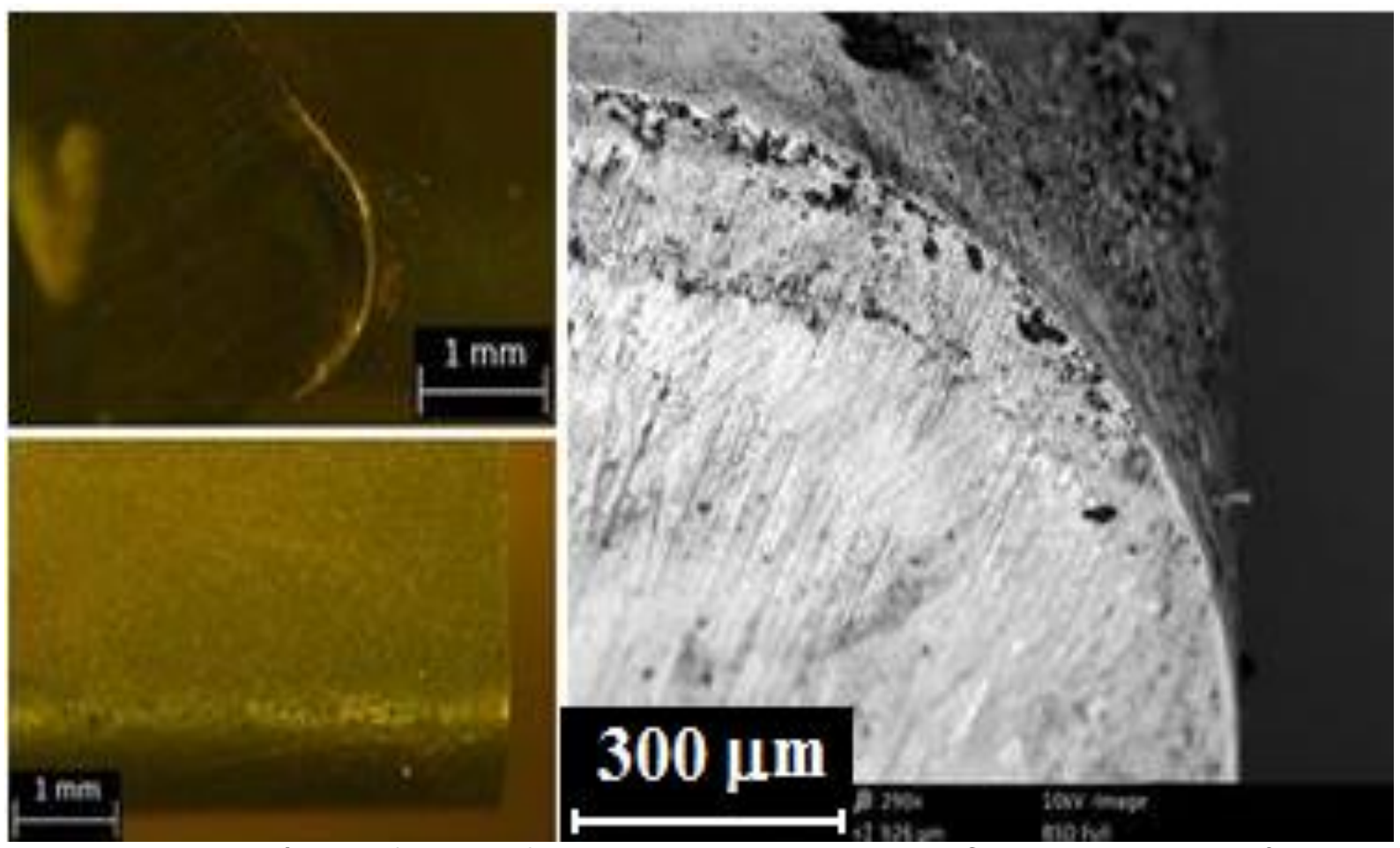

Figura 107 - Análise do flanco da ferramenta utilizada no material C1 em lupa estereoscópica (Aumento 20X) e MEV (Aumento 290x)

\subsection{ANÁLISE COMPARATIVA DE RUGOSIDADE}

Os resultados obtidos para as rugosidades $\mathrm{Ra}$ e $\mathrm{Rz}$ são apresentados nas Figuras 108, 109, 110 e 111, com as respectivas análises de variância dos dados para um nível de significância de 0,05, nas Tabela 18, 19, 20 e 21.

Os resultados encontrados correspondem aos descritos na seção 2.10.5, uma vez que, embora teoricamente se espere a mesma rugosidade para todos os materiais testados, devido à utilização dos mesmos parâmetros de corte, as condições microestruturais desempenharam papel importante na alteração dos resultados finais obtidos. (TRENT; WRIGHT, 2000; SHAW, 2005; GERMAN COPPER INSTITUTE, 2008; MACHADO et al, 2011)

Os dados obtidos apontam para a redução da rugosidade com o aumento da quantidade de fase $\beta$, sendo este comportamento observado nas quatro condições de corte escolhidas. Invariavelmente, o material A1, com maior percentual de fase $\beta$, permaneceu com os menores valores de rugosidade $\mathrm{Ra}$ e $\mathrm{Rz}$ para as quatro condições testadas, sendo este aspecto relacionado com a microestrutura mais refinada do material, em comparação ao material $A 3$. Este resultado é similar ao descrito na seção 2.10.5 (TRENT; WRIGHT, 2000; GERMAN COPPER INSTITUTE, 
2008), pois as microestruturas refinadas estão associadas a uma maior resistência mecânica entre os materiais utilizados, diminuindo os efeitos de deformação plástica nos picos formados, e consequentemente reduzindo a distorção do perfil teórico.

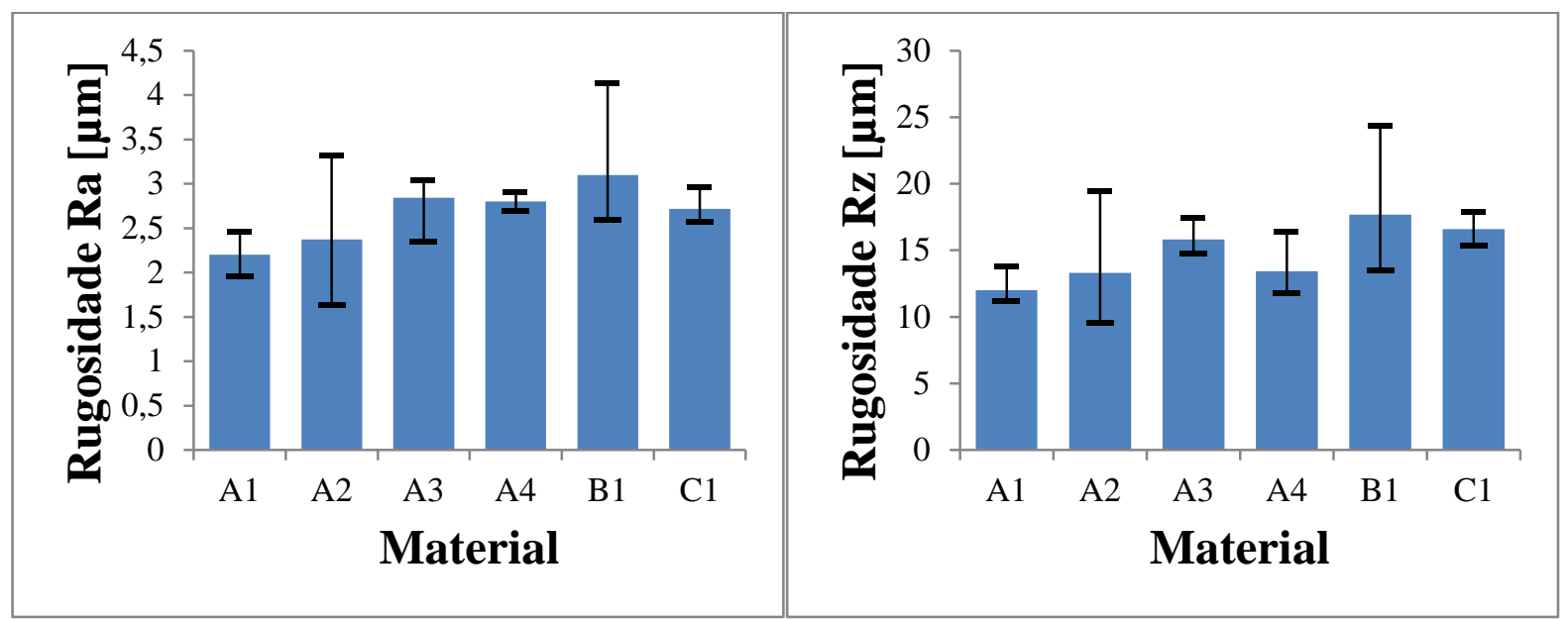

Figura 108 - Rugosidades Ra e Rz dos materiais usinados no processo 1

Tabela 18 - Análise de variância das rugosidades Ra e Rz dos materiais usinados no processo 1

\begin{tabular}{cccccccc}
\hline \multirow{2}{*}{ Rugosidade } & $\begin{array}{c}\text { Fonte da } \\
\text { Variação }\end{array}$ & $\begin{array}{c}\text { Entre } \\
\text { grupos }\end{array}$ & $\begin{array}{c}\text { Dentro } \\
\text { dos } \\
\text { Grupos }\end{array}$ & Total & Fo & Fc & p-value \\
\hline \multirow{2}{*}{$\mathrm{Ra}$} & $\mathrm{SS}$ & 244,59 & 282,58 & 527,2 & & & \\
& $\mathrm{GL}$ & 5 & 54 & 59 & 9,35 & 2,39 & 0,0000019 \\
& $\mathrm{MS}$ & 48,92 & 5,23 & - & & & \\
\hline \multirow{2}{*}{$\mathrm{Rz}$} & $\mathrm{SS}$ & 5,39 & 8,27 & 13,65 & & & \\
& $\mathrm{GL}$ & 5 & 54 & 59 & 7,04 & 2,39 & 0,0000397 \\
& $\mathrm{MS}$ & 1,08 & 0,15 & - & & & \\
\hline
\end{tabular}

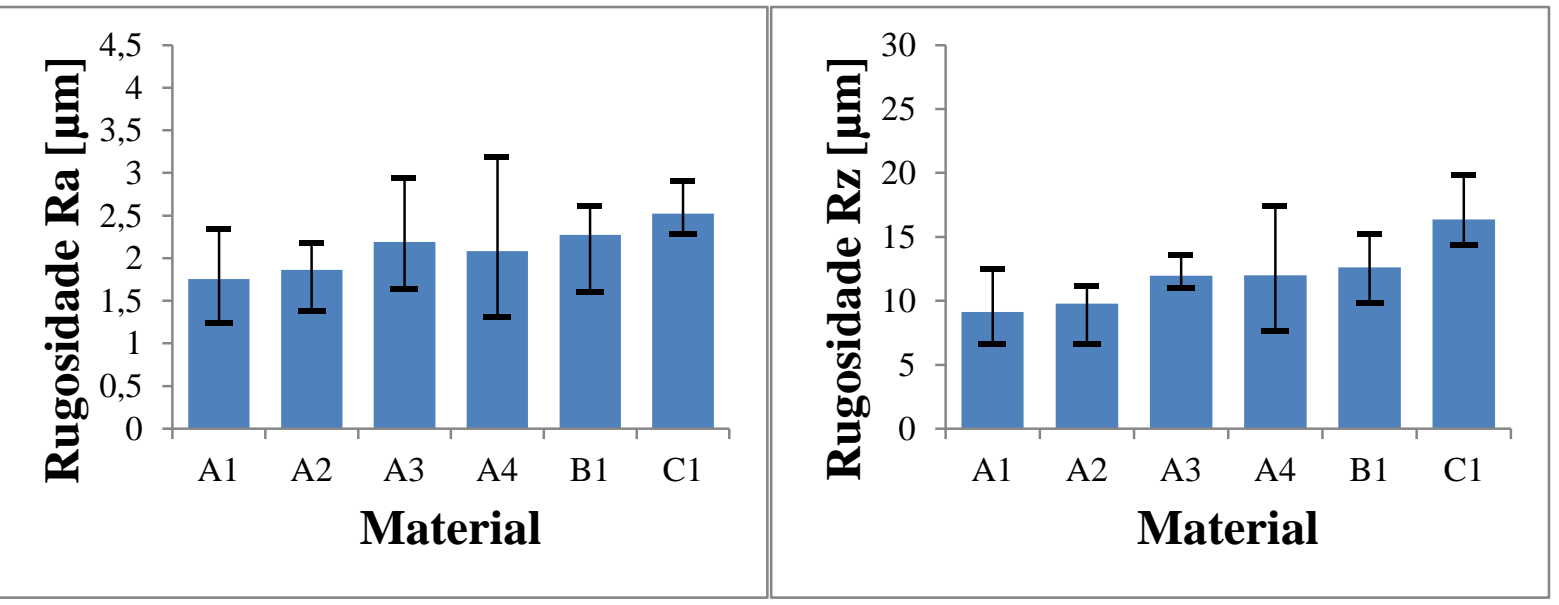

Figura 109 - Rugosidades Ra e Rz dos materiais usinados no processo 2 
Tabela 19 - Análise de variância das rugosidades $\mathrm{Ra}$ e $\mathrm{Rz}$ dos materiais usinados no processo 2

\begin{tabular}{cccccccc}
\hline Rugosidade & $\begin{array}{c}\text { Fonte da } \\
\text { Variação }\end{array}$ & $\begin{array}{c}\text { Entre } \\
\text { grupos }\end{array}$ & $\begin{array}{c}\text { Dentro } \\
\text { dos } \\
\text { Grupos }\end{array}$ & Total & Fo & Fc & p-value \\
\hline \multirow{2}{*}{$\mathrm{Ra}$} & $\mathrm{SS}$ & 3,88 & 12,51 & 16,39 & & & \\
& $\mathrm{GL}$ & 5 & 54 & 59 & 3,35 & 2,39 & 0,0103818 \\
& $\mathrm{MS}$ & 0,78 & 0,23 & - & & & \\
\hline \multirow{4}{*}{$\mathrm{Rz}$} & $\mathrm{SS}$ & 326,27 & 258,27 & 584,5 & & & \\
& $\mathrm{GL}$ & 5 & 54 & 59 & 13,64 & 2,39 & 0 \\
& $\mathrm{MS}$ & 65,25 & 4,78 & - & & & \\
\hline
\end{tabular}

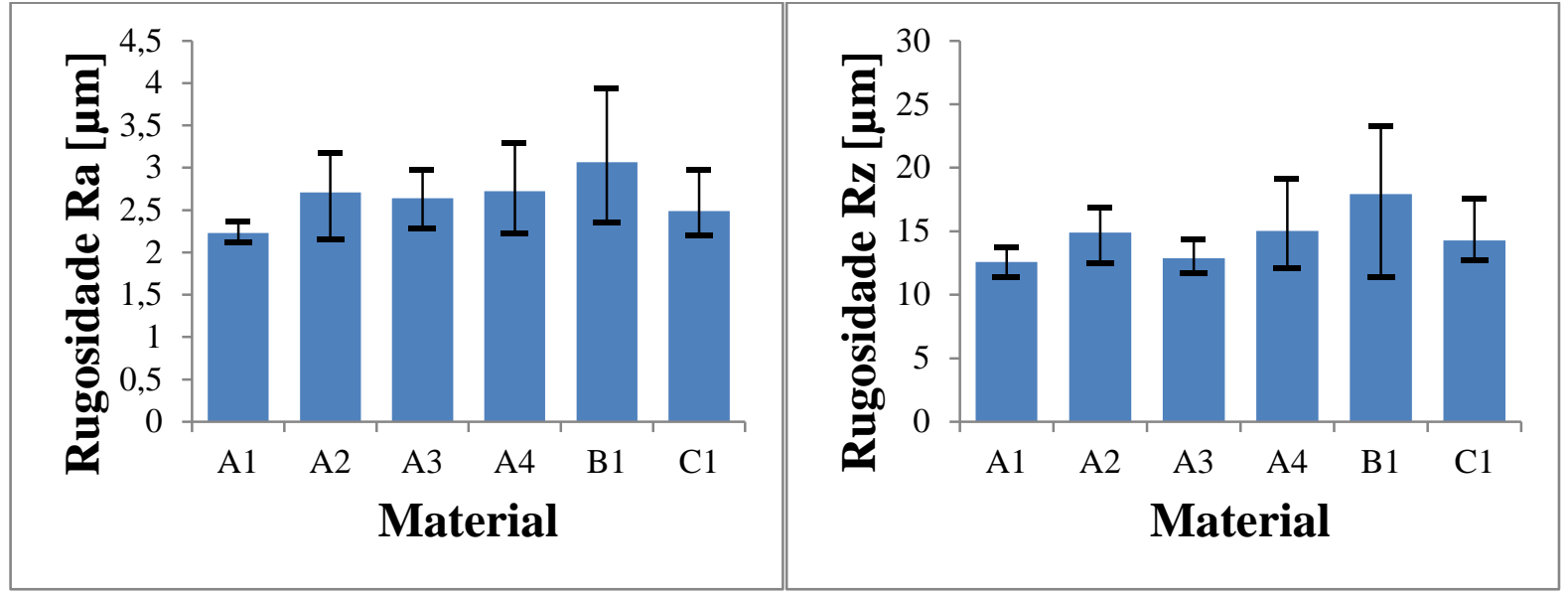

Figura 110 - Rugosidades Ra e Rz dos materiais usinados no processo 3

Tabela 20 - Análise de variância das rugosidades Ra e Rz dos materiais usinados no processo 3

\begin{tabular}{cccccccc}
\hline Rugosidade & $\begin{array}{c}\text { Fonte da } \\
\text { Variação }\end{array}$ & $\begin{array}{c}\text { Entre } \\
\text { grupos }\end{array}$ & $\begin{array}{c}\text { Dentro } \\
\text { dos } \\
\text { Grupos }\end{array}$ & Total & Fo & Fc & p-value \\
\hline \multirow{2}{*}{$\mathrm{Ra}$} & $\mathrm{SS}$ & 3,84 & 7,06 & 10,9 & & & \\
& $\mathrm{GL}$ & 5 & 54 & 59 & 5,88 & 2,39 & 0,0002096 \\
& $\mathrm{MS}$ & 0,77 & 0,13 & & & & \\
\hline \multirow{2}{*}{$\mathrm{Rz}$} & $\mathrm{SS}$ & 184,81 & 233,62 & 418,4 & & & \\
& $\mathrm{GL}$ & 5 & 54 & 59 & 8,54 & 2,39 & 0,0000052 \\
& $\mathrm{MS}$ & 36,96 & 4,33 & & & & \\
\hline
\end{tabular}
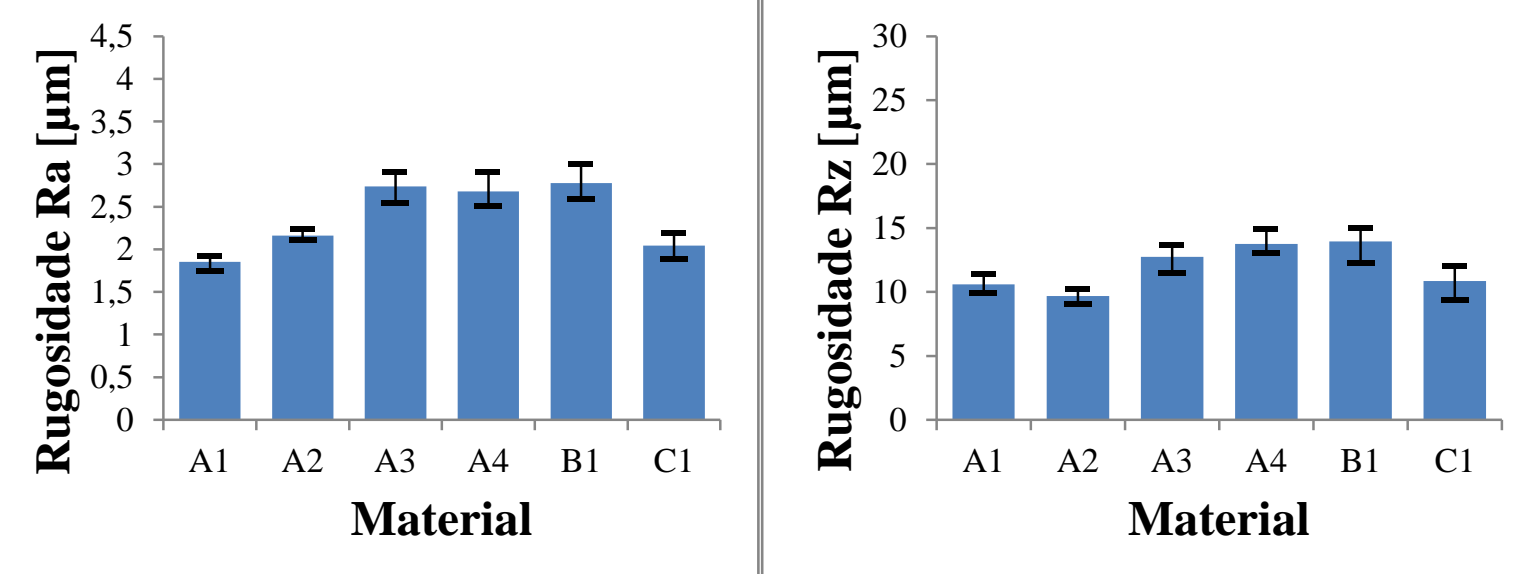

Figura 111 - Rugosidades Ra e Rz dos materiais usinados no processo 4 
Tabela 21 - Análise de variância das rugosidades $\mathrm{Ra}$ e $\mathrm{Rz}$ dos materiais usinados no processo 4

\begin{tabular}{cccccccc}
\hline Rugosidade & $\begin{array}{c}\text { Fonte da } \\
\text { Variação }\end{array}$ & $\begin{array}{c}\text { Entre } \\
\text { grupos }\end{array}$ & $\begin{array}{c}\text { Dentro } \\
\text { dos } \\
\text { Grupos }\end{array}$ & Total & Fo & Fc & p-value \\
\hline \multirow{2}{*}{$\mathrm{Ra}$} & $\mathrm{SS}$ & 2,73 & 6,17 & 8,9 & & & \\
& $\mathrm{GL}$ & 5 & 54 & 59 & 4,77 & 2,39 & 0,0011061 \\
& $\mathrm{MS}$ & 0,55 & 0,11 & - & & & \\
\hline \multirow{2}{*}{$\mathrm{Rz}$} & $\mathrm{SS}$ & 160,78 & 28,93 & 189,7 & & & \\
& $\mathrm{GL}$ & 5 & 54 & 59 & 60,03 & 2,39 & 0 \\
& $\mathrm{MS}$ & 32,16 & 0,54 & - & & & \\
\hline
\end{tabular}

Outro aspecto importante é evidenciado na Figura 112, e refere-se aos resultados de rugosidade do material $\mathrm{C} 1$, o qual apresentou maiores valores principalmente nas condições de menores velocidades de corte, sendo este comportamento explicado pelo dano superficial causado pelos fragmentos dos cavacos e/ou aresta postiça de corte. Este comportamento era esperado (BOOTHROYD, 1975; SHAW; 2005)

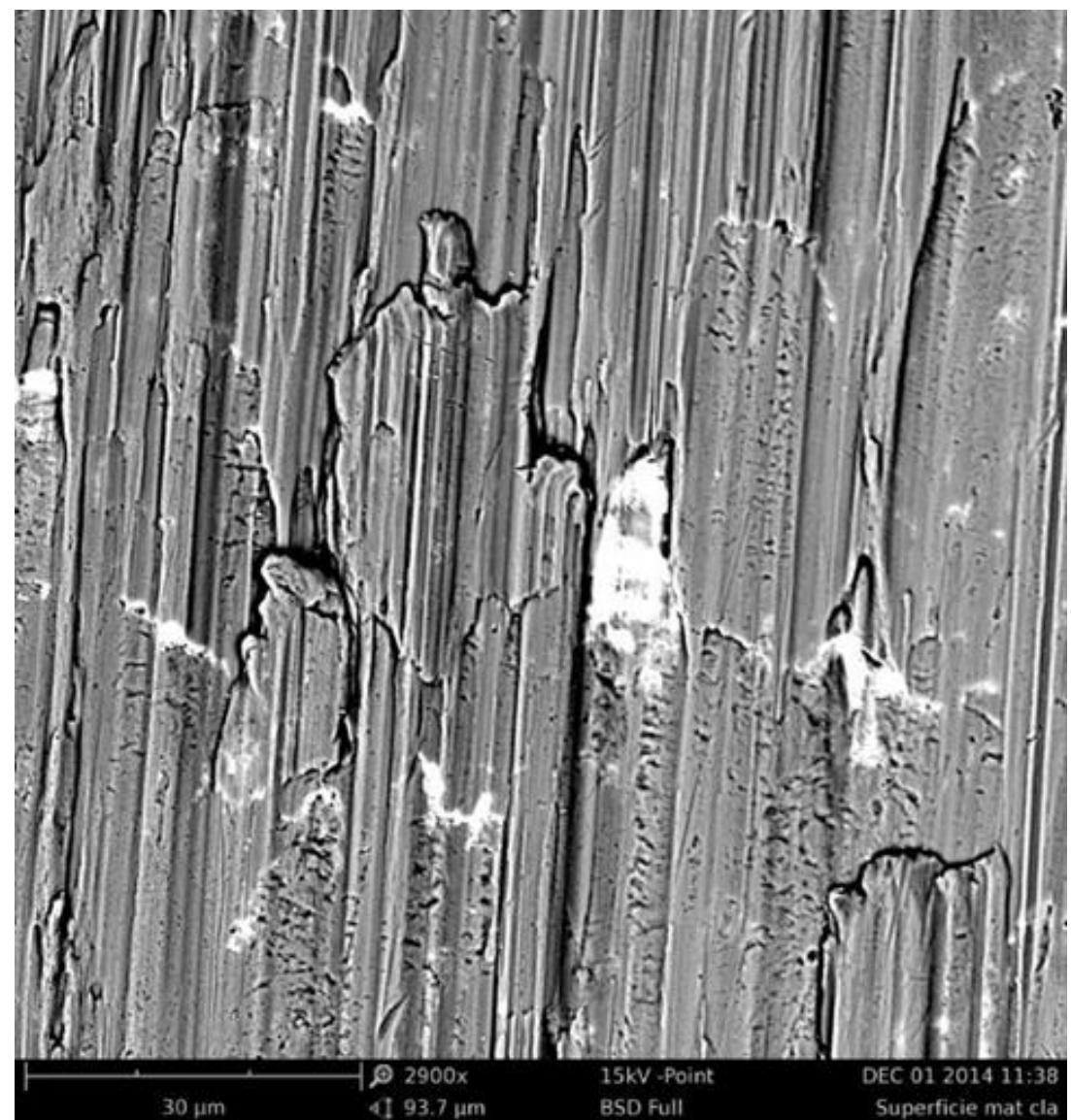

Figura 112 - Análise em MEV da superfície do material C1 (2900 X) 


\section{CONCLUSÃo}

Com base nos dados apresentados, os quais quando aplicável foram submetidos a estudos estatísticos, afirma-se que a variação da fração volumétrica da fase $\beta$ influencia em pontos importantes relativos ao comportamento mecânico e nos processos de usinagem:

- Elevação das propriedades mecânicas do material, sendo possível obter maiores valores de resistência mecânica, o que pode contribuir para o desempenho em serviço do produto;

- Redução do recalcamento dos cavacos usinados, com a consequente redução das forças de corte e de avanço, bem como das temperaturas de usinagem calculadas;

- Com isso, maiores frações de segunda fase, com o consequente aumento da área de interfaces contribuem para alteração do comportamento do cavaco e consequentemente das variáveis relacionadas à usinagem;

- As ligas de latão com chumbo apresentam comportamento e mecanismos de falha significativamente diferentes dos presentes nos latões isentos de chumbo, os quais são baseados na fusão do elemento chumbo presentes nos contornos de grão, e com isso as estratégias de usinagem comuns a este material não devem ser aplicadas sem ajustes aos materiais sem chumbo. Quanto às quatro variáveis avaliadas na usinabilidade dos latões, pode-se afirmar que 0 elemento chumbo tem maior contribuição na redução das forças de corte e na obtenção de formas de cavaco mais favoráveis. Outro ponto importante são as menores contribuições deste elemento na vida útil da ferramenta e no aspecto superficial.

- Foi evidenciado, tanto pelas abordagens analítica quanto metalográfica, a ocorrência de temperaturas acima da relacionada à transformação de fase $\beta^{\prime} \rightarrow$ $\beta$, sendo a estrutura $\beta$ desordenada de elevada ductilidade a quente, superior à observada para a fase $\alpha$. Este ganho de ductilidade influencia diretamente na formação de cavacos contínuos, os quais independentemente das velocidades e condições de corte empregadas, não alteraram este comportamento.

- Com isso, este trabalho contribui com uma abordagem do ponto de vista do material usinado para estimativa das temperaturas presentes na usinagem de 
latões bifásicos. Os resultados permitem afirmar que os latões bifásicos são fortemente dependentes das temperaturas de corte presentes no processo. Este fato é evidenciado em estudos com refrigeração localizada na área de cisalhamento primário, os quais foram apresentados na revisão bibliográfica;

- Portanto, os resultados apresentados levam a entender que o efeito térmico nas condições testadas cumpre um papel mais importante do que o das taxas de deformação, uma vez que nas condições em que foi possível analisar esta variável, os valores encontrados permaneceram em faixas próximas em relação ao estimado pela revisão bibliográfica;

- As diferentes formas de cavaco obtidas também são um indicativo das diferentes respostas das microestruturas utilizadas no processo de usinagem. A ocorrência de cavaco serrilhado semicontínuo apenas nos materiais com propriedades mecânicas inferiores indicam para a preferência no emprego de materiais com encruamento prévio. Esta variável, juntamente com a variação das cargas mecânicas e térmicas, influencia diretamente nos resultados favoráveis obtidos para as rugosidades $R a$ e $R z$ dos materiais com maiores frações de fase $\beta$, os quais estão associados a menor plasticidade da superfície usinada, bem como a menor incidência de vibrações no processo de corte;

- Entende-se que este trabalho pode contribuir para o emprego destes latões com diferentes tratamentos térmicos em processos de usinagem devidamente adaptados, e consequentemente trazer benefícios econômicos no uso em larga escala, pois evitaria a adição elementos alternativos ao chumbo, frequentemente associados à inviabilização da reciclagem em escala industrial, bem como falhas de peças em processos de conformação ou em serviço. 


\section{SUGESTÕES DE TRABALHOS FUTUROS}

Os resultados obtidos até o momento indicam para a existência de condições favoráveis para o uso da liga 60/40 no mercado, sendo a principal contribuição deste projeto o esclarecimento da necessidade do emprego de tratamentos térmicos adequados nestes materiais, pois influenciam diretamente nos resultados obtidos no processo de usinagem. Também pode se afirmar que é possível realizar a usinagem de latões isentos de chumbo, quando observados as alterações necessárias para o processo, sendo elas o emprego de geometrias para quebra dos cavacos, aplicação de fluidos de refrigeração, associados ao devido controle microestrutural.

Dentre as possíveis abordagens industriais para utilização de latões isentos de chumbo, admitindo o fato de que as forças de corte provavelmente serão maiores do que as observadas para os latões de corte livre, este trabalho pode servir de base em cinco principais aspectos:

- Desenvolvimento de trabalhos mais aprofundados com relação ao controle das temperaturas obtidas durante o processo de usinagem de latões, com o uso de sistemas de monitoramento, buscando condições favoráveis para a quebra do cavaco;

- Estudo da influência da utilização de fluidos de refrigeração na zona de cisalhamento primário, para promover a quebra do cavaco, e a sua consequente contribuição na redução das forças de corte obtidas;

- Estudos em tecnologia de ferramentas de usinagem com geometrias melhoradas para a quebra dos cavacos, e agregadas a tratamentos superficiais os quais podem contribuir para redução do atrito do cavaco com a zona de cisalhamento secundária, e a sua consequente contribuição na redução das forças de corte obtidas;

- Estudos em escala industrial da capabilidade das dimensões das peças usinadas, bem como durabilidade dos ferramentais de processo;

- Estudos com uso de tecnologias mais avançadas da operação de microcorte dos latões bifásicos, com enfoque nas regiões de transição ordem-desordem. 


\section{REFERÊNCIAS BIBLIOGRÁFICAS}

A. KHEZRI-YAZDAN, K. N. SUBRAMANIAN. Elevated temperature deformation behaviour of alpha-beta brass bicrystals, Part 1: Ordered beta. Journal of materials science, v.19, p 3185-3190, 1984a

A. KHEZRI-YAZDAN, K. N. SUBRAMANIAN. Elevated temperature deformation behaviour of alpha-beta brass bicrystals, Part 2: Disordered beta. Journal of materials science, v.19, p 3185-3190, 1984b

A. KHEZRI-YAZDAN, K. N. SUBRAMANIAN. Elevated temperature deformation behaviour of alpha-beta brass bicrystals, Part 3: Supporting studies; Journal of materials science, v.19, p 3185-3190, 1984c

ASM METALS HANDBOOK; volume 16, Machining, 1990b, ASM International

ASM METALS HANDBOOK; volume 2, Properties and selection: Nonferrous alloy and special-purpose materials, 1990c, ASM International, $3470 \mathrm{p}$.

ASM METALS HANDBOOK; volume 3, Alloy Phase Diagrams, 1990a, ASM International

ASM METALS HANDBOOK; volume 4, Heat treating, 1990, ASM International

ASTAKHOV, V. Tribology of metal cutting. Oxford: Elsevier Ltd. 2006. 417p.

ASTM B36-13, 2013. Standard Specification for Brass Plate, Sheet, Strip, And Rolled Bar, brass plate, brass rolled bar, brass sheet, brass strip, ASTM International

ASTM E3, 2011. Standard Guide for Preparation of Metallographic Specimens, ASTM International.

ASTM E8 / E8M, 2013. Standard Test Methods for Tension Testing of Metallic Materials, ASTM International.

ASTM E92, 2003. Standard Test Method for Vickers Hardness of Metallic Materials, ASTM International.

ATSUMI H.; IMAI, H.; LI, S.; KONDOH, K.; KOSAKA, Y.; KOJIMA, A.. High-strength, lead-free machinable $\alpha-\beta$ duplex phase brass $\mathrm{Cu}-40 \mathrm{Zn}-\mathrm{Cr}-\mathrm{Fe}-\mathrm{Sn}-\mathrm{Bi}$ alloys. Materials Science and Engineering A, vol. 529, p 275-281, 2011

BARBOSA, P. A. Estudo do comportamento mecânico na usinagem de aços inoxidáveis, dissertação de doutorado, 2014

BOOTHROYD, G. Fundamentals of Metal Machining and Machine Tools. USA: Scripta Book Company, 1975. 350p. 
BROOKS, C. R. Heat treatment, structure and properties of nonferrous alloys, American Society of Materials, 1985

CA CODE 116876; "California Health and Safety Code Sections 116876, Article 4. Lead Materials", 2005

CDA, COPPER DEVELOPMENT ASSOCIATION. Free-Cutting Brass (UNS C36000) for Automatic Screw Machine Products, Acessado em 16.09.2012 às 10h40, http://www.copper.org/applications/rodbar/alloy360/free_cutting.html

CDA, COPPER DEVELOPMENT ASSOCIATION; The Brasses - Properties \& Applications, Section 8 - Brief History of Brass, 2005

COSTA, E. S.; Disciplina: Processos de usinagem; Centro Federal de Educação Tecnológica de Minas Gerais, 2006

COUTINHO, T. A. Metalografia de não-ferrosos, 1980, Editora Edgard Blucher, $128 \mathrm{p}$.

CULLITY, B. D. Elements of X-Ray diffraction, 1956, Addison-Wesley Publishing Company, $531 \mathrm{p}$.

DAVIM, J. P, MARANHÃO, C. A study of plastic strain and plastic strain rate in machining of steel AISI 1045 using FEM analysis, 2008

DIETER, G. E. Metalurgia Mecânica, 2ª Edição, Editora Guanabara Dois, 1981

ELV; "End-of-life vehicles", Directive 2000/53/EC of the European Parliament and of the Council of 18 September 2000.

ERNST, H., MERCHANT, M. E. Chip formation, friction and high quality machined surfaces, Surface Treatment of Metals, vol. 29, 1941

FONTAINE, A. L., KEAST, V. J. Compositional distributions in classical and lead-free brasses, Materials Characterization, vol. 57, p 424-429, 2006

GARCÍA, P.; RIVERA, S.; PALACIOS, M.; BELZUNCE, J.. Comparative study of the parameters influencing the machinability of leaded brasses, Engineering Failure Analysis, vol 17, p. 771-776, 2009

GERMAN COPPER INSTITUTE. Recommended machining parameters for copper and copper alloys, Deustches Kupferinstitut, 2010

GIALANELLA, S.; LUTTEROTTI, L.. Metastable structures in $\alpha-\beta$ brass, Journal of Alloys and Compounds p. 317-318, 2001

GROOVER, M. P. Fundamentals of modern manufacturing - Materials, processes and systems, John Wiley \& Sons, 3를 Edição, 2007 
HERNANDEZ, M. H., HERNANDEZ, A. J., RIVERA, C. G., RODRIGUES, M. H. Bismuth segregation and crack formation on a free lead yellow brass tap, Engineering Failure Analysis, vol 28, p 63-68, 2013

HOFMANN, U., MAGD, E. E. Behaviour of Cu-Zn alloys in high speed shear tests and in chip formation processes, Materials Science and Engineering A, vol 395, p. 129-140, 2004.

IMAI, H.; KOSAKA, Y.; KOJIMA, A.; LI, S.; KONDOH, K.; UMEDA, J.; ATSUMI H. Characteristics and machinability of lead-free P/M Cu60-Zn40 brass alloys dispersed with graphite, Powder Technology, vol 198, p. 417-421, 2010

IQBAL, S. A.; MATIVENGA, P. T.; SHEIKH, M. A. A comparative study of the toolchip contact length in turning of two engineering alloys for a wide range of cutting speeds, International journal of advanced manufacturing technology, 2008

ISO 3685; Tool-life testing with single-point turning tools, 1993

KLOCKE, F.; LUNG, D.; NOBEL, C. Angepasste Zerspanprozesse fur bleifreie Kupferwerkstoffe, MM Maschinenmarkt, vol 36, p. 74-77, 2012

KLOCKE, F.; LUNG, D.; NOBEL, C. Ansätze zur Hochleistungszerspanung bleifreier Kupferwerkstoffe", Metall-Forschung, p. 496-499, 2012

LEE, S.Y.; CHUN, Y.B.; HAN, J.W.; HWANG, S.K.. Effect of thermomechanical processing on grain boundary characteristics in two-phase brass, Materials Science and Engineering A, v. 363, p. 307-315, 2003

LOCONSOLO, V.; NOBILI, L. Manuale degli ottoni, Consedit sas, Milão, 1995, 171 p.

LORENZ, U., HOPPER, M., ZEIGER, K.. BlueBrass ${ }^{\circledR}$ : Bleifreies Zerspanungsmessing für existierende Recyclingkreisläufe, Metall-Forschung, $p$. $531-534,2010$

MACHADO, A. R., ABRÃO, A. M., COELHO, R. T., SILVA, M. B.; Teoria da usinagem dos materiais, $2^{\mathrm{a}}$ edição, Ed. Blucher, 2011, 397 p.

MAPELLI, C.; VENTURINI, R.; Dependence of the mechanical properties of an $\alpha / \beta$ brass on the microstructural features induced by hot extrusion, Scripta Materialia, vol 54, p. 1169-1173, 2006

MERCHANT, M. E; Mechanics of the metal cutting process, Orthogonal cutting and type 2 chip, Journal of Applied Physics, v.16, 1954

MEYERS, M. A. CHAWLA, K. K. Mechanical Behavior of materials, Cambridge University Press, 2009

MOREIRA F.R, MOREIRA J.C. Os efeitos do chumbo sobre o organismo humano e seu significado para a saúde, Rev Panam Salud Publica, vol. 15, p. 119-129, 2004 
NAKAMURA, M.S.; Intoxicação por chumbo, Revista de Oxidologia, 2002.

NAKAYAMA et al. Chip Formation Mechanism in Single Crystal Cutting of Beta Brass, 1970

NBR 6162. Movimentos e relações geométricas na usinagem dos metais, ABNT, 1989

NBR 6175. Processos mecânicos de usinagem, ABNT, 1971

NILSEN, C. F.; SUBRAMANIAN, K. N. Role of strain-rate and phase boundary geometry on the deformation behaviour of two-phase bicrystals of alpha-beta brass, Journal of materials science, vol. 19, p. 768-776, 1984

NOBEL, C.; KLOCKE, F., LUNG, D., WOLF, S. Machinability Enhancement of LeadFree Brass Alloys, 6th CIRP International Conference on High Performance Cutting, HPC2014, Procedia CIRP 14, p. 95 - 100, 2014

PADILHA, A. F.; Materiais de Engenharia - Microestrutura e Propriedades, 2000, Editora Hemus

REACH, 2006. Registration, Evaluation, Authorisation and Restriction of Chemicals, Regulation (EC) No 1907/2006 of the European Parliament and of the Council of 18 December 2006.

RoHs, 2002. Directive on the restriction of the use of certain hazardous substances in electrical and electronic equipment; European Directive 2002/95/EC.

S.152. Health; consumer products; lead poisoning; prohibition against lead, 2007

SCHMIDT, A.O. Machining Theory and Practice, 1950, American society for Metals, Cleveland, Ohio

SHAW, M. C. Metal Cutting Principles. New York: Oxford University Press, 2005. $594 \mathrm{p}$.

SHAW, M. C. The size effect in metal cutting, Sadhana, Vol. 28, Part 5, pp. 875-896, 2003

SUÁREZ, L. ; RODRIGUEZ, P. C.; CABRERA, J. M.; ROMAY, A. M.; MALLORQUÍN, D. M.; COMA, A.; Hot working analysis of a CuZn40Pb2 brass on the monophasic ( $\beta$ ) and intercritical $(\alpha / \beta)$ regions, Materials Science \& Engineering A, vol. 627, p. 4250,2015

TAHA, M. A., EL-MAHALLAWY, N. A., HAMMOUDA, R. M., MOUSSA, T. M, GHEITH, M. H.; "Machinability characteristics of lead free-silicon brass alloys as correlated with microstructure and mechanical properties", Ain Shams Eng Journal. 2012 
TAY, A. A. O.; A review of methods of calculating machining temperature, Journal of Materials Processing Technology, vol. 36, p. 225-257, 1993

TRENT, E. M., WRIGHT, P. K. Metal cutting. 4 ed., Ed. Butterworth-Heinemann, 2000, 446p.

TSAO, M. C.; CAMPBELL, J. D.. Plastic shear properties of metals and alloys at high strain rates; Air Force Materials Laboratory, 1973

VILARINHO, C., DAVIM, J.P., SOARES, D., CASTRO, F., BARBOSA, J., Influence of the chemical composition on the machinability of brasses, Journal of Materials Processing Technology, vol. 170, p. 441-447, 2005

WOBKER, H. G.; FRIEDRICH, T.; DENENKA, B.; KOHLER, J.; GROVE, T. Entwicklung von Lösungen für die spanende Bearbeitung einer entzinkungsbeständigen, bleifreien Kupfer-Zink-Legierung, Metall-Forschung, $p$. 493-496, 2011 